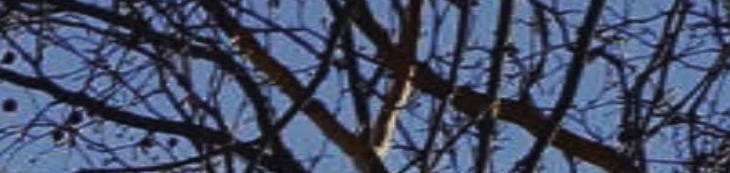
S.

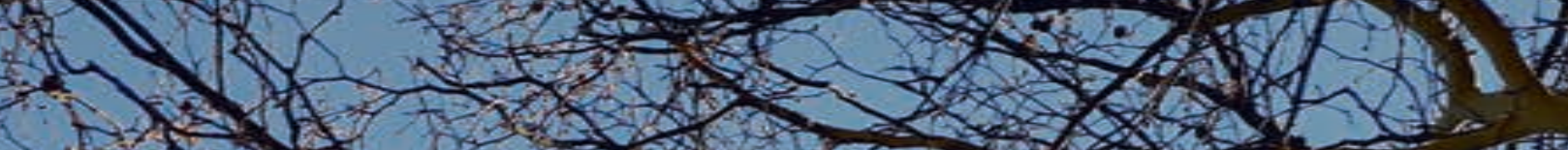

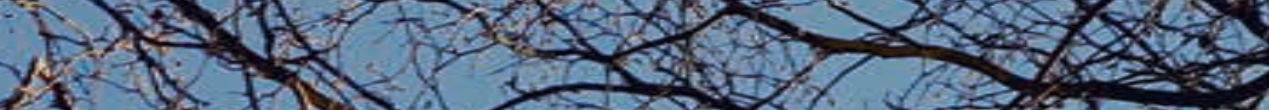

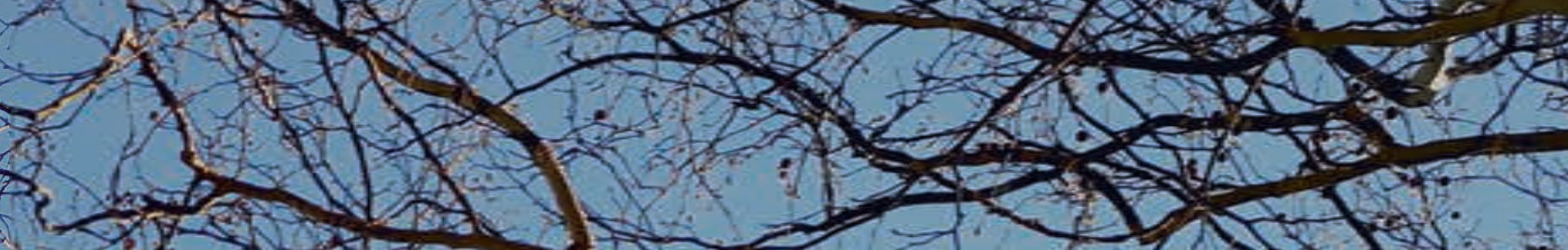
3.

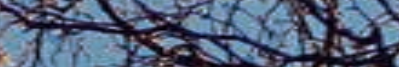

fo b os

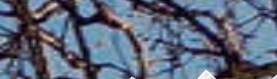

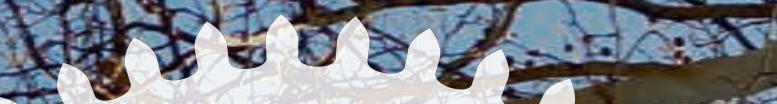

$\because>\frac{1}{3}$

सेख्य

18

$\infty$

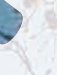

3

-

Strategizing
beyond boundăries
policy entrepreneurship for
climate-smart agriculture
Marijn Faling

Strategizing
beyond boundăries
policy entrepreneurship for
climate-smart agriculture
Marijn Faling

Strategizing
beyond boundăries
policy entrepreneurship for
climate-smart agriculture
Marijn Faling

Strategizing
beyond boundăries
policy entrepreneurship for
climate-smart agriculture
Marijn Faling

Strategizing
beyond boundăries
policy entrepreneurship for
climate-smart agriculture
Marijn Faling

A 1 . 2 2.010 .015 

Strategizing beyond boundaries policy entrepreneurship for climate-smart agriculture 


\section{Thesis committee}

\section{Promotor}

Prof. Dr C.J.A.M.Termeer

Professor of Public Administration and Policy Group

Wageningen University \& Research

\section{Co-promotors}

Dr G.R. Biesbroek

Associate professor, Public Administration and Policy Group

Wageningen University \& Research

Dr S.IS.E Karlsson-Vinkhuyzen,

Assistant Professor, Public Administration and Policy Group

Wageningen University \& Research

\section{Other members}

Prof. Dr D. Huitema, Vrije Universiteit Amsterdam, The Netherlands

Prof. Dr J. Edelenbos, Erasmus University Rotterdam, The Netherlands

Prof. Dr H.A.C. Runhaar, Wageningen University \& Research, The Netherlands

Dr Å. Persson, Stockholm Environment Institute, Sweden

This research was conducted under the auspices of the Graduate School of Social Sciences (WASS) 


\title{
Strategizing beyond boundaries policy entrepreneurship for climate-smart agriculture
}

\author{
Marijn Faling
}

Thesis

submitted in fulfilment of the requirements for the degree of doctor at Wageningen University

by the authority of the Rector Magnificus

Prof. Dr A.P.J. Mol,

in the presence of the

Thesis Committee appointed by the Academic Board

to be defended in public

on Monday 27 May 2019

at II a.m. in the Aula. 


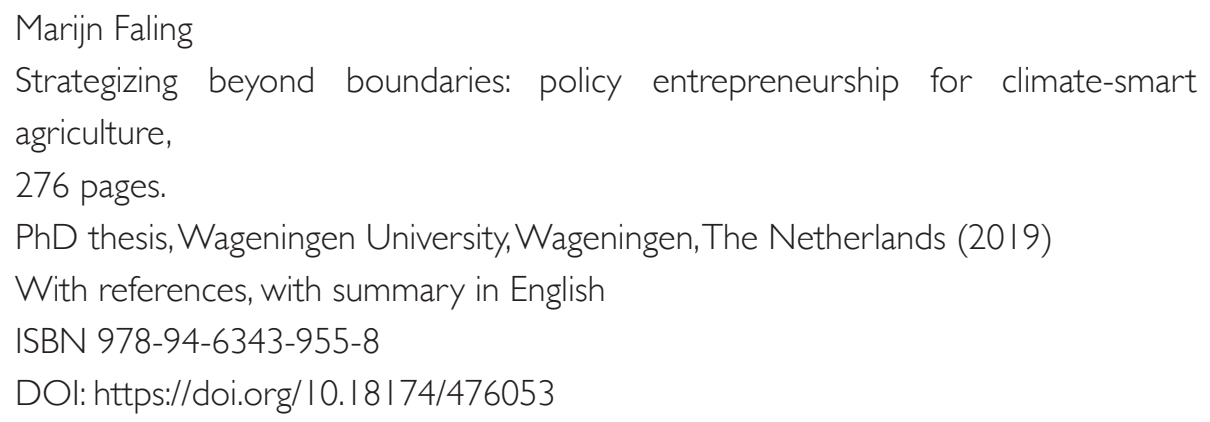




\section{Abstract}

Many contemporary climate change and food security initiatives, including climatesmart agriculture (CSA), call for connecting and integrating different government levels, policy domains, and organizations. This boundary-crossing is frequently accompanied by difficulties including turf wars and power struggles, which risk to thwart policy development. Although the literature argues that policy entrepreneurship contributes to the crossing of level, domain, and organizational boundaries, knowledge on these dynamics is fragmented, and insights into entrepreneurial strategies, embedded in the policymaking context, are limited. Consequently, the aim of this dissertation is to understand how policy entrepreneurship contributes to the crossing of boundaries to achieve CSA. The aim is addressed through three research questions: (i) how and why do policy entrepreneurs cross boundaries for climate-smart agriculture; (ii) how does the policymaking context influence cross-boundary policy entrepreneurship for climate-smart agriculture; and (iii) how can cross-boundary policy entrepreneurship in the policy process for climate-smart agriculture be conceptualized?

To understand policy entrepreneurship's contribution to the crossing of boundaries, the dissertation focuses on two case studies of CSA policy development: the Global Alliance for Climate-Smart Agriculture, and the National Climate-Smart Agriculture Strategy in Kenya. These cases have been studied through a mixed-methods research design, including a systematic literature review, congruence analysis, and frame analysis.

The dissertation proposes a conceptual framework that describes cross-boundary policy entrepreneurship as a complex set of strategies that interplay with the policymaking context. This strategizing process is characterized by entrepreneurship interpreting and acting upon the policymaking context in order to reconfigure the policy process, with both intended and unintended effects. This is an ongoing process, whereby the dynamic policymaking context requires entrepreneurs to continuously reassess their strategies. The key strategies to cross boundaries include patchwork framing, impartial leadership, and process manipulation. The policymaking context is characterized by differences in interests, ideas, and institutions. 
Although many strategies can influence the ideas, interests, and institutions in certain levels, domains, and organizations, my findings show that patchwork framing serves mostly to adapting interests, whereas impartial leadership and process manipulation are predominantly linked to altering ideas and institutions, respectively. Through their actions, entrepreneurs are continuously engaged in defining and redrawing boundaries. In order to accommodate different actors entrepreneurs kept the boundaries of CSA consciously vague. Despite various resulting challenges including to work with differing interests, facilitate idea exchange in light of distrust, and face eroding support for initiatives, the entrepreneurs in both the analysed cases managed to realize CSA policy development. This dissertation shows that whereas CSA accommodates the continued existence of differences in ideas and interests and enables the rebranding of existing practices, simultaneously it streamlines discussions and facilitates the creation of new initiatives. However, contrary to the often highlighted notion of CSA as radical transformation, it rather signifies a small but significant reconfiguration of existing policies. 



\section{Table of Contents}

Abstract

$\begin{array}{lll}\text { I Introduction } & \text { I3 }\end{array}$

I.I Background and problem definition I5

I.2 Cross-boundary policy entrepreneurship for CSA: key concepts $\quad 17$

$\begin{array}{ll}\text { I.2.I Policy entrepreneurship } & 17\end{array}$

I.2.2 Crossing boundaries 20

I.2.3 Climate-smart agriculture $\quad 22$

I.3 Aim, questions, and relevance 24

I.4 Research approach and methodology 26

$\begin{array}{ll}\text { I.4.I Research methodology } & 27\end{array}$

$\begin{array}{ll}\text { 1.4.2 Case study selection } & 29\end{array}$

I.5 Structure of the dissertation 30

2 Policy entrepreneurship across boundaries: a systematic literature review 33

Abstract 34

2.I Introduction $\quad 35$

2.2 Methodology 37

2.2.I Data collection 37

2.2.2 Eligibility criteria and exclusion of studies 38

2.2.3 Data abstraction process: the coding of studies 39

2.2.4 Data analysis: the $\boldsymbol{\varphi}$-coefficient 40

2.2.5 Limitations 43

2.3 Characterising the literature 43

2.4 Cross-boundary strategies $\quad 47$

2.4. I Types of cross-boundary strategies 47

2.4.2 Directions of cross-boundary strategies $\quad 50$

2.4.3 Functions of cross-boundary strategies 51

2.5 Conditions for cross-boundary strategies 53

2.6 Implications of cross-boundary strategies 55

2.7 Discussion $\quad 57$

2.8 Conclusion 61

Acknowledgement $\quad 62$

Supplementary material $\quad 62$ 
3 The Strategizing of Policy Entrepreneurs towards the Global Alliance for Climate-Smart Agriculture

Abstract

3.I Introduction

3.2 Policy entrepreneurship across multiple boundaries: a framework for analysis

3.2.I Strategizing as interactional process 69

3.2.2 Strategizing in different phases 71

3.3 Methods and methodology $\quad 72$

3.3.I Data collection $\quad 72$

$\begin{array}{ll}\text { 3.3.2 Data analysis } & 73\end{array}$

3.3.3 Limitations $\quad 74$

3.4 Results: three entrepreneurs, three episodes towards establishment GACSA

3.4.I Episode I (2009-20 I0): the development of Climate-Smart Agriculture

3.4.2 Episode 2 (2011 -2013): creating attention for CSA 77

3.4.3 Episode 3 (2013 - 20I5): Establishing a global alliance on CSA 79

3.5 Discussion

3.6 Conclusions

Policy implications

4 Cross-boundary policy entrepreneurship for climate-smart agriculture in Kenya

Abstract

4.I Introduction

4.2. Cross-boundary entrepreneurship in policy process frameworks 94

4.2.1 Cross-boundary policy entrepreneurship 95

4.2.2 Advocacy Coalition Framework (ACF) 96

4.2.3 Punctuated Equilibrium Theory (PET) 97

4.2.4 Multiple Streams Approach (MSA) 98

4.2.5 Comparing boundary-spanning strategies $\quad 100$

4.3. Methodology 102 
4.4 Results 104

4.4.I CSA policy development from three lenses 104

4.4.2 Constructing an integrated narrative 105

4.4.3 Background and run-up to the CSA working sessions 107

4.4.4 Getting the Kenyan government on board 108

4.4.5 Internalizing the policy proposal 110

4.5 Discussion $\quad 112$

4.6 Conclusion $\quad 115$

$\begin{array}{ll}\text { Acknowledgements } & 116\end{array}$

5 Framing agriculture and climate in Kenya: a longitudinal perspective $\quad 119$ $\begin{array}{ll}\text { Abstract } & 120\end{array}$

5.1 Introduction 121

5.2 Theoretical section: on climate-smart agriculture and policy frame change

5.2.I Policy frames 122

5.2.2 The framing of climate-smart agriculture $\quad 123$

5.2.3 Explanatory factors of policy frame change $\quad 124$

$\begin{array}{ll}5.3 \text { Methodology } & 125\end{array}$

5.3.I Demarcating the research $\quad 125$

$\begin{array}{ll}\text { 5.3.2 Data sources } & 125\end{array}$

$\begin{array}{ll}\text { 5.3.3 Data coding } & 126\end{array}$

$\begin{array}{ll}\text { 5.3.4 Data analysis } & 126\end{array}$

$\begin{array}{ll}5.4 \text { Results } & 127\end{array}$

$\begin{array}{ll}\text { 5.4.1 The } 2005-2010 \text { period } & 127\end{array}$

5.4.2 The $2008-2012$ period $\quad 129$

5.4.3 The 2012-2017 period $\quad 132$

$\begin{array}{ll}5.5 \text { Discussion } & 136\end{array}$

5.6 Conclusion $\quad 138$

6 Discussion, reflections, and conclusion |4|

6.I Understanding entrepreneurship for climate-smart agriculture $\quad 143$

6. I.I The cross-boundary strategizing framework 144

6.1.2Strategizing to cross boundaries for CSA: the particular
strategies

6.1.3 Interests, ideas, and institutions: the policymaking context $\quad 155$ 
6.2 Reflections on research approach, theory, and case studies $\quad 160$

6.2.1 Case study design and generalizability $\quad 160$

6.2.2 Validity and reliability $\quad 162$

6.2.3 Theoretical reflections $\quad 163$

6.3 Directions for future research $\quad 164$

6.4 Policy implications and recommendations $\quad 166$

6.5 Conclusions 168

Appendix: References,Annexes 171

Annexes $\quad 186$

Annex I (belonging to chapter 2) 186

Annex 2 (belonging to chapter 5) 254

Summary 263

Acknowledgements 269

About the author 272

Publications 273

Completed training and supervision plan 274 




\section{I.I Background and problem definition}

Many policy initiatives nowadays call for the involvement of different levels of government, policy domains, and organizations in policy and governance processes (van Meerkerk and Edelenbos 2018, O'Flynn 2013, Kettl 2006). Contemporary societal problems, including climate change and development, are perceived as inherently complex. People tend to have different interpretations of the nature of problems and of appropriate solutions, and the knowledge and capacity to address problems is frequently lacking (Head and Alford 2015, May and Jochim 2013). Responses generally call for the engagement of multiple stakeholders in policy initiatives to garner the resources required to adequately address the challenges (Lipper et al. 2014). Many policy processes consequently crosscut the boundaries between levels of government, policy domains, and organizations.

Climate-smart agriculture (CSA) is an initiative from the United Nations Food and Agriculture Organization ( $F A O$ ) that advocates the involvement of levels, domains, and organizations. It emerged in 2010 and, since its inception, a wide variety of actors - including international donors and national governments - have been showing a growing interest in it (Crouch et al. 2017). CSA is an initiative with the threefold aim of sustainably increasing production for food security and development, adapting and building resilience to climate change, and reducing greenhouse gas (GHG) emissions from the agricultural sector (Lipper et al. 2014). It includes a call for coordinated action across different levels and domains of government, and across public, private, and civil society organizations, in order to realize the proposed transformations (Lipper et al. 20 I 4). CSA promotes the integration of agriculture, environment, food security and development through the interlinking of different ministries and levels of government with private actors and civil society (FAO 20I0). Through its focus on food security, climate, and development and the involvement of an amalgam of actors, CSA is a contemporary and quintessential example of an initiative that promotes the crossing of boundaries. Boundaries refer to dividing lines that mark the limits of entities to define their nature and scope. CSA incorporates a call for the crossing of boundaries between levels of government (e.g. international and local levels of authority), policy domains (e.g. environment and agriculture), and organizations (e.g. government and business). 
To respond to the increasing call for cross-boundary policy initiatives and avoid the potential challenges involved in crossing boundaries, a profound understanding of the processes and strategies to cross boundaries is essential.The majority of studies on the crossing of boundaries take an institutional approach ( $\mathrm{O}$ 'Leary and Vij 2012 , Candel and Biesbroek 20 I6, Jordan and Lenschow 2010 , Zelli and Van Asselt 20 I 3). However, the role of agency in the crossing of boundaries is indispensable. The crossing of boundaries is essentially dependent on the actions and interactions of actors and the practices upon which they draw to reconfigure the policymaking context in which they are situated. Actors, embedded in policy processes, thus deserve more structural attention (van Meerkerk and Edelenbos 2018). Various studies suggest that policy entrepreneurship is crucial in pushing and strengthening cross-boundary policy processes (Peters 20 I5, Candel and Biesbroek 20 I 6, Jochim and May 2010, Mintrom and Thomas 2018, Schaltegger, Beckmann, and Hockerts 2018). Nevertheless, these studies provide limited conceptual insight into the conditions that facilitate the crossing of boundaries, the strategies entrepreneurs deploy to cross boundaries, and the effects of their cross-boundary behaviour. It is worth studying these issues, because, given the nature of boundaries as demarcating differences among entities, cross-boundary policy entrepreneurship will most likely involve particular strategies including maintaining relations across policymaking cultures and coordinating activities across scales (Williams 2002, Boasson 20 I 8, van Meerkerk and Edelenbos 20l8). Insights into these processes will also contribute to the CSA policy literature, in which technical and depoliticised approaches to the crossing of boundaries dominate (Lipper et al. 2014, Chandra, McNamara, and Dargusch 2018).

In this dissertation, I aim to understand how policy entrepreneurship contributes to the crossing of boundaries to achieve CSA policy development. I focus on the role of entrepreneurship in the policy process: the strategies through which entrepreneurs push for CSA and the CSA policymaking context in which entrepreneurship is embedded. The incorporation of entrepreneurship in the policy process enables an analysis of when, how, and with what effect policy entrepreneurs operate to cross boundaries.

My research contributes to the policy entrepreneurship literature by analysing how entrepreneurs operate to promote CSA, thereby providing insight into the entrepreneurial strategies to cross boundaries more generally. Furthermore, 
it addresses the literature on cross-boundary processes and institutions, such as studies on integration, coordination, and boundary-spanning policy regimes, by providing an actor perspective for the more institution-focused literature. It contributes to the growing literature on the governance of CSA by highlighting the dynamics involved in developing CSA policy and offering a critical account of CSA policy processes. The research is of societal relevance by producing insights into the steering processes for CSA and critically assesses the value of CSA as a concept to realize the crossing of boundaries for more sustainable agricultural production.

The remainder of this chapter presents the research strategy that I deployed in this dissertation. Section 1.2 discusses policy processes, boundary-crossing, and policy entrepreneurship as key concepts. Section 1.3 elaborates the aim of this dissertation and presents the research questions and the way in which this dissertation contributes to different literatures. In section 1.4, I discuss the methodology and methods used in this dissertation, and subsequently I outline the structure of the remainder of the dissertation in section 1.5.

\section{I.2 Cross-boundary policy entrepreneurship for CSA: key concepts}

\section{I.2.I Policy entrepreneurship}

The study of entrepreneurship originated in economics but was quickly espoused in other disciplines, including political science, where it was linked to the pushing of policy and politics (Schoorl 2012). Since its inception, policy entrepreneurship as a field of study has grown considerably and currently stretches over various disciplines and fields of study, including political science, environment studies, and policy studies (Petridou, Narbutaité Aflaki, and Miles 2015). Many studies assign a vital role to policy entrepreneurship in policy processes (Kingdon 1995, Mintrom and Norman 2009, Brouwer and Huitema 20 I8, Roberts and King 1991). Early scholarship on policy entrepreneurship focused predominantly on entrepreneurs' skills and traits, thereby highlighting actors' individual characteristics (Dahl 2005, Polsby 1985). The study of policy entrepreneurship expanded with Kingdon's seminal Multiple Streams Approach (Kingdon 1995), which shifted the focus from individual agentic traits to the activities of entrepreneurs in policy change processes. After Kingdon's publication, the study of entrepreneurship boomed, leading to a range of different 
interpretations and definitions (Boasson 2018, Roberts 1992). Currently, myriad foci exist on policy entrepreneurship. Entrepreneurs are variously defined by their traits or actions, referred to as individuals or groups, and interpreted as empirical phenomena or analytical constructs, to name but a few differences (Petridou, Narbutaité Aflaki, and Miles 20 I5, Huitema and Meijerink 20 I0).

In this dissertation, I understand policy entrepreneurship as agency deployed by actors to influence policy processes and effect policy change, using resources and strategies to achieve a desired outcome (based on Green 2017). Policy is the output of this process. Policy is understood broadly here and entails the collection of decisions or instruments defined under the auspices of the government, including formal and voluntary regulations, service provision, and organizational change (e.g. setting up a new government unit or governmental structural reform) (Cairney $20 \mathrm{l}$ ). Policy entrepreneurship differs from other forms of agency in its deliberate use of strategies to effect policy change. Entrepreneurship thus refers to 'a set of behaviours in the policy process, rather than a permanent characteristic of a particular individual or role' (Ackrill and Kay 20 I I, 78). I therefore avoid the individualization of agency as the purposeful behaviour of an exceptional individual (Grint 201I, Galanti and Capano 2015), which would reduce entrepreneurship to an idiosyncratic phenomenon, thereby obstructing theorization and/or generalization (Bakir and Jarvis 2017). Interpreting entrepreneurship as a set of actions means that it can be deployed by any actor, from government to civil society, from individual to group. Furthermore, it enables the exploration of the phenomenon of entrepreneurship rather than the identification of (the personality of the entrepreneur. This perspective is consequently useful to identify actions and strategies that contribute to (cross-boundary) policy processes.

Entrepreneurial strategies have received widespread attention in past studies on policy entrepreneurship. These studies have over the years cumulatively produced a list of (categories of) strategies. The best known and most widely acknowledged entrepreneurial strategies include demonstrating, framing, coalition building, networking, venue shopping, and interpreting focusing events (see for instance Kingdon 1995, Roberts and King 1991, Huitema and Meijerink 2009, Brouwer 2013, Schneider and Teske 1992, Mintrom 2000). Various studies have been hinting at a role for policy entrepreneurship in the crossing of policy boundaries (Peters 20 I5, May and Winter 2009, Candel and Biesbroek 2016). These studies have provided 
piecemeal insight into strategies to cross boundaries. In order to push their pet proposals, entrepreneurs may operate at various levels simultaneously (Bakir and Jarvis 2017), may transmit knowledge across previously unlinked subsystems (Jones and Jenkins-Smith 2009), may realize effective coordination by creating sufficiently powerful ideas to unite various actors across boundaries (Peters 20 I5), may facilitate the development of coordination mechanisms in polycentric settings (Boasson 2018), and are capable of creating links between levels and spheres of climate governance (Huitema, Boasson, and Beunen 2018). These insights, however, are fragmented across various studies. A conceptual framework that captures the complex reality of cross-boundary entrepreneurship and presents it in a unifying set of components is lacking.

In addition, the policy entrepreneurship literature increasingly acknowledges that policy entrepreneurship should be studied vis-à-vis the policymaking context in which it operates (Bakir and Jarvis 2017). Strategies do not occur in a void, but rather are embedded in a particular policymaking context (Mintrom and Norman 2009, Bakir and Jarvis 2017). An account of the context is needed because other factors besides policy entrepreneurship, such as socio-political changes or crisis events, codetermine change. Furthermore, context determines when which type of entrepreneurship will have what effect (Ackrill, Kay, and Zahariadis 20 I3, Zahariadis and Exadaktylos 2016, Bakir and Jarvis 2017). When attempting to assess when, how, and with what effect policy entrepreneurship realizes policy change, it is thus imperative to take into account the interplay between entrepreneurship and the policymaking context. This requires a conceptual account of the factors that are essential in explaining policy processes.

The public policy literature has a long tradition of studying policy processes (Sabatier 2014). The proposed frameworks and theories categorize phenomena and identify critical elements and their relations to create a simplified account of a complex reality (Ostrom 2007). They incorporate a set of elements including actors, institutions, events, resources, and processes that interact in different dynamic ways over a period of time to produce policies that divert from the status quo (Sabatier 2014, Schlager 1999). Policy process frameworks generally capture the dynamics between these elements and highlight the way in which governing agencies define priorities and measures and formulate policy in the pursuit of their priorities (based on Cairney 2011, Peters and Pierre 2016, Sabatier 1988, Baumgartner and 
Jones 1993, Kingdon 1995). Consequently, the policy process literature is suitable for identifying the relevant factors in the policymaking context that, together with policy entrepreneurship, codetermine policy change (see figure I. I).

Policy change thus comes about through a combination of contingencies, including crisis events, mandatory requirements, economic or political changes, and policy failure, actors who interpret these contingencies, and policy entrepreneurs who deploy various strategies to push issues onto the policy agenda (Schlager 1999). Integrating policy entrepreneurship in policy process theories more strongly and explicitly would enable the study of the interplay between entrepreneurship and the policymaking context.

In this dissertation, I study a particular type of policy processes, by focusing on policy processes for CSA policy development. These require the crossing of boundaries, as CSA endorses the integration of agriculture, climate change, development, environment, and food security and preaches coordinated action across different levels and domains of government, and across the public, private and civil society organizations in order to realize the proposed transformations.

Figure I.I. Cross-boundary policy entrepreneurship and the policymaking context

\section{Influences}

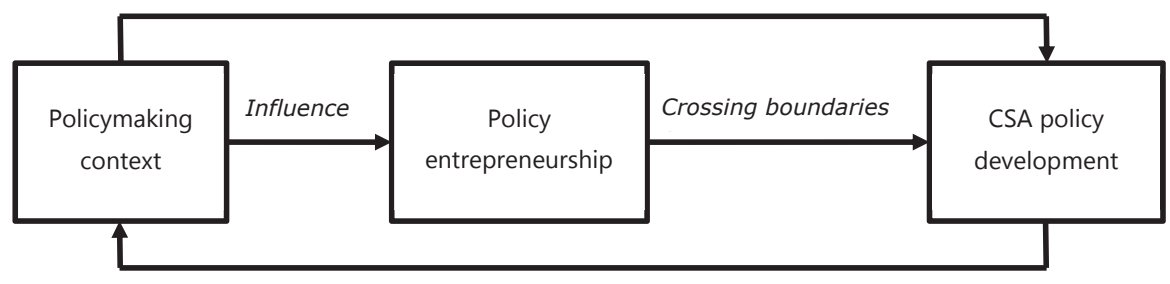

Influences

\section{I.2.2 Crossing boundaries}

The dynamics involved in the crossing of boundaries have elicited wide scholarly interest. Some research focuses on characterising a particular category of problem types, including the 'wicked problem' (Rittel andWebber 1973) and 'nexus' literatures (Ringler, Bhaduri, and Lawford 2013). Other scholars focus on characterizing complex policymaking arenas that involve multiple compartmentalized authorities, including the literature on polycentricity (Jordan et al. 2018, Ostrom 2010) and fragmentation (Biermann et al. 2009). A third strand of literature analyses 
institutionalized interactions across boundaries, including boundary-spanning policy regimes (Jochim and May 2010), policy integration (Biermann, Davies, and van der Grijp 2009, Candel and Biesbroek 20 I6), multi-level governance (Hooghe, Marks, and Marks 200I), and functional regulatory spaces (Varone et al. 20 I 3). This dissertation links to these literatures and builds on insights generated by these strands of research where useful.

In this dissertation, I take an inductive approach to boundaries and focus on boundaries between levels of government (including global governance and national and local government), policy domains (including agriculture and climate change), and organizations (including business, government, and civil society). Although differences exist between the dynamics involved in the crossing of level, domain, or organizational boundaries, the processes and challenges involved in crossing boundaries are, at least on a general level, comparable (Candel and Biesbroek 20 I6, Peters 20 I5, Varone et al. 20 I3). The varied literature on boundaries has produced various categories of boundaries, including physical, cognitive, social, and institutional boundaries (Westerink 20 I 6, van Broekhoven et al. 20 I5). These have been identified for different purposes, but mainly with a view to studying boundary spanning and collaboration. This is a somewhat different focus than entrepreneurship crossing boundaries, as the latter involves processes of policy development. Consequently, I expect the dimensions of boundaries between levels, domains, and organizations for boundary-spanning entrepreneurship to possibly be somewhat different from the predefined categories. Therefore, I take an inductive approach to boundaries to be able to explore the dimensions of boundaries that policy entrepreneurship perceives and encounters in crossing them.

Boundaries refer to dividing lines between entities, that serve to define their nature and scope. They divide countries, government and non-governmental actors, and administrative levels such as national and local government. By defining the nature and scope of entities, boundaries demarcate what is included and what is excluded. As such, they define what is expected from each entity and structure interactions among entities (van Meerkerk and Edelenbos 20 I, O'Flynn, Blackman, and Halligan 2013). Because boundaries highlight differences among entities, they instigate contestation, conflict, and misunderstandings (Westerink 2016). Different actors may have different interpretations of the nature of boundaries (van Broekhoven et al. 2015, Termeer and Bruinsma 2016). Moreover, boundaries are dynamic and 
hence subject to continuous change. Actors involved in policymaking processes continuously make implicit or explicit decisions on the categorization of entities. Consequently, as a result of processes of interaction, negotiation, and sense-making, boundaries are constructed, reproduced, and contested (Termeer and Bruinsma 2016).

Policy entrepreneurs engage in these processes of interaction, negotiation, and sense-making when crossing boundaries. I interpret the crossing of boundaries as the intended or unintended connecting of entities across level, domain, or organizational boundaries through various strategies in order to develop policy. Connecting refers to interaction, which could relate to sharing ideas, cross-fertilization, or considering decisions from across boundaries. Concretely, it may entail developing a shared problem definition or creating inter-agency platforms for joint deliberation (Termeer and Bruinsma 2016, Quick and Feldman 2014).

Because boundaries demarcate differences, the crossing of boundaries is a difficult process frequently fraught with challenges, including turf wars and power struggles (van Meerkerk and Edelenbos 2018, Margerum and Robinson 2016, Candel and Biesbroek 2016, O'Flynn, Blackman, and Halligan 2013). Crossing boundaries might involve challenges related to differences in problem definition and response (e.g. Briassoulis 2004), the division and transfer of resources including money and knowledge (Marks, Hooghe, and Blank 1996), and differing communication cultures (Googins and Rochlin 2000). Addressing these pitfalls entails a complex endeavour. Recent literature has demonstrated that progress towards interlinking across boundaries has consequently been falling short (Stafford-Smith et al. 2017, Persson and Runhaar 2018, Hajer et al. 2015). Understanding the role of agency, including vis-à-vis its environment, is crucial in order to capture policy processes that play out on multiple levels and domains and among multiple organizations, such as with CSA (Beunen and Patterson 2017, Mintrom and Thomas 2018).

\section{I.2.3 Climate-smart agriculture}

Climate-smart agriculture is an initiative coined by FAO in 2010 . It was devised in reaction to an enhanced realization about the interlinkages among climate change, food security, development, environment, and agriculture. Climate change threatens agricultural production, the livelihoods of people dependent on agriculture, and food security. Meanwhile, a growing world population demands an increase in 
food production, to be addressed by agriculture production, a main source of GHG emissions and environmental deterioration. CSA is intended to promote the transformation of the agricultural sector to sustainably increase agricultural output for food security and development, build resilience to climate change, and curtail emissions from the sector (Behnassi, Boussaid, and Gopichandran 20 I4, Lipper et al. 20 I4, Steenwerth et al.20 I4). The approach endorses the integration of agriculture, environment, food security, and development, and coordinated action across different levels and domains of government and across organizations in order to realize the proposed transformations (FAO 20I0, Lipper et al. 2014). Thus, the approach requires the crossing of boundaries between levels of government (e.g. international and local levels of authority), between domains (e.g. environment and agriculture), and between organizations (e.g. government and business). CSA is a broad approach rather than a set of practices, meaning that it entails the possibility of a wide range of differentiated strategies rather than universally applicable solutions. Increasingly, a variety of actors embrace CSA, and various policies, projects, and partnerships around CSA have been initiated, from global to local government level (Sibanda et al. 2017).

Some studies highlight the nature and characteristics of these initiatives but, given the relatively recent invention of CSA, when I was starting this dissertation there were no studies focusing on the dynamics of CSA policy development. Many publications (predominantly grey literature) focus on what should be done and state that the adoption of CSA should entail the integration of different organizations, sectors, and levels. For instance, FAO in its CSA Sourcebook states that 'better aligned policy approaches across agricultural, environmental and financial boundaries and innovative institutional arrangements to promote their implementation will be needed' (FAO 20 I0, I7). Lipper et al. $(2014,1070)$ state that 'increased coordination of agricultural, climate change/environmental and food system policies' is required. Most studies refrain from identifying the processes required to achieve this, apart from some suggestions related to creating cross-border platforms such as the Comprehensive African Agriculture Development Platform (CAADP) (Scherr, Shames, and Friedman 20 I2), facilitating farmer and civil society participation (Lipper et al. 20 I4, Scherr, Shames, and Friedman 2012), or science - policy dialogues (Neufeldt et al. 2013). In sum, CSA is a novel initiative that advocates connections across levels, domains and organizations, which could benefit from a scrutiny into its dynamics. 


\section{I.3 Aim, questions, and relevance}

In the previous section I argued that many contemporary problems including climate change and food security require the crossing of boundaries. This process is often pushed by policy entrepreneurship, but knowledge on policy entrepreneurs' strategies to cross boundaries and on their embeddedness in the policymaking context remains limited. Understanding these processes is vital for addressing contemporary complex problems, which are believed to require actions from an amalgam of entities across level, domain, and organizational boundaries, such as illustrated in the case of CSA. With this dissertation, I contribute to the literatures on policy entrepreneurship, cross-boundary policy processes, and CSA by studying how, under what conditions, and with what effects the strategies of policy entrepreneurs contribute to the crossing of boundaries to achieve CSA. The central aim of this dissertation therefore is:

To understand how policy entrepreneurship contributes to crossing boundaries in policy processes for climate-smart agriculture.

Addressing this aim requires an understanding of the strategies through which policy entrepreneurs cross boundaries to achieve CSA; the CSA policymaking context in which policy entrepreneurs are embedded; and the dynamic relationship between the policymaking context and policy entrepreneurship. To achieve this aim, I formulated three research questions.

I. How and why do policy entrepreneurs cross boundaries for climate-smart agriculture? The purpose of this question is to understand the strategies by which policy entrepreneurs cross boundaries for CSA.The insights contribute to the policy entrepreneurship literature by offering an understanding of the strategies required for the specific task of crossing boundaries. Second, insights from this question contribute to the CSA literature by highlighting the role of entrepreneurs in CSA policy development, thereby providing a micro-level perspective on the development process of CSA policies. Third, answers to this question serve as input for practitioners who aim to influence policy processes. Crossing boundaries is increasingly considered a core activity for actors involved in policymaking processes, and the answers to this question offer tools and suggestions for the crossing of boundaries. 
2. How does the policymaking context influence cross-boundary policy entrepreneurship for climate-smart agriculture?

This question serves to understand the policymaking context for CSA and highlights how the policymaking context, characterized by various entities across boundaries, influences policy entrepreneurship for CSA. Insights following from this question contribute to the identification of the characteristics of and challenges involved in the crossing of boundaries. These might entail, for instance, different institutional environments at different levels of government, or different organizations with different interests and practices. These findings contribute to the CSA literature by exemplifying the policymaking context in which CSA is introduced. The findings demonstrate the opportunities and challenges involved in promoting CSA. This enhances knowledge on the process of crossing boundaries and the political challenges involved in the development of CSA policy.

3. How can cross-boundary policy entrepreneurship in the policy process for climate-smart agriculture be conceptualized?

This question captures the dynamic relationship between cross-boundary policy entrepreneurship and the policymaking context for CSA, resulting in a conceptual framework. The framework highlights the building blocks to understand cross-boundary policy entrepreneurship - policymaking context and policy entrepreneurship - and identifies on a general level the relationships among these building blocks. It thus contributes to the entrepreneurship literature by offering insights into how and under what conditions policy entrepreneurs cross boundaries to achieve CSA. The conceptual framework provides directions for scholars interested in the phenomenon of crossing boundaries by guiding them in relation to the constellation of factors relevant to analyse complex problems. It serves policymakers by presenting the factors that require consideration when influencing the crossing of boundaries. 


\section{I.4 Research approach and methodology}

This section captures how the research questions were approached, operationalized, and researched. It highlights how the research is grounded in a critical realist perspective, which takes an abductive approach to reality (Bertilsson 2004). Because the social world is composed of structures that may change and actors that are capable of learning, social phenomena are not fixed or static, but, rather, dynamic and continuously evolving. Approaching reality as a set of permanent and definitive building blocks would fail to do justice to the processual nature of the world. Whereas a static approach would allow for predetermining a set of actions to reach a certain goal, acknowledgement of the processual nature of reality renders a fixed approach impracticable and undesirable. Therefore, this research adopts a processual perspective. This starting point informs the methodology chosen and the methods applied. These choices are discussed in detail below.

My research rests on the critical realist assumption that our knowledge of reality is limited, as human knowledge is capable of capturing only part of the world around us. Social science is an attempt to understand the world, and some theories and explanations are more capable than others of explaining the world (Bhaskar 1998, Fletcher 2017, Danermark et al. 2002). Reality is stratified in the sense that unobservable causal processes lie at the root of reality and cause observable events to occur. These events occur independent of our observation, and therefore some events are experienced, observed, and understood through human (subjective) interpretation, whereas others are not. Events can thus be experienced and measured empirically, making them a useful object of study to identify underlying unobservable causal processes (Fletcher 2017). Theory and conceptual frameworks serve to make sense of reality by identifying underlying structures of reality and their interrelations that cause observable events and phenomena to occur (Danermark et al. 2002).

Because causal processes cannot be observed, we can at best infer relations from what is observable. Consequently, causal processes can be interpreted in multiple different - ways. That is, different theories attempt to capture and describe a similar reality by selecting certain particular activities, phenomena, and causal mechanisms underlying observable events that help us make sense of the world. Because the subjective interpretation of reality depends on the lens of analysis, different theories 
attempting to explain the same phenomenon may all have explanatory value. In order to capture reality, research establishes and modifies the most appropriate theories. This abduction of relation thus serves not to establish a certain law or truth about reality, but rather orients our understanding of our surroundings by offering the best explanation available. Social scientists therefore look for tendencies rather than truths.

Critical realism highlights the interplay between structure and agency. It assumes that structures are enduring features that shape agency and can be reproduced over time and that agency, although shaped by structures, also co-shapes these structures (Carter and New 2004, Bhaskar 1998). This means that reality is not composed of static and enduring entities, but rather of ongoing, interactive, and emergent processes that play out at different levels and are inspired by different contextual structures (Vandenbussche, Edelenbos, and Eshuis 20 I 8).

\section{I.4.I Research methodology}

From a critical realist perspective, case studies are very suitable approaches to study the interaction between structures, actions, and events to identify and explain causal processes (Geertz 2008, Wynn and Williams 2012). The processual and complex nature of the social world is best captured through a combination of extensive and intensive data. Extensive data consist of more macro-level observations and serve to identify general trends and patterns, whereas intensive data consist of in-depth interpretive data to gain a thorough understanding of the phenomena under study (Fletcher 2017). Combining extensive and intensive data can lead to the identification of irregularities in patterns and processes in the social world. Furthermore, extensive data may support the establishment of a longitudinal perspective to embed a processual account of reality in different temporal contexts. The above considerations have led to a multi-method approach (Table I.I).

First, a systematic literature review was conducted to assess the existing literature on policy entrepreneurship, see chapter 2.The review served to identify pre-established theories and insights on cross-boundary entrepreneurship. These theories and insights served to create a tentative framework as a starting point for my empirical case study research. Systematic literature reviews facilitate the collection of fragmented pieces of information in a transparent and replicable manner. In this dissertation, these pieces of information helped to provide a comprehensive overview of the 
scattered insights on cross-boundary entrepreneurship. Systematically reviewing the literature limits and/or explicates researcher bias (Gough, Oliver, andThomas 2012).

Second, I conducted a qualitative case study, covered in chapter 4. Case studies are helpful for learning about complex social phenomena thanks to their richness in narratives (Flyvbjerg 2006). Case study methods enable in-depth, rich, and longitudinal analysis of a complex world composed of multiple interrelated contingencies and events. This method served to collect intensive data on crossboundary entrepreneurship to enable the identification of underlying causal processes and readjust the conceptual framework. This case study entailed close examination of policy entrepreneurship and the policymaking context in order to enhance understanding of these phenomena and identify those aspects and patterns that were worth highlighting in order to capture the complexity of the phenomena under study (Hyett, Kenny, and Dickson-Swift 20 I 4).

Third, a particular sub-type of case study, a congruence analysis, was conducted to study cross-boundary policy entrepreneurship from a processual perspective and further extend the conceptual framework with an account of the policymaking context and its relation to policy entrepreneurship, see chapter 3. It focused on the actions of policy entrepreneurs, the underlying processes through which the policymaking context co-shaped entrepreneurs' activities, and the processes linking entrepreneurship to policy change. Congruence analysis is an analytical tool developed to make causal inferences from a single case study, with the aim of identifying key parts of causal processes (Beach and Pedersen 2016). The theoretical starting point for the congruence study was the insights gained from the review in the first study about cross-boundary strategies, the conditions for these strategies to occur, and the implications of entrepreneurial cross-boundary strategies. The congruence study produced a processual interpretation of policy entrepreneurship by enabling the linking of observable events or occurrences (such as a certain meeting or event) to underlying unobservable structures and processes (such as for instance belief systems or general mood) (Beach and Pedersen 2016).A congruence study is thus particularly suitable for a processual approach to studying cross-boundary policy entrepreneurship.

A policy content analysis was conducted to create extensive data on the development of CSA-related policies over time. A processual interpretation of 
social phenomena requires a longitudinal perspective on the process under study (policy entrepreneurship and policy change processes for CSA). A longitudinal approach enables the assessment of the sequential interconnectedness among phenomena over time to identify generalizable trends and patterns (Pettigrew 1997). Therefore, the intensive in-depth data were complemented with extensive data retrieved through a partly deductive and partly inductive policy frame analysis and a quantitative content analysis to produce a view on widespread trends in policy development over time.

Table I.I provides an overview of the methodologies deployed in each study. As details on these methodologies are available in the respective chapters, I do not discuss them further here.

Table I.I. Research approaches in the different chapters

\begin{tabular}{|c|c|c|c|}
\hline Method & Objective of the approach & Methodologies & Chapter \\
\hline $\begin{array}{l}\text { Systematic } \\
\text { literature review }\end{array}$ & $\begin{array}{l}\text { Assess existing literature to identify pre- } \\
\text { established theories and insights on cross- } \\
\text { boundary policy entrepreneurship }\end{array}$ & $\begin{aligned} \text { - } & \text { Systematic literature review } \\
\text { - } & \text { Descriptive statistics } \\
& \text { (correlation, phi coefficient) }\end{aligned}$ & 2 \\
\hline $\begin{array}{l}\text { Congruence case } \\
\text { study }\end{array}$ & $\begin{array}{l}\text { Identify causal processes underlying } \\
\text { observable events to refine insights from } \\
\text { study I. Collect intensive data to make } \\
\text { sense of complex reality through thick } \\
\text { description }\end{array}$ & $\begin{array}{l}\text { - Interviews } \\
\text { - Observation } \\
\text { - Policy document analysis } \\
\text { - Literature review } \\
\text { - Survey }\end{array}$ & 3 \\
\hline $\begin{array}{l}\text { Qualitative case } \\
\text { study }\end{array}$ & $\begin{array}{l}\text { Collect intensive data to make sense of } \\
\text { complex reality through thick description }\end{array}$ & $\begin{array}{l}\text { - Interviews } \\
\text { - Observation } \\
\text { - Policy document analysis }\end{array}$ & 4 \\
\hline Content analysis & $\begin{array}{l}\text { Collect extensive longitudinal data to } \\
\text { identify widespread macro-level trends in } \\
\text { policy process }\end{array}$ & $\begin{array}{l}\text { - Policy document analysis } \\
\text { - Interviews } \\
\text { - Literature review }\end{array}$ & 5 \\
\hline
\end{tabular}

\section{I.4.2 Case study selection}

The careful selection of case studies provides a powerful tool to unravel patterns in causal processes that result in critical tendencies and perceptions that enable theorization (Flyvbjerg 2006). I selected two case studies for my research in chapters 3,4 and 5. The cases are so-called critical cases, which can be defined as 'having strategic importance in relation to the general problem' (Flyvbjerg 2006, 229). CSA policy processes have strategic importance in relation to the general problem as these are likely to be successful examples of the crossing of various policy boundaries. Both cases have sufficient variation and richness to enable indepth insights into the phenomenon of cross-boundary policy entrepreneurship (Boezeman 2015, 25). The use of critical cases allows for a phenomenon to be 
studied in its real-life context (Yin 2003). Whereas the two cases demonstrate variation in level under observation and actor involvement, they are similar in terms of cross-boundary context and study topic. I selected two case studies as multiple individual cases to enable replication and extension. The first case, the congruence case study, focuses on the development process of the Global Alliance for ClimateSmart Agriculture (GACSA). This is the first, most notable, and widespread multiactor initiative around CSA and already has over 200 members, including countries such as the United States and the Netherlands, companies such as Yara and Danone, intergovernmental institutions such as the African Union, and various civil society organizations. The second case, the qualitative case study, was undertaken in Kenya. The case was selected because Kenya is highly dependent on agriculture, threatened severely by the effects of climate change, and targeted by various levels and actors to develop CSA policies (Bryan, Ringler, Okoba, Roncoli, et al. 2013). Furthermore, a variety of actors, including CGIAR's Climate Change, Agriculture and Food Security programme, the World Bank, and the African Union, have actively supported the development of a CSA Strategy in Kenya and GACSA at the global level. Initial analysis demonstrated that both cases involve policy entrepreneurship. The GACSA case and the Kenyan case both display significant efforts by a few actors who actively pushed for the development of each policy arrangement. The cases in my dissertation do not serve comparative evaluation but rather deliver complementary insights into the entrepreneurial strategies to cross boundaries.

\section{I.5 Structure of the dissertation}

The main body of the dissertation is composed of research articles, which have been published (chapters 2, 3) in, or submitted (chapters 4, 5) to peer-reviewed academic journals. All chapters contribute to one or more of the research questions. Chapter 2 brings together the fragmented insights into cross-boundary policy entrepreneurship by presenting the findings from a systematic literature review that assesses policy entrepreneurs' strategies to cross boundaries, the conditions that enable entrepreneurs to engage in cross-boundary strategies, and the implications of their cross-boundary strategies. Chapter 3 uses the results of the systematic literature review to develop and test a framework to study a processual approach to policy entrepreneurship that acknowledges the dialectic relation between contextual conditions and policy entrepreneurship, by focusing on the development 
process of the GACSA. Chapter 4 follows up on one of the conclusions from chapter 3 - that studying cross-boundary entrepreneurship requires a firmer embedding of entrepreneurship in context. It therefore takes a multi-theoretical approach, utilizing three policy process frameworks (advocacy coalitions, multiple streams, punctuated equilibrium) to analyse the development of the National CSA Strategy in Kenya. The in-depth insights from the case study in Kenya are complemented with a longitudinal frame analysis described in chapter 5. This study identifies general trends and patterns of CSA-relevant policy development in Kenya over time, something largely lacking in the academic literature. Finally, chapter 6 synthesizes the results from the aforementioned studies, answers the research questions, discusses the relevance of the dissertation for science and society, and provides directions for follow-up research. 


\section{Policy entrepreneurship across boundaries:}

\section{a systematic literature review}

This chapter is published as: Faling, M, R. Biesbroek, S Karlsson-Vinkhuyzen and KTermeer (2018) 'Policy entrepreneurship across boundaries: a systematic literature review'. Journal of Public Policy, doi: I 0. I0 I 7/S0 | 438 | 4X 8000053 


\section{Abstract}

Although policy entrepreneurs are assigned an important role in crossing policy boundaries and addressing complex problems, our understanding of the process is limited. This article systematically reviews 5 I studies on conditions, strategies, and implications of cross-boundary entrepreneurship. Findings shows that $(I)$ the literature predominantly mentions issue promotion and coalition-building as crossboundary strategies; (2) vertical boundary-crossing is discussed more frequently than horizontal boundary-crossing; (3) the most reported boundary-crossing function is to expand issue arenas; (4) conditions that enable cross-boundary strategies include institutional overlap, issue interpretation, power vacuum, overruling policies, lacking resources; and (5) implications of entrepreneurship include raised opposition, increased competition over leadership, augmented complexity hindering collective action, raised costs and resources, and issues regarding trust, legitimacy, and authority. Policy entrepreneurship allows for micro-level insights in the emergence of crossboundary processes. We suggest future research to focus on causal processes between conditions, strategies, and implications to better understand their interplay 


\section{I Introduction}

Many contemporary societal challenges seem to span various policy boundaries. They cross domains - arenas in which issues such as agriculture or defence traditionally have been addressed, steered, and governed\{Peters, 2015 \#40;Boin, $2016 \# \mid 91\}$ - and levels - levels of government within an established territory, with interacting authority structures - that range from the global to the local levels (Berkes 2002, Boin and Lodge 2016, Briassoulis 201 I, Koppenjan and Klijn 2004b, Peters 2015, Scharpf 1991). Climate change for example is increasingly addressed from multiple levels - municipal to global - and occupies multiple policy domains - from agriculture to environment. Another example of a crosscutting challenge is enduring poverty. To address this challenge, all member states of the UN unanimously adopted the 17 Sustainable Development Goals (SDGs) in 2015, the implementation of which imply coordination among various domains and levels (Hajer et al. 20 15).Traditional policy domains and levels are increasingly considered inadequate to accommodate the complexities and uncertainties inherent to contemporary societal problems (Candel and Biesbroek 2016; Head 2008; Rittel and Webber 1973; Kettl 2006). Consequently policy processes are viewed to progressively crosscut the boundaries of policy domains and levels (Williams 2002, Jochim and May 2010, May and Jochim 2013). Policy boundaries are understood here as constructed separations or demarcations used to understand and categorize policy issues (see O'Flynn, Blackman, and Halligan 2013). Hence, boundaries are an analytical rather than a demarcated empirical construct, which implies that it is not always evident where one domain ends and another begins (Nohrstedt and Weible 2010 , see also discussions in Abbott 1995).

The process of spanning various policy boundaries excites scholarly interest, reflected in attention for related concepts, including boundary-spanning policy regimes (Jochim and May 20l0), policy integration (Candel and Biesbroek 2016, Biermann, Davies, and van der Grijp 2009) and horizontal management (Peters 2015). This literature often refers to the importance of policy entrepreneurs understood broadly as (semi) public or private actors undertaking a set of strategies towards certain policy outcomes (Kingdon 1995, Mintrom and Norman 2009, Zahariadis and Exadaktylos 2016) - in the process of crossing policy boundaries. Some authors suggest that policy entrepreneurs strengthen policy support among policy fields by forging linkages among different arenas (May and Winter 2009). 
Other studies highlight how policy entrepreneurs adapt arguments from across policy boundaries to strengthen their advocacy efforts and by doing so drive the diffusion of knowledge across horizontal and vertical boundaries (Jones and Jenkins-Smith 2009, Pump 201 I). Peters (2015) demonstrates how strategies of policy entrepreneurs are essential in the politics of working across policy areas, for instance by creating sufficiently powerful ideas to make policy coordination effective, something that happened with homeland security in the aftermath of $9 / 11$.

Although the literature suggests that policy entrepreneurs play an important role in the crossing of policy boundaries, we have a limited understanding of the actual process through which policy entrepreneurs cross boundaries and about the conditions for, and implications of, boundary-crossing. Following the study by Pettigrew (1997), we understand process as a "sequence of individual and collective events, actions, and activities unfolding over time in context". As such, we argue that the actions of entrepreneurs have implications, which drive policy processes, while simultaneously these actions are embedded in and enabled and constrained by certain contextual conditions (see also Garud, Hardy, and Maguire 2007, Oborn, Barrett, and Exworthy 201 I). The outcomes of these processes are generally seen as some form of policy change (Mintrom and Norman 2009).Such a processual approach avoids an idiosyncratic study of actions of individuals detached from their environment, and necessitates the analysis of conditions, strategies (i.e. the actions of entrepreneurs) and implications. In this study, we are therefore interested in the conditions under which entrepreneurs engage in cross-boundary strategies. For example, a lack of knowledge within government around a particular issue might create a void for policy entrepreneurs to fill.This knowledge is important to be able to co-create an environment in which cross-boundary challenges can be addressed with the help of policy entrepreneurs. Moreover, insights in the cross-boundary strategies of policy entrepreneurs is of crucial importance as it contributes to understanding and applying tactics to foster cross-boundary processes within those contexts. Strategies are understood here as (sets of) activities, manoeuvres or actions of a particular kind for a particular purpose (Grinyer and Spender 1979, cited inWernham 1985, Zahariadis and Exadaktylos 2016). These outputs can include changes in policy paradigms, policy systems or policy instruments and decision-making procedures. Finally, knowledge about the implications of crossboundary strategies of policy entrepreneurs is of interest as it may allow for a better understanding of how strategies contribute to specific policy outcomes. For 
example, whereas cross-boundary strategies may lead to increased support for entrepreneurs' proposals, it may equally excite opposition.

To deepen our understanding of the cross-boundary strategies by policy entrepreneurs, the conditions under which they undertake these strategies and the implications of their actions, we systematically review the large body of policy entrepreneurship literature. The article is structured as follows. First we explain the methods deployed for undertaking the systematic literature review (second section). We then report the results of our study by presenting a general characterization of the literature (third section). We then turn to presenting cross-boundary strategies in the literature and examining the directions, functions, and types of strategies mentioned (fourth section). This is followed by presenting the conditions for cross-boundary strategies (fifth section) and the implications of cross-boundary strategies (sixth section). Finally, we argue that policy entrepreneurs use several cross-boundary strategies, cross various policy boundaries, and do so for different functions (seventh section).

\subsection{Methodology}

The systematic review is used here as a qualitative approach to the literature that combines a systematic and transparent data collection process and an open and inductive process to analyse data (Gough, Oliver, and Thomas 2012, Petticrew and Roberts 2008). In this section we provide an overview of the steps taken in the review process, following the PRISMA protocol for systematic reviews (Moher et al. 2009); see also figure 2.I. See Annex I for more detailed background on the steps taken.

\subsection{Data collection}

To identify eligible studies, we conducted an electronic search in Scopus and Web of Knowledge, the two largest electronic scientific databases for the social sciences (Falagas et al. 2008). We conducted our search in September 2016, and did not use any year delineation. We selected keyword, title and abstract information as sources for electronic searching. The literature on policy entrepreneurs is extensive, scattered over various disciplines and approaches, and uses different modifiers, including policy, institutional, and norm entrepreneur (Petridou 2014). Given the 
explorative nature of this article and to avoid sampling bias, we include any type of entrepreneurship towards policy change. Consequently, we used a broad search string consisting of "entrepreneur", "strategy" and "policy". Articles on business entrepreneurs were excluded, given the focus of this article on policy change. We did so through the Boolean NOT operator, followed by a list of terms associated with business ("corporate", "enterprise", "business"). To determine the level of search precision, we sampled 10\% of the excluded literature (332 of 3.317 studies) and estimated the amount of falsely excluded studies by screening the abstracts. The exclusion criteria resulted in 1.5\% of falsely excluded studies, which we found to be an acceptable percentage. Only English articles were considered for language proficiency reasons. The Boolean search revealed a total of 774 articles for full review.

\subsubsection{Eligibility criteria and exclusion of studies}

We assessed the abstracts of 774 articles on the basis of the content of the studies: they had to address policy entrepreneurs' strategies for policy change. Strategies are defined as (sets of) activities, manoeuvres or actions of a particular kind and for a particular purpose, available to the entrepreneur (Scharpf 1991, Brouwer 2015). We excluded 299 studies that did not focus on entrepreneurial strategies (e.g. on characteristics of entrepreneurs). As it is impossible to assess all literature on the basis of its abstract, we thereafter screened the full text of the remaining 475 studies, again on the basis of their focus on strategies for policy change. In this round, we excluded 233 studies that were not about policy entrepreneurship or strategies. We also selected on the basis of study design: only empirical articles that used primary data were included, in order to review findings based on direct observations and exclude theoretical and interpretative extrapolations (excluding 9 studies). This resulted in a list of I 44 studies suitable for full-text reading and analysis. We conducted a full-text exploration on the selection of 144 studies to select the articles discussing cross-boundary strategies. We only included articles that make explicit reference to entrepreneurial strategies across policy boundaries of level and domains. Cross-boundary strategies are understood as activities whereby the entrepreneur targets a domain or level different from where he/she is positioned, or links multiple domains or levels. This resulted in 5 I relevant studies for review. Although this number may seem rather small, given the wealth of studies on policy entrepreneurship it is an acceptable sample for an explorative review (Intindola, Weisinger, and Gomez 2016). 


\section{Initial assessment literature}

Scopus search "entrepreneur" AND "policy"; at random check of

abstracts for search terms and synonyms

\section{Boolean search}

Scopus, WoS. title, abstract, key words. "entrepreneur" AND

"strategy" AND "policy" AND NOT "business"

\section{Screening abstracts}

Content, type

Excluding not on entrepreneurs' strategies for policy change (299)

\section{Screening full text}

Excluding not on entrepreneurs' strategies for policy change (233)

Excluding non-empirical papers (98)

\section{Screening full text}

Excluding not mentioning crossboundary strategizing (93)

\section{Final selection literature}

Literature: English, empirical studies on crossboundary strategies for policy change

\section{Coding on categories}

Deductive

General characteristics, conditions, strategies, implications

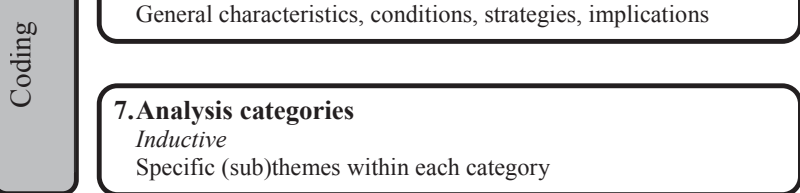

Specific (sub)themes within each category

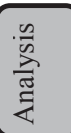

\section{Chi-square test}

Phi-coefficient measures strength of association between categorical variables

Figure 2.I The systematic review process.

\subsubsection{Data abstraction process: the coding of studies}

To analyse the qualitative data in the sampled articles, we deployed an interpretive synthesis, to organise concepts identified in the studies into an umbrella theoretical structure by identifying recurring or prominent topics in the literature and summarising main findings under different concepts (Dixon-Woods et al. 2005). To do so, we designed a data extraction protocol and table to summarise and capture the content of the selected $5 \mathrm{I}$ articles (see Annex I). We captured the general and 
background characteristics of each study (year, author, topic and regional focus, type of entrepreneur). We subsequently coded each study for three categories related to the research question discussed in the introduction. First, we coded for crossboundary strategies: (sets of) activities, manoeuvres or actions of a particular kind and for a particular purpose, whereby the entrepreneur targets a domain or level different from where he/she is positioned, or links multiple domains or levels. Second, we coded for conditions, to be understood as (one of) the premise(s) upon which the appearance, occurrence and/or manifestation of the cross-boundary strategising depends. Third, we coded for implications, the consequence(s) following from and directly dependent on the strategies of the entrepreneur.

Using Atlas.ti 7 we conducted a thematic analysis of the evidence to identify prominent or recurring (sub)themes within each category, based on our interpretation of the evidence (Dixon-Woods et al. 2005). To safeguard the quality of our analysis, we discussed interpretations of categories and (sub)themes among the researchers on a regular basis. Table 2.I provides an overview of the different categories (sub)themes and definitions. The variables from the data extraction table were imported in IBM SPSS 22 to enable qualitative and quantitative analysis of the relationship between and co-occurrence of our variables.

\subsubsection{Data analysis: the $\varphi$-coefficient}

To understand the linkages between the different characteristics of strategies - type, direction, and function - we conducted a $\times 2$ test to calculate the $\varphi$-coefficient. The $\varphi$-coefficient is a measure of the strength of association between two categorical variables, with an interpretation similar to other correlation coefficients. Its value ranges from -1 for a perfect negative association to $+\mid$ for a perfect positive association (Field 2009). 


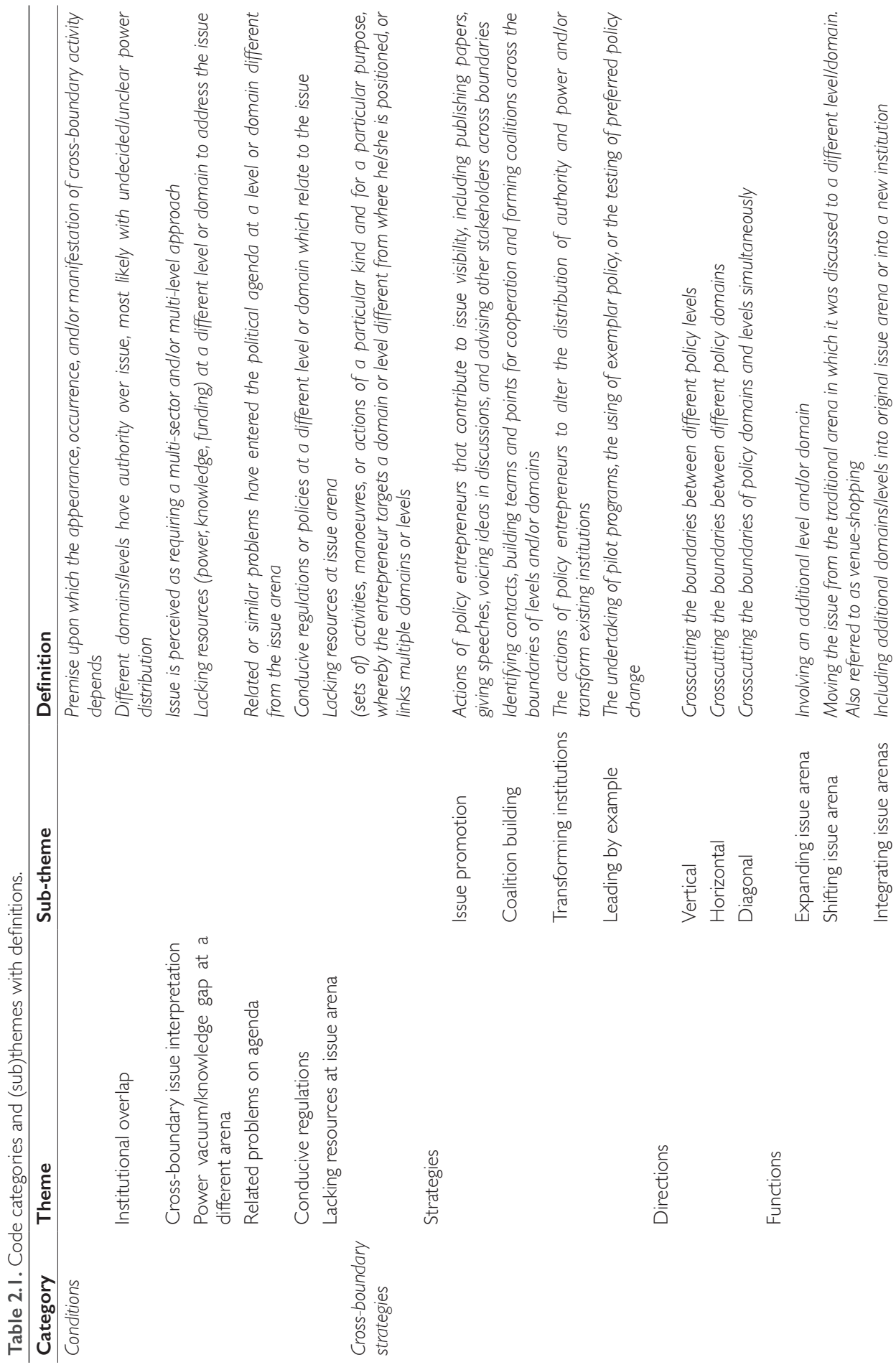


Chapter 2

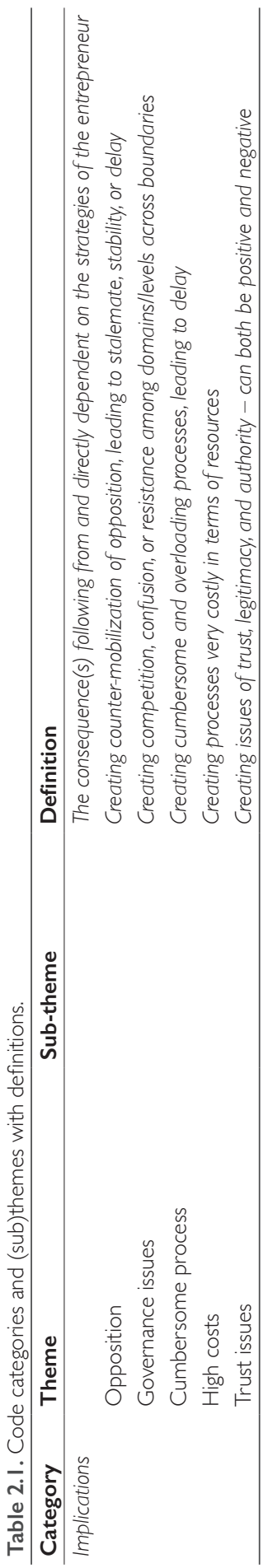




\subsubsection{Limitations}

Although systematic reviews have great advantages over traditional reviews, there are limitations to be considered. By selecting scientific, peer reviewed English literature, this study excludes other literature that might have contributed to our understanding of cross-boundary entrepreneurial strategies, such as PhD theses or other sources not in the databases used. Although a systematic analysis of the literature limits bias and increases transparency of the process, the thematic analysis of evidence leaves open a certain level of interpretation and is limited in transparency. We have attempted to limit this bias by reporting on our thematic analysis and by discussing interpretation among the author team. Ideally a systematic review would set a benchmark regarding quality appraisal of studies included. However, because of limited reporting on methods and the great variety of quality judgements among different disciplines, trainings and preferences, it is unfeasible to identify best practices (Paterson et al. 200I). Moreover, different research questions in the selected articles require different approaches and methods. We accept these as limitations to the research and discuss the implications in the final sections of the article.

\subsection{Characterising the literature}

This section presents the general characteristics of the literature on policy entrepreneurship. The majority of the 5 I selected studies is a single-case study (78\%) with a few studies comparing multiple cases of policy entrepreneurship in a cross-boundary setting. The majority of studies fails to report on study design and methodology entirely (31\%); only 18\% of the studies contain a separate methods section (i.e. description of case selection, data collection, analysis). The methods used most include interviewing (67\%) and document study (47\%). Other methods include survey (7\%) and observation (7\%). Regarding analysis (addressed by only 18\% of studies), studies refer mostly to coding (14\%); others use statistics (4\%) and social network analysis (4\%). Figure $2.2 \mathrm{a}$ presents the amount of publications per year and illustrates an increase in studies that cover cross-boundary entrepreneurial strategies - in line with a general trend in publications, and publications on policy entrepreneurship (Petridou 2014). Most studies cover topics such as environment and water, security and climate (figure 2.2b), which cover issues typically indicated as "wicked" or complex, such as terrorism, water management, and climate change 
adaptation (see for instance Jochim and May 20 I0, Peters 20I5).The types of actors acting as policy entrepreneurs predominantly include political actors, administrative actors, and non-governmental organisations (NGOs) (figure 2.2c). The studies included in our analysis predominantly take a supranational focus (32\%, of which $26 \%$ focusses on the European Union), followed by a national (29\%), subnational (26\%), and lastly global focus (I 3\%) (figure 2.2d). As for national-level studies, 16\% of the articles focus on the United States (US) and 6\% of the articles discuss policy entrepreneurship in China. Most articles focus on high-income countries (65\%), followed by middle-income countries ( $18 \%)$. Very few studies (4\%) focus on lowincome countries, and some studies focus on a mix (13\%). Moreover, it seems to be a relatively recent phenomenon to focus on policy entrepreneurship in lowerincome countries (Cairney and Jones 2016); the majority of studies until 2012 focussed on high income countries, and from 2012 onwards authors increasingly seem to study policy entrepreneurship in middle- and lower-income countries.

Policy entrepreneurs are predominantly state actors: political (28\%) and administration (24\%), followed by NGOs (21\%). The studies we analyse discuss administration and political actors as policy entrepreneurs mostly in high-income countries, and NGOs as entrepreneurs in low-income countries. In middle-income countries entrepreneurship is mostly undertaken by political actors and NGOs.

In the following synthesis sections, we present a processual analysis of policy entrepreneurship towards policy change by focussing on cross-boundary strategies. To contextualise these strategies, we subsequently focus on the contextual conditions in which cross-boundary strategies are embedded, and the contextual implications of cross-boundary strategies. 
FIGURE 2.2A. Papers published per year.

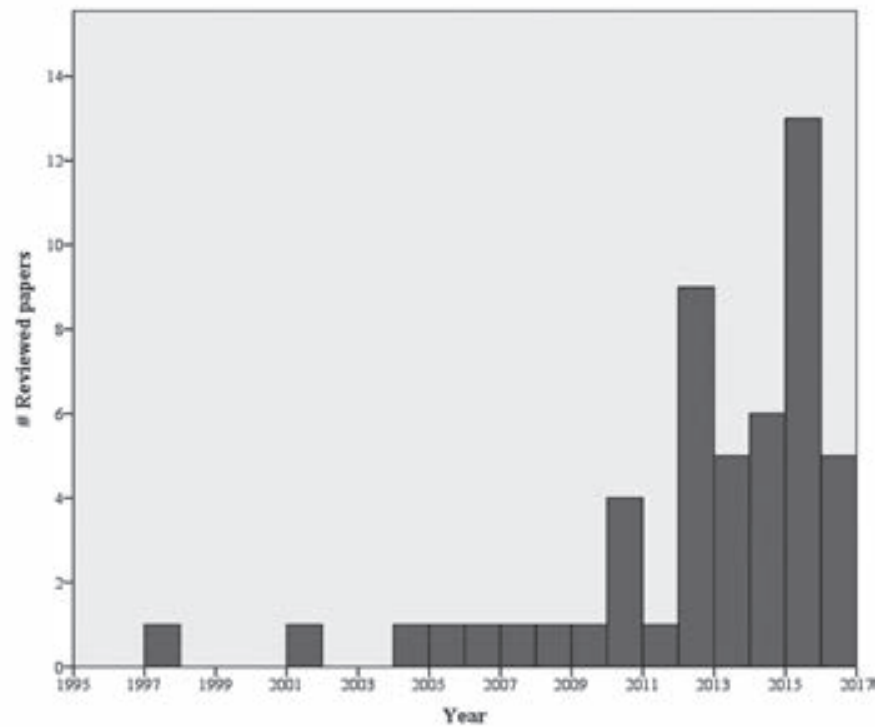

FIGURE 2.2B. Topics covered in papers.

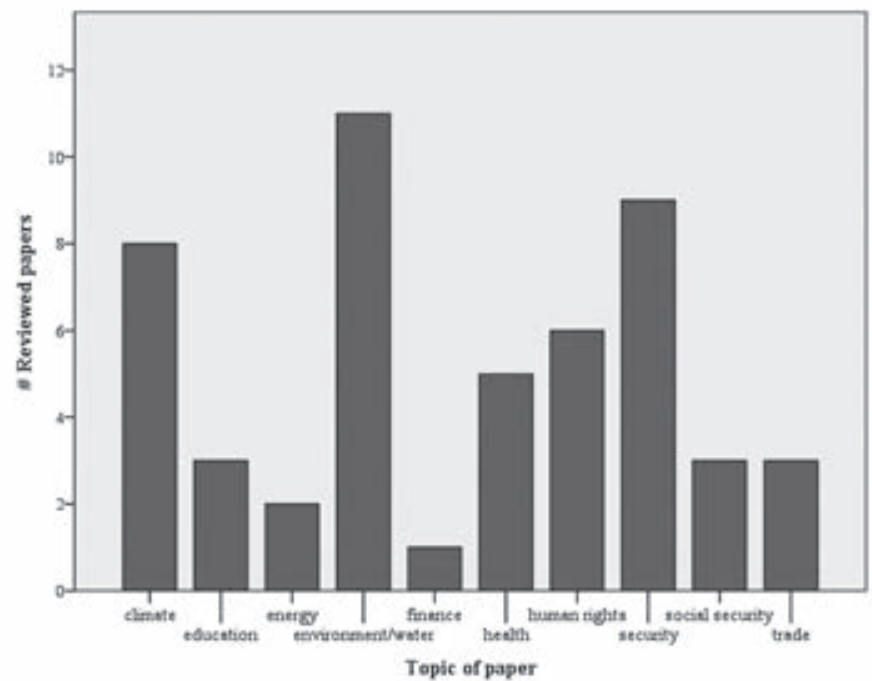


Chapter 2

FIGURE 2.2C. Actors as entrepreneurs in papers.

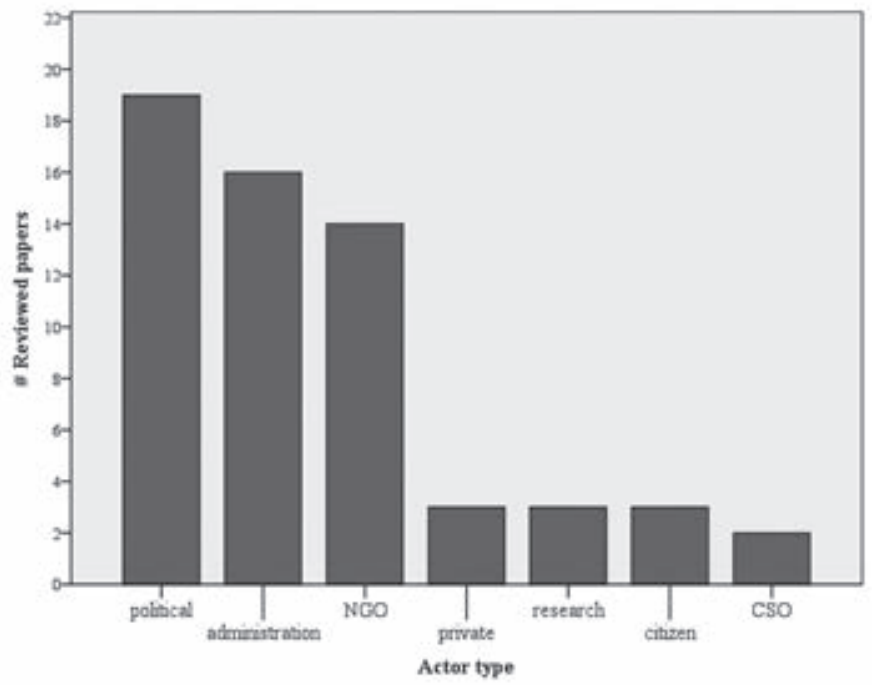

FIGURE 2.2D. Level targeted by entrepreneur in papers.

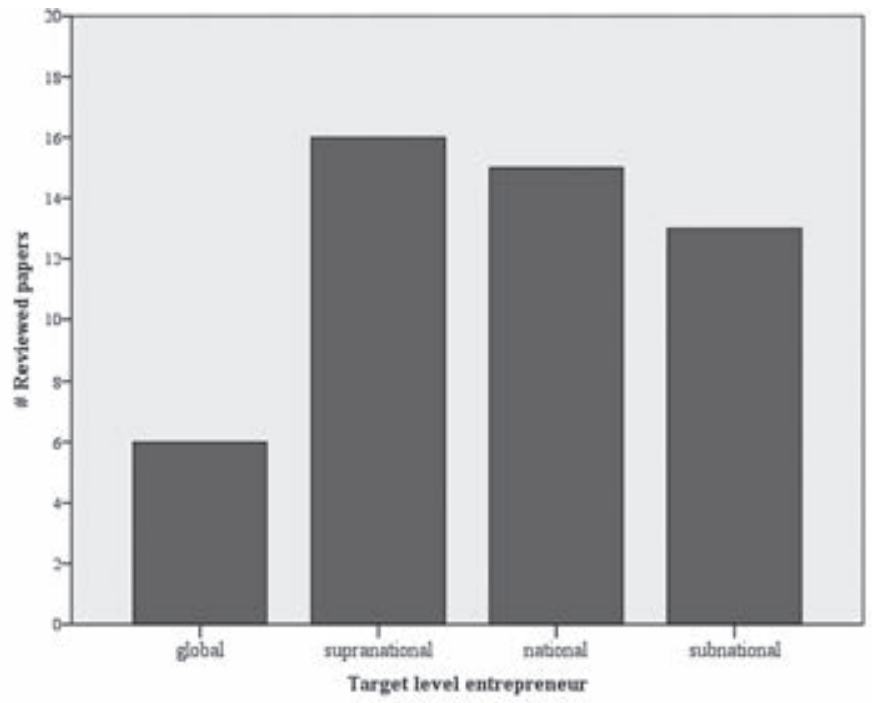




\subsection{Cross-boundary strategies}

We now turn to a discussion of the cross-boundary strategies mentioned in our sample of the literature. We found a large number of strategies reported in the literature, which we clustered in three main constitutive elements of crossboundary strategies - types of strategies such as framing and coalition building; directions of strategies: horizontal, vertical, or diagonal; and functions of strategies, such as expanding or shifting the issue arena. See table 2.2 for an overview of the strengths of associations between directions, functions, and strategies.

Table 2.2. Phi-coefficients for strategies, functions and directions.

\begin{tabular}{|c|c|c|c|c|c|c|}
\hline & \multicolumn{3}{|l|}{ Direction } & \multicolumn{3}{|l|}{ Function } \\
\hline & Horizontal & Vertical & Diagonal & Expand & Shift & Integrate \\
\hline Expand & $\begin{array}{l}-.168 * * * 1 \\
-\end{array}$ & $\begin{array}{l}.180 \text { 米米 } \\
-\end{array}$ & $\begin{array}{l}-.054 \\
25 \%\end{array}$ & & & \\
\hline Shift & $\begin{array}{l}-.031 \\
-\end{array}$ & $\begin{array}{l}.006 \\
-\end{array}$ & $\begin{array}{l}.040 \\
25 \%\end{array}$ & & & \\
\hline Integrate & $\begin{array}{l}.304^{* * * * *} \\
25 \%\end{array}$ & $\begin{array}{l}-.290 \text { ***** } \\
25 \%\end{array}$ & $\begin{array}{l}.030 \\
25 \%\end{array}$ & & & \\
\hline Promoting & $\begin{array}{l}-.257^{*} * * * * 1 \\
-\end{array}$ & $\begin{array}{l}.332 \text { ****** } \\
\text { - }\end{array}$ & $\begin{array}{l}-.185^{* * *} \\
50 \%\end{array}$ & $\begin{array}{l}.124^{*} \\
-\end{array}$ & $\begin{array}{l}-.075 \\
-\end{array}$ & $\begin{array}{l}-.092 \\
-\end{array}$ \\
\hline Framing & $\begin{array}{l}.302 \text { 米米保 } \\
\text { - }\end{array}$ & $\begin{array}{l}-.429 \text { ****** } \\
\text { - }\end{array}$ & $\begin{array}{l}\left..29\right|^{* * * * *} \\
25 \%\end{array}$ & $\begin{array}{l}-.239 * * \\
-\end{array}$ & .132 米 & $\begin{array}{l}.194 \text { ****** } \\
25 \%\end{array}$ \\
\hline Coalition building & $\begin{array}{l}.068 \\
-\end{array}$ & $\begin{array}{l}-.029 \\
-\end{array}$ & $\begin{array}{l}-.026 \\
25 \%\end{array}$ & .204* & $\begin{array}{l}-.104 \\
-\end{array}$ & $\begin{array}{l}-.177 \text { ***十 } \\
25 \%\end{array}$ \\
\hline Institutional manipulating & $\begin{array}{l}.050 \\
25 \%\end{array}$ & $\begin{array}{l}-.037 \\
-\end{array}$ & $\begin{array}{l}-.015 \\
25 \%\end{array}$ & $\begin{array}{l}-.212^{* * * *} \\
-\end{array}$ & $\begin{array}{l}.094 \\
25 \%\end{array}$ & $\begin{array}{l}.204^{*} * * 6 \\
25 \%\end{array}$ \\
\hline Leading by example & $\begin{array}{l}-.133^{* * * * *} \\
25 \%\end{array}$ & $\begin{array}{l}.096 \\
25 \%\end{array}$ & $\begin{array}{l}.047 \\
25 \%\end{array}$ & $\begin{array}{l}.060 \\
25 \%\end{array}$ & $\begin{array}{l}-.003 \\
25 \%\end{array}$ & $\begin{array}{l}-.090 \\
25 \%\end{array}$ \\
\hline
\end{tabular}

Note: Percentages refer to the amount of cells with an expected count less than 5 . As this study is an exploration of the literature, we accepted this limitation, but decided to publish the percentage of cells that have an expected count lower than 5. All cells in grey have an expected count less than 5.

*, ***, ***** Significant at $0.10,0.05,0.01$, respectively.cross-boundary

\subsection{Types of cross-boundary strategies}

Despite the different topics, contexts, and types of actors as policy entrepreneurs, the literature analysed discusses a variety of strategies, which we cluster into five categories: issue promotion, issue framing, coalition-building, manipulating institutions and leading by example.

The first category of cross-boundary strategies is issue promotion. Issue promotion refers to the actions of policy entrepreneurs that contribute to issue visibility, 
including publishing articles, giving speeches, voicing ideas in discussions and advising other stakeholders across boundaries (Brouwer and Biermann 201 I, Font and Subirats 2010). This is the strategy most mentioned: 56 times in 28 of the articles. In our sample of articles, issue promotion has a weak positive association with vertical boundary-crossing (.33), and negatively with horizontal (-.26) and diagonal boundary-crossing (-.19), suggesting that policy entrepreneurs promote issues in other levels and domains rather than across horizontal or diagonal boundaries. One example of issue creation in vertical direction is by Boekhorst et al $(2010)$ \{, 2009 \#98;Boekhorst, 2010 \#27\} who show the role of the World Wildlife Fund in promoting Integrated River Basin Management in China. The authors exemplify how local stakeholders promoted an Integrated River Basin Management approach at various regional events and through various media channels and organized a roundtable for stakeholders at the regional level, to expand the issue arena to also include the regional level. We find a weak positive association in the literature between issue promoting and expanding the issue arena (. I2).

A second category of cross-boundary strategies is building coalitions. This refers to identifying contacts, building teams and points for cooperation and forming coalitions across the boundaries of levels and/or domains (Brouwer and Biermann 201 I, Mintrom and Norman 2009). Coalition building is mentioned 35 times in 24 papers. This strategy is not significantly associated with any particular direction of boundary-crossing, however our sample illustrates how policy entrepreneurs deploy coalition-building strategies mostly in relation to vertical boundary-crossing (23). In terms of the function of crossing boundaries, in the literature coalition-building is mostly associated with expanding the issue arena (.20), and negatively with integrating issue arenas (-. 18). This illustrated for instance by Douglas et al. (2015) who discuss the diffusion of drug courts in the US and report how individuals from the municipal government founded the National Association of Drug Court Professionals to promote the concept of drug courts, share information among different states, develop guiding principles and lobby Congress. The entrepreneurs thereby expanded the issue of drug courts to higher policy levels.

A third category discussed in the selected articles is manipulating or transforming institutions. This includes the actions of policy entrepreneurs to alter the distribution of authority and power and/or transform existing institutions (Ackrill, Kay, and Zahariadis 2013, Meijerink and Huitema 2010, Zahariadis and Exadaktylos 2016) 
\{Zahariadis, 2016 \#4;Ackrill, 2013 \# |02\}. This strategy is discussed in the literature 22 times in 20 different articles. There is no significant association between institutional transformation and the direction of boundary-crossing. The papers in our sample discuss policy entrepreneurs who deploy institutional manipulation tactics mainly in association with expanding the issue arena (.21). For example, Newman (2008) explains how national data privacy authorities pushed the EU to adopt data privacy policies by threatening to block trans-border data flows if countries would not accept legislation to protect citizens' privacy. As such, the national data privacy authorities used the power granted to them as institutions at the national level to influence affairs at the regional level by exerting power over inactive policymakers. Institutional transformation is not associated significantly with any particular direction, meaning that it is used for horizontal, vertical and diagonal boundary-crossing.

The fourth category of cross-boundary strategies is issue framing. Framing broadly refers to the use of narratives and stories to make sense of an issue by selecting particular relevant aspects, connecting them into a sensible whole and delineating issue boundaries (Dewulf et al. 2005, Stone 2002). This strategy is discussed 25 times in 20 different articles. Framing is linked to idea promotion; the distinction we make is based on the author's delineation of the action - e.g. is the frame or the promotion action described. Framing is in the sample of literature positively associated with horizontal (.30) and diagonal (.29) boundary-crossing, and thus policy entrepreneurs mainly frame their issues across different domain boundaries. Through framing policy entrepreneurs seem to integrate issue arenas, given the weak positive association (.19). An example includes a study by Hermansen (2015) on the establishment of a donor-side REDD+ initiative in Norway as a result of two environmental NGOs joining forces and linking their respective issues of concern. In their attempt to convince the government of forest protection, they sent letters to the Prime Minister, and the Ministries of Finance, Foreign Affairs, and International Development, wherein they presented rainforest preservation as a solution to climate change. Eventually, and in reaction to this letter, the government of Norway establishes the International Climate and Forest Initiative (NICFI) whose objective is to reduce GHGs resulting from deforestation in developing countries (Hermansen 20I5).

The fifth and last category of cross-boundary strategies we found in the literature is leading by example: undertaking pilot programs, using an exemplar policy, 
or testing preferred policy changes at a different policy level or across domain boundaries (Huitema and Meijerink 2009). This strategy is discussed II times in 9 different articles. Most studies discuss this strategy in relation to vertical boundarycrossing (10), although we found no significant association. Only in one instance is diagonal boundary-crossing discussed: policy entrepreneurs within the local water department use pilot projects to convince other departments at the national level to join their initiative (Uittenbroek, Janssen-Jansen, and Runhaar 2016). Leading by example is predominantly discussed in relation to expanding the issue arena (9), although there is no significant association. Meijerink and Huitema (20I0) for instance discuss how policy entrepreneurs use smaller-scale implementation to gain experience with the proposed policy. They highlight how in the Netherlands policy entrepreneurs first introduced "Plan Stork" as a pilot program before the adoption of the generic "Space for the River" policies to gain experience.

\subsubsection{Directions of cross-boundary strategies}

The literature discusses three directions in which policy entrepreneurs cross policy boundaries: vertical, horizontal, and diagonal.

Vertical boundary-crossing refers to policy entrepreneurs deploying strategies that crosscut the boundaries between different policy levels - for example, between the regional EU level and the national level. Vertical strategies occur I I 4 times in 43 of the articles - some studies mention multiple vertical cross-boundary strategies. Vertical boundary-crossing can occur both top-down and bottom-up, although most studies mention strategies towards higher policy levels (83) and far less to lower policy levels (28). In the literature, vertical boundary-crossing is mainly associated with expanding the issue arena (.18) and with issue promotion (.33). An example of vertical boundary-crossing through issue promotion is the inclusion of actors in Spain who lodged complaints with the EU to challenge the dominant domestic water agenda in Spain. As a result, the European Commission sent a letter to Spain's Ministry of Environment to express its concern with Spain's water management (Font and Subirats 20l0). 
The second direction, horizontal boundary-crossing, refers to strategies that crosscut the boundaries between administrative policy domains and issue departments within the same policy level. Horizontal strategies occur 27 times in the literature, in 20 different studies. Horizontal boundary-crossing is in the literature mostly associated with strategies of issue framing (.43). An example includes the work of Diez (2010) who discusses how an alliance of actors working in different federal bureaucratic agencies in Mexico developed arguments to counter homophobia, and convince the government and the public at large of the need of a gay-rights campaign. They did so by means of framing homophobia (I) as an obstacle to fight aids to involve the public health sector, and (2) as a human rights issue, thereby prohibiting discrimination against homosexuals. Moreover, horizontal boundarycrossing is significantly associated in the literature with integrating issue arenas (.30).

The third direction is diagonal boundary-crossing, which refers to the activities that cross both horizontal and vertical boundaries simultaneously. This cross-boundary direction is mentioned seven times in seven different articles. The literature moderately associates this direction with framing strategies (.29), but there is no association with any of the functions of crossing boundaries. An example of diagonal boundary crossing is provided by Kugelberg et al. (2012). They study the process of Slovenian National Food and Nutrition Policy development, and report how the policy entrepreneur within the WHO European Region on public health wanted to engage the Slovenian Ministry of Agriculture in the development of this policy, and proposed to undertake the EU Common Agriculture Policy impact assessment, which would benefit the Ministry. The entrepreneur thereby convinced the Ministry to become engaged in the policy process (Kugelberg, Jönsson, and Yngve 20 I2).

\subsubsection{Functions of cross-boundary strategies}

We found that the analysed literature mentions three functions of cross-boundary strategies: to expand the issue arena to additional domains and/or levels, shift the issue arena to a different domain or level or integrate an additional issue arena into the original or a new issue arena.

The first function, which occurred most in the literature ( 105 times in 36 of the articles), is expanding the issue arena by involving an additional level, domain or both. Our findings show that arena expansion is weakly associated with vertical boundary-crossing (.18). The strategies discussed to expand the issue arena are 
predominantly issue promotion (.32). For instance, DeFranco et al. (2015) report how the UN Special Advisor for Genocide Prevention met with EU key figures to persuade them to prioritize the so-called Responsibility to Protect (R2P), a global political commitment endorsed by all UN member states to prevent genocide, war crimes and ethnic cleansing, in order for the EU to take a more active role.

The second function of cross-boundary strategies is for policy entrepreneurs to shift the issue arena from the arena in which it was addressed to a new or different arena at a different domain or level, so as to shift jurisdiction over the issue. This is often referred to in the literature as "venue-shopping": finding an arena that provides the best prospects for achieving one's preferred policies (Baumgartner and Jones 2010, Pralle 2003a). This function is discussed 27 times in 16 of the articles. The analysed literature suggests that shifting issue arenas is not associated with any direction or strategy in particular; shifting issue arenas is thus expected to be done through various strategies and in different directions. An example of shifting issue arenas is provided by Perkmann and Spicer (2007) who discuss how local authorities situated close to European borders promoted the coordination across borders between different municipalities with the EU, in order for the EU to support transnational cooperation across borders.

The third function of cross-boundary strategies is the integration of domains, levels or both into the original issue arena or combine them into a newly established arena. This strategy is discussed 13 times in nine articles. Integration of issue arenas occurs significantly in association with horizontal boundary-crossing (.30) and through strategies of institutional manipulation (.20) and framing (.19). An example is the work of Carter and Jacobs (2014) who explain the emergence of the UK Climate Change and Energy Policy. This study discusses how the UK Secretary of State at the Department for Environment, Food and Rural Affairs created a new government institution, the Inter Departmental office for Climate Change (OCC), which they handed over the responsibility for the development of a climate change bill. The OCC united and represented all main departments affecting GHG emissions including environment, energy, business and overseas development (Carter and Jacobs 2014). As such, policy entrepreneurs established a new institution to integrate different policy domains and have them address the issue of climate change jointly. 


\subsection{Conditions for cross-boundary strategies}

The cross-boundary strategies policy entrepreneurs employ do not happen in a vacuum. Strategies are embedded in contextual conditions, which codetermine their appearance. The literature refers to several different types of conditions for policy entrepreneurs to engage in cross-boundary strategies. Conditions refer to the structural premises that affect the manifestation of cross-boundary strategies (Blavoukos and Bourantonis $20 \mathrm{l}$ I).We clustered these in six main categories.

The first set of conditions for cross-boundary strategies refers to institutional overlap, for instance, if the authority over the issue is with different levels and/or domains (Ackrill and Kay 20 II, Maltby 2013, Newman 2008, Zito 200 I). This condition is mentioned predominantly in relation to EU policy processes whereby authority over certain issues is distributed among different Directorates-General, with non-discrete and undecided power levels between them. The articles report the functionality of this overlap as it provides opportunities to entrepreneurs to pick the arena most appealing to exert their influence (see also Meijerink and Huitema $2010)$. This condition is also discussed in relation to vertical boundary-crossing. For instance, the literature presents how in some government systems, such as Canada, different levels of government have become increasingly involved in overlapping areas of public policy. Consequently, policy entrepreneurs may move freely from one level to another in an attempt to find the level at which they can try most advantageously to achieve their desired outcome (Pralle 2006, Schattschneider 1960).

A second condition mentioned in the literature is that the issue is interpreted as requiring a multisector or level approach. If that view is perceived as salient, legitimate and credible, this facilitates entrepreneurs to cross boundaries along similar lines. Rosen and Olssen (2013), for instance, argue that because marine ecosystem management requires an integrated approach - as the drivers of degradation often transcend policy sectors and nation state boundaries - policy entrepreneurs crossed policy domain boundaries.

A third condition mentioned in the literature is the existence of a power vacuum or knowledge gap around an issue. This situation might occur when an issue is newly introduced within a certain policy level or domain, or when uncertainties 
around an issue lead to a failure in addressing the issue (Palmer 2010). The power vacuum creates an opportunity space for opportunists looking to further their aims (Tomlins 1997). Policy entrepreneurs might use this window of opportunity (Black and Hwang 2012). The literature also reports how this vacuum might be caused by a process of devolution (Forbes 2012). Decentralized authority might lead to local authorities lacking the knowledge and resources to address the issue in question. These conditions might force local authorities to look for support in terms of finance, knowledge and expertise and may reach out to external experts - such as policy entrepreneurs - for support. The inverse is also possible. When a certain issue is increasingly addressed from the supranational level, policy entrepreneurs might realize that when they are to have an impact they must strategize towards a higher policy level (Verger 2012).

Fourth, the literature shows how conditions to cross boundaries may exist when (related) problems enter the political agenda of a level or domain that is different from the issue arena. These "focussing events" offer the opportunity for entrepreneurs to get relevant actors involved. Björkdahl (2013) exemplifies how Sweden reached for the EU and UN as suitable arenas for the promotion of conflict prevention as their norm would find resonance with the contexts of the regional EU and global UN arena. In the case of the UN Sweden linked its idea of conflict prevention to the UN-doctrine on the R2P. As such Sweden managed to find fertile ground for its notion.

Fifth, conducive conditions at a different level or domain may also be used to exert pressure on the issue arena. Multiple studies mention how policy entrepreneurs refer to policies at higher governmental level to force the issue level to abide by stronger regulations. An example is the work of Dietz (2010) discussed earlier that shows how policy entrepreneurs in Mexico battled for the acceptance of homosexuality and referred to international norms of (sexual) human rights to put pressure on the government (Diez 20l0).

Finally, policy entrepreneurs require various resources including support, finance and knowledge. When these resources are lacking in one issue arena, policy entrepreneurs can use cross-boundary strategies to seek additional resources at other levels or domains. In the above-discussed case of acceptance of homosexuals in Mexico, support was mainly lacking. Mexico was contending with high levels of 
homophobia and policy entrepreneurs promoting sexual rights had very little room for manoeuver. Consequently policy entrepreneurs moved both vertically, making reference to international norms, and horizontally, framing homophobia as a threat to public health, because discrimination and taboo on homosexuality would deter homosexuals from having themselves tested, in order to raise support and put pressure on policymakers (Diez 2010).

\subsection{Implications of cross-boundary strategies}

Policy entrepreneurs engaging in cross-boundary activities due this for various reasons. However, apart from the known motives of increase in resources money, knowledge, support - or successful policy change there are additional consequences and implications involved in deploying cross-boundary strategies. We define implications as the consequences following from and directly dependent on cross-boundary strategies. The literature we analysed discusses various implications.

The first implication is that raising awareness and support might also equally raise opposition to the policy entrepreneur's proposal. As such, crossing boundaries might backfire on the entrepreneur, triggering effective counter-mobilisation, leading to stalemate, stability or delay instead of change (Brinkerhoff 20 I5, Budabin 20 I 5, Diez 2010, Orchard and Gillies 2015, Verger 2012). Orchard and Gillies (2015) discuss the role of the US presidency in refugee protection in the early 20th century. They show that the President aims to raise support for his cause with the international community, in an attempt to sidestep opposition at the domestic level. This exposed his proposal to a range of other states' interests and constraints, raising opposition and limiting his ability to pursue normative change (Orchard and Gillies 20 I5).

A second implication of cross-boundary strategies is that when an entrepreneur assembles institutions from different levels and/or domains to collaborate, this might have implications for governance and leadership. The literature analysed lists several of these implications including competition over leadership (Alimi 20 I 5, Forbes 2012 , Gorton, Lowe, and Zellei 2005), confusion in management (Newman 2008), or reluctance to collaborate from the side of some parties involved (Mukhtarov et al. 2013, Uittenbroek, Janssen-Jansen, and Runhaar 2016). Uittenbroek et al. (2016), for example, discuss how the water department of Philadelphia, US, for the 
implementation of the green storm water infrastructure needed to collaborate with other municipal departments. Although the water department reached out, other departments increasingly proved unsure about the value and hence were reluctant to collaborate.

A third frequently reported implication of cross-boundary strategies is that involving multiple arenas in a large network might be too cumbersome and overloading for collective policy action. Miksel and Song (2004), for example, discuss the passing of the Reading First initiative in the US and find that involving multiple arenas in large networks to achieve specific policy innovations might sometimes compromise collective policy action, because too many actors from different levels and domains slowed down the process. The authors suggest small networks or close circles within larger networks to attain the desired policy objectives in a more efficient manner (Miskel and Song 2004).

Fourth, crossing policy boundaries into additional or different arenas may be costly in terms of resources (Alimi 2015, Pralle 2006, Rosen and Olsson 20I3). Pralle (2006), for example, discusses the policy process around domestic use of pesticides. She describes how policy entrepreneurs needed additional resources upon diversifying their target arenas to include both national and local levels. Therefore, she concludes, small and resource-poor interest groups have little possibilities of undertaking cross-boundary strategies (Pralle 2006). Nevertheless, crossing into additional domains or levels might also raise new resources. Several articles describe how the efforts of entrepreneurs led to an increase in knowledge, expertise, finance and time (Douglas, Raudla, and Hartley 20 I5, Heinze, Banaszak-Holl, and Babiak 20।6).

A fifth and last implication of crossing boundaries reported in the literature is when a policy entrepreneur enters an arena where it has no traditional authority or reputation it may lead to issues regarding trust, legitimacy and authority (Alimi 20I5, Arieli and Cohen 20 I3, Forbes 20I2, Mukhtarov et al. 20I3, Newman 2008). To illustrate this, Alimi (Alimi 2015) discusses the development of a global drug policy and describes how in this process a multi-stakeholder partnership around the promotion of global drug policy called itself a "global mission" as a strategic line in order to pretend to a certain level of legitimacy to create a global process (Alimi 2015). At the same time, crossing boundaries might also lead to enhanced trust and legitimacy (Arieli and Cohen 20 I3, Budabin 20 I5, Heinze, Banaszak-Holl, and Babiak 
2016). Heinze et al. (2016), for example, argue that collaboration across policy boundaries actually fostered trust and legitimacy between the involved institutions.

\subsection{Discussion}

We started this article with the observation that many contemporary challenges transcend the boundaries of policy levels and domains, and that policy entrepreneurs are assumed to play an important role in bridging these boundaries. This systematic review is an exploration of the literature on policy entrepreneurship, to inquire how the cross-boundary strategies of policy entrepreneurship are covered. We have looked specifically at the directions, functions and types of strategies; the conditions under which policy entrepreneurs engage in cross-boundary strategies, and the implications of their actions. In this section, we present four main findings and identify directions for future research.

We find that the literature on policy entrepreneurship pays limited explicit analytical or conceptual attention to cross-boundary strategies. An exception is the notion of "venue shopping", "venue shifting" or "venue manipulation" (Boasson and Wettestad 20 I4, Boekhorst et al. 20 I0, Carter and Jacobs 20 I4, Meijerink and Huitema 2010 , Mukhtarov et al. 2013, Pralle 2006), an activity related to shifting the decisionmaking authority to a different arena, which is discussed not only in the policy entrepreneurship literature but also more broadly in relation to the policy process literature, most importantly punctuated equilibrium theory (Baumgartner and Jones 20 I0, Pralle 2003a). The increasing number of articles addressing boundary-crossing in our sample might well be aligned to the increasing attention for crosscutting policy issues.

Most studies analysed differ in terms of their set-up (e.g. testing theory versus explaining outcome), adjectives for entrepreneur (e.g. policy, norm, political), and disciplinary focus (e.g. international relations, environmental studies). This is not unique for cross-boundary entrepreneurship, as we see similar patterns in the wider entrepreneurship literature (Petridou 2014). However, as a consequence of this variety, our sample of papers is very diverse. Our key elements of boundary crossing processes - conditions, strategies, and implications - function as framework to organize this wide variety of articles. Through deploying the framework, we identify 
certain patterns and general observations in the selected literature. We find that the type of cross-boundary strategy mentioned most is issue promotion, followed by coalition building and issue framing. Other reviews on the policy entrepreneurship literature more generally show similar insights by stressing the key role of the dissemination and framing of new ideas, building coalitions, providing examples and manipulating institutions (Brouwer 2015, Meijerink and Huitema 2010, Mintrom and Vergari 1996, Petridou, Narbutaité Aflaki, and Miles 20 I5). Our review adds to these observations a quantified analysis of the occurrence of different strategies in the literature on policy entrepreneurship, which allows for stronger conclusions. With regard to the direction of strategies, our sample of literature mentions vertical boundary-crossing much more often than horizontal boundary-crossing. It appears that the foremost important function of cross-boundary strategies is to expand the issue arena. The literature also demonstrates certain patterns regarding the cooccurrence of types, directions, and functions of strategies, of which two are most apparent. First, issue promotion is in the literature predominantly associated with vertical boundary crossing and expanding issue arenas. Policy entrepreneurs are thus likely to use issue promotion strategies to expand the issue arena to different - lower or higher - policy levels. This dynamic shows similarities to the concepts of "uploading" and "downloading" of policy ideas in the policy process literature. For instance, Meijerink and Wiering (2009) discuss how river basin management as a concept has moved from the level of municipalities and states to a multi-level focus also involving the supranational (EU) level, and explain this by referring to uploading and downloading of this concept through change agents - in our case policy entrepreneurs (see also Zito 2013). Second, framing is associated mostly with horizontal boundary-crossing and with shifting issue arenas, meaning that policy entrepreneurs are likely to use framing strategies to shift the arena where their issue of concern is discussed to a different policy domain. Baumgartner and Jones (2010) in their explanation on stability and change in American policy discuss how framing can contribute to the shifting of societal understanding about climate change, thereby shifting the government's understanding of issues, and subsequently change understanding of the jurisdiction or authority over climate change, for instance by involving health and environment committees. Studies on entrepreneurship across boundaries might thus capitalize on notions of uploading and downloading and the punctuated equilibrium approach to further their conceptual understanding. At the same time, policy entrepreneurship can enrich other policy process theories by providing a micro-level focus on policy change. 
Our research has contextualised policy entrepreneurship by identifying conditions under which policy entrepreneurs are likely to engage in cross-boundary action, and implications of their endeavours. With the exception of some attempts, many policy entrepreneurship studies have either embraced contextual conditions by adopting in-depth case study methods, which inevitably reduce possibilities of making inferences beyond the single case, or ignored contextual conditions by creating decontextualised lists of possible strategies. Despite the diversity in articles, we manage to cluster different sets of conditions that influence the strategies and implications, including institutional overlap, issue interpretation, power vacuum, related issues entering a different political agenda, stronger regulations at a different level and lacking resources. Our article is a modest effort in the direction of better understanding under what conditions entrepreneurs engage in cross-boundary strategies.

The clusters of implications we distil from the literature include raising opposition, increased competition over leadership, augmented complexity hindering collective action, raised costs and resources, and issues regarding trust, legitimacy, and authority. These implications resemble some of the issues acknowledged in the literature on leadership and multi-stakeholder collaborations, whereby various actors from different sectors, domains, or levels are brought together. Leadership studies acknowledge the important role of leadership to cross boundaries, while reporting how these kind of collaborative efforts may run into various difficulties and challenges regarding authority, trust and legitimacy and competing institutional logics (Bäckstrand 2006, Noble and Jones 2006, Crosby and Bryson 2010, Head and Alford 2015). The literature identifies forging agreement and building trust and legitimacy as important aspects of cross-boundary initiatives, but tells us little about the mechanisms through which this can be done. Organisational literature has particular focus on the institutional context in which entrepreneurial strategies are embedded. This is illustrated, for instance, by Khan et al's (2007) study on unintended consequences of entrepreneurship. Organisational studies also highlight how entrepreneurship involving a diverse audience might complicate legitimacy and support (Lounsbury and Glynn 200I, Garud, Hardy, and Maguire 2007). This research on entrepreneurial strategies is an effort towards providing insight in the micro-level processes of crossing policy boundaries. 
Unfortunately, we were unable to find causal or significant connections between conditions, strategies, and implications. This is attributable to a lack of significant associations between these variables, which can at least partly be ascribed to what Goggin (1986) refers to as the "too few cases/too many variables" problem. This demonstrates the richness in variety of different strategies, deployed by different actors, in different contexts. The level of variation in variables outstrips by any order of magnitude the number of cases, meaning there is too much variation in variables to make useful and reliable inferences about the relationship between variables (Goggin 1986). Moreover, the majority of articles we analysed is based on a singlecase study. Despite the richness provided through thick description and thorough analysis of the subject matter (Reus-Smit and Snidal 20I0), this design complicates pronunciation upon the role of contextual conditions and their impact on the selection of strategies and therefore run the risk of having little explanatory range (King, Keohane, and Verba 1994). This variation illustrates the current state of the boundary-crossing policy entrepreneurship literature. Bringing some convergence in these debates and identifying key lessons and/or general recommendations for research and practice would require further maturing of the field in terms of types of cases, theories and methods used, as well as a shift from inductive studies to more theory testing types of studies that confirm (or disprove) findings from earlier studies on the valuable strategies, implications and contexts. One possible solution to further our knowledge by identifying linkages between conditions, strategies and implications would be to use methods such as Qualitative Comparative Analysis (QCA) to systematically combine and contrast cases to identify causation, and eliminate other explanatory variables. These methods allow for complex causation by assessing multiple (combinations of) variables by their necessary or sufficient contribution to the phenomenon to be explained (Berg-Schlosser et al. 2009). Future research applying methods such as QCA could further enhance our understanding of the relationship between conditions, strategies and implications and help determine in which situation policy entrepreneurs will deploy what kind of strategies, and what the implications of their actions will be.

Our findings raise new questions and observations for further investigation. First, entrepreneurs may not always explicitly aim to cross boundaries; it can also be a side effect or strategy to get what they want. Notwithstanding their motivation, however, these activities may contribute to dismantling the boundaries between levels or domains. Although it is beyond the scope of this article, it would be 
valuable to identify the extent to which policy entrepreneurs are aware of the opportunities and constraints offered by different policy levels and domains. Conditions such as issue interpretation highlight the role of the psychology and motives of entrepreneurs to engage in cross-boundary strategies. It is not only the actual context but also the entrepreneur's perception of that context that informs behaviour. Future research could benefit from linking to the organisational psychology literature, which focusses on the motivations of the actor in context to better understand the conditions and the entrepreneurs' perceptions of conditions vis-à-vis cross-boundary strategies (see, for instance, Palich and Bagby 1995, Shane, Locke, and Collins 2003).

Second and related, to investigate the opportunities and possibilities for entrepreneurs to undertake cross-boundary activities it is essential to further look into the characteristics and background of entrepreneurs that undertake crossboundary strategies. Are certain connections or linkages required for entrepreneurs to cross boundaries? To what extent is the power position of the entrepreneur a determinant for successful cross-boundary activities? Is access to certain resources required to enable cross-boundary strategies? These and related questions are vital to further our comprehension of how entrepreneurs are an integral part of addressing complex societal problems.

\subsection{Conclusion}

The starting point of this article was the interest in the role of policy entrepreneurs in the process of transcending the boundaries of policy levels and domains. Through a systematic review of 51 peer-reviewed studies, we explored how policy entrepreneurs cross multiple policy boundaries by looking at the directions, functions and types of strategies; the conditions under which policy entrepreneurs engage in cross-boundary strategies; and the implications of their cross-boundary actions. Despite the assumed importance of policy entrepreneurs in the bridging of policy boundaries, the literature on policy entrepreneurship pays limited conceptual attention to cross-boundary strategies. On the basis of our systematic review, we conclude that policy entrepreneurs predominantly deploy strategies of issue promotion, issue framing and coalition-building. This is particularly done by crossing vertical boundaries between policy levels, although the literature also 
mentions the crossing of horizontal boundaries. By crossing boundaries, policy entrepreneurs either expand the issue arena, shift the issue arena or integrate issue arenas across boundaries. We conclude that there are certain types, directions and functions of strategies co-occurring more frequently than others, suggesting that generalisable patterns are emerging. The literature has increasingly addressed contextual conditions and implications of cross-boundary entrepreneurship, but we conclude that there is still much to gain from future research that scrutinises the relationship between conditions, strategies and implications. Further research on policy entrepreneurship across boundaries is crucial if we are to address current complex problems including migration, terrorism, climate change and sustainable development. Not only will it increase our understanding of how policy processes can be influenced at the micro-level, it will also offer tools to create a viable context to address complex challenges, and knowledge about the potential implications of cross-boundary endeavours to minimise the implications of entrepreneurship that hinder its endeavours.

A previous version of this article was presented at the 9th General Conference of the European Consortium for Political Research (ECPR) in Montréal, 26-29 August 2015.

\section{Acknowledgement}

The authors would like to thank the three anonymous reviewers for helpful comments on the previous draft of the article. Replication materials are available at https://dataverse.harvard.edu/dataset.xhtml?persistentld =doi:I0.79/0/DVN/ M8NGVF

\section{Supplementary material}

To view supplementary material for this article online, please visit https://doi. org/ / 0.10 I7/S0 I 438 I 4X18000053 



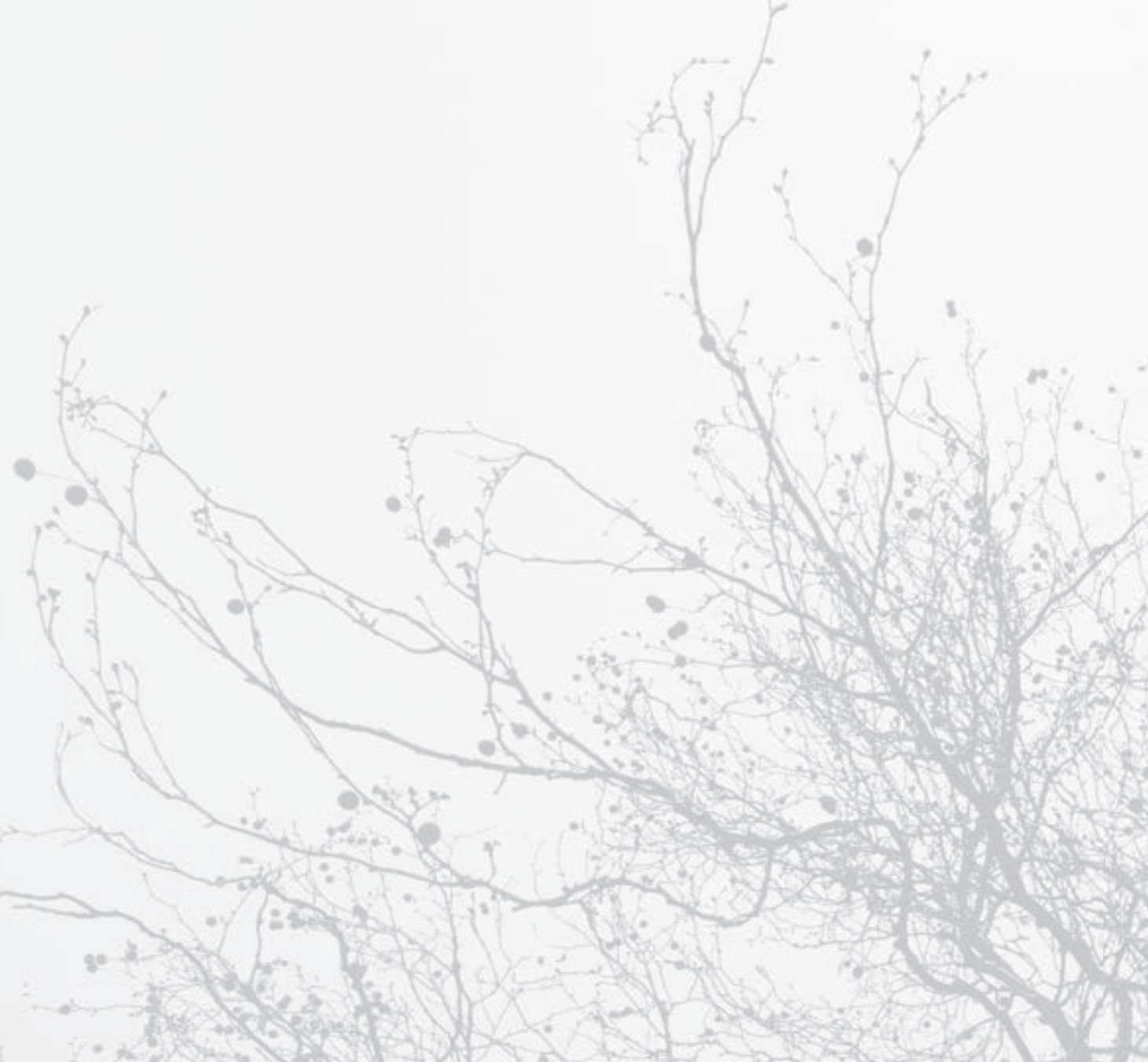

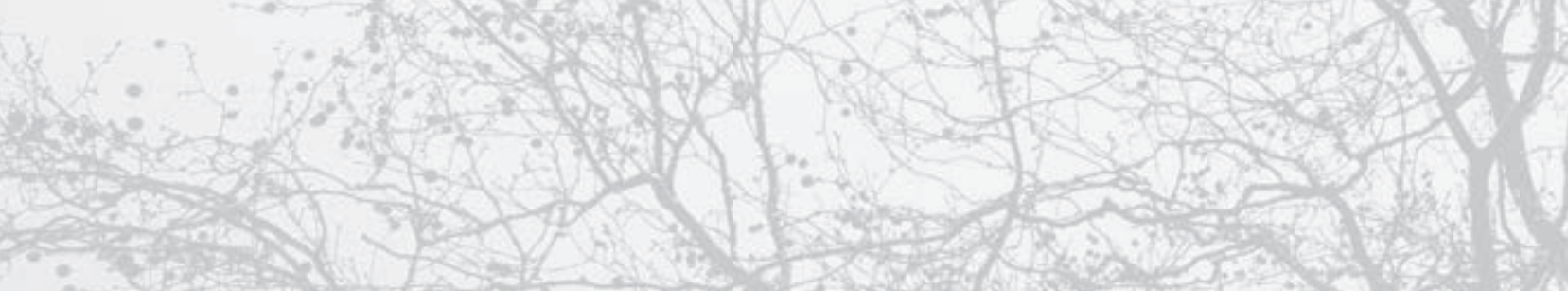

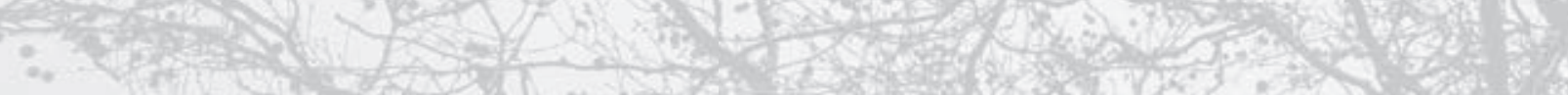

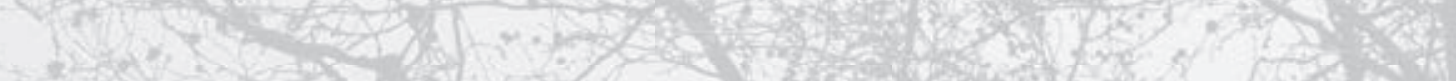

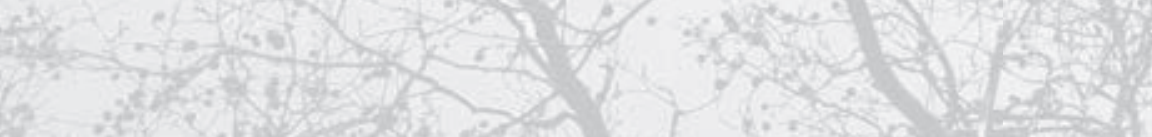

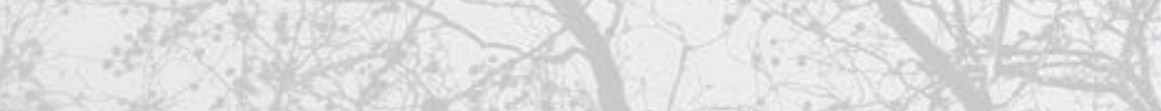

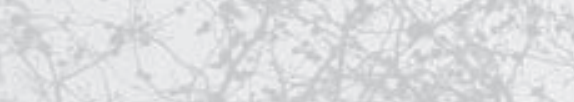

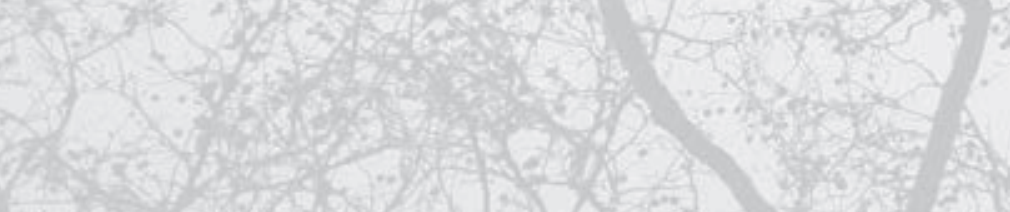

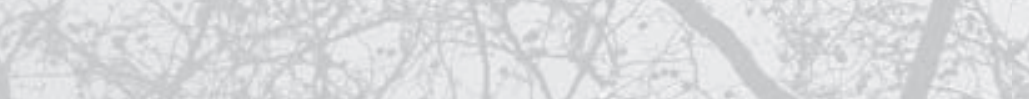

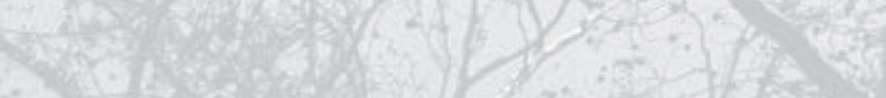
(2)

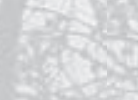

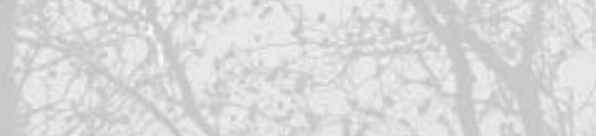

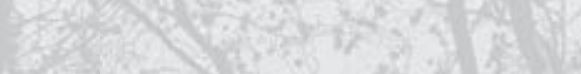




\section{The strategizing of policy entrepreneurs towards the \\ Global Alliance for Climate-Smart Agriculture}

This chapter is published as: Faling, M, R Biesbroek and S Karlsson-Vinkhuyzen (2018) 'The strategizing of policy entrepreneurs towards the Global Alliance for Climate-Smart Agriculture'. Global Policy 9:3, 408-419 


\section{Abstract}

Global collaborations across level, domain, and sector boundaries are on the rise. This article analyses policy entrepreneurship for the establishment of the Global Alliance for Climate-Smart Agriculture (GACSA), a global multi-actor collaboration to address climate change and foster food security and development. We explore policy entrepreneurship as a process embedded within specific contexts. To that end we focus on the strategizing process, consisting of conditions, activities, and implications. Through a congruence case study based on interviews, documents, survey, and observation we find that: ( I ) accommodating a varied global community requires flexibility and adaptability from entrepreneurs towards a dynamic and changing environment; (2) the variety of actors constituting GACSA compromises vigour of the collaboration, and confuses the meaning of CSA; (3) whereas collective entrepreneurship is often depicted as joint operation of multiple actors, it might also be characterized by conflicting activities and/or successive involvement; (4) policy entrepreneurship is useful to establish collaborations, but its role is temporary. Entrepreneurs must therefore be sensitive to their potential obsoleteness and with-draw at the right moment. Our results show that policy entrepreneurship is a useful lens to study global policy processes, while providing guidelines to inspire and support practitioners to engage with global policy processes. 


\section{I Introduction}

Population growth, ecological degradation, and climate change are among the key factors threatening agricultural production, development, and global food security (Brown and Funk 2008, Godfray et al. 20 I0). Agricultural outputs need to increase to meet the rising demand for food. This will, in turn, further enhance the burden placed on natural resources, climate and environment. Simultaneously climate change and environmental degradation are expected to threaten agricultural production, thereby compromising food security and sustainable development. Climate-smart agriculture (CSA) has been introduced by the UN Food and Agriculture Organization (FAO) in 2010 to break this vicious circle. CSA is an approach that claims the transformation of agricultural systems to effectively address the adverse impacts of climate change, increase resilience and agricultural outputs, and mitigate greenhouse gases where feasible. The approach focuses on synergies and trade-offs between agriculture, food security, climate change and development. CSA interventions range from the rehabilitation of irrigation systems to reduce water loss, expanding the capacity of storage ponds to harvest rainwater, and introducing intercropping with drought-tolerant varieties to precision farming or manure management. To realize CSA, proponents advocate increased collaboration between a wide variety of public, private and civil society actors from different policy levels and domains (FAO 20I0, Lipper et al. 20I4). In 20I4, the Global Alliance for Climate-Smart Agriculture (GACSA) was created as multi-actor collaborative platform to share knowledge, foster learning, and create a space for discussions between different stakeholders on CSA. The alliance brings together multinational corporations, governments, farmers associations, NGOs, international and regional organizations, as well as a variety of different research institutes.

This global multi-actor collaborative platform is illustrative for a proliferation of policy processes that are no longer confined to national governments but increasingly involve multiple sectors and levels (Crosby, 't Hart, and Torfing 2017, Head and Alford 20 I5, Williams 2002), specifically at the global level (Biermann, Davies, and van der Grijp 2009, Stone 2008, Moomaw et al. 20 I7). Given the growing popularity of global multi-actor collaborations, it is increasingly relevant to understand the processes through which these collaborations are established. 
In collaborative forms of governance different public and non-state actors engage in collective decision-making to jointly address problems (Ansell and Gash 2008), often cut-ting across level, domain, and scale boundaries. In these collaborative processes an important role is assigned to agency (Harting et al. 20 I 0, Huitema and Meijerink 2010, McNamara 2014, Meijerink and Stiller 2013, Termeer and Bruinsma 2016). Studies have shown that exploring global policy dynamics from a micro agencycentered perspective sheds light on the crucial role of actors in the dynamics through which constellations like GACSA get operationalized (Braithwaite and Drahos 2000, Partzsch 2017). Such a micro perspective allows us to understand how actor's activities are influenced by contextual developments, and how these activities in turn transform or reproduce macro-level patterns in the policy process (Torfing 2012) thereby increasing insight in the mechanisms underlying policy development. Nevertheless, there is limited understanding of the specific processes and dynamics leading to establishing global collaborations, as most literature has a useful, but slightly different, focus (Bryson, Crosby, and Stone 20 I5).

Some of the existing policy literature emphasizes the role of 'boundary-spanners' or 'meta-governors' and their role in existing collaborations (Sørensen 2007, Torfing 2012, Williams 2002), whereas other literature concentrates on the role of leadership in international governance (Saz-Carranza 2015, Prakash et al. 2015). Within the public policy literature several scholars focus on micro-level processes, and particularly on the role of policy entrepreneurs. Whereas policy entrepreneurship has been mainly studied in relation to policies at the national level (Boasson and Huitema 2017), we argue here that global collaborations are also likely to emerge as a result of policy entrepreneurs' activities (Stone and Ladi 20 I5). A few recent studies that have adopted Kingdon's multiple streams framework to explain the formation of collaborations, for example, point to the critical role of policy entrepreneurs in the process (see for instance Cornforth, Hayes, and Vangen 2015, Lober 1997, Takahashi and Smutny 2002).

The aim of this paper is to explain the establishment of GACSA. We critically examine the role of entrepreneurs in the formation of GACSA in an attempt to increase understanding of how policy entrepreneurs strategize to advocate their ideas to different target groups and bring together different levels, domains and actor types in a collaboration at the global level. 
The article proceeds as follows. In the next section we introduce policy entrepreneurship and the strategizing process as our framework for analysis. Section 2 presents the methods. In section 3 we report the results in three episodes: the development of the concept, the creation of attention for CSA, and the establishment of a global alliance. In the discussion we reflect on the contribution of this study in understanding policy entrepreneurship for global collaborations. It highlights critical linkages between conditions, activities, implications and reflects on the influence of context on entrepreneurship, the differences in approaches between entrepreneurs, and the limitations to entrepreneurship for maintaining collaborations over time. The final section presents the conclusions of the article.

\subsection{Policy entrepreneurship across multiple boundaries: a framework for analysis}

Policy entrepreneurs are actors operating in or out of government whom are willing to take risk and leverage their resources - time, money, expertise - to push ideas and achieve their objectives of creating new policies or transforming existing ones, often in return for a personal gain - for example, a promotion or job opportunity (DiMaggio 1988, Kingdon 1995, Mintrom and Norman 2009, Zahariadis and Exadaktylos 20 I6).The literature assigns policy entrepreneurship to individuals (e.g. Brouwer and Biermann $20 \mathrm{ll}$, Schneider and Teske 1992), organizations (e.g. Newman 2008, Roberts and King 1996), or parts of organizations (e.g. Phillips and Tracey 2007, von Heland, Clifton, and Olsson 20 I4). Policy entrepreneurship requires having access to resources such as contacts, possessing certain skills such as alertness to opportunities, and undertaking certain activities, including issue promotion and coalition building (Petridou 2017). Since we are particularly interested in the actions codetermining the emergence of collaborations, we focus on the entrepreneurial strategizing process.

\subsection{Strategizing as interactional process}

To study entrepreneurship, we build on earlier works suggesting that it is important to consider entrepreneurial strategies in their context (Meijerink and Huitema 2010, Mintrom and Norman 2009). Faling et al. (2018) argue that it is important to consider entrepreneurial activities, the contextual conditions in which they are undertaken, and the implications of the activities for the (policy) output. That is, 
taking a processual approach to strategizing prevents a static focus on strategy as a variable but rather approaches it as a dynamic process in action (Green 2017), to analyse a 'sequence of events that describes how things change over time' (Pettigrew 1997, 338). Recent literature increasingly acknowledges the importance of context in studying policy entrepreneurship by arguing to pay more attention to the way in which context shapes entrepreneurship, and to the way in which implications of entrepreneurs' actions shape policy processes. A recent and noticeable example is a paper by Boasson and Huitema (2017) that differentiates between entrepreneurship aiming at altering the distribution of authority and entrepreneurship aiming at altering norms and cognitive framework, and different actions to further these aims. In this paper, we adopt the framework proposed by Faling et al. (2018) to study strategizing as a dynamic process. We briefly introduce the key concepts of conditions, strategies, and implications that are central to the framework below.

First of all, contextual conditions refer to the nature of the issue under analysis, and the context within which the issue occurs. Conditions are not objective givens, but subjective constructs designed, understood, interpreted and updated by actors. Many conditions may exist, but only a limited number influences behaviour and choices of actors. For instance, a resource gap - knowledge, funding, or policy impact - around an issue might create opportunities for policy entrepreneurs to promote their desired change by providing expertise and support (Faling et al. 20 I 8). Carter and Jacobs (2014), for example, explain how Friends of the Earth, an international network of environmental organizations, could convince the UK government to adopt radical climate and energy policies, following the government's imminent failure to deliver on its emission reduction targets.

Second, we expect to find certain activities undertaken by entrepreneurs to establish collaboration(s). Most important and well-known activities by entrepreneurs include building coalitions to unite stakeholders with different views, framing messages to attract support, and leading by example (see for instanceMeijerink and Huitema 2010).

Third, we focus on the implications of entrepreneurs' activities. Every activity has certain implications and these implications, which can be positive and negative, intended or unintended, influence the contextual conditions for the next activities by 
the entrepreneur. Implications thus include any result following from entrepreneurial activities, such as changes in characteristics, capacities, and propensities of affected entities, until subsequent mechanisms (either entrepreneurial activities or other happenings) act upon them (Bennett and Checkel 2014). For instance, when an entrepreneur raises enthusiasm with an audience, it might equally raise opposition, leading to deadlock or delay instead of the anticipated change. Orchard and Gillies (20 I5), for example, discuss how US President Roosevelt aimed to raise support for refugee protection at the global level, but equally raises constraint and opposition from other states, thereby limiting his ability to achieve actual change.

We thus refer to the combination of conditions, activities, and implications as the strategizing process. The verb 'strategizing', rather than the noun 'strategy' highlights the dynamic nature of the process (Whittington 2003). Strategizing is generally done consciously, but the process is not necessarily scripted, as it can also be spontaneous or reactive (Koppenjan and Klijn 2004a). Entrepreneurs are not expected to be fully calculating and rational actors; they might also operate through trial-and-error, be led by path dependency and follow the direction most comfortable to them (Pralle 2003b).

\subsubsection{Strategizing in different phases}

We build our notion of strategizing on work of Klijn and Koppenjan who depict dealing with complex problems like 'a sports match played in a number of rounds' $(2016,83)$. In line with their approach, we argue that strategizing is a dynamic process that evolves over time, and which can be demarcated analytically into different episodes. The start of each episode is characterized by certain contextual conditions. These influence or trigger the entrepreneur to undertake certain activities. During this interactive process, the entrepreneur discusses, challenges, and negotiates with other actors from different levels or domains. This is a highly uncertain and erratic period during which the implications of the activities undertaken by the entrepreneur become apparent. The episode ends with an important or 'crucial' decision, for example the adoption of a certain piece of legislation, or appointing a new person in charge. The outcomes of this episode influence the contextual conditions for the next episode (Figure 3.1). 
Figure 3.I. The strategizing process. The process consists of different episodes. Each episode is characterized by specific contextual conditions; conditions influence the activities undertaken; activities have certain implications, which co-define contextual conditions of the subsequent episode. The process in its entirety explains the observed outcome.

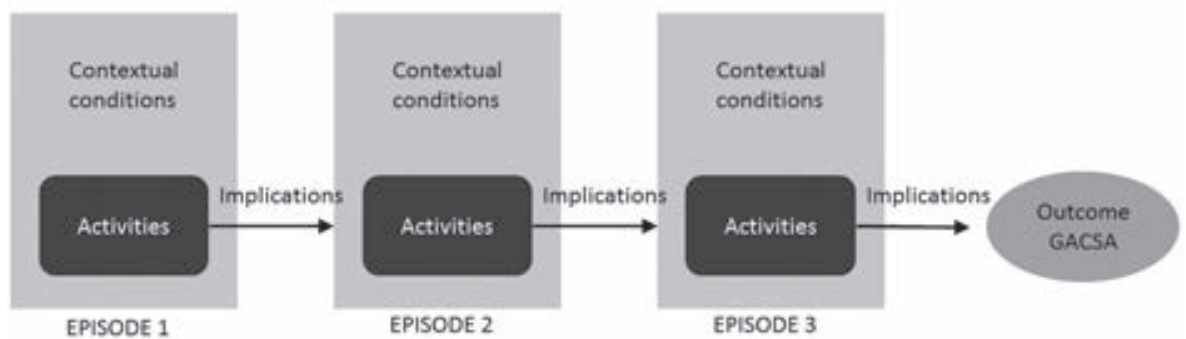

\subsection{Methods and methodology}

\subsection{Data collection}

To explain the establishing of the alliance, we conducted an explaining-outcome congruence case study. This methodology provides within-case insights about the phenomenon to be explained, and allows for making probabilistic claims about the function of underlying causal mechanisms (Beach and Pedersen 2016).

To collect data we made use of different methods. First, we conducted a scoping survey among participants in the 2016 GACSA Annual Forum $(N=43)$. The survey aimed to identify who the GACSA participants considered to be most important in the establishment of the alliance, that is, who they considered to be the policy entrepreneurs. The survey contained several questions covering the Alliance's achievements, organizational culture, and definitions of CSA. Second, we conducted 24 interviews with key actors involved in the establishment of GACSA, including the actors identified as policy entrepreneurs. Most interviews were held in Rome during the 2016 GACSA Annual Forum and some over Skype between May and July 2016. Interviewees were identified through the survey, meeting reports and snowball sampling. We conducted interviews with different actors to get a good understanding of the different perspectives on GACSA (see Table 3. I). Third, we used documentation and archival records - meeting announcements and notes, press statements, speech records - to inform the reconstruction of events. Documentation was obtained through internet searches and through interviewees, 
the latter particularly for accessing documents not publicly available. Fourth, during three GACSA meetings - 2015 member consultation meeting, 2016 Strategic Committee Meeting, and the 2016 Annual Forum - we obtained insight through observation and informal conversations.

Table 3.I. Interviewees

\begin{tabular}{|c|c|c|c|}
\hline Interview \# & Organization & Date & Location \\
\hline 1 & Partnerships, CGIAR & 16 June 2016 & Rome, Italy \\
\hline 2 & Researcher, ActionAid & 5 November 2015 & Amsterdam, Netherlands \\
\hline 3 & Lead, The Nature Conservancy & 23 June 2016 & Skype \\
\hline 4 & Civil servant, UK & 15 June 2016 & Rome, Italy \\
\hline 5 & Civil servant, Nigeria & 29 June 2016 & Skype \\
\hline 6 & President, Solutions from the Land & 16 June 2016 & Rome, Italy \\
\hline 7 & Project Manager, FAO & 15 June 2016 & Rome, Italy \\
\hline 8 & CEO, CGIAR & 23 June 2016 & Skype \\
\hline 9 & DG Agro & 8 July 2016 & The Hague, Netherlands \\
\hline 10 & Co-chair, GACSA & 15 June 2016 & Rome, Italy \\
\hline II & Civil servant, Netherlands & 12 June 2015 & The Hague, Netherlands \\
\hline 12 & Civil servant, France & 16 June 2016 & Rome, Italy \\
\hline 13 & Policy Officer, World Farmer's Organization & 15 June 2016 & Rome, Italy \\
\hline 14 & Advisor, World Bank & 5 July 2016 & Skype \\
\hline 15 & Civil servant, USA & 14 June 2016 & Rome, Italy \\
\hline 16 & Policy advisor, UN & 17 June 2016 & Rome, Italy \\
\hline 17 & Co-chair, GACSA & 16 June 2016 & Rome, Italy \\
\hline 18 & Director, wbcsd & 6 July 2016 & Skype \\
\hline 19 & Policy advisor, Norway & 17 June 2016 & Rome, Italy \\
\hline 20 & Special representative, World Bank & 21 June 2016 & Skype \\
\hline 21 & Advocacy manager, Oxfam Novib & 5 June 2015 & Amsterdam, Netherlands \\
\hline 22 & Director, EcoAgriculture & 21 June 2016 & Skype \\
\hline 23 & Chairperson, Asian Farmers Association & 15 June 2016 & Rome, Italy \\
\hline
\end{tabular}

\subsubsection{Data analysis}

Data analysis was done through coding in Atlas.ti. A code book was designed iteratively. We identified general codes for our key concepts - for example, condition, activity, implication, episode -prior to coding, and variables within each of these concepts on the basis of the data. After data collection, we reconstructed a general storyline of the process and sent it to key interviewees for a 'member check', to improve the accuracy, credibility, and reliability of the study. Thereafter we explored the mechanisms underlying the process of strategizing for GACSA. Mechanisms were identified by looking for the processes that were found to be of critical importance to link entrepreneurial activities to implications and effect 
within a given context (Falleti and Lynch 2009). An example of a mechanism is the link between the promotion of CSA and increased opposition towards CSA, which can be explained through the mechanism of opaqueness of the decision-making process and a developed-country framing of CSA.

\subsubsection{Limitations}

Although the main focus of the paper is on policy entrepreneurs' activities we acknowledge that other factors could have been important in explaining the establishing of GACSA. This study therefore does not claim to provide a full account of the factors leading to the institutionalization of CSA, but to gain critical insights in the role of entrepreneurs that are influenced by contextual conditions.

Despite our aim for full coverage of all actors involved in the process, we were unable to interview actors from South Africa andVietnam. Although these countries played an important role in the first phase(s) of the establishment of the alliance, they later distanced themselves from the process. Their motivation for withdrawing could have provided additional insights in the criticized aspects of the alliance. We compensated for their absence by interviewing other critical actors, and questioning other interviewees about South Africa and Vietnam's role.

\subsection{Results: three entrepreneurs, three episodes towards establishment GACSA}

We identify three episodes in the establishment of GACSA: (I) idea development; (2) attention creation; and (3) alliance building. We identified three actors as policy entrepreneurs: (I) the director-general Agriculture from the Dutch Ministry of Economic Affairs (DG Agro), who has been involved predominantly in the first and second phase; (2) the WorldBank contributing with multiple staff members to the establishment of GACSA in all three phases; (3) the UN Special Representative of the Secretary-General for Food Security and Nutrition (SRSG), who has been involved mainly in the third phase. The following sections describe the strategizing process by means of the different episodes, subdivided in conditions, activities, and implications See table 3.2 for an overview. 


\subsection{Episode I (2009-20 I0): the development of Climate-Smart Agriculture}

Although the interlinkages between climate change, food security, and agriculture have long been recognized, a focusing event in the shape of the food price crisis is needed to put the interdependencies of the issues on the global political agenda. The 2009 food price crisis is characterized by sharp price increases for basic commodities. The crisis hits the more vulnerable segments of society disproportionally hard, and exemplifies the challenges of securing sustainable development under realities of climate change (Behnassi, Boussaid, and Gopichandran 2014, Wheeler and Von Braun 20।3). Following the crisis the interlinked issues increasingly appear on global agendas. The 2009 FAO World Summit on Food Security Declaration reads 'any recipe for confronting the challenges of climate change [for food security] must allow for mitigation options and a firm commitment to the adaptation of agriculture' (FAO 2009, 2). Around the same time, the 17th session of the Commission on Sustainable Development (CSD-17) acknowledges that 'agriculture can and must adapt to climate change if we are to survive. Climate change also poses an important challenge for future food security' (UN ECOSOC 2009, 4I). It demonstrates the recognition of the need to mobilize various stakeholders at different levels to address climate, food and agricultural challenges globally in an integrated manner. Several actors are meanwhile increasingly crossing paths at various events where these issues are more and more discussed.

Two entrepreneurs are particularly serious about their objective to bring together the 'separate silos' of agriculture, climate and food: the Dutch DG Agro and the Senior Director Agriculture from the World Bank, whose starting point is a critical attitude towards the - in their view - fragmented and poorly coordinated processes around climate change, food security, and agriculture (interviews 9, I I, 14, 15). They are frustrated with the lack of progress on agriculture within the United Nations Framework Convention on Climate Change (UNFCCC), and the lack of any deliberative international body to address agriculture and climate change in an integrated manner. Notwithstanding other international initiatives to address climate and agriculture, such as the UN Food and Agriculture Organization's (FAO) actions, or the CGIAR research program on climate change, agriculture, and food security (CCAFS), the entrepreneurs envisage to build a separate arena for the collaboration between different actors, sectors, and levels. The DG Agro states that: 
within the UN governments might agree on a Convention, but when it comes to implementation this Convention fails. Negotiations take place in separate silos in New York or Brussels, whereas instead we need to invite other stakeholders from multiple silos and groups to make implementation work. (interview 9)

The entrepreneurs discuss their ideas in their respective networks to sense if others share their frustration and ideas. Confident in finding resonance, they form a small but diversified coalition of governmental actors from the US, Ethiopia, South Africa, New Zealand, Norway, Vietnam, and FAO and jointly engage in issue promotion by organizing the first Global Conference on Agriculture, Food Security and Climate Change in 2010 in the Netherlands. The entrepreneurs aim to boost the development of a different approach to agriculture, 'place the issue on the agenda globally, and build political momentum' (interview 20). They strategically select a diverse group of stakeholders, including farmers organizations, international organizations, foundations, and governments from both Western and Southern countries, which they envision will be able to spread the entrepreneurs' ideas and translate it into action. Both the varied audience and high-level representation among them Kofi Annan, former UN Secretary-General - aimed to create prestige and visibility among different actor groups, according to one of the entrepreneurs (interview 9). After discussions with the entrepreneurs, FAO during the conference introduces a scoping paper on Climate-Smart Agriculture: a 'triple-win' approach 'that sustainably increases productivity, resilience (adaptation), reduces/removes GHGs (mitigation), and enhances achievement of national food security and development goals' (FAO 20I0, ii). The Conference, chaired by one of the entrepreneurs, concludes with a Roadmap for Action that calls for a paradigm shift towards viewing agriculture as a solution to food and economic crises, to broaden and initiate partnerships based on inclusive engagement (Global Conference 20 I0). Whereas the Roadmap suggests agreement among participants and a unilateral interest in the promotion of CSA, it is drafted by a small group mainly consisting of the coalition that organized the conference.

Whereas the concept of CSA raises enthusiasm with many participants it also raises opposition. Some NGOs express their concerns. In their view CSA symbolizes carbon markets, global free trade, and increasing food production, risking to become a tool for high-income countries buying off their mitigation responsibilities (interviews 2 , 
12,21). Opposition argues the process lacks representation of smallholder farmers and indigenous peoples in the activities of the entrepreneurs. Oxfam represents civil society in a plenary statement to the Ministerial Roundtable of the Conference: 'According to CSOs these people [small holder farmers, indigenous people and women] have not been present, nor consulted, nor genuinely participated in this process' (Oxfam Novib 20 I 0, I). Despite the successful efforts of the entrepreneurs to involve different stakeholders in search for common ground, some governments, businesses and NGOs experience unequal power relations leading to exclusion from the process. The closed process of drafting the Roadmap for Action and the traditional set-up of the conference with governments at the center and others in observer positions are particularly criticized (Oxfam Novib 20 I0)(interview 9, 19). As one government official puts it: 'there was a close working group, and there was no proper consultation with the other participants. The meeting could have been much more open and inclusive'.

\subsubsection{Episode 2 (20I I -20I3): creating attention for CSA}

Despite the criticism, the enthusiasm from actors like the Clinton Foundation, private parties, and governments inspires the two entrepreneurs to continue with CSA. The broad interpretation of CSA creates a common ground to depart from, but some actors raise the question what is - and what is not - CSA. Although the entrepreneurs have initiated CSA as an alternative approach to those initiated by existing institutions, developments regarding agriculture in the UNFCCC negotiations seem to impact the broader interest in CSA in the second episode: support for collaboration around CSA declines with Parties requesting a formal Program of Work around agriculture at the 17th UNFCCC Conference of the Parties (COPI7), and rises again when at the I8th UN Conference of the Parties (COPI8) their request is rejected (Muldowney, Mounsey, and Kinsella 20I3). In the words of a researcher: 'CSA was important to us because we were looking for an alternative platform to get agriculture into the UNFCCC' (interview 8). The entrepreneurs DG Agro and the WorldBank have created political momentum, and now face the challenge of how to take the collaborations forward.

With input from conference participants the entrepreneurs list a number of different initiatives to promote CSA (Global Conference 2010). They engage in issue-promoting activities, both jointly and individually, to raise support for and address criticism against CSA. They organize various dialogues in Africa, and 
convince Vietnam to host the second Global Conference in, 20I2. This focus beyond the Western world is a strategic move to showcase non-Western countries' support for CSA, counter the view of CSA as backdoor for mitigation obligations, and aim for equal representation of relevant stakeholders (interviews 9, 14). To demonstratethe value of CSA, the World Bank sets up a CSA pilot project in Kenya. The Agricultural Carbon Project aims to showcase the feasibility of CSA in practice. Moreover, the World Bank reports on the project in its presidential speeches, news items, and blogs (see for instance Warutere $20 \mathrm{II}$ )(interview, 20). Key to the project is the - controversial - BioCarbon Fund to mobilize finance through conserving carbon in agro-ecosystems (Atela 2012). While this project demonstrates the feasibility of CSA, it reemphasizes concerns regarding developed countries passing their mitigation responsibilities onto non-Western countries. Meanwhile, the DG Agro and the Dutch Minister of Agriculture promote CSA at various events. The Dutch government, in cooperation with the DG Agro, signs an agreement with the Clinton Foundation to roll out a CSA project in Tanzania and Malawi. The Dutch ministry finances the Clinton foundation (NL Ministry of Economic Affairs 20I3), to further enthuse the Foundation and the US government for CSA (interview 9). Whereas the entrepreneurs interact with the Clinton Foundation as representative for civil society and non-governmental organizations at large, many in fact, do not identify with the Clinton Foundation. Meanwhile, the DG Agro and the Ministry engage in framing different messages to different audiences. The Dutch Minister for instance highlights the value of CSA for Dutch corporations: 'As agricultural exporter it is our job to address food insecurity through global agricultural policy. Besides, this [deal with the Clinton Foundation] is an opportunity for innovative businesses with an abundance of agricultural expertise to invest in Africa' (translated from Dutch by the authors Government 2013). At the third Global Conference in South Africa, the entrepreneur DG Agro emphasizes the necessity to address food insecurity, the importance of the position of women farmers and the importance of ending poverty, hunger and malnutrition. The DG Agro deploys different frames to emphasize different aspects of CSA, depending on the targeted audience. A broad umbrella concept like CSA, which can be tailored to different audiences by including specific messages, has a specific function for the entrepreneurs (interviews 9, 20). Following the increased attention for CSA and the aim to have an impact, the entrepreneurs decide they want to institutionalize the initiative by creating an alliance, with a leading role for both entrepreneurs. The alliance should coordinate the exchange of resources globally, support farmers in their daily practices and 
facilitate fundraising, by offering a value-free space and a simple organizational structure that allows for balanced discussions between different stakeholders (interviews 4,6,7). Discussions about the alliance take place within a small coalition of actors (interview 4).

Although the entrepreneurs desire to launch the alliance in, 2013, potential participants are not (yet) sufficiently convinced to participate. Most stakeholders feel their concerns have not been adequately addressed. Most actors continue to criticize the uncertainty and closed-door atmosphere surrounding the process, leading to distrust among several actors and towards the entrepreneurs (interviews 4, 8). As one government official describes: 'The proposal was to have a charter, but the process was still fairly tight and opaque with regards to the engagement of other countries, and there was a lot of questioning of what it was about... what CSA was about'. The entrepreneurs conclude that catching the wide variety of interpretations of and the uncertainty about CSA in a charter that accommodates a wide variety of views would require more time.

\subsubsection{Episode 3 (2013 - 20I5): Establishing a global alliance on CSA}

Whereas the World Bank and DG Agro have decided to develop an alliance, opposition and discussion among some actors complicate matters. Some critics fear investments in CSA will divert finance away from smallholder farmers, as these will promote public-private partnerships unattainable for smaller parties. Because the approach lacks clear guidelines on what comprehends CSA, any stakeholder can label its activities as climate-smart - a practice referred to as corporate greenwashing. Some disapprove having large corporations like Monsanto and Unilever around the table. Others criticize GACSA for overly focusing on technical and farm-level interventions, relative to the ecosystem and landscapes component of CSA as acknowledged in FAO's definition of CSA (FAO 2010). To get the process moving again, a breakthrough seems to be needed.

The deadlock was overcome during the Third Global Conference in December, 20 I3. Support of several governments, including the USA, Norway and South Africa, and stronger involvement of FAO give new stimulus to the process. But above all, a breakthrough was realized through the involvement of a third entrepreneur, the United Nations Special Representative for Food Security and Nutrition (SRSG). The UN is looking for venues to promote the linkages between agriculture, food 
security, and climate change. As a result of closed discussions about the alliance, the Dutch State Secretary for Agriculture and the UN Secretary General decided to launch the Alliance during the Climate Summit, held in September 2014. This gave a boost to the process and increased the willingness of other parties to get actively involved (interview 5, 16). The SRSG takes the lead in a set of conference calls to set up the alliance (interviews I, 8, 16). Whereas the other two entrepreneurs focused on small groups to push for CSA, the SRSG strategically builds a large coalition by inviting many people to join. He aims to address concerns regarding inclusiveness and transparency of the coalition. The coalition grows extensively and conference calls contain over 100 participants (interviews I, 3, 4, 8, 9). Although this seems to have the desired effect as actors feel increasingly included, the calls are chaotic and lengthy (interviews 9, 10, 13, 19, 20). Some continue to question the legitimacy of the Alliance (interview 23). High-level support from the US State Secretary and the Dutch Minister for Economic Affairs and Agriculture serve to enthuse as many other stakeholders as possible in the run-up to the launch of the alliance (interview 8).

During the Climate Summit the Global Alliance for Climate-Smart Agriculture (GACSA) is launched through an Action Statement. In reaction to concerns raised by NGOs, governments, and research organizations about the balance between adaptation and mitigation and to acknowledge regional differences, the Action Statement refines the 'triple win' approach as an approach that is contextspecific. CSA is framed as aiming for 'sustainable and equitable increases in agricultural productivity and incomes, greater resilience of food systems and farming livelihoods, and reduction and/or removal of greenhouse gas emissions associated with agriculture (including the relationship between agriculture and ecosystems), wherever possible' (GACSA 20 14, 2). By reframing CSA from 'triple-win' approach to an approach in which mitigation is conditional, the coalition addresses concerns around mitigation responsibilities (interviews II, 19, 22). In general, however, GACSA claims to be a collaborative platform which facilitates debate, and therefore largely refrains from addressing conflictual debates about the meaning of CSA. The launch of GACSA marks the end of the SRSG's active involvement. At the same time, the DG Agro steps back as co-chair and entrepreneur from the process.

After four years the efforts of the entrepreneurs around CSA result in GACSA, financially supported by the Netherlands, Norway and the USA. As of, 2016, the 
alliance consists of over 140 members. The understanding of what GACSA is or ought to achieve remains vague, and sustained funding remains an issue (interviews 12, 17, 22). GACSA acknowledges there is room for improvement, for instance through better communication and openness to improve transparency. The free and voluntary membership has become a challenge to GACSA's decisiveness, and increased involvement of private parties and farmers is considered to be essential for the credibility of the Alliance. Nevertheless, CSA seems to be increasingly acknowledged and appreciated in different venues. Around 80 per cent of countries mention agriculture in their Intended Nationally Determined Contributions (INDCs), and I 5 per cent mention CSA (Strohmaier et al. 20 I6). In September, 2015 a majority of countries adopted the 2030 Agenda for Sustainable Development which underscores the link between climate change and agriculture (United Nations 2015b). At the 2015 COP2I agriculture reappeared on the UNFCCC agenda. The preamble of the Paris Agreement recognizes 'the fundamental priority of safeguarding food security and ending hunger, and the particular vulnerabilities of food production systems to the adverse impacts of climate change' (United Nations $2015 a, 1)$.

Agriculture itself remains absent from the Paris Agreement. Although the Alliance is characterized by disagreement and is typified by critics as discussion group rather than decisive body with substantive influence, GACSA might have contributed to the debates around the integration of climate, food, and agriculture, and might have inspired countries to take up food security, agriculture, development and climate in an integrated manner (interviews 7, 10). 


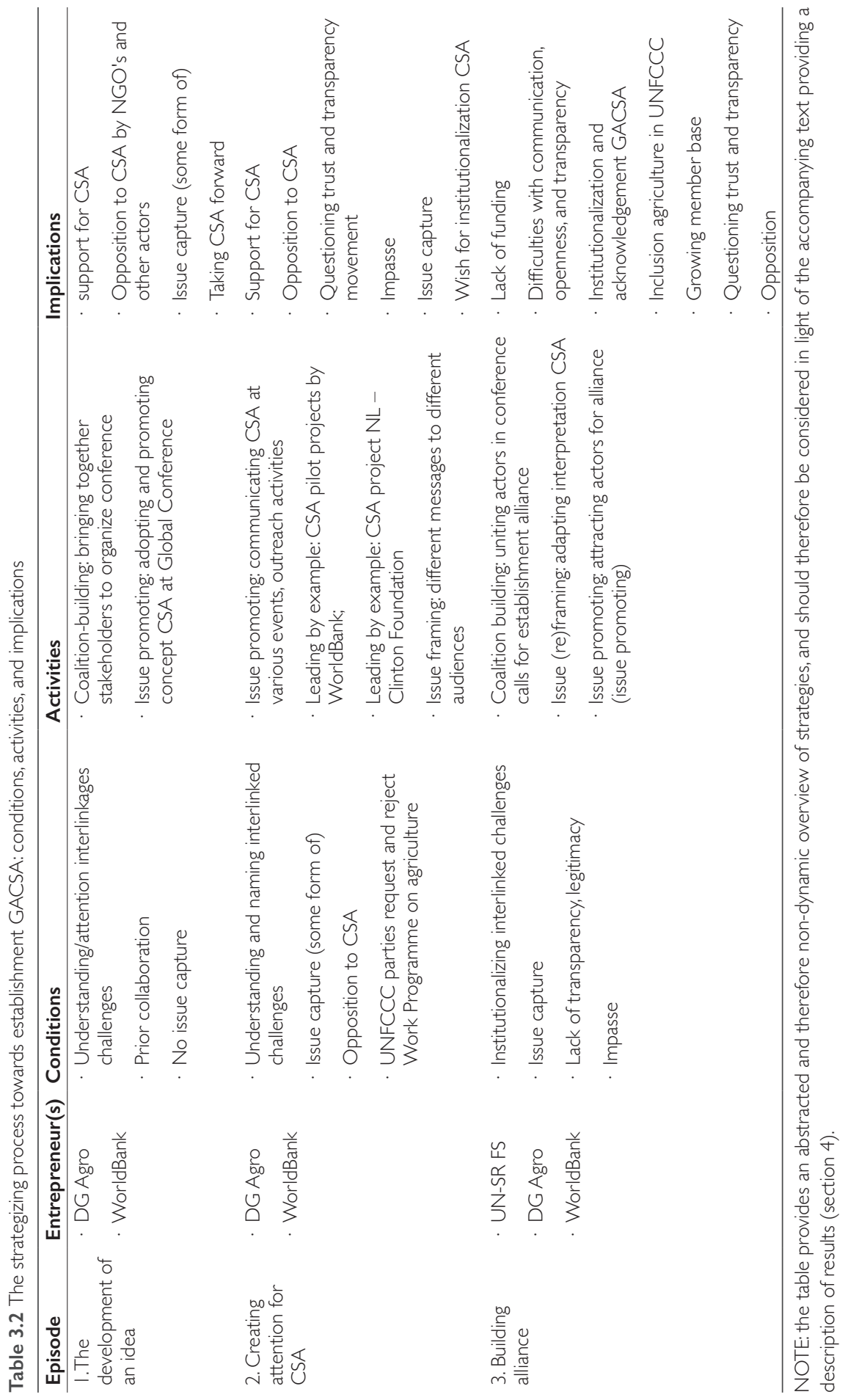




\subsection{Discussion}

Actors from different policy levels, sectors, and domains from around the globe increasingly collaborate to address complex and pressing societal problems. It is therefore increasingly important to understand and explain the dynamics through which these collaborations are developed. In this paper we discuss development of the Global Alliance for Climate-Smart Agriculture (GACSA), through the lens of a dynamic policy entrepreneurship framework that differentiates between conditions, activities, and implications. Below we discuss our main findings and their implications for research and policy practice.

First, based on the framework we argued that strategizing is a process that unfolds in different episodes, whereby conditions form the starting point for activity choice, and whereby activities have certain implications. These implications - together with other external contextual conditions - in turn create the conditions for the following episode. Our study demonstrates the value of adopting the perspective provided by this framework as it goes beyond listing strategies or decontextualized explanations of the emergence of (global) collaborations. To illustrate, the DG Agro and the WorldBank started organizing events around CSA as an activity in reaction to the conditions of some recognition of the challenges surrounding food security, climate change, and poverty eradication. The interpretation of CSA by the entrepreneurs subsequently had the implication of increased opposition from certain groups, which inspired the policy entrepreneurs to adapt their activities and reframe CSA to address opposition. Simultaneously, the unfolding of the process was linked to wider events, such as the prospects and possibilities for discussing agriculture in the UNFCCC process and the level of interest for CSA. The need for considering contextual conditions as well as the sequential nature of policy processes is often advocated in policy studies literatures (Trampusch and Palier 2016), but few policy entrepreneurship studies have been able to conceptualize and operationalize this. Our conceptual framework that considers the dynamic interplay between conditions, activities and implications - or strategizing - helps us to better understand and explain how policy entrepreneurs operate, and appreciate the process of establishing collaborations between a diversity of actors from different levels, domains, and sectors to address global complex problems. 
Second, given the wide variety of (potential) actors united in the process of establishing (global) collaborations, policy entrepreneurs get confronted with an array of different (and sometimes competing) interests, ideas, and responsibilities. They have to navigate in a policy environment characterized by non-hierarchical and unclear power relations and high levels of complexity due to the multiplicity of target audiences. The policy entrepreneur(s) involved in building such a collaboration thus needs to deploy specific activities, such as strategically composing varied coalitions, softening up varied audiences through a broad interpretation an framing of their 'pet proposals', or high-level support for their initiative. We expect these strategies to be essential in other efforts for collaborative governance, as they touch upon the starting conditions for collaborations to occur, such as equal representation, clear incentives to participate, and facilitative leadership (Ansell and Gash 2008). Our study shows how policy entrepreneurs are manoeuvring in this complex environment, thereby adapting their activities to changes in their direct environment, partly responding to the implications of their own activities. For instance, when the entrepreneurs noticed an overrepresentation of Western actors and rising critique on the (perceived) industrialized country-focus, they asked South Africa to host the conference, to seek a more balanced and representative support from different actors. Such 'opening-up' strategies are well recognized in the literature. Moreover, whereas DG Agro and the World Bank in the first episode formed a small coalition of actors to discuss the promotion of CSA, the SRSG observed the dissatisfaction with the closedness of the process, and opened it up to other interested actors. This is in line with the argument that policy entrepreneurs strategically decide when to involve which actors (Berkes 2009, Brouwer and Biermann 20 I I, Olsson et al. 2007) and that these decisions can dramatically differ between episodes. Our findings also point to differences in the interpretations of context and the desired activities undertaken by the entrepreneurs, despite their shared aim for the establishment of the collaboration. For example, whereas the SRSG wanted to involve as many actors as possible to improve transparency and legitimacy of the collaboration, the DG Agro believed that although 'involving all relevant stakeholders' is a beautiful adage, it is impracticable and undesirable, and success can also be achieved with a smaller group. Individual characteristics (beliefs, norms, experiences) of the entrepreneur therefore matter in their selection of activities, and consequent implications. Our findings show that the DG Agro's selective approach in the first episode led to criticism and opposition to the collaboration, while the inclusive approach from the SRSG in episode three greatly 
enhanced the complexity of the process but addressed some of the criticism raised by the other entrepreneur earlier in the process. Collective policy entrepreneurship is often described in the literature as multiple actors jointly creating an idea and nurturing it through initiation, design, and implementation (see for instance Roberts 2006). This study, however highlights how - in a global environment characterized by complexity and diverging interests - entrepreneurs among themselves might actually have different interpretations of the context, leading to deviating and possibly even conflicting activities, and successive instead of parallel involvement. Difference in interpretation may lead to stalemate or deadlock because the entrepreneurs will oppose each other's activities. However, as we see with in our GACSA case, these different interpretations might actually complement each other, and thereby boost change. Adopting the processual perspective of this study allowed us to capture these dynamics and how they reinforce each other.

Third, this research showcases that the role of the policy entrepreneur might be temporary and loses its significance once collaborations are in place (Mitchell and Shortell 2000, Takahashi and Smutny 2002). Whereas entrepreneurs seem to be effective and useful in building collaborations, they might not be the most suitable candidates for maintaining and leading collaborations. In our case we observed how both DG Agro and SRSG withdrew their involvement after the institutionalization of GACSA, whereas within the World Bank responsibilities for GACSA were turned over to lower levels of authority. We have two possible explanations for this. First, as GACSA becomes more institutionalized and formalized, leadership becomes solidified. This reduces the institutional void in which the entrepreneurs can manoeuvre. An established and institutionalized collaboration often involves formalized leadership, which makes the role of the policy entrepreneur redundant as certain rules and principles become solidified. The process of setting up a collaboration is significantly different from maintaining a collaboration, and requires different personal skillsets, characteristics, resources and activities. Whereas policy entrepreneurs might be effective in raising support for an idea and building collaborations, they may not excel at maintaining, sustaining, or adapting particular collaborations to changing conditions over time - roles generally associated with leadership functions (see for instance Galanti and Capano 2015, Mattli and Seddon 20 I5, Selznick 20 I I). Our study therefore suggests that policy entrepreneurship that aims to unite actors across level, domain, and sector boundaries at the global level requires a high-level position to allow the entrepreneur to demonstrate legitimacy 
and authority among different actor groups, and have access to broad networks across boundaries, for instance to obtain resources, support, and start pilot cases. Hence, policy entrepreneurship might be the appropriate function for processes of innovating and starting change, leadership might be more apt for aims related to stability and continuity in processes. It would be valuable to study these processes of transformation whereby policy entrepreneurship makes way for leadership, and where policy ideas become institutionalized in collaborations, as this would enhance our insights in processes of not only initiating the establishment of collaborations, but also the transformation towards maintaining and deepening the collaboration.

Fourth, although we can conclude that the entrepreneurs have been successful in establishing the alliance, the unexpected implications of their activities to establishing a global collaboration demonstrate dynamic complexities in such processes. The continuous struggle of entrepreneurs to address opposition, discuss and settle leadership issues, address the complexity involved in working with a variety of actors, and create trust and legitimacy mirrors the ongoing discussion in the organization and management literature on collaborations (Bryson, Crosby, and Stone 2015, Crosby and Bryson 2005, Sénit, Biermann, and Kalfagianni 2017). Overcoming these challenges is, however, necessary for establishing such a global collaboration. This is reflected in the ongoing episode after establishing the alliance (2016-onwards), as it is characterized by considerable disagreement regarding the interpretation of CSA, indistinctness regarding the exact role and position of the collaboration, and a lack of trust among members. It is therefore crucial that the governing of complex global collaborations, which are characterized by actors with diverging aims, interests, and authority, involves facilitation and management of these differences (Klijn and Koppenjan 2016). Specifically for cross-cutting, complex and controversial issues such as climate change, policy entrepreneurs require to find solutions to address different (perceptions of) problems from different viewpoints that emerge from the multiplicity of actors at different jurisdictions and scales that experience problem (and solutions) differently. In the case of GACSA this has led to ambiguity and vagueness of both the concept of CSA and GACSA itself, as a functional tool to accommodate this diversity.

Fifth and finally, adopting this framework has proven useful in providing a more dynamic and processual approach to policy entrepreneurship for collaborative forms of governance such as GACSA. It offers a lens to study entrepreneurial 
strategies as part of a process, thereby specifying the causal mechanisms through which changes are achieved. In doing so, it highlights the role of entrepreneurship vis-à-vis other factors in policy change processes (Green 2017). Furthermore, the framework provides insight in unintended and 'negative' consequences of activities, a topic which is understudied in current policy entrepreneurship literature. We argue that a better understanding of the role of context requires a (re)focus on the process of strategizing. This allows us to better capture the dynamic process through which context helps or hinders entrepreneurship to create policy change (Boasson and Huitema 2017).

\subsection{Conclusions}

The Global Alliance for Climate-Smart Agriculture (GACSA) is a cross-boundary collaboration to promote the global adoption for climate-smart agriculture (CSA) and to address food insecurity, enduring poverty, and climate change. It aims to bring together actors from governments, international organizations, multinational corporations and farmers associations. This multi-level, multi -domain, and multi -actor collaboration is part of a wider global trend focusing on collaborative endeavours in both academia and decision-making practice. It is consequently becoming increasingly important to analyse and understand the dynamics through which global policies and collaborations evolve. By focusing on the strategizing process and the role of policy entrepreneurs, this paper provides an in-depth and micro-level account of the role of entrepreneurs in establishing boundary-crossing collaborations.

Based on our findings we conclude that policy entrepreneurship offers a useful analytical lens to study and explain the emergence of global collaboration initiatives. The case study on GACSA shows that strategizing for global collaboration is indeed a dynamic and interactive process between contextual conditions, the activities of entrepreneurs, and their implications which evolves in multiple episodes. Taking a processual approach to policy entrepreneurship that is context-sensitive is vital to explain why GACSA was established and which role entrepreneurs played. We propose to further study the dynamic interplay between contextual conditions, activities and implications - the strategizing process - in the emergence of other global collaborations. 


\section{Policy implications}

- In a period characterized by complexity, policy entrepreneurs must be flexible and adaptive vis-à-vis their environment, to anticipate changing contextual circumstances.

- The umbrella term of climate-smart agriculture seems attractive to unite a variety of actors, but requires explicit and continuous consideration of contradictory interpretations to address conflicting viewpoints, interests and responsibilities.

- The promotion of climate-smart agriculture encompasses multiple and different instances of issue promotion and issue framing, to introduce and sell the concept to different audiences.

- The role of policy entrepreneurs is often temporary, therefore they must be sensitive to their potential obsoleteness, and know when to withdraw. 




$$
\begin{array}{r}
4 \\
\hline
\end{array}
$$




\section{Abstract}

Policymakers increasingly call for the crossing of sector, domains and level boundaries to address contemporary challenges such as climate change. Policy entrepreneurs are believed to facilitate the crossing of boundaries. This study aims to enhance understanding of how, why and with what effect entrepreneurs operate to cross policy boundaries. This requires an account of both entrepreneurial strategy and the policy environment in which entrepreneurs operate. We thereto embed entrepreneurship in the multiple streams, advocacy coalitions, and punctuated equilibrium frameworks. We use qualitative methods (interviews, document content analysis, observation) to analyse the policy development of climate-smart agriculture (CSA) in Kenya. CSA is a crosscutting strategy to sustainably increase agricultural productivity, resilience and food security while curtailing greenhouse gas emissions. Our results demonstrate that cross-boundary entrepreneurial strategies include venue-shopping to soften up communities across boundaries; framing ideas in multiple ways to address different audiences; demonstrate brokerage between different coalitions through impartial leadership and creating a neutral institutional setting; and process manipulation such as quick-and-dirty consultations to by-pass complexity and tediousness related to the scattered policy environment. Policy entrepreneurs target varied ideas, interests and institutions across boundaries in order to establish linkages across boundaries. This requires additional resources including connections, funding and time. Simultaneously the cross-boundary policy environment offers opportunities, for instance regarding choice of audience and potential resources to tap. We propose a more careful approach to policy entrepreneurship that distinguishes between strategy and policy environment to reveal causal processes of entrepreneurship. 


\section{I Introduction}

Policy entrepreneurs play an important role in policy processes (Mintrom and Norman 2009, Brouwer and Huitema 20 I 8). Recently, scholars have emphasized the increasingly complexity and interdependency of societal problems, and policymakers have increasingly called for collaborative action among different actors to address these problems, thereby stretching the policy process across various boundaries (Candel and Pereira 2017, Williams 2002, Crowley and Head 2017, Cejudo and Michel 2017). For instance, the Paris Agreement recognizes 'the importance of the engagements of all levels of government and various actors [... ] in addressing climate change' (Paris Agreement). In the '2030 Agenda' the United Nations acknowledges that '[g]overnments and public institutions will also work closely on implementation with regional and local authorities, subregional institutions, international institutions, academia, philanthropic organizations, volunteer groups and others' and recognizes 'that ending poverty must go hand-in-hand with strategies that build economic growth [...] while tackling climate change and environmental protection' (United Nations 2015b, II).

Crossing domain, level and sector boundaries requires significant political and strategic work (Mintrom and Thomas 20 I 8, Briassoulis 2004, Candel and Biesbroek 2016). Recent studies suggest policy entrepreneurs play an important role in crossing and bridging boundaries (Faling et al. 2018, Mintrom and Thomas 2018, Schaltegger, Beckmann, and Hockerts 2018), but our understanding of the process of boundary-crossing and the role of policy entrepreneurs therein is limited at best (Candel and Biesbroek 2016, van Meerkerk and Edelenbos 20 I8, Faling et al. 20 I8). The policy entrepreneurship literature has long treated policy entrepreneurs as individuals acting in a void, but increasingly acknowledges the need to incorporate the policy environment that co-determines whether, when, how and with what effect policy entrepreneurs operate (Mintrom and Thomas 2018, Bakir and Jarvis 2017, Faling et al. 2018).

In this paper we aim to enhance understanding of how the policy environment influences on cross-boundary policy entrepreneurship. To that end, we analyse three policy frameworks that have been used in other multi-theoretical exercises and are considered among the most well-known policy frameworks: the advocacy coalitions framework (ACF), punctuated equilibrium theory (PET) and the multiple 
streams approach (MSA) (Brouwer and Huitema 2018, Capano 2009, John 2003, 2018 , Mintrom 20 I3). These are likely to offer complementary insights through their respective foci on independent development of problems and solutions (MSA), the exploitation of multiple venues (PET), and coalition dynamics (ACF) (Brouwer 2013, Cairney 2013, Carter and Jacobs 2014, Mintrom and Norman 2009). We apply insights from the three frameworks to the empirical case of climate-smart agriculture (CSA) policy development in Kenya. CSA has been endorsed as an approach to transform the agricultural sector to address the interlinked challenges of food security, development and climate change (FAO 20 I0). CSA thus aims to marry different domains, multiple governance levels and stakeholder groups (FAO, 20I0), and is therefore a typical case to study cross-boundary policy entrepreneurship.

This paper contributes to the theoretical advancement of policy entrepreneurship studies by identifying how policy entrepreneurs crosscut various policy boundaries and how entrepreneurship is co-shaped by the surrounding policy environment. Furthermore, the research contributes to the literature on boundary crossing (e.g. policy integration, boundary-spanning) by denoting how and why cross-boundary arrangements emerge and change (Candel and Biesbroek 2016, van Meerkerk and Edelenbos 2018). We argue that cross-boundary policy entrepreneurship entails to address varied ideas, interests and institutions across boundaries. This enhances the resources required for pushing pet proposals, meanwhile creating particular opportunities, for instance regarding choice of target audience. We will show that due to this particular policy environment entrepreneurs have to deploy bricolage framing, demonstrate brokerage, and engage in institutional manipulation to address complexity and tediousness of cross-boundary processes. A more encompassing approach to entrepreneurship, we argue, is necessary to explain how and with what effect policy entrepreneurs operate.

\subsection{Cross-boundary entrepreneurship in policy process frameworks}

Below we discuss the concept of cross-boundary policy entrepreneurship, elaborate on the policy environment, and briefly present the policy process frameworks of ACF, PET, and MSA. For each of the frameworks we first briefly discuss background and origin. Thereafter, to highlight the different views on the role of entrepreneurs 
in realizing policy change, we discuss per framework its notion of the change process with particular focus on the impact of the policy process on agency and how agency impacts on the policy process.

\subsection{Cross-boundary policy entrepreneurship}

Policy entrepreneurship refers to agency deployed by actors to effect policy change, using resources and strategies available to achieve a desired outcome (Faling, Biesbroek, and Karlsson-Vinkhuyzen 20 I 8, Green 20 I7).What sets entrepreneurship apart from other forms of agency is the use of strategies and actions to effect change, treating entrepreneurship as a label for a 'set of behaviours in the policy process, rather than a permanent characteristic of a particular individual or role' (Ackrill and Kay 201 I, 78), as has been done previously in the literature (Boasson and Huitema 2017). The individuals deploying entrepreneurial behaviour are referred to as policy entrepreneurs. Entrepreneurship can be employed by actors in and out of government, at different levels, and different domains. Cross-boundary policy entrepreneurship denotes entrepreneurial actions that crosscut policy boundaries.

As discussed above, different sorts of boundaries can be identified, including boundaries between levels of government (from global to local), boundaries between domains or subsystems (e.g. between agriculture and environment), and between different sectors (for instance government and international donor). Boundaries are understood as constructed separations or demarcations used to understand and address policy issues (see O'Flynn, Blackman, and Halligan 20I3). They form an analytical rather than a demarcated empirical construct, which implies that it is not always evident where one domain ends and another begins (Nohrstedt and Weible 2010, see also discussions in Abbott 1995). Boundaries characterize dividing lines between different policymaking practices and backgrounds, and crossing boundaries therefore connotes addressing these differences.

We understand the cross-boundary environment in which entrepreneurs operate to be composed of various dimensions of categories impacting on entrepreneurship, including the intra-organizational level, the policy level and the broader context (Bakir and Jarvis 2017, Vandenbussche, Edelenbos, and Eshuis 2018). Because of the policy-orientation in this paper, we are particularly interested in the level of the policy environment, but acknowledge characteristics of other dimensions in case the policy frameworks acknowledge these as relevant to the policy process. 
The policy environment refers to the set of political, economic and social factors that co-determine policy processes and are relatively enduring (but no permanent) characteristics of the world. These shape actors' behaviour and can be reproduced or transformed by entrepreneurs and other actors over time (Fletcher 2017). The dynamics resulting from the fact that actors reproduce the environment, while they are simultaneously shaped by the environment, comprise the policy process. The policy environment may include the availability of resources including knowledge and money, interests of policymakers and civil society, and prevalent beliefs and norms. Below in our discussion of the policy process frameworks we identify the particular characteristics of the policy environment that the respective lenses identify as relevant to the policy process.

\subsubsection{Advocacy Coalition Framework (ACF)}

The advocacy coalition framework (ACF) has been developed by Sabatier and Jenkins-Smith in the 1980 s as reaction to a the static stage perception of policymaking, a lacking acknowledgement of the integration of institutions and political behaviour, and the neglect of the role of scientific and technical information in the depiction of policymaking processes (Sabatier and Weible 2014). Sabatier and Jenkins-Smit were inspired by Ostrom's Institutional Analysis and Development Framework (Ostrom 2009) and Heclo's work on learning and linking macro socio-economic context to micro-level agency processes (Heclo 1978, Sabatier and Weible 2014), which they blended with a notion of belief systems and combined into the advocacy coalition framework.

Central to explaining policy change in the ACF are ideas. Advocacy coalitions people from across boundaries including policymakers, civil society, businesses, who share belief systems and engage in coordinated activity - are the main unit of analysis in ACF (Sabatier et al. 2005). In an ACF interpretation of the policy process different beliefs should thus be aligned in order for cross-boundary collaboration to occur. Belief systems are considered rather resistant to change, consequently ACF assumes policy change processes may takes over a decade. The framework roughly acknowledges four factors influencing belief systems and instigating policy change: external events such as economic or political changes (or events in other subsystems), internal events like scandals or failures, or policy-oriented learning or negotiated agreements among coalitions (Jenkins-Smith et al. 2014, Sabatier 1988, Sabatier and Weible 20 I4, Weible, Sabatier, and McQueen 2009, Wellstead 2017). 
Although ACF does not elaborate its specific role, studies applying the ACF recognize entrepreneurship as potentially important factor to influence beliefs (Brouwer 2013, Mintrom and Norman 2009, Sabatier and Jenkins-Smith 1996). Policy entrepreneurship mainly functions to interpret and translate events like shocks or introduce new knowledge to draw attention (Nohrstedt 20 I I) or boost learning (Mintrom andVergari 1996, Mintrom 20 I3, Smith et al. 20 I5), and stimulate learning or facilitate negotiated agreement between coalitions in order to influence belief systems of coalitions across boundaries. Although learning often occurs within a single subsystem, it may also transcend subsystem boundaries (Weible, Sabatier, and McQueen 2009). As such, policy entrepreneurship may create a demand for integrative solutions. Frequent reference is made to policy entrepreneurs using framing to manipulate problem understanding or highlight shared belief systems to influence subsystems or coalition boundaries, thereby contributing to inclusion or exclusion of actors, and interaction and/or competition between entities across boundaries (Johansson 1999, Mintrom 2013, Mintrom and Vergari 1996, Nohrstedt and Olofsson 20 I 6, Shannon and Schmidt 2002, Smith et al.20 I5).According to ACF policy entrepreneurship may deploy the role of brokerage to influence institutional set-up, thereby influencing beliefs. Brokerage entails the provision consensus-based decision rules, demonstrating impartial leadership, negotiation skills, funding, and commitment (Sabatier and Weible 2007). Koebele (2016) found that establishing collaborative forums enables learning and trust-building between coalitions, through repeated face-to-face meetings between actors across boundaries that facilitates safe negotiation and formal agreement among coalitions (Koebele 2016, Sabatier et al. 2005).

\subsubsection{Punctuated Equilibrium Theory (PET)}

The punctuated equilibrium theory (PET) was developed in the 1990s by Baumgartner and Jones following their dissatisfaction with incremental and technical depictions of policy processes that dominated the literature. Using the concept of punctuated equilibrium, which originates in biology, to explain evolution processes characterized by stability, gradual change, and large disruptions (Sabatier and Weible 2014), Baumgartner and Jones studied change processes in the United States (Baumgartner and Jones 1993).

PET highlights the interaction between a policy monopoly - institutionalized power over political understandings - and interventions by previously uninvolved actors 
and institutions with new ideas who question and challenge existing monopolies and policies. Cross-boundary collaboration could thus occur through pressuring existing institutions to enable a cross-boundary monopoly. Monopolies are based on powerful and simple images, and are generally resistant to change (i.e. negative feedback). New ideas 'catch fire' following changes in issue understanding and media or public attention. Mobilization of formerly uninvolved actors pressures the policy arena to open up to proponents of new ideas, thereby overwhelming monopolies (i.e. positive feedback). Overthrowing of a policy monopoly is thus the condition for policy change to occur. PET acknowledges how proponents of change may look for different jurisdictional venues to advance their case (Baumgartner and Jones 1993). PET thus interprets change as stemming from the sometimes hostile takeover of power by proponents of new ideas or from the shifting of jurisdictional venues. Issue definition is the driving force behind both stability and change. Relevant target actors to realize change include previously uninvolved actors, or disinterested and apathetic people, including government agencies, political leaders, interest groups, and the public (Cairney $20 \mathrm{I}$ I). Furthermore, the mobilization of citizens is important to increase pressure on existing monopolies.

The framework acknowledges policy entrepreneurship and various ways in which it may cross boundaries (Baumgartner and Jones 1993, Mintrom and Norman 2009). Studies highlight policy entrepreneurs deploying framing strategies to alter issue perception and affect the mobilization of formerly apathetic audiences to put pressure on existing institutions (Baumgartner and Jones 1993, Capano 2009). Monopolists, initially unwilling to share resources with opposition, might be pressured by a growing opposition to open up. Frequent reference is made policy entrepreneurship targeting the policy setting by influencing the jurisdictional venue in which an issue is addressed. When public attention pushes issues higher onto the agenda, policy entrepreneurs may exploit the momentum to assign an issue to the preferred venue, which may be at a different level or domain (Baumgartner and Jones 1993, Capano 2009, Princen 2013). Issue complexity may result in the existence of many interconnected potential venues of policymaking and ambiguous information, increasing the relevance of framing as a strategy (Princen 2013).

\subsubsection{Multiple Streams Approach (MSA)}

For the development of the multiple streams approach (MSA) Kingdon was inspired by the garbage-can model of organizational choice proposed by Cohen, 
Marsh and Olsen (1972), because he wanted to emphasize the dynamic, chaotic and complex nature of reality, as opposed to the organized depiction of the process by the policy cycle. The MSA represents collective choice not merely as the sum of individual efforts but as a combination of context-dependent cognitive and affective processes and structural forces.

Central to MSA's interpretation of the policy process is the presentation of issues in a way so that they are well received by policymakers. Cross-boundary interactions could occur by triggering policymakers' interests in cross-boundary collaboration. MSA emphasizes the independent existence of three streams: problems - issues policymakers want to address; policies - solutions generated by specialists; and politics - national mood, pressure-group campaigns, and administrative or legislative turnover. Participants drift in and out of decisions, and dump unrelated problems and solutions in the 'primeval soup' of ideas. It's a chaotic process; ambiguity causes differing interpretations and confusion among participants. Key to understanding change are 'policy windows', favourable moments following crises or administration changes to link separate streams and draw attention to problems, find solutions, and/ or have policies adopted (Kingdon 1995). The key to change is to raise policymakers' interest with ideas that are feasible and of interest to policymakers, which is a rather pragmatic interpretation. Although MSA acknowledges other participants in the process, the main target audience comprises of policymakers.

Policy entrepreneurship plays a central role in MSA. From a MSA perspective it is of central importance that policy entrepreneurship triggers the interests of policymakers to realize policy change. Thereto, entrepreneurship interprets or cocreates the policy setting by means of policy windows and/or linking the independent streams of politics, policy, and problems. To advocate new ideas that link different streams policy entrepreneurs should engage in 'softening up'; getting policymakers used to new ideas and building acceptance for entrepreneurs' proposals. Entrepreneurial activities include introducing bills, holding congressional hearings, speeches, and floating trial balloons. Investing insufficiently in softening up may result in rejection of proposals (Kingdon 1995). Policy entrepreneurs' ideas need to be worked out, technically feasible, and budgetary sound. Focusing events generally drive the opening of windows, hence policy entrepreneurs need to highlight and exploit these by linking the three streams, to push for their ideas (Ackrill, Kay, and Zahariadis 2013, De Rynck 2016, Zaun, Roos, and Gülzau 2016, Zahariadis 2008, 
Zohlnhöfer 2016). The coupling of streams through framing might involve the crossing of levels, domains and actor types. Kingdon argues policy entrepreneurship may include persuading participants in the process to join coalitions, either through convincing them, fuelling their fear of losing out, or granting concessions to potential participants (Kingdon 1995).

\subsubsection{Comparing boundary-spanning strategies}

Three different frameworks agree on some underlying core assumptions while also having different understandings of policy change (see Cairney and Heikkila 20 I7), see table 4.I.

First, each framework has a different interpretation of the components in the policy environment necessary to realize policy change. ACF envisages change through the alteration of beliefs, and is most elaborate on strategies to influence coalitions and inter-agency relations by discussing the manipulation of problem understanding or highlighting of belief systems to influence coalition composition. PET views change as occurring through changing institutions. It emphasizes the mobilization of formerly apathetic public through issue definition to boost positive feedback and confront monopoly and authority. MSA refers to changing policy interests by softening up of policy communities and interpreting the setting by means of external 'focusing' events. A second main difference between the frameworks is the target audience. ACF's notion of coalitions means that policy entrepreneurship could target a variety of different actors involved in certain coalitions. Within a PET perspective policy entrepreneurship should target the apathetic audience (also citizens) to create a positive feedback effect, and in MSA experts an policymakers within government should be targeted predominantly. With regards to crossboundary policy processes, whereas ACF entails beliefs should be targeted to enable cross-boundary collaboration, PET assumes institutions should be targeted, and MSA views the influencing of interests as essential to enable cross-boundary collaboration.

Despite these differences some similarities between the frameworks can be identified. First, ideas play a role in each framework, though in different ways. The ACF considers changes in beliefs of coalition members to be the key to policy change, whereas issue definition in PET's interpretation of the change process may lead to activation of an otherwise apathetic audience and a consequent 
change in authority, and in MSA ideas function to couple previously unrelated streams and trigger policymakers' interests. This links to the second similarity: the acknowledgement of framing. Although this strategy plays a role in each framework, it has a different purpose. The ACF regards framing as a tool mainly to influence beliefs, PET depicts framing as a tool to mobilize audiences, and MSA views framing as a tool to couple formerly unrelated streams. Third, coalition-building both plays a role in the ACF and in MSA. For the ACF coalitions are based on beliefs, whereas the MSA interprets coalition formation as following from persuasion or participants' fear of losing out. Fourth, all three frameworks acknowledge external events as an important factor determining policy change. Within the ACF external events could be interpreted to influence beliefs or boost learning, in a PET approach external events function to redefine issues and mobilize an apathetic audience, whereas in the MSA entrepreneurship uses external events to couple streams.

Each of the frameworks highlights particular boundary-spanning strategies, hence their combined application should present a more encompassing overview of boundary-spanning entrepreneurship.

Table 4.I. Policy process frameworks cross-boundary policy entrepreneurship.

\begin{tabular}{llll}
\hline & ACF & PET & MSA \\
\hline Notion of & Policy change explained & Institutionalized policy & External events facilitate \\
through changes in beliefs, & monopolies get challenged & the opening of policy \\
& caused by external events, & through positive feedback & windows, which create \\
internal events, learning & from new ideas/images & favourable momentum \\
& or negotiated agreement & getting support, following & to couple three streams \\
& between advocacy & external events or issue & of policy, politics, and \\
coalitions & definition & problems \\
Necessary & Ideas. Influence beliefs & Institutions. Influence & Interests. Raise \\
change & of policymakers across & authority over issue & policymakers' interests \\
& boundaries & to open monopoly & for cross-boundary \\
Factors & & up to cross-boundary & collaboration \\
influencing & constellations of power & \\
policy change & External socio-economic- & External events, media & Focusing events enable the \\
& level changes (e.g. failure & audience perceptions raise & linking of certain political, \\
& of policy, redistribution & opposition which pressures problem factors & which influence interests \\
& resources among & existing monopoly & \\
& coalitions), micro-level & & \\
& learning by coalitions, & & \\
negotiated agreement all & & \\
impact on policymakers & & \\
beliefs, making them & & \\
susceptible to change & &
\end{tabular}


Table 4.I. continued

\begin{tabular}{|c|c|c|c|}
\hline & ACF & PET & MSA \\
\hline $\begin{array}{l}\text { Boundary } \\
\text { crossing aspects } \\
\text { assumed in each } \\
\text { framework }\end{array}$ & $\begin{array}{l}\text { - Advocacy coalitions } \\
\text { cross actor boundaries } \\
\text { - Partiality of subsystem } \\
\text { autonomy leads to } \\
\text { external events' and } \\
\text { other subsystems' } \\
\text { influence } \\
\text { - Interactions among } \\
\text { coalitions from different } \\
\text { subsystems occur }\end{array}$ & $\begin{array}{l}\text { - Issue (re)definition may } \\
\text { cross issue boundaries } \\
\text { - Involvement apathetic } \\
\text { public from across } \\
\text { boundaries } \\
\text { - Potential to address } \\
\text { issues in different venues }\end{array}$ & $\begin{array}{l}\text { - External events influence } \\
\text { policy windows across } \\
\text { boundaries } \\
\text { - Problems, policies and } \\
\text { politics across various } \\
\text { boundaries can be linked }\end{array}$ \\
\hline $\begin{array}{l}\text { Cross-boundary } \\
\text { strategies } \\
\text { entrepreneurs } \\
\text { may deploy }\end{array}$ & $\begin{array}{l}\text { - Interpreting/framing } \\
\text { external (or other } \\
\text { subsystems') events } \\
\text { to influence beliefs or } \\
\text { boost learning between } \\
\text { coalitions } \\
\text { - Introduce new } \\
\text { knowledge to boost } \\
\text { learning processes } \\
\text { between coalitions } \\
\text { - Reframing subsystem } \\
\text { boundaries } \\
\text { - Influencing coalition } \\
\text { composition } \\
\text { - Create professional } \\
\text { forums/venues to } \\
\text { facilitate negotiation } \\
\text { between coalitions } \\
\text { - Provide impartial } \\
\text { leadership, skills, funding, } \\
\text { commitment }\end{array}$ & $\begin{array}{l}\text { - Issue (re)definition } \\
\text { across boundaries } \\
\text { through framing to } \\
\text { mobilize formerly } \\
\text { apathetic public } \\
\text { - Creating or using public } \\
\text { attention to assign issues } \\
\text { to particular venues } \\
\text { - Move issues across } \\
\text { boundaries to different } \\
\text { venues }\end{array}$ & $\begin{array}{l}\text { - Softening up } \\
\text { - Interpret and frame } \\
\text { focusing events } \\
\text { - Use framing strategies } \\
\text { to couple formerly } \\
\text { unrelated problems, } \\
\text { policies, and politics } \\
\text { - Coalition-building } \\
\text { through persuasion, } \\
\text { fuelling fear of losing out, } \\
\text { or granting concessions }\end{array}$ \\
\hline
\end{tabular}

Sources: Sabatier and Weible 20 I4, Kingdon 2004, Baumgartner and Jones 1993, Sabatier 2007

\subsection{Methodology}

To empirically investigate how the three policy process frameworks help understand boundary-spanning policy entrepreneurship, we conducted a qualitative case study. This method is particularly suitable to study the relationship among setting and entrepreneurship in detail, and enable theorization (Gerring 2004). The case of CSA in Kenya was selected following typical case sampling in which the case represents a stable, cross-case relationship. In that way the case allows us to further comprehend our existing knowledge on entrepreneurship in a new setting of cross-boundary policy (Seawright and Gerring 2008). CSA was launched 
in 2010 as an approach to transform the agricultural sector to increase resilience of farmers, enhance agricultural outputs, and reduce GHG emissions. It promotes the inclusion of various sectors including agriculture and climate change, various levels from global to local, and various actor types including businesses and NGOs (Faling, Biesbroek, and Karlsson-Vinkhuyzen 2018). CSA policies were developed through the involvement of an amalgam of actors from different global, regional, and national organizations and various ministries. The case of CSA policy development in Kenya is thus a typical example of a cross-boundary policy issue in a developing country context, as it puts forward collaborations between the Ministries of Environment and Agriculture, with inputs from different other actors including the international UN Food and Agriculture Organization (FAO) and the CCAFS-CGIAR. Kenya was one of the first countries to adopt CSA policy, and the novelty of CSA within Kenyan national policy leads one to suspect the presence of policy entrepreneurship in the case. The case of Kenya is expected to be representative for other cases of CSA adoption characterized by high donor presence/dependence, embeddedness in regional and global fora, reliance on agriculture for the national economy, and a significant vulnerability to climate change.

Data was collected through interviewing, document analysis, and observation to understand experiences and practices of key informants and locate them in context. Data collection took place from December 2016 to May 2017. The first step was a literature and web-based search for secondary documents (reports, policy statements, internal organizational documentation, meeting notes) on CSA policy initiatives in Kenya. Through an initial analysis of these documents an outline of events was drawn (see section 4.I) which helped to focus the interviews. Interviews - open-ended, semi-structured and topic list based - served to identify additional policy documents and interviewees, identify policy entrepreneurs (we asked all interviewees to identify who was most significant in realizing and/or pushing for CSA policy), and gain insight in the change process. We interviewed 37 actors, including policy officers from different ministries, and actors from different IOs, NGOs and research organizations involved in CSA development in Kenya. Observation of the launch of the Kenya CSA Strategy provided insights in the key actors, relationships, and views on the CSA Strategy.

We coded the interview transcriptions using Atlas.ti v7.0, to categorize and interpret data. First, we focused on basic and complementary code categorizations 
including the setting (such as external events), entrepreneurs (to identify key actors), entrepreneurial strategies (to highlight all activities undertaken towards the development of CSA policy), and components of the policy framework (ACF, PET, MSA).This approach allowed for an assessment of the applicability of strategies and setting as identified in the analytical approach, while also enabling the identification of additional strategies and processes not covered in the analytical framework(s).

We acknowledge that combining multiple theories in a single paper runs the risk of superficial explanations: each theory has unique epistemological assumptions to and would require elaborate research and case description. We accept this limitation given that the aim of this paper is not only to explain our case, but to contribute to the theoretical development of entrepreneurship studies by embedding it in more encompassing understandings of the policy process.

\subsection{Results}

Having outlined our theoretical and methodological approach, in this section we present how the process of CSA policy development can be interpreted from each framework separately (table 4.2). We subsequently demonstrate how the three frameworks can be combined into a comprehensive narrative of the case by highlighting various linkages between policy setting and entrepreneurship and how these relate to produce cross-boundary policy change, on the basis of the insights provided by each lens.

\subsection{CSA policy development from three lenses}

This section briefly demonstrates how the policy process of CSA policy development in Kenya can be explained by the application of the separate lenses of ACF, PET and MSA by highlighting each framework's necessary conditions for policy change, the factors each framework identifies as influencing the policy process, and the cross-boundary strategies of entrepreneurs. We also critically appraise the explanatory value of each framework (table 4.2). Each lens offers partial understanding by highlighting different aspects of the case. With regards to the characteristics of the policy environment and strategies of entrepreneurs, the ACF views CSA policy development as resulting from framing external events, deploying brokerage and building trust to facilitate the learning within and among coalitions 
in order to influence policymakers' beliefs. PET highlights how the institutionalized monopoly position of the agriculture ministry gets challenged by venue shopping of entrepreneurs to promote the link between climate and agriculture and raise resources for CSA policy development, and highlighting the responsibility of the Environment ministry in integrating climate in agriculture. The MSA lens captures how external events interpreted by policy entrepreneurs open a window of opportunity to present CSA as a solution to climate change and declining aid to agriculture, following softening up and a changing national mood around the issue, thereby raising policymakers' interest in change. Whereas we see important overlaps in each framework's appreciation of external events and the use of framing strategies, they differ on other aspects, including perceived pathways to change. A more elaborate comparison of the lenses is presented in table 4.2. Rather than arguing that these frameworks offer conflicting explanations of the policy process we state that these different foci must be supplemented for the pursuit of a more detailed, relevant and comprehensive explanation of the case and to highlight how ideas, institutions and interests that matter in explaining policy change. To that end, in the next section we present an integrated narrative that combines insights from the three respective lenses to offer a more varied account of cross-boundary policy entrepreneurship.

\subsubsection{Constructing an integrated narrative}

Below we present an integrated narrative of CSA policy development in Kenya, making use of the conceptual tools provided by ACF, PET and MSA. We analyse the activities of three entrepreneurs that supported the development of a CSA Strategy in Kenya. The first two entrepreneurs are the Climate Advisor at COMESA (Common Market for Eastern Africa) and the Regional Climate Change, Agriculture, and Food Security (CCAFS) Program Leader of CGIAR, who move CSA from the regional to the national level. The third entrepreneur is the Coordinator of the Climate Change Unit at the Ministry of Agriculture, Livestock and Fisheries, who pushes the translation of CSA in national policy. We present the process of CSA policy development in three phases: the starting phase which gives rise to policy entrepreneurship, the pushing of CSA by the first two entrepreneurs from the regional to the national level, and the integration of CSA in national policy by the third entrepreneur. 
Table 4.2. CSA policy development in Kenya from three lenses.

\begin{tabular}{ll}
\hline & ACF \\
\hline $\begin{array}{l}\text { Necessary } \\
\text { condition for } \\
\text { policy change }\end{array}$ & $\begin{array}{l}\text { Ideas. Influence belief in CSA of } \\
\text { policymakers across boundaries. }\end{array}$ \\
& \\
$\begin{array}{l}\text { Factors } \\
\text { influencing } \\
\text { policy change }\end{array}$ & $\begin{array}{l}\text { External events of drought and } \\
\text { agriculture aid decline influence } \\
\text { beliefs in linkage agriculture and } \\
\text { environment, Actor turnover } \\
\text { within coalition (PS ENV to AG) } \\
\text { influences distribution of attitudes } \\
\text { favour CSA, }\end{array}$
\end{tabular}

Cross-boundary - Entrepreneurs interpret/frame entrepreneurial CSA as compensation for strategies
PET

Institutions. Influence authority to open monopoly of agriculture up to environment.

External events of drought and aid decline, combined with changed perceptions on the link between agriculture

- climate pressures agriculture monopoly to open up to environment. Kenyan context not susceptible to change, risking CSA policy rejection

- Entrepreneurs redefine agriculture as environmental issue - COMESA entrepreneur frames CCA as way of addressing $C C$ in $A G$ and thus emphasizes the assignment of CC (also in AG) to environment ministry, thereby pushing pressure on monopoly AG

- COMESA and CCAFS shop venues for support agriculture climate

- COMESA and CCAFS shop venues for funding domestication process CSA by highlighting CSA contribution to individual agendas agencies

No overthrowing but instead opening up of policy monopoly. Not mobilizing apathetic audience, rather focused on policymakers, perceptions had been changing already
MSA

Interests. Raise

policymakers'

interests for CSA

and collaboration agriculture and environment.

Focusing events of drought, declining aid to agriculture and an enhanced appreciation of the link between agriculture and climate change raise the interest of policymakers in CSA.

- CCAFS and COMESA collaborate to soften up communities across different forums

- CCU entrepreneur softens up county governments to enhance susceptibility to CSA by consulting and informing them

- Frame drought as focusing event requiring action in terms of CSA adoption

- Persuade Kenyan government to join workshop through various frames, including promising future return of possible climate funds to AG sector (GCF)

No clear and unambiguous frame but rather multiple frames for issue of CSA. Entrepreneurs predominantly target policymakers instead of lay audience as well. 


\subsubsection{Background and run-up to the CSA working sessions}

An ACF lens allows the identification of two advocacy coalitions spanning the global, regional and national level. The agriculture coalition, with advocates such as the Agriculture Ministry and UNFAO, incarnates a 'productionist' belief system concerned with increasing agricultural production for food security and economic growth, with (limited) consideration for the environment. In Kenya specifically, elites have traditionally been large farm owners with a consequent belief in agricultural development through modernization and technical innovation, creating a bias towards economic prosperity of large exporting farmers (Bates 2005, Gow and Parton 1995, Maina, Newsham, and Okoti 2013). A second coalition with the Environment Ministry and several NGOs is the 'social vulnerability' coalition, which beliefs climate change impacts most heavily on vulnerable people, and proposes interventions including mitigation and livelihoods diversification to enhance people's well-being. Following PET, the policy monopoly over agriculture, at least in Kenya, is in hands of the 'productionists'. As CSA involves objectives from both coalitions it potentially crosscuts coalition boundaries and may have the potential to shift the Productionist policy monopoly.

According to MSA changes in general mood may instigate demands for policy change. Similarly PET incorporates mobilization of bias: a changed policy image enhances public attention for issues, thereby increasing the pressure for change. The process of CSA policy development in Kenya indeed seems to result from an enhanced appreciation of the interlinkages between climate and agriculture. Although knowledge about the vulnerability of agriculture to climate change has been generally acknowledged (Rosenzweig and Hillel 1998), the publication of the 2007 UN Fourth Assessment Report of the IPCC places agriculture as cause of climate change onto the international agenda (IPCC 2007). Various initiatives are thereupon undertaken to highlight and address the related challenges of agriculture and climate change. For instance, Kenya together with other African countries formulate a common position on agriculture (EDRI 2010), FAO launches the concept of CSA (FAO 20I0), and various decisions of the African Union acknowledge the link between agriculture and climate change, including the Arusha Declaration and CAADP (AMCEN 2012). After CSA has been launched at the global level it is being taken up by various institutions and actors. 
In 2014 the actors from COMESA and CCAFS discuss their shared aim to domesticate climate-smart agriculture into national policy. The organizations have been collaborating on what would be termed in the MSA-framework 'softening up' of policy communities on the link between climate and agriculture since 2009 by advocating their ideas at inasmuch different forums as possible. The COMESA entrepreneur explains: "primarily we wanted to find a forum where we could engage and could demonstrate the linkages between agriculture and climate change" (interview 10). The CCAFS and COMESA entrepreneurs and their organizations engage in various activities including giving speeches, organizing events and publishing reports (interview I0, I I), or in words of PET they shop favourable venues to find support for their proposals, thereby enhancing pressure on existing monopolies, with different levels of success. They co-establish the NEPAD-iNGO Alliance on CSA, which aims to "support the uptake of CSA practices and approaches by at least 6 million farm households by 2025" through engagement with national institutions (FAO 2015). The alliance nevertheless comes away empty handed, as national governments feel insufficiently included in decision-making processes, and the alliance fails to attract funding (interview II, 36). Subsequently, and to further 'soften up' African national governments, NEPAD and COMESA continue 'venue shopping' and organize an annual forum for African country governments, the Africa CSA Alliance (ACSAA). It is framed as spearheading the implementation of the African Union Vision to reach 25 million farm households practicing CSA by 2025 (Vision 25×25) (FAO 20I5).

\subsubsection{Getting the Kenyan government on board}

Early 2015 CCAFS and COMESA decide to organize a series of working sessions and invite some of the governments from their network to design national CSA programs. Their invitation is based on the governments' perceived susceptibility to CSA. The CCAFS and COMESA entrepreneurs jointly instruct governments to create CSA Taskforces consisting of representatives from both coalitions: the Ministries of Environment and Agriculture. As such they deploy what ACF would refer to as professionalized leadership and funding to stimulate learning among coalitions. A collaborative agriculture policy design process by the Ministry of Environment and Agriculture would require an opening up of the institutionalized policy monopoly the 'Productionists' contain over agriculture. The entrepreneurs, but predominantly the one from COMESA, engage in various framing activities to persuade the Kenyan government to join. The COMESA entrepreneur is 
a Kenyan and has worked closely with Kenyan Environment officials as co-chair of the National Climate Change Taskforce. He consequently has easy access to Kenyan officials, particularly within the Environment Ministry, and enjoys their trust. As highlighted in ACF trust is important for opponents to be able to listen to each other's views, look for mutually acceptable compromises and keep promises (Sabatier and Weible 2007). Building on this relationship of trust, the COMESA entrepreneur first approaches his contacts within the Ministry of Environment. The Ministry of Environment is charged with monitoring, investigating, and reporting on compliance with the National Climate Change Act 2016 by all sectors (Kenya 2016). It is thus in the interest of both ministries to comply. The entrepreneur from COMESA suggests to his contacts at Environment to approach and convince the Ministry of Agriculture by arguing that the Agricultural sector could use the CSA initiative to implement the Climate Change Act. From a PET perspective, the COMESA entrepreneur further pushes the process of challenging the monopoly over agriculture set in by the Climate Change Act. Moreover, the entrepreneurs refer to other - international and regional - commitments Kenya has agreed on by stating: "We told [the PS Environment] that CSA can help transform agriculture, and also deliver on the climate change commitments that Kenya wants and needs to deliver on." (interview 10). One of the donors supporting the process explains "we've signed the Paris Agreement, we have done the Nationally Determined Contributions, but you see you cannot just put your signature somewhere, you need to implement these things. And then the fact that there are opportunities to get the GCF, there is all this support from donors to support the processes, so I think that would also make policymakers more interested." (interview II). This is in line with change processes as perceived from MSA whereby interests of policymakers, for instance by promising future returns and highlighting concessions, create an enabling environment for change. ACF helps to understand the third frame deployed by the entrepreneurs, by highlighting how changes in stable parameters such as socio-economic contingencies can be interpreted to instigate change. The COMESA entrepreneur highlights declining aid investments in agriculture and argues that these may be compromised by CSA which may 'catalyse increased investments from domestic and international financing sources, including climate finance' (concept note on working sessions CSA programs, 20I5). Fourth, simultaneously the entrepreneurs use what MSA would term a focusing event of droughts threatening agricultural production to raise awareness about the need to mainstream climate change in government policy. 
The ministries create a CSA Taskforce and jointly engage in the development of a national CSA policy document. Following ACF, the entrepreneurs from CCAFS and COMESA act as brokers by bringing together different coalitions to facilitate knowledge exchange and influence policymakers' beliefs. Nevertheless, beliefs appear rather resistant to change. As one of the working session organizers states: "the way the policy changes isn't through the involvement of science. It is through golf courses and dinners [... ] people are busy, people don't have time to listen to the very detailed specifics and they don't have the knowledge base to do that. So they trust people. And it is because of that trust that becomes the most important thing. If you don't have trust, you are basically nowhere." (interview 28). Furthermore, during the COMESA-CCAFS project the principal secretary for Environment moves to become the principal secretary for Agriculture. ACF acknowledges the influence of turnover of individuals on the distribution of attitudes within coalitions.

\subsubsection{Internalizing the policy proposal}

The set-up of the working sessions is based on the tight schedule of CCAFS and COMESA, leaving little room for deliberation. Following PET, images may be accepted or rejected depending on the institutional arena in which they are raised. In the final stages of the project the CSA policy runs the risk of being rejected due to the misfit with the Kenyan policy environment. As an interviewee from the Ministry of Agriculture shared: "It is one thing to understand CSA, the second piece is how to translate that into the political realities of our particular job and ministry and work environment" (interview 2). The proposed policy clashes with the Kenyan environment on two dimensions. First, whereas the CCAFS and the COMESA entrepreneur support the creation of a CSA document with concrete and tangible activities, Kenyan high officials aspire an overarching framework to guide and align different on-going activities related to CSA. Second, despite the constitutional devolution of most agricultural responsibilities to the local level, the CSA policy had been designed without county consultations, and criticism from county governments is mounting. Addressing these issues requires more resources than the timeline of the regional project would allow. Consequently the Head of the Climate Change Unit from the Agriculture ministry decides to disengage from the COMESA project, as he 'want[s] an implementable initiative rather than something unworkable on paper' (interview I). Not wanting to let go of CSA he decides to carry forward the process, thereby retaining authority over the CSA strategy within the Ministry of Agriculture. Given the Ministry's limited resources, he starts looking 
for additional funding and expertise. First, he enlarges the CSA taskforce to include additional expertise from the Ministry of Environment, Agriculture, and Water and Irrigation (MWl). He engages in venue shopping by selecting additional donors with similar agendas, including FAO, ICRAF, and DFID, and persuades each of them to provide for the necessary funding and expertise. He does so by emphasizing how CSA contributes to their individual agendas. For instance to convince FAO to contribute, the entrepreneur mentions "so we told FAO that from our perspective we think that the CSA Framework Programme [...] presents us with a very good opportunity not just to implement the Programme, but ultimately also to realize some of the objectives of the National Adaptation Plan [which FAO was working on]" (interview I). However, enlarging the team incorporates additional challenges: "In terms of managing all these offices, it has not been easy because the bigger the group, the more difficult it is to control. [...] getting everybody on board and discuss from different perspectives has not been easy, but we wanted to bring in additional expertise, as CSA crosscuts several sectors" (interview I). The CCU entrepreneur thus continues to act as broker by enlarging the CSA taskforce, keeping the level of conflict within acceptable limits and reaching reasonable solutions among participants. Concrete activities include taking authoritative decisions on whom to engage and how to proceed, and facilitating further knowledge sharing among participants in the CSA Taskforce by offering a neutral environment outside of the ministries offices to discuss. Simultaneously, the CCU entrepreneur and his team engage in organizing county consultation processes, to soften them up: "by going to the counties and solicit statistics from them you know our thinking was also creating awareness with the counties that there is a CSA Strategy that is being developed, so that if now eventually you give them the Strategy to implement, they will actually do so" (interview I).To save time the CCU entrepreneur organizes six regional county consultation meetings. A taskforce members explains: "What we have done is to force them [the counties] to give us representatives of the big groups, so that at the end of the day you maybe have consulted someone in charge of somebody heading or representing the marginalized, and that is as well as consulting the marginalized community. That is the shortcut we are taking. Because of the expenses." (interview 3). After these consultations the CSA strategy is launched. The impending closing of a policy window contributes to the felt urgency to finalize and launch the CSA policy. Upcoming elections might shift priorities, and a timely launch of a CSA strategy would enable the harmonization of the mushrooming CSA initiatives in the country. Like one of the participants in the process states: "a challenge is institutionalization. 
If someone is a champion of the process [...], and the person leaves, you sort of have to go back, and you need someone else to champion the process, to ensure continuation. To overcome that communication challenge documentation is very important, so that it is institutionalized. [...] that is also why the launch of the strategy was so important" (interview 4).

\subsection{Discussion}

Our aim in this paper has been to contribute to the policy entrepreneurship literature by understanding I) how policy entrepreneurs cross policy boundaries and 2) how and which aspects of a cross-boundary policy environment coshape entrepreneurship. Because the entrepreneurship literature provides limited conceptual clues about the policy environment in which entrepreneurs operate, we made use of the policy process literature to identify how the policy environment co-shapes policy entrepreneurship (Schlager 1999). We employed the advocacy coalitions, multiple streams and punctuated equilibrium framework for insights in the link between policy environment and entrepreneurship.

Our study of the development of the Kenya CSA Strategy suggests that crossing boundaries entails particular entrepreneurial strategies. First, entrepreneurship across boundaries involves the softening up of various audiences by shopping multiple venues to create sufficient support for policy proposals and to address opposition against proposals. Our case demonstrates that this provides opportunities as policy entrepreneurs may pick the preferred venue based on similar ideas or existing relations and networks, but may also involve difficulties as this demands a continued strategic effort to address many audiences (Boasson 2018, Pralle 2003b). Second, because cross-boundary entrepreneurship needs to target multiple audiences to raise support for their proposal, entrepreneurs frame their message in multiple ways to address different audiences. They variously framed CSA as tool to comply with various agreements at different levels and domains (e.g. global Paris Agreement on climate, regional Malabo Declaration on agriculture, and national Climate Change Act), to address the external event of drought, and to attract funding to compensate for diminishing development support. So, contrary to an often heard view in policy entrepreneurship literature (Tversky and Kahneman 198I, Verger 2012, Kingdon 1995), a simple coherent message may not be preferable to create 
linkages across boundaries. Third, entrepreneurship across boundaries seems to require brokerage between different groups, such as different coalitions to align ideas (Faling, Biesbroek, and Karlsson-Vinkhuyzen 2018). Concrete brokerage activities include demonstrating authority, providing impartial leadership, funding and providing a 'neutral' institutional environment. This is particularly relevant in the targeting of audiences across boundaries to get all relevant actors on the same page (Long, Cunningham, and Braithwaite 2013). Fourth, because processes may get tedious and cumbersome due to the scattering of audiences across different levels, domains and sectors, our case shows that policy entrepreneurs may engage in process manipulation (Karlsson and Middleton 20I5). For example, organizing quick-and-dirty consultations with county governments and assigning policy responsibility to a single instead of two ministries, simplify an otherwise lengthy, difficult and expensive process.

Our study provides insights in the various components of the policy environment that impact on the operating of policy entrepreneurs. We found that the three frameworks all identify external events (e.g. disasters) or socio-economic or political contingencies as relevant to be highlighted, emphasized or interpreted by policy entrepreneurs to affect the policymaking process. In addition to these general factors, each frameworks identifies particular relevant characteristics of the policy process. Whereas all three frameworks acknowledge the role of ideas, institutions and interests, they assign varying importance to them. As noted in table 4.I and 4.2, ACF views the changing of policymakers' ideas (understanding of the world) as necessary condition for policy change to occur, for PET institutional change (constellations structuring authority, attention, and relations) is essential for policy change, whereas MSA centres its explanation of policy change around the manipulation of policymakers' interests (opportunity providing political motivation). These three components of a policy environment seem to be central in understanding change processes and have been identified similarly in various other literatures in different constellations (Hajer 1995, Kern 2011, Meadowcroft 2011, Scott 2008, Béland 2009, May and Jochim 20 I3). We argue that ideas, interests and institutions offer different options for policy entrepreneurs to influence the policy process. These ideas, interests and institutions differ across boundaries. For instance, where the Ministry of Environment believes environmental sustainability should be prioritized, the Ministry of Agriculture believes in economic growth. The Ministry of Agriculture traditionally has a more central and authoritative role in policymaking 
processes as compared to the Ministry of Environment, and whereas the interest of the Ministry of Agriculture might be economic growth, the Ministry of Agriculture might have an interest in enhancing its influence on important emitting sectors like agriculture. Our analysis suggests that policy entrepreneurs may variously (try to) target ideas, interests and institutions, with consequences for the strategies that policy entrepreneurs deploy. Whereas influencing ideas predominantly involves learning processes and the facilitation of knowledge exchange, the targeting of institutions mainly involves authority and decision manipulation and changing interests seems related to persuasion. Ideas, interests and institutions co-shape one another (May and Jochim 2013). An interest by policymakers to implement the Climate Change Act may instigate a willingness to put in place an institutional structure for deliberation. Some strategies may serve different purposes. For instance, framing may be deployed to influence beliefs across coalitions (Mintrom and Norman 2009), to raise policymakers' interests with one sector (e.g. agriculture) to mainstream another issue (e.g. climate), or to influence authority over an issue (Faling, Biesbroek, and Karlsson-Vinkhuyzen 2018). Within entrepreneurship studies ideas and institutions have recently been recognized by Boasson and Huitema (2017) who distinguish between structural entrepreneurship aimed at altering the distribution of authority and cultural entrepreneurship aimed at altering norms and cognitive frameworks. With our analysis we expand and elaborate on their position.

Ideas, interests and institutions thus differ across levels, domains and sectors, and addressing these differences to smoothen interactions across boundaries seems to require additional resources including connections, efforts, funding, expertise, and time (Faling et al. 2018, Pralle 2006, Rosen and Olsson 2013, Alimi 2015). At the regional level the entrepreneurs capitalized on their joint resources to push their proposal. In the national context the CCU entrepreneur had to involve additional organizations to facilitate the county consultations and the various rounds of deliberations and knowledge dissemination between the Ministries.

Our results thus illustrate the usefulness of distinguishing between strategy and ideas, interests and institutions as characteristics of the policy process. This distinction helps to uncover the causal process behind policy entrepreneurship. We therefore propose a careful approach to entrepreneurship that conceptually distinguishes between strategy and policy environment in order to better understand the process through which entrepreneurship contributes to policy change. Our case of CSA 
policy development in Kenya has certain characteristics as it is influenced by strong role of donor agencies, some level of prior collaboration among ministries, and poor policy implementation, to name but a few (Alila and Atieno 2006, Maina, Newsham, and Okoti 20 I3, Smith, Jones, and Karuga 2004, O'Brien and Ryan 1999). Although other studies found some evidence of similar cross-boundary strategies in different contexts (for instance Boasson and Huitema 20 I7) the research on cross-boundary policy entrepreneurship is still limited and studying cross-boundary strategies in other settings would provide valuable insights in the portability of cross-boundary entrepreneurship to other situations. Follow-up comparative research with multiple cases or single case studies on the basis of careful process tracing could further this hypothesis by systematically assessing the linkages between strategies and the dimensions of the policy process targeted for policy change.

\subsection{Conclusion}

Policy entrepreneurship is important for establishing connections across domain, level and sector boundaries. To theorize about entrepreneurship and determine how, why and with what effect entrepreneurs operate, it is essential to conceptually embed entrepreneurship in its policy environment. To that end we combined entrepreneurship with the policy process frameworks of multiple streams, advocacy coalitions and punctuated equilibrium to study the decision-making process around the climate-smart agriculture (CSA) Strategy in Kenya. CSA is a crosscutting approach to sustainably increase agricultural productivity, resilience and food security while curtailing greenhouse gas emissions. With this research we have contributed to the policy entrepreneurship literature by enhancing our understanding of I) cross-boundary policy entrepreneurship and 2) the dimensions of the policy environment relevant to cross-boundary policy entrepreneurship. Our results demonstrate that the linking of different levels, domains and sectors entails a particular set of strategies including venue-shopping to soften up communities across boundaries, deploying multiple frames for multiple audiences, brokerage to build a neutral institutional environment, and process manipulation to curtail complexity. Policy entrepreneurs need to address varied ideas, interests and institutions across boundaries. This requires a multitude of resources including connections, funding and time. Simultaneously a cross-boundary setting comes with opportunities, for instance related to choice of audience and jurisdiction to address. 


\section{Acknowledgements}

A previous version of this paper was presented at the Annual Work Conference of the Netherlands Institute of Government (NIG), in Maastricht, the Netherlands, 9-10 November, 2017. The authors acknowledge the valuable contributions to the paper by Prof. Katrien Termeer and Dr. Sylvia Karlsson-Vinkhuyzen. The authors like to thank the interviewees for their participation in the research, and the Stockholm Environment Institute Africa and the University of Nairobi for their support to data collection. 



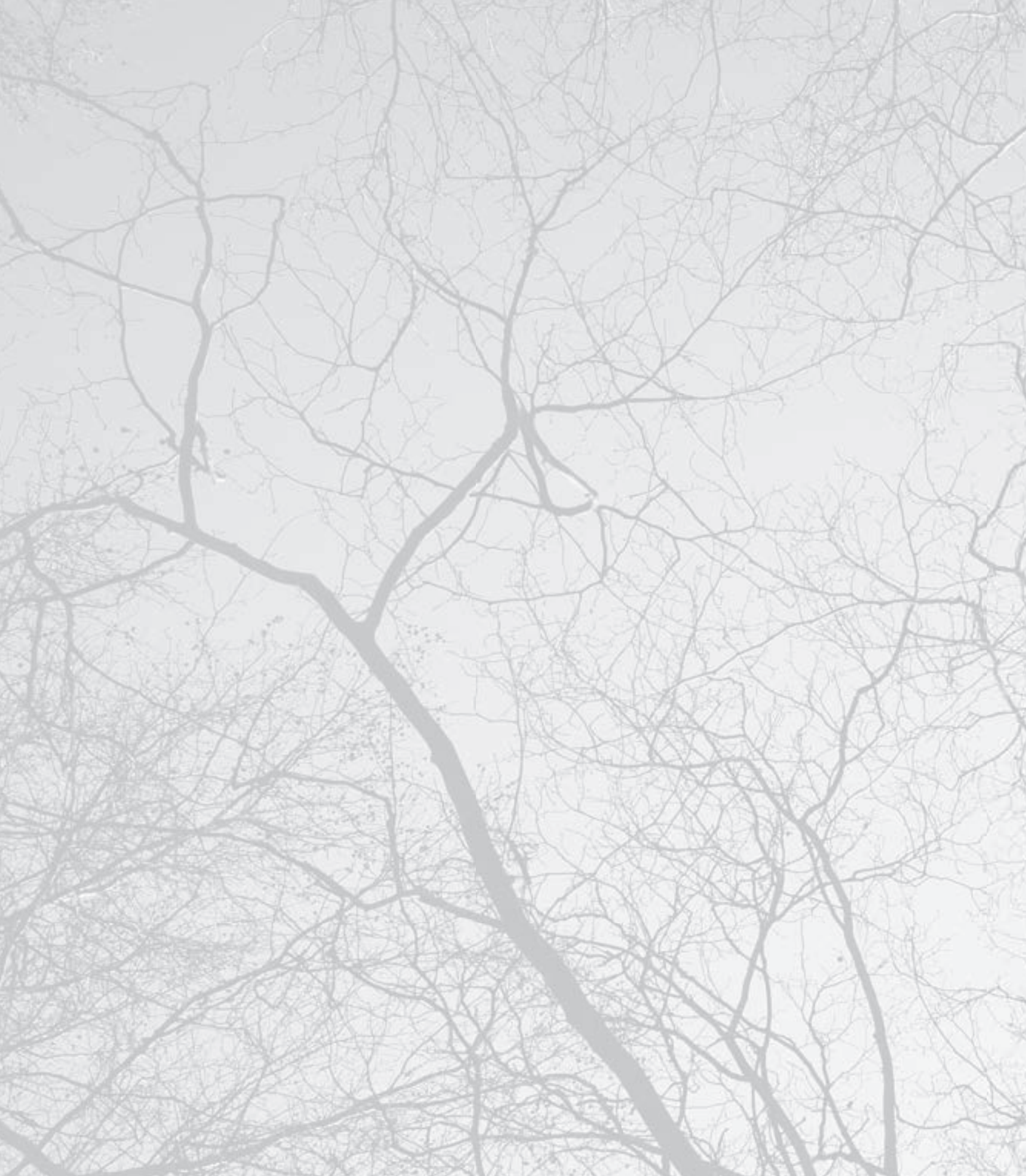




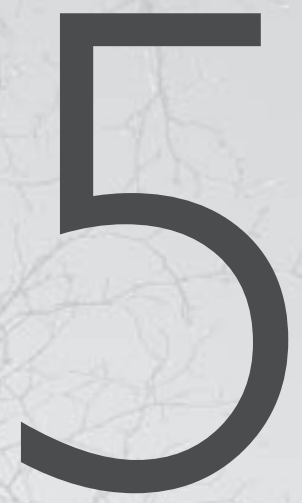

\section{Framing agriculture and climate in Kenya: a longitudinal perspective}

This chapter is under review as: Faling, M (sub) 'Framing agriculture and climate in Kenya: a longitudinal perspective', Environmental Science and Policy 


\section{Abstract}

Climate change threatens agricultural production in Kenya and jeopardizes economy, livelihoods and food security. The 2017 Kenya Climate-Smart Agriculture Strategy claims to guide a transformation of Kenya's agricultural system through an integrated approach to agriculture, climate change, development, environment and food security. By undertaking a longitudinal analysis of policy frames, this study temporally contextualizes climate-smart agriculture (CSA) policy adoption to understand whether CSA is as transformative tool versus business-as-usual. A policy frame analysis on the Ministries of Agriculture and Environment between 2002 and 2017, complemented with in-depth interviews addresses the question how policy frames for agriculture, climate change, development, environment and food security have evolved over time, and which factors contribute to explaining policy frame development. Findings demonstrate that (a) CSA in Kenya is an incremental shift away from existing policy frames rather than a radical transformation, (b) a discrepancy exists between Strategic Plans and sectoral policies; and (c) policy frames are influenced by donors, regional and global fora and personal networks. CSA might be valuable to enable the development of a shared identity among both ministries. However, this study suggests that its relevance is limited to those contexts that acknowledge a complex relationship among agriculture, climate change, development, environment, and food security prior to CSA policy adoption 


\section{I Introduction}

Extreme climatic events threaten agricultural production in Kenya, putting pressure on economy, livelihoods and food security (Bryan, Ringler, Okoba, Koo, et al. 2013). The Kenyan government consequently needs to enhance the resilience, productivity, and sustainability of the agricultural sector. In 2017, the government launched the Kenya Climate-Smart Agriculture Strategy, jointly developed by the Ministry of Agriculture and the Ministry of Environment. It describes CSA as an "excellent opportunity for the transformation [of its agricultural systems] by uniting agriculture, development and climate change under a common agenda"(MALF 20 I7). Whereas CSA is promoted as an innovative transformative tool to realize the required integration adjustments, more critical voices question CSA's transformative potential and refer to CSA as 'old wine in new bottles' (Lipper et al. 20 I 8, Faling, Biesbroek, and Karlsson-Vinkhuyzen 20 I8, Steenwerth et al. 2014).

In this paper I analyse the value of the CSA Strategy for Kenya, assess whether it is a transformative tool or represents business as usual, and identify the factors that generally explain policy development in Kenya. Contextualizing change processes in a longitudinal study helps to explain origin, disposition and development of the object under study (Pettigrew 1997, 1990). Therefore I analyse how the Kenyan ministries of Agriculture and Environment between 2002 and 2017 have addressed agriculture, climate change, development, environment and food security.

Because perceptions frequently inspire the approach governments take, they are a suitable indicator of government action around CSA-related issues. I therefore conduct a policy frame analysis (Dekker 2017). The central question in this paper is: how have the ministries of agriculture and environment in Kenya framed agriculture, climate change, development, environment, food security, and their connections? And (how) can shifts in frames be explained?

The paper contributes to the CSA literature by enhancing insight into the process of CSA incorporation into policy. Because CSA is a rather new approach, insights into the contribution of the concept and the process of incorporation into policy are still limited. Cases of successful CSA policy uptake are studied with close scrutiny to see what lessons they provide (Chandra, McNamara, and Dargusch 2018). Because antecedent conditions are expected to shape present and future reality, 
understanding how CSA fits in a longitudinal analysis of positions by ministries of agriculture and environment will enhance our understanding of CSA and what it has to offer. If Kenya is to be used as providing lessons to be transferred to other contexts an understanding of the temporal context is imperative (see Pettigrew 1990). Understanding how CSA relates to previous policy approaches will enable the interpretation of the transformative potential of the approach.

The article proceeds as follows. In the next section I discuss the analytical approach to policy frames. In the third section the methodology of the paper is discussed. The results section presents a comprehensive analysis of the frames in strategic plans and policy documents, and the factors explaining frame change. In the discussion I reflect on whether CSA is transformation or old wine in new bottles, I discuss the policy frames in the two types of policy documents, and reflect on the factors explaining change.

\subsection{Theoretical section: on climate-smart agriculture and policy frame change}

\subsection{Policy frames}

Policy frames play an important role in policy processes. These are 'interpretive schemata and ordering devices' necessary for decision-makers to contextualize and socially construct the reality of policy issues (Dekker 2017, Stone 1989). Frames contain aspects of a perceived reality including causal assumptions about problems, objectives and appropriate responses. They thus present certain perspectives by highlighting particular aspects of reality while ignoring others (Nilsson 2005, Entman 1993, Dekker 2017). Policy frames are often constructed to capture the current and desired situation and communicate about it (Rein and Schon 1977, 240, Dekker 2017).

Policy frames co-determine policy action, alongside other factors including institutional arrangements or external events (Hertin and Berkhout 2003, Lenschow 2002, Nilsson 2005, Candel and Biesbroek 20 I 8). In the case of Kenya, policy frames also sometimes function as 'shopping list' or 'signal' to potential donors to indicate the country's policy priorities in order to attract funding (Faling and Biesbroek, submitted). Policy frames might be ambiguous and incoherent across sources, thus 
providing an unclear action perspective. Ambiguity can be caused by layering of frames, limited resources, bounded rationality of policymakers, or to accommodate and unite different perspectives (Schon and Rein 1995, Yanow 1996, Dekker 2017. Vij et al. 2018). In Kenya donors, international NGOs, and research organizations frequently participate in policy processes by providing funding, knowledge and technical support (Njoroge, Ratter, and Atieno 2017, O'Brien and Ryan 1999). The influence from multiple different sources is thus likely to create a certain ambiguity in policy frames across documents.

\subsubsection{The framing of climate-smart agriculture}

Climate-smart agriculture (CSA) is an approach to address the potential challenge of feeding a growing world population under a changing climate, by proposing transformations in the agriculture sector (Behnassi, Boussaid, and Gopichandran 2014, Lipper et al. 2014). It presents agriculture, climate change, development, environment and food security as closely linked by acknowledging a complex interpretation of issues and their interconnectedness. CSA acknowledges agriculture's vulnerability and contribution to climate change, identifies adverse consequences of climate change for development and food security and signifies the prominence of agriculture to address these challenges (see figure 5.I). The changes it proposes serve to increase agricultural outputs and farmers' incomes to enhance resilience, development goals and food security, while mitigating emissions from the sector, where possible. CSA preaches context-specificity and acknowledges differing interpretation of CSA depending on the situation. For example, whereas some corporations promote synthetic agrochemicals and sustainable intensification as climate-smart agriculture, the World Bank interprets trading carbon offsets as CSA. Others, predominantly NGOs, interpret climate-smart agriculture as small-scale, agro-ecological farming (Faling et al. 20 I8, International 20 I4, Karlsson et al. 20 I 8). Despite these different interpretations, an essential and agreed-upon governance component of CSA entails the acknowledgement and accommodation of linkages among agriculture, climate change, development, environment and food security (Faling, Biesbroek, and Karlsson-Vinkhuyzen 2018, Negra 20।4). 
Figure 5.I. Climate-smart agriculture narrative. Perceived connections between issues. $\mathrm{AG}=$ agriculture, $\mathrm{CC}=$ climate change, $\mathrm{DV}=$ development, $\mathrm{EV}=$ environment, FS = food security

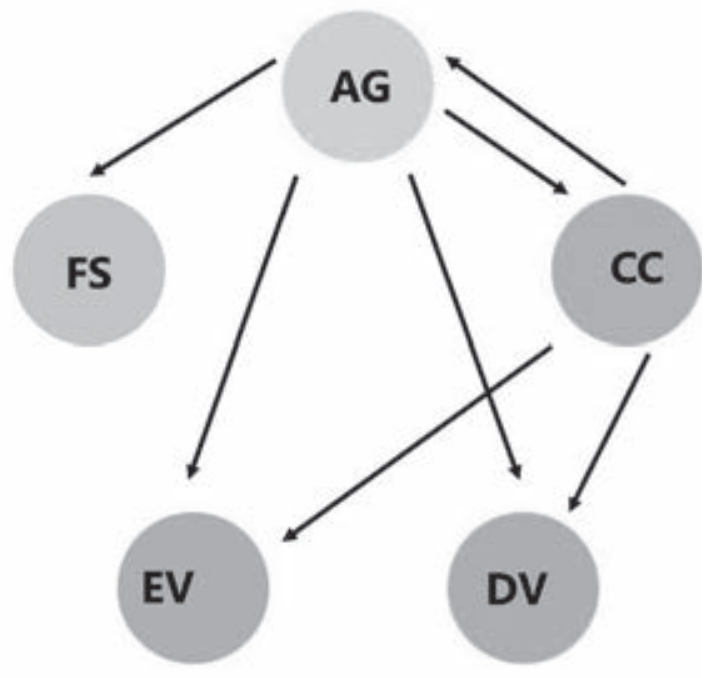

\subsubsection{Explanatory factors of policy frame change}

Policy frames change following different contingencies. Different socio-politicaleconomic mechanisms have proven to influence frames including focusing events, policy entrepreneurship, and administrative culture, to name but a few (Candel and Biesbroek 2016, Baumgartner and Jones 1993). For instance, Fiss and Hirsch (2005) demonstrate in their study on globalization discourse diffusion that changing economic and political conditions, such as levels of integration in the global market, codetermine frame change. Also, actor changes or interactions between sectors might influence the presence of one frame or another (Steensland 2008, JenkinsSmith et al. 20 I 4, Hall 1993, Mahoney andThelen 20 I0). In addition, changes in policy integration (frames) are brought about by strategic and functional considerations including public demands, international organizations' demands, and control over jurisdictions (Tosun and Lang 2017). The literature on explanations of general policy change highlights additional factors including external events, social learning, or internal governmental dynamics (Massey et al. 2014, Hall 1993, Mahoney and Thelen 2010). 


\subsection{Methodology}

\subsection{Demarcating the research}

The study analyses policy documents from the two ministries that have been involved in the development of the CSA Strategy: the ministry responsible for agriculture and the ministry responsible for environment. Although both ministries have alternated their titles and jurisdiction over the years (e.g. Ministry of Agriculture and Irrigation, Ministry of Agriculture, Livestock and Fisheries), their general function has largely remained unchanged. Throughout the study I will refer to 'Ministry of Environment' and 'Ministry of Agriculture' for feasibility reasons. The period under study is $2002-2017$. The time period was selected for pragmatic reasons, as the availability of policy documents is generally limited, but even more so regarding policy documentation from preceding and during the era under President Moi (before 2002).

\subsubsection{Data sources}

Policy documents were used to identify policy frames and factors influencing frame change. To enable comparison between ministries and over time, I selected the Strategic Plans of both ministries, launched in 2005, 2008, and 2013, for analysis. These sector-wide Plans serve as operational blueprint and to guide prioritization by ministries. Because the Strategic Plans provided only three measurement points per ministry, and because policy documents might be ambiguous across sources, I complemented these with all other available policy documents (policies, strategies, programmes) published by each ministry. This resulted in 59 documents for analysis (annex 2).

The policy reports are complemented with 15 semi-structured interviews conducted in 2016 to identify frames and explain frame changes (annex 2). The interviews provided retrospective evidence, with consequences for reliability of findings, as human memory is selective and may be faulty (Yow 20 14). An additional literature analysis served to complement insights from the interviews, both historically to better understand past patterns of policy development and more recent to directly underpin and test oral accounts of the interviewees. A member check with three experts was done to assess the value of my results. 


\subsubsection{Data coding}

The policy documents were analysed through a largely deductive frame analysis, starting from predetermined categories, to identify policy frames and explanatory factors linked to frame change (David et al. 20l I). A code book and a data extraction table can be found in annex 2 .

Based on a broad interpretation of CSA I coded all text relating to the following issues: agriculture, climate change, environment, development, food security (annex 2). Because policy frames consist of causal assumptions about problems and appropriate responses, a policy frame contains an understanding of the issue (e.g. climate change as natural threat externally imposed on Kenyan citizens and therefore unable to be curtailed) and a causal relationship among issues (e.g. how climate change impacts on agriculture through an increase in extreme weather events). These causal relationships indicate either a problem or a solution (e.g. problem: unpredictable weather decreases yields, or solution: agroforestry to mitigate and adapt to climate change). Annex 2 entails an operationalization of frames.

For the identification of explanatory factors I deployed an open coding technique. I identified explanatory factors following indicators including 'this policy was developed following [...]' or 'in accordance/line with [...]' or similar expressions. In addition I coded references to other policies, events and agencies.

\subsubsection{Data analysis}

The analysis of the Strategic Plans was based on three areas of interest: the importance the Plans assign to each issue, the particular interpretation of each issue, and the framing of relationships among issues. First, to assess the importance each Strategic Plan attaches to the individual issues, I counted how often each issue appeared in the quotes identified per document, and then divided this number by the total amount of quotes to control for document size (e.g. if climate change was coded 26 times in a total of 68 quotes, climate change would get value .38 (26/68). Second, to identify the dominant policy frame on each issue per document I assessed the content of each quote to identify the interpretation of each issue. Third, to analyse the Ministries' framing of relations among issues, I focused on whether a relationship is acknowledged, what is the direction of the relationship (e.g. agriculture influencing on environment or vice versa), and whether it is a positive, negative or neutral relationship. For the qualitative analysis (interpretation 
of the issue and the linkages) all quotes were organised according to ministry, year, sector(s), type of statement; and subsequently interpreted in an iterative way for general trends and patterns, following the operationalization as described above.

\subsection{Results}

Below I discuss the framing of the Ministries of Agriculture and Environment regarding the issues of agriculture, climate change, development, environment and food security. Table 5.1 provides an overview of issue interpretations. Figure 5.2 displays relative importance of the issues and issue linkages acknowledged in the Strategic Plans of both Ministries. Below I present per time period an overview of agriculture-climate change-development-environment-food security related events and contingencies, discuss per ministry's Strategic Plan the attention each issue receives, the dominant frames deployed, and issue linkages, contrast these with issue frames and attention in the sectoral policies, and discuss the factors explaining each Ministry's focus.

\subsection{The $2005-2010$ period}

Agriculture has traditionally received undivided policy attention in Kenya as catalyst for growth, whereas environment has largely been viewed as subordinate to development. This standpoint is emphasized in the national Economic Recovery Strategy (ERS) launched in 2002. The ERS focuses on macro-economic development, food security, and income and employment creation through strengthening of extension services and access to credit. It superficially addresses environmental preservation. In 2006 the $12^{\text {th }}$ UNFCCC Conference of the Parties is held in Nairobi. In preparation for this event civil society steps up its climate change awareness and action, and unites in two coalitions which will later form the Kenya Climate Change Working Group (KCCWG). These coalitions consist of civil society and community farmer groups and are supported by various international development organizations.

\section{Agriculture: modernization through environmental conservation}

The state of the environment receives most attention in the Plan and is considered key to agricultural development (.50), whereas climate change, though mentioned, seems to play a very limited role (0.08). The other issues of development (.28) 
and food security (.23) receive more or less equal attention. In the 2005 - 2009 Strategic Plan of the Ministry of Agriculture, the agricultural sector is framed as key to national development and food security. According to the ministry, the sector needs to be boosted predominantly through industrialization, private investments, and trade. Development in the agricultural sector will boost food security - framed as sufficient available food - and macro-economic growth, which will trickle down and address poverty. Climate change and environmental deterioration hamper agricultural development, therefore environmental conservation needs to be strengthened. In terms of linkages, the Agriculture Ministry predominantly frames agriculture as having a positive impact on the issues of development, environment, and food security. Climate change is framed as having an adverse impact only on agriculture.

The sectoral policies of the Ministry in this period display a somewhat different frame.The central focus on the environment is not reflected in the sectoral policies, which frame agriculture predominantly as catalyst for development. Environment however does receive increasing attention in sectoral documents until 2009, after which its focus shifts again. Instead, the sectoral policies predominantly embrace a policy frame where agriculture acts as catalyst for development. Climate change equally receives scant attention in sectoral policies.

\section{Environment: the multiple threats to the environment}

Development (.79) is the key focus of the Environment Strategic Plan, climate change receives significant attention as compared to the Agriculture Strategic Plan (.14), whereas food security is not mentioned. The Environment Strategic Plan deploys a policy frame in which the environment is central to national development. Whereas Agriculture focuses predominantly on macro-economic growth, Environment frames the environment as key to realizing sustainable development, improving livelihoods and addressing poverty. Climate change and agriculture are framed as threats to the environment. Simultaneously the Plan frames the adverse impact of environmental degradation on development as significant. The framing in the Environment Strategic Plan is thereby more negative as compared to the Agriculture Strategic Plan.

The Ministry's sectoral document (only one in this period: the Forest Policy) demonstrates a similar policy frame as compared to its Strategic Plan. It demonstrate 
an equal focus on the value of environmental preservation for societal development, and highlights agriculture and climate change as impacting negatively on the environment. Contrary to the Strategic Plan, it does identify the environment's mitigation potential by highlighting the role of forests for carbon sequestration.

\section{Explaining policy frames}

The policy frames in this time period can be partly traced back to certain events and activities that took place. Agriculture's focus in the Strategic Plan on industrialization, private investment and trade results from donors like the World Bank and the IMF who have introduced structural adjustments focused on liberalization and privatization since the 1980s (O'Brien and Ryan 1999). The Strategy for Revitalizing Agriculture (SRA) that is based on the National Economic Recovery Strategy equally breathe private investments, as endorsed by international development partners (Poulton and Kanyinga 2014). Both ministries' policy frames on environment present environment as subordinate to development, as has traditionally been the approach by both government and donors (Wamicha and Mwanje 2000). The Environment Strategic Plan is in its focus on development, climate change and environment inspired by global fora including the World Summit on Sustainable Development in 2002. The foreword of the Strategic Plan states that it "builds on the commitments set out in the ERS, the national Development Plan, Agenda 21, The Johannesburg Plan of Action and the Millennium Development Goals" (Ministry of Environment Strategic Plan 2005 - 2010).

\subsubsection{The $2008-2012$ period}

The Kenya Vision 2030, a long-term development blueprint to transform Kenya into an industrialized and middle income country, is launched in 2008. Despite opposition from various civil society organizations, environmental concerns are only marginally included in the Vision. Agriculture is viewed as key for growth. From 2008 a new format dictates that Strategic Plans have to be aligned with Vision 2030 and that policy development requires inter-ministerial consultations. Climate change slowly gains a more prominent focus in government. As one interviewee states: "the international community plays a role in the introduction of climate change, as funding around climate change is huge. All big international donors [...] are focusing on it" (interviewee 14). A Climate Change Unit is established in the office of the Prime Minister in 2008. In run up to the 2009 UN Climate Change Conference in Copenhagen African governments unite in a common African platform for the 
acknowledgement of the link between agriculture and climate change in the climate negotiations. Kenya is closely involved in the process. In 2010 Kenya adopts a new Constitution, which recognizes the right to environmental protection for present and future generations, and acknowledges climate change mitigation and adaptation (Constitution 2010). In 2010 the Government adopts a National Climate Change Response Strategy, which obliges the mainstreaming of climate change in all projects and policies.

\section{Agriculture: development is threatened, technical interventions required}

The 2008 - 2012 Strategic Plan pays most attention to development (.47) and food security (.40) as compared to the other issues; whereas climate change still receives negligible attention (.09). It presents a more integrated picture as compared to the previous Plan. It does equally portray agriculture as key to national development. The policy frame shifts somewhat to portraying inputs, technology and credit to boost agriculture, instead of private investment and trade. Development of the agricultural sector will lead to development, framed as economic growth, and food security, which again is framed in terms of food availability. Climate change is framed as hampering not only the agricultural sector, but also development. Whereas in the previous plan development was mainly portrayed as an issue of macro-economic growth, this Plan acknowledges development also as matter of equity and poverty alleviation. The Plan focuses more heavily in negative linkages among the issues by acknowledging the adverse impact of agriculture on food security and environment, but most importantly by framing how climate change threatens agriculture, food security and development.

Overall, attention for the different issues waxes and wanes in the Agriculture's sectoral policies. Whereas environment is central in 2009, development is key in 2010, and food security, due to the National Food Security Policy, in 201 I. Climate change is covered for the first time in 2009. In line with the National Climate Change Response Strategy the Ministry incorporates climate change structurally in its sectoral policies from $201 \mathrm{I}$ onwards. It is perceived an external natural threat, and no solutions are offered.

\section{Environment: agriculture's adverse impacts on environment}

The Plan again pays most attention to development (.37), although the issues of climate change $(.31)$ and agriculture (.27) receive almost equal attention. Food 
security is incorporated in the Strategic Plan, but receives negligible attention (.0 I). Again, the Strategic Plan frames the environment as key to sustainable development and poverty alleviation, but in alignment with Agriculture acknowledges the importance of the environment for macro-economic growth. Agriculture and climate change are again framed as threatening the environment, but unlike the previous Plan, the 2008 - 2012 Strategic Plan displays an action perspective by highlighting various interventions the Ministry can take to address these threats. In general, the 2008 - 2012 Plan frames issues as increasingly linked, and starts acknowledging positive linkages among issues as well. An exception is the central focus on the adverse impacts of agriculture on the environment. Although the Environment Plan pays much more attention to climate change as compared to the Agriculture Plan of the same period, the Environment Plan only frames climate change in terms of its adverse impacts on the environment.

Whereas development loses the Ministry's undivided attention somewhat in the 2008 - 2012 Strategic Plan, it continues to receive unabated attention in the sectoral policies. Unlike the Strategic Plan, the Ministry's sectoral policies pay limited attention to agriculture. The sectoral policies refrain from addressing food security entirely. Climate change is increasingly addressed in the sectoral policies in line with the Strategic Plan, most notably through the adoption of the National Climate Change Response Strategy.

\section{Explaining policy frames}

Vision 2030 proves influential for the development of policy frames in the Agriculture Strategic Plan. It frames development as matter of agricultural processing and technical interventions, and highlights sustainability and equity concerns, in line with the Vision. Although environment is not separately recognized in the Vision, the Environment Strategic Plan predominantly highlights how environment is essential for development, and how the expected growth, resulting partly from agriculture, will put pressure on the environment. Agriculture's focus on poverty is related to the Millennium Development Goals, which were signed in 2000. The government's enhanced focus on climate change is mirrored predominantly in the policy frame of the Environment, in both its Strategic Plan and sectoral policies. 


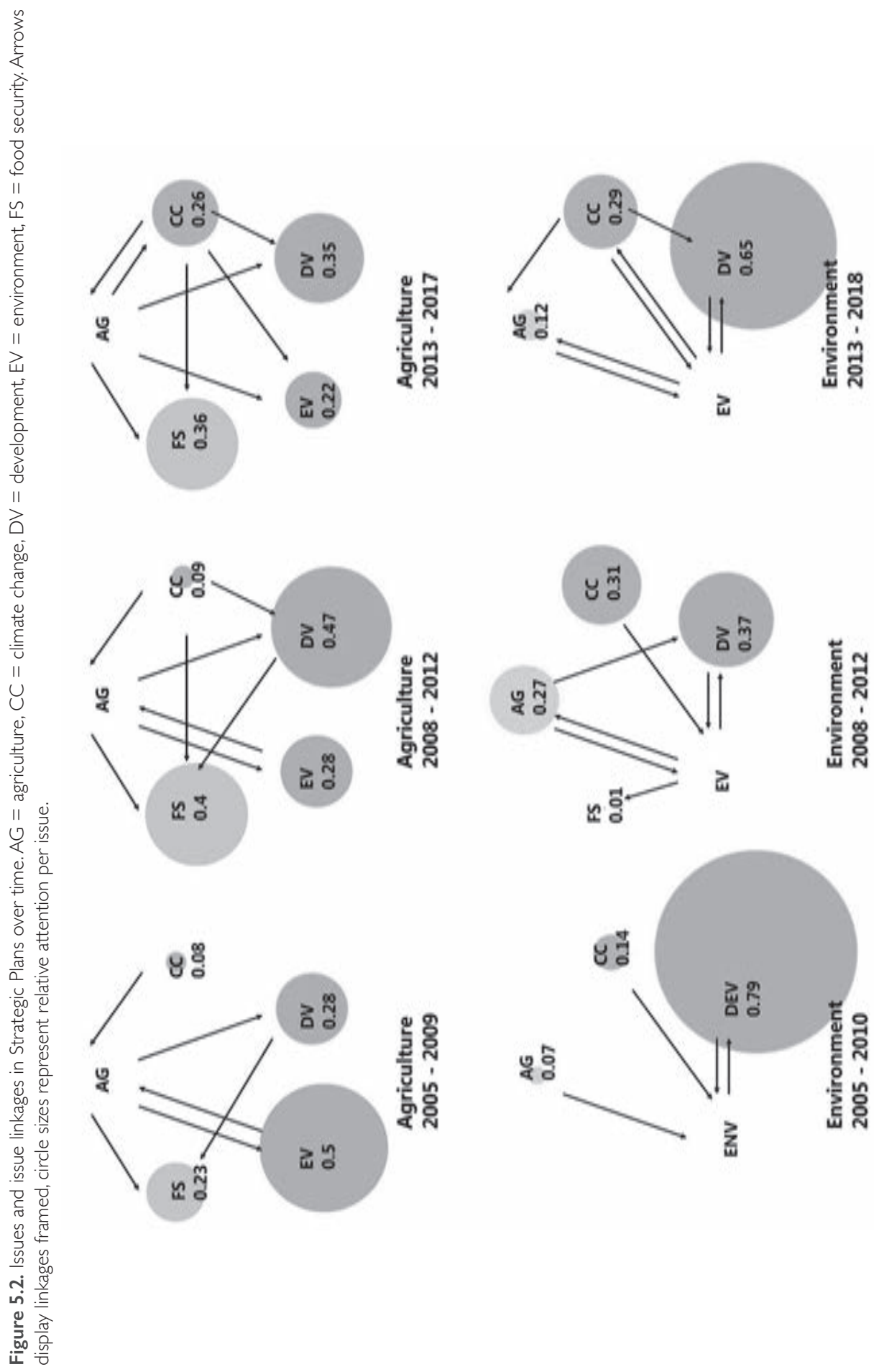




\subsubsection{The $2012-2017$ period}

In 2015 the United Nations General Assembly adopts the 2030 Agenda, which comprehends the Sustainable Development Goals (SDGs) that aim to address various social and economic development issues. Initiatives such as the UNDP and FAO programme to incorporate agriculture in Kenya's National Adaptation Plan, reemphasize and strengthen linkages among different ministries. As one interviewee states "these programmes facilitate and strengthen collaboration and interaction among relevant line ministries" (interview 15). These development thus attempt to mainstream climate change in other Ministry's policy documents.

\section{Agriculture: the rise of climate change}

In this Plan, food security receives most attention (.36), but climate change (.26) receives much more attention as compared to previous Plans, and the other issues of development (.35) and environment (.22) get relatively equal attention. The Plan acknowledges that the agricultural sector needs to be boosted in a sustainable manner, to avoid reducing outputs as a result of environmental deterioration. Thereto subsistence farming needs to be transformed to modern and commercial agriculture. Climate change is framed as hampering not only agriculture, but also development, environment and food security. Adaptation interventions from the agricultural sector are therefore required. Agricultural development is thus framed as leading to growth, a healthy environment, and resilience to the adverse impacts of climate change. The policy frame adopted in this Strategic Plan thus acknowledges complex linkages among the issues, most importantly climate change is framed as impacting negatively on all the other issues.

The sectoral policies of the Ministry generally retain their focus on development in this time period, although environment and food security are more strongly covered in 2015 and 2016 respectively. Unlike in the Strategic Plan, climate change remains marginally covered in the sectoral policies. The sectoral policies repeatedly refer to sustainable development and the SDGs in their sectoral policies after 2015.

\section{Environment: the multiple threats of climate change}

Development gains more prominent attention again (.65), whereas the adverse impacts of agriculture have lost some attention (.27). Climate change remains an integral part of the Environment Strategic Plan's frame (.3I), and food security has been disappeared again from the Plan. The focus on the environment as key 
to development remains a constant throughout the Environment Strategic Plans. This time the Plan frames development as not only entailing macro-economic growth and poverty alleviation, but as also entailing wealth and employment. The adverse impacts of climate change and development are viewed to threaten the environment, whereas environmental deterioration hampers development. The Plan thus frames environment and development as interlinked in multiple ways. Climate change is framed as threatening not only environment, as in the previous Environment Strategic Plan, but also threatening agriculture and development.

Development remains the key issue for sectoral policies, also in this period. Whereas the Strategic Plan distances itself from food security again, the sectoral policies of Environment address food security in 2013,2015 and 2016. Climate change is wellcovered in sectoral policies, particularly with the National Climate Change Action Plan 2012 and the National Adaptation Plan 20 I 5, which offer a range of adaptation and mitigation interventions in all sectors of the economy.

\section{Explaining policy frames}

Both ministries frame the issues under study as increasingly interlinked. Part of the Ministries' acknowledgement of mutual relations is inspired by the development of a common African position on agriculture in the UNFCCC, which enhanced joint involvement of both ministries in climate-related issues; a process pushed by various international organizations. In 2010 the Agricultural Sector Development Strategy (ASDS) is developed. It mirrors the regional Comprehensive Africa Agriculture Development Programme (CAADP) and its principles of accountability, transparency and inclusiveness. It furthermore promotes a shift from agriculture as subsistence practice to agriculture as commercial business, which is reflected in the 2012-2017 Strategic Plan.

The Environment Strategic Plan is influenced partly by UN programmes and activities. It frames the relation between environment and development by referring to the Green Economy, following the UN Environment's contribution to the Rio +20 process. Although climate change is discussed as an anthropogenic issue, the Ministry of Environment hardly proposes resolutions, except for Green Economy and Clean Development Mechanism, in line with the Post-20I 5 Agenda. 


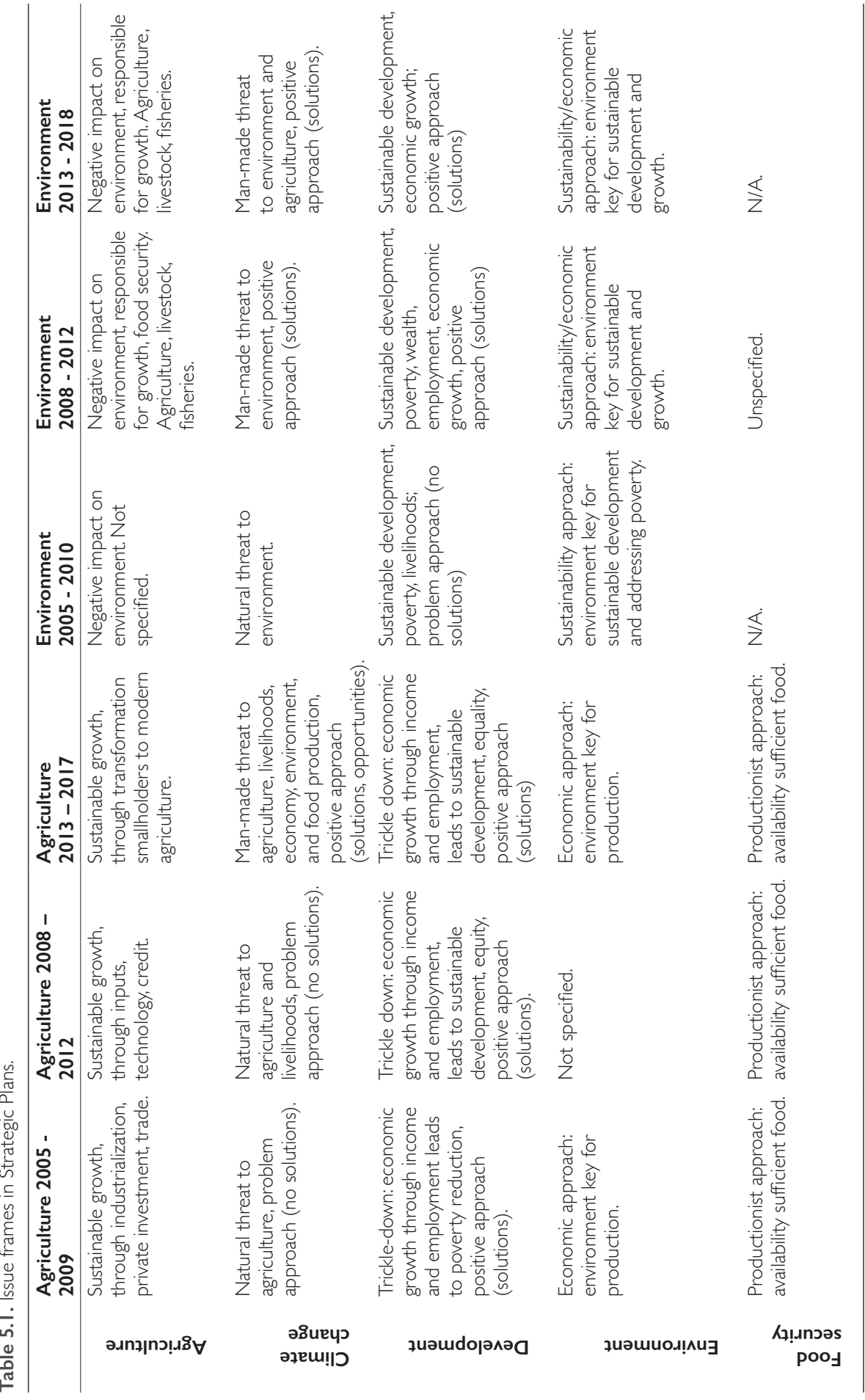




\subsection{Discussion}

This paper analyses policy frame development regarding CSA-related issues in Kenya. It studies Agriculture and Environment Ministries' policy documents to identify the development of frames on agriculture, climate change, development, environment and food security. Thereby it analyses the origin and nature of CSA policy adoption and identifies whether CSA should be interpreted as radical divide from existing practices, component of a gradual change process, or as old wine in new bottles. Following my analysis, I here discuss three key findings.

First, the CSA Strategy is a continuation of an existing trend in both ministries' policy frames, which display a gradual increase in comprehensiveness and complexity regarding the nature of the issues and their mutual relationships. Climate change particularly is increasingly covered and framed as connected to the other issues. This trend is particularly visible in the Strategic Plans. The CSA Strategy displays a minor frame shift as compared to preceding frames. The most clear difference of the CSA Strategy is the acknowledgement of agriculture's contribution to climate change. The development of a CSA Strategy is thus a logical step given the historical development of policy frames. Often CSA is presented as a transformative approach to address climate change and food insecurity (Lipper et al. 2014, Chandra, McNamara, and Dargusch 2018). The policy frame analysis in this paper suggests that in Kenya, CSA is a continuation of an existing trend characterized by an increasing acknowledgement of the complexity of the issues and the complex and multi-dimensional linkages rather than a radical transformation. Although the CSA Strategy in Kenya will thus not bring a transformation of its agricultural system, in light of implementation possibilities this could be good news. Compatibility with pre-existing policy frames has been shown to be conducive to (environmental) policy integration (Persson and Runhaar 2018). Smaller or more incremental changes encounter less resistance as compared to radical changes, and require less adaption from actors involved (Termeer, Dewulf, and Biesbroek 20 I7). Although the assessment of change is highly subjective to certain choices including object of study and time frame, the policy frame development process in Kenya around agriculture, climate change, development, environment and food security seems incremental rather than transformative (Capano 2009, Knill and Tosun 2012). Although CSA is thus presented as transformation from existing practices, this case suggests that the value of CSA as tool to address contemporary challenges including climate 
change and food insecurity is limited to those contexts characterized by an acknowledgement a certain level of connectedness among the issues of agriculture, climate change, development, environment, and food security.

Second, a certain discrepancy exists between Strategic Plans on the one hand and sectoral policies on the other. Whereas the Strategic Plans display a gradual trend of increasingly complex and integrated frames of agriculture, climate change, development, environment and food security, sectoral policies show a more erratic pattern. Overall, the sectoral policies do reverberate the increased integrative policy frames of the Strategic Plans. However, some policies keep a narrow focus on the particular issue of concern and link this mostly to more traditional issues including development and economic growth. This might be due to the particular purpose sectoral policies may serve (e.g. a Horticulture Policy or a Solid Waste Management Strategy). Furthermore, it might be explained by limited availability of resources (Alila and Atieno 2006, Maina, Newsham, and Okoti 20 I3), inadequate internal consultation across government (O'Brien and Ryan 1999), or by subcontracting policy drafting to consultants or donors (Maina, Newsham, and Okoti 2013). Struggling with the implementation of policy integration is not unique to Kenya. While policy frameworks such as strategies are adopted rather easily, a move towards more binding (or concrete) measures that interfere with sectoral policymaking and existing institutional structures is much more challenging (Widmer 2018).

Third, my analysis suggests policy integration frames are influenced by a variety of different factors. Both ministries' policy frames carry the signature of global and bilateral donors and partners, who through various projects and programmes codetermine policy frames and directions. Studies concentrating on policy integration generally stress the role of IGOs in placing integration on national agendas (Tosun and Lang 2017, Köhler 20 I I). My findings underpin what has been argued before: certain policy initiatives, including in Kenya are at least partly donor-driven (Alila and Atieno 2006, O'Brien and Ryan 1999). Simultaneously policies are inspired by national development goals including its Economic Recovery Strategy and Vision 2030, our results indicate. However, overall the pattern of factors influencing on policy frames is somewhat muddled. Interviewees indicated that policy documents are frequently influenced by rather opaque processes, including personal networks and events, subcontracting policy development to consultants, and donor support. 
Faling and Biesbroek (submitted) demonstrate that the development of the National CSA Strategy was developed through close involvement of various donors, international organizations and foreign government departments. Followup research would be valuable to identify how Strategic Plans and sectoral policies relate, and how policy development processes usually evolve.

\subsection{Conclusion}

Agricultural production in Kenya is threatened by climate change, thereby jeopardizing economy, livelihoods and food security. The government in 2017 launched the Kenya Climate-Smart Agriculture Strategy, which presents climatesmart agriculture (CSA) as a transformation of its agricultural systems through integrating agriculture, climate change, development, environment and food security. By undertaking a longitudinal analysis of policy frames around these issues and their linkages, I contextualized CSA-policy adoption to understand whether CSA is a transformative approach or old wine in new bottles.

My research has shown that CSA policy is a continuation of a trend characterized by enhanced complexity. It is thus rather an incremental shift away from existing practices instead of a radical transformation. The close proximity to existing approaches might actually enable successful implementation as it meets less resistance. In Kenya policy are influenced by national development plans, donors, regional and global fora, personal networks. This study suggests that the value of CSA is limited to those contexts that acknowledge a certain level of connectedness among the issues of agriculture, climate change, development, environment, and food security. 



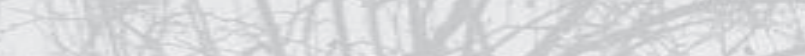

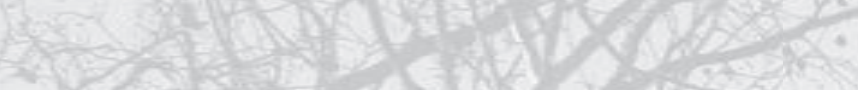

M.

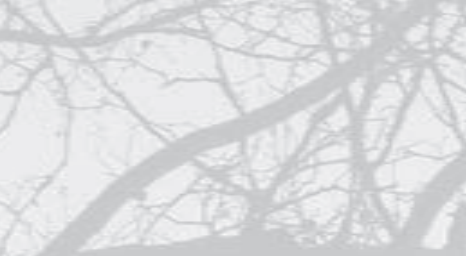

90

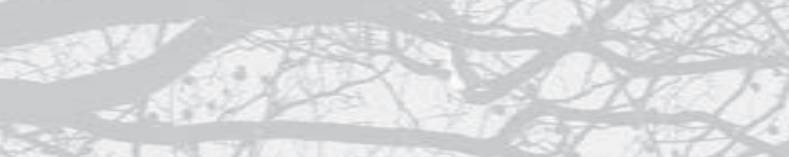

ser

पts

sesise

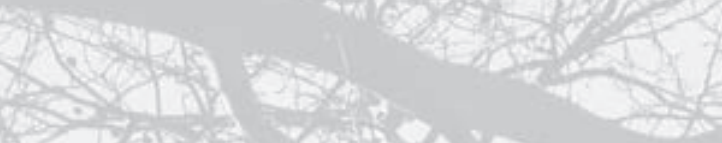

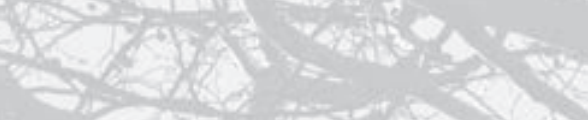

48

$=7$

S

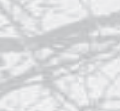

Pes
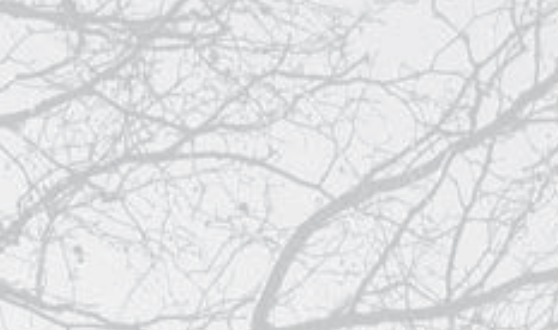

sic

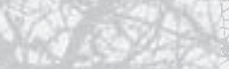

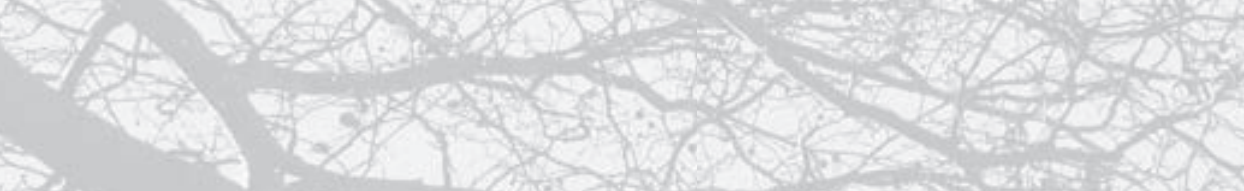

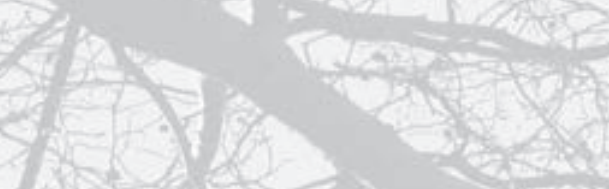

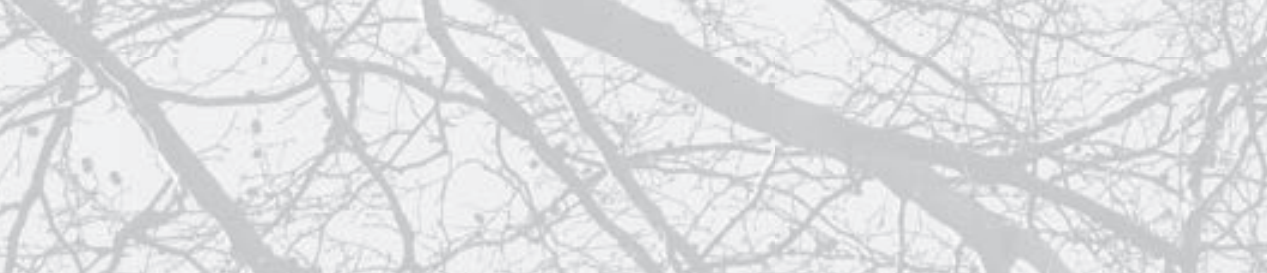

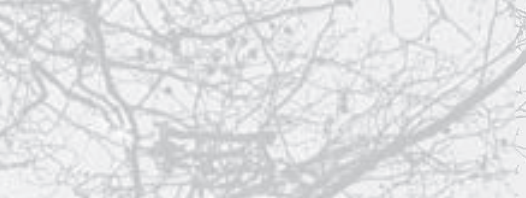

$302=2$ 


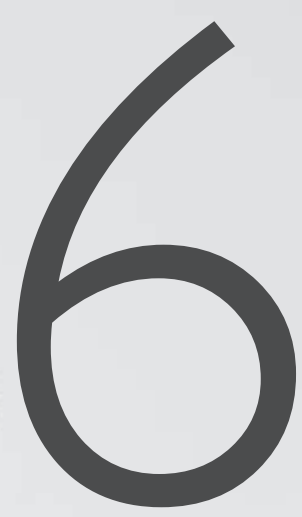

Discussion, reflections, and conclusion 

The observation that many initiatives, including climate-smart agriculture (CSA), emphasize the need to link levels, domains, and organizations was the starting point of this dissertation. These initiatives call for the involvement of various actors in decision-making processes, including local governments, businesses, international organizations, farmers, and research organizations. Previous research has demonstrated that crossing boundaries often involves difficulties, including turf wars and power struggles, which may thwart policy development. Although the literature argues that policy entrepreneurship contributes to the crossing of boundaries, knowledge is fragmented and insight into entrepreneurial strategies to cross boundaries is limited. This is what inspired the focus of this dissertation.

In this dissertation, I aimed to understand how policy entrepreneurship contributes to the crossing of boundaries to develop climate-smart agriculture policy. This aim was broken down into three research questions: (i) how and why do policy entrepreneurs cross boundaries for climate-smart agriculture; (ii) how does the policymaking context influence cross-boundary policy entrepreneurship; and (iii) how can cross-boundary policy entrepreneurship for climate-smart agriculture be conceptualized?

This concluding chapter draws together the most important findings to reflect on cross-boundary policy entrepreneurship for CSA. Section 6.I presents answers to the research questions and reflects on the scientific implications of the findings. Section 6.2 reflects on the methodological choices and the implications of these choices, and section 6.3 presents directions for further research. In section 6.4, I discuss the policy implications of my research, after which I end with conclusions in section 6.5 .

\section{I Understanding entrepreneurship for climate-smart agriculture}

One of the key findings from this dissertation is that, in the CSA policy process, cross-boundary policy entrepreneurship and the policymaking context are intrinsically linked in a dynamic and reciprocal way. A detailed account of the interplay between entrepreneurship and the policymaking context is required to understand the CSA policy process. Presenting my findings in a way that does justice to this 
interplay necessitates discussing this interplay (question 3) before pursuing policy entrepreneurship (question I) and policymaking context (question 2) in greater depth separately. I therefore reverse the order of the questions and present the conceptual framework as developed in answer to question 3 first, before answering questions I and 2.

\section{I.I The cross-boundary strategizing framework}

In this section, I formulate an answer to the third research question: how can crossboundary policy entrepreneurship in the policy process for climate-smart agriculture be conceptualized? I have constructed a conceptual cross-boundary strategizing framework (CFS) in which I present the elements and the connections among elements relevant to understand cross-boundary policy entrepreneurship for CSA (see figure 6.1). I first briefly discuss the steps that I took in the various chapters to build the CSF, before presenting the framework by discussing the general assumptions and details.

\section{Building the cross-boundary strategizing framework}

The interpretation of entrepreneurship as a process served as the starting point for the construction of the CSF. Process refers to the sequence of events and actions that take place in context (Pettigrew 1997). To operationalize 'process', I identified three elements, namely, conditions, strategies, and implications (see also Garud, Hardy, and Maguire 2007, Oborn, Barrett, and Exworthy 20 I I). I systematically reviewed the policy entrepreneurship literature to identify conditions, strategies, and implications of cross-boundary policy entrepreneurship (chapter 2). Conditions of institutional overlap, issue interpretation, and power vacuum were found to facilitate cross-boundary entrepreneurship. The systematic review revealed that strategies of issue promotion, coalition building, and transforming institutions are used by entrepreneurs to cross boundaries, and that cross-boundary entrepreneurship may involve unforeseen consequences including opposition, competition over leadership, enhanced complexity of the process, higher costs and resource requirements, and distrust.

The application of the CSF to the empirical case of the Global Alliance for ClimateSmart Agriculture (GACSA) in chapter 3 helped further refine and extend the framework. In addition to arguing that conditions codetermine strategies and that strategies have implications, I found that implications of entrepreneurs' 
strategies, such as increased opposition or complexity, are part of the conditions that influence the subsequent choice of strategy by the entrepreneur. This led to the realization that cross-boundary entrepreneurship is played out in rounds. By studying cross-boundary entrepreneurship for the development of GACSA in chapter 3 and the National CSA Strategy in Kenya in chapter 4, I identified a set of entrepreneurial strategies to cross boundaries deployed in both cases: patchwork framing, unbiased leadership, and process manipulation. Detecting these strategies in these varied cases provides sound reasons to believe these are relevant to the crossing of boundaries for CSA more widely. The studies in chapter 3 furthermore reaffirmed the contextual conditions and implications as identified in chapter 2 . After analysing the empirical GACSA case, I noticed that policy entrepreneurship studies, including the CSF that I deployed, pay limited conceptual attention to the aims and effects of entrepreneurship, apart from the implications that I identified. The lack of insight regarding the aims and effects of entrepreneurship precludes a complete understanding of entrepreneurship as a process, because it obscures the identification of changes in the policymaking context following entrepreneurship (in combination with other contingencies). Therefore, in chapter 4, I used the most notable policy process frameworks of multiple streams, advocacy coalitions and punctuated equilibrium to identify the aspects of the policymaking context that policy entrepreneurs aim to reconfigure across different levels, domains, and organizations. This resulted in the identification of ideas, interests, and institutions that together constitute the policymaking context relevant to cross-boundary policy entrepreneurship. The policy process frameworks in addition helped identify the exogenous dimension of the policymaking context, including crisis events and socio-politico-economic conditions. What differentiates these from ideas, interests, and institutions is that they are generally beyond the entrepreneurs' sphere of influence.

\section{The underlying assumptions of the cross-boundary strategizing framework}

The CSF is based on a processual understanding of policymaking, as discussed above. A static interpretation would identify elements that together lead to a certain outcome. The CSF depicts CSA policy development, for instance, as the result of a combination of the following elements: a context characterized by the threat of climate change, a window of opportunity in the form of wider acknowledgement of the link between agriculture and climate change in the 2009 FAO World Summit on Food Security Declaration and the 17th session of the Commission on Sustainable 
Development, and a set of entrepreneurial strategies including framing and networking. A processual understanding, on the other hand, identifies the sequence of events that together demonstrate how policy processes evolve over time.

The CSF portrays policymaking as the entirety of processes, defined by the constant flux of the separate elements of policymaking context and policy entrepreneurship. This constant flux is brought about by new information, (natural) events, and other contingencies that reconfigure the policymaking context and consequently policy entrepreneurship. Policy entrepreneurship in turn aims to change the policymaking context by addressing interests, ideas, and institutions (based on Vandenbussche, Edelenbos, and Eshuis 2018, Zhang 2017, Pettigrew 1997). This is a continuous and ongoing process. Process is thus understood as the sequence of events and actions taking place in context (Carter and New 2004, Fletcher 2017). The CSF consequently encapsulates policy entrepreneurship as a process that evolves in rounds (Koppenjan and Klijn 2004a,Teisman 2000).

The processual nature prompts a focus on relations, patterns, and processes, in which dynamics and developments are highlighted. More conventional questions regarding 'what is' consequently become inadequate in themselves to grasp the strategizing of policy entrepreneurs to realize CSA. A processual interpretation of reality highlights questions regarding how and why entrepreneurial strategies are deployed, how strategies are adapted over time following contextual developments, and what the aims and effects of strategies are with regard to achieving CSA.

\section{Strategizing as a complex process}

Following from the above-described underlying assumptions, the framework consists of the dynamic elements of the CSA policymaking context and policy entrepreneurship, and their interactions.

First, the CSA policymaking context consists roughly of two dimensions: exogenous processes and events, and the internal policymaking context. Both dimensions influence entrepreneurship, whereas only the second dimension is influenced directly by entrepreneurship.The first dimension of exogenous processes and events refers to the processes that occur independent of the entrepreneur's strategies, such as climatic events, changes in administration, or developments in relation to multilateral negotiations, including the incorporation of agriculture in the United 
Nations Framework Convention on Climate Change (UNFCCC) negotiations. The other dimension consists of the policymaking context that entrepreneurship aims to influence. The policymaking context is composed of three elements: interests, ideas, and institutions. Entities are generally characterized by differences in interests: e.g. market access versus addressing poverty; ideas: e.g. human prosperity versus ecological sustainability; and institutions: e.g. the Climate Change Unit within the Kenyan Ministry of Agriculture versus the National Environmental Management Authority within the Ministry of Environment. Policy entrepreneurs through their strategies aim to define, redraw, emphasize, or remove the boundaries of interests, ideas, and institutions. Section 6.1.3 provides a detailed discussion of the policymaking context and its influence on cross-boundary policy entrepreneurship.

Figure 6.I The cross-boundary strategizing framework

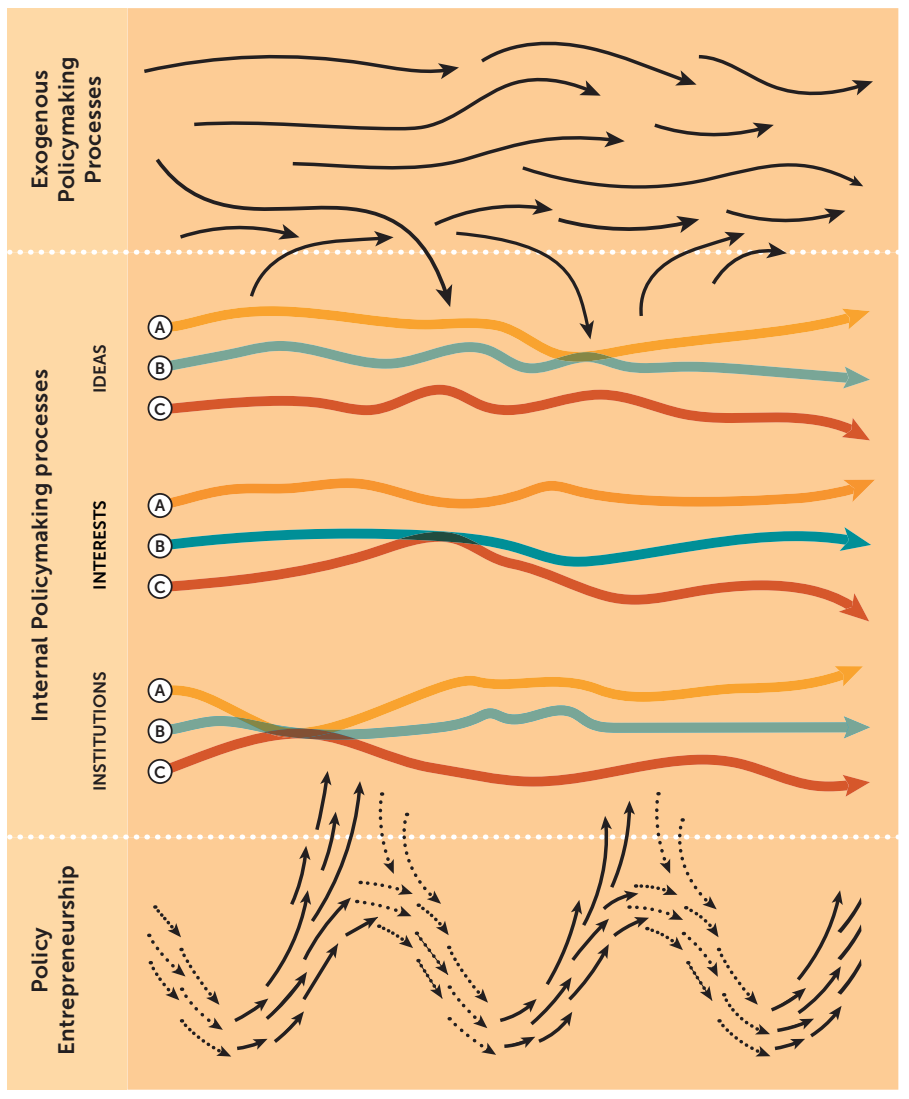

The figure is inspired by Bakir and Jarvis (2017), Geels and Schot (2010), Kingdon (1995), Koppenjan and Klijn (2004). Exogenous processes, internal policymaking processes, and policy entrepreneurship have been separated for analytical purposes, in reality these processes are closely interwoven. 
Second, entrepreneurship for CSA entails an orientation on strategy as both reactive to the wider policy process in which the entrepreneur is situated and influential in reconfiguring the policymaking context. I refer to this in chapters 2 and 3 as strategizing: entrepreneurs interpreting and acting upon the policymaking context in order to reconfigure the policy process, with both intended and unintended effects. How the policy entrepreneur interprets the policymaking context therefore influences strategy choice. To cross policy boundaries for CSA, entrepreneurs deploy three types of strategies: patchwork framing: deploying different CSA frames to different audiences; impartial leadership: uniting different entities through neutral facilitation; and process manipulation: sidestepping rules and practices that complicate processes. The strategies are discussed in more detail in section 6.1.2.

Strategizing is a complex process: it is variable, interpretation-dependent, and can have unforeseen consequences. It is variable because entrepreneurs determine their actions on the basis of context, which is in constant flux. Entrepreneurs consequently continuously reassess and readjust their strategies vis-à-vis the policymaking context in which they operate. To illustrate this with an example from chapter 3, the framing by the World Bank and Dutch DG Agro CSA entrepreneurs as a triple win for adaptation, mitigation, and food security led to support from donors. It simultaneously provoked opposition from others, including developing countries, who interpreted CSA as a 'trick' to pass on mitigation responsibilities from developed to developing countries. The entrepreneurs, on realizing the objection that they had unintentionally created, readjusted their communication about CSA by indicating that mitigation was optional, to curtail protest. Strategizing is interpretation-dependent, because context cannot be identified objectively. Actions are thus based on the entrepreneur's interpretation of the policymaking context. Because interpretations frequently differ, activities among entrepreneurs, even with seemingly shared objectives, frequently differ as well. Strategizing has unforeseen consequences because the effects of entrepreneurship are a combined result of wider policy processes and entrepreneurial strategies. This is likely, given that entrepreneurs do not always properly assess the policymaking context, many contingencies are beyond the control of entrepreneurs, and other actors' reactions and interactions are unpredictable. For example, in the process of setting up GACSA, the United Nations' Special Representative of the Secretary-General on Food Security and Nutrition (SRSG) wanted to involve many actors to ensure the transparency and legitimacy of the collaboration, whereas the DG Agro believed 
success could also be achieved with a small coalition. Our findings in chapter 3 show that the DG Agro's selective approach in the first episode led to swift decision making on the one hand, but to criticism and opposition on the other, whereas the inclusive approach by the SRSG led to increased complexity and consequent delays, but addressed some of the criticism raised by the other entrepreneur.

\section{Reflections on and contributions to the existing literature on policy entrepreneurship}

Although the entrepreneurship literature increasingly appreciates entrepreneurship as context-dependent, there is limited research covering the mutual influence of entrepreneurship and context (Bakir and Jarvis 2017); among the seminal works are the publications by Roberts and King (1991) and Roberts (1992), who approach policy entrepreneurship as processual and contextualize entrepreneurship by means of the entrepreneur's background and the stage of the policy process in which the entrepreneur is engaged. Mintrom and Norman (2009) embed policy entrepreneurship in various policy process frameworks to avoid an idiosyncratic treatment of policy entrepreneurship and call for the further permanent inclusion of entrepreneurship in context. These have been valuable starting points for my understanding of entrepreneurship in context.

Since I started this dissertation, a number of scholars have further contributed to policy entrepreneurship by conceptualizing the relationship between policy context and entrepreneurship, particularly in climate governance. For instance, Brouwer and Huitema (2018) and Green (2017) differentiate between entrepreneur, strategies, and context. The added value of these conceptualizations is the identification of different components of context and the explicit acknowledgement of the contextdependency of entrepreneurship. Bakir and Jarvis (2017) set out to identify the interactions among various contexts and entrepreneurs but, despite acknowledging how different dimensions of context influence one another, discuss predominantly the influence of context on entrepreneurship.

What characterizes the abovementioned studies is that they pay limited attention to entrepreneurship's influence on the policymaking context. They treat context largely as a given (hence static) entity and do not fully embrace a processual approach to policymaking. The CSF contributes to the policy entrepreneurship literature by highlighting the processual and complex nature of cross-boundary policy entrepreneurship for CSA. Although the framework captures cross- 
boundary entrepreneurship for CSA specifically, it might be useful for other crossboundary policy processes as well. Contemporary policy initiatives to address complex problems, including crime prevention and healthcare, are equally viewed as requiring the crossing of boundaries (van Meerkerk and Edelenbos 2018, May and Jochim 2013), and frequently involve policy entrepreneurship for policy development (Mintrom and Luetjens 2017, Mintrom and Thomas 2018). This gives substantive reason to believe that the dynamics captured in the CSF are relevant for these issues as well. Therefore, the framework, although particular to crossboundary processes, provides a first attempt to develop a 'process-oriented, context-contingent, dynamic and integrative framework' of entrepreneurship as called for by Bakir and Jarvis $(2017,472)$.

By providing an account of entrepreneurship as processual and embedded in context, my dissertation contributes to the development of entrepreneurship theory in several ways. A processual analysis helps to analyse sequences of events, which reveal how policy processes evolve over time. This leads to a better and more detailed account of which strategies, in which context, in what way, have which effect (and which do not work). A processual approach also nuances the discussion about the focus of the entrepreneurship literature on success cases. Many scholars call for the study of unsuccessful cases of entrepreneurship because a focus on successful entrepreneurship biases the selection of cases and therefore limits the validity of findings (Boasson and Huitema 2017). A processual approach to entrepreneurship enables the identification of a series of conditions, subsequent actions, and following effects, some of which may bring the entrepreneur closer to the desired policy change, and others moving in the opposite direction away from the acceptance of their pet proposals. As the cases demonstrate: entrepreneurs strategize through trial-and-error and adjust their strategies depending on the circumstances. Distinguishing between success and failure is too simplistic, as most cases are in between these extremes, interpretations of success and failure may differ, and adjudicating on failure or success ignores the dynamic nature of policy (McConnell 2010). Studying the multiple rounds of strategizing, even in ultimately successful cases, would enable the identification of less successful instances of policy entrepreneurship, and this would teach us about what works, how it works, and under what enabling contextual conditions. 


\section{I.2 Strategizing to cross boundaries for CSA: the particular strategies}

This section addresses the first research question: how and why do policy entrepreneurs cross boundaries for climate-smart agriculture? In this section, I discuss in more detail the strategies to cross boundaries that I identified in my dissertation and reflect on the particular contextual conditions that instigate entrepreneurs to undertake any or all of these strategies. I also highlight here how these insights contribute to the existing knowledge on policy entrepreneurship.

My dissertation has demonstrated in chapters 4 and 5 that policy entrepreneurs deploy three particular and unique strategies to cross boundaries for CSA: patchwork framing, impartial leadership, and process manipulation. The first strategy, patchwork framing, refers to entrepreneurs deploying different CSA frames to different audiences across level, domain, and organizational boundaries. A policymaking context characterized by a general interest in an integrated approach to agriculture and climate, but no institutional capture of CSA, seems to encourage policy entrepreneurship to deploy framing strategies to raise interest in CSA among different actors. My findings demonstrate that policy entrepreneurs wanting to cross boundaries assess their audience's interests, make an appraisal of the CSA components in which the audience might be interested, and frame CSA accordingly, in line with what Dewulf and Bouwen (20I2)\{Dewulf, 2012 \#660;Dewulf, 2012 \#660\} refer to as interactional framing. For instance, in chapter 3, I show how CSA is recommended by the World Bank and Dutch DG Agro entrepreneurs to Dutch corporations as providing an opportunity for businesses to invest in Africa, whereas it is promoted to NGOs as tool to improve the position of women farmers and target the poorest segments of society. The broadness of CSA is particularly suitable for patchwork framing, as its definition is very general. Its vagueness simultaneously accommodates potentially incompatible objectives while lacking guidelines or principles to prioritize among these objectives. For instance, it embraces agroecology, which is based on the appreciation of biodiversity and the functioning of natural ecosystems, while opening the door to monoculture, genetically modified seeds, and the use of herbicides and pesticides. It supports the commodification of carbon through offset schemes that are generally inaccessible to subsistence farmers and may increase the demand for land and hence the dispossession of people lacking land rights, while promising to engage the most vulnerable farmers. Entrepreneurs consequently deploy different, not necessarily compatible, frames to different audiences that might become interested in CSA for different reasons. 
Actors in consequent interactions thus deliberate over CSA on the basis of differing interpretations (Dewulf and Bouwen 2012).

The second strategy to cross boundaries for CSA is showing impartial leadership. My dissertation has shown in chapters 3 and 4 that policy entrepreneurs promoting CSA deploy leadership strategies the moment that they perceive an increased interest in CSA, but when noteworthy institutions have not (yet) captured CSA. Policy entrepreneurship in this case consequently concentrates on establishing coalitions to unite a diverse set of stakeholders interested in CSA. Bringing together a variety of actors from disparate levels, domains, and organizations may be accompanied by a lack of trust or unequal power relations (Bryson, Crosby, and Stone 2015). To forestall potential resistance from participants across boundaries, entrepreneurs act as neutral facilitators, for example by providing third party funding to eliminate discussions on budgets and contributions or by creating a neutral work environment not associated with either of the parties involved, for instance a multiactor platform or inter-ministerial taskforce. By demonstrating impartiality in their leadership, policy entrepreneurs aim not to be associated with any of the other actors in the coalition. However, policy entrepreneurs' involvement is not always necessarily impartial, nor always perceived as impartial by participants. Chapter 3 demonstrates that, despite the impartial leadership strategy followed, at some point the entrepreneurs were viewed by civil society organizations (CSOs) and lowincome countries as siding with corporations and high-income countries, thereby arousing suspicion of, and opposition to, the entrepreneurs.

The third strategy is process manipulation. CSA policymaking processes may become tedious, complex, and lengthy as a result of the involvement of a wide variety of actors with different backgrounds, interests, and ideas. Policy entrepreneurs are generally interested in continuation and progress, for instance because they fear policy windows will close or funding will dry up (Boasson 20 I 8). My dissertation has shown that, if policy entrepreneurs become impatient, they manipulate policymaking processes by bypassing certain agreed-upon processes, in order to speed them up. In chapter 3, I discuss how the entrepreneurs from the World Bank and the Dutch DG Agro entrepreneurs included a small coalition of actors, including at first Oxfam and later the Clinton Foundation to represent NGOs more widely. Chapter 4 elaborates how entrepreneurs organized quick-and-dirty policy consultations with county governments in Kenya, to tick the box of county representation and comply 
with the national constitution. These manipulations of policymaking processes might be advantageous in the short term, but bypassing actors or neglecting institutional procedures may backfire on entrepreneurs in the longer term, for instance through enhanced criticism or distrust of the initiative, as with GACSA.

The processual nature of policymaking means that the presented strategies are closely connected. For instance, framing might be used to build a coalition in order to raise resources to finance more encompassing framing campaigns to promote CSA. Although strategies are interdependent and similar contextual conditions may give rise to different strategies, and the same strategy can have different results, the two cases show the linkages between certain strategies and contextual conditions. First, when policy entrepreneurs observed limited institutional capture of CSA and identified an interest in integrated solutions, they engaged in patchwork framing (inspired by pilot projects and trial balloons) to promote CSA and raise actors' interest. Second, in light of a (perceived) general interest in embracing the CSA concept, policy entrepreneurs demonstrated impartial leadership to create a coalition and facilitate mutual learning among actors across boundaries. Third, the entrepreneurs demonstrated impartial leadership by setting up new institutions, such as the inter-ministerial taskforce in Kenya, in order to address unequal power relations. Fourth, when policymaking processes became, or threatened to become, too cumbersome or tedious in the eyes of policy entrepreneurs, they turned to the manipulation of policy processes to push the development of CSA policy. Thus, they worked their way around existing institutions to facilitate progress.

\section{Reflections on, and contributions to, existing insights on entrepreneurial strategies}

This dissertation has furthered the understanding of the strategies deployed by policy entrepreneurs, by focusing on cross-boundary strategies and their embedding in context. Several researchers have identified entrepreneurial strategies for policy change (for instance Mintrom 1997, Kingdon 1995, Roberts and King 1991, Brouwer 20I3). This dissertation's focus on the crossing of boundaries has deepened the understanding of entrepreneurial strategies in the following ways.

First, the message that entrepreneurs put forward is not always coherent. Some studies on policy entrepreneurship argue that policy entrepreneurs should deploy a simple and straightforward message to sell their ideas (Tversky and Kahneman 1981, Verger 2012, Kingdon 1995). Various climate governance scholars increasingly 
conclude that policy entrepreneurs targeting a varied audience frame their proposals in different ways, depending on the audience (Brouwer and Huitema 2018, Boasson and Huitema 2017 , Mintrom and Luetjens 2017). Whereas they generally argue that entrepreneurs deploy different frames, they implicitly seem to assume these frames ultimately carry a similar message. Mintrom and Luetjens (2017), for example, explain how climate change policy entrepreneurs use 'interactional' framing by highlighting some elements of a frame and leaving out others, in interaction with their audience. Brouwer and Huitema discuss how an entrepreneur argues that 'the story is always the same, but the emphasis is always different' $(2018,1265)$. My research has demonstrated that the underlying message spread by entrepreneurs is not always straightforward or coherent, and frames might not necessarily be compatible. This results in discussions and collaborations based on differing and sometimes conflicting interpretations of CSA, as in the GACSA case.

Second, policy entrepreneurship studies increasingly identify the importance of entrepreneurs acting as neutral or impartial parties (Mintrom and Thomas 20 I8). My dissertation has highlighted the entrepreneurial strategy of acting as an impartial leader, including the creation of a neutral work environment by setting up multiactor platforms or providing third party funding. The cross-sector partnerships literature acknowledges that indeed impartial leadership might contribute to trust building, which is perceived as essential for cross-sector collaborations (Bryson, Crosby, and Stone 2015).

Third, whereas some studies approach policy entrepreneurship in a normative manner by calling for more entrepreneurship to address complex societal challenges (see for instance Mintrom and Thomas 2018), my dissertation has demonstrated that certain entrepreneurial strategies seem to bypass existing accountability mechanisms and agreed-upon procedures, thereby jeopardizing input and throughput legitimacy: excluding those being governed from decisionmaking processes or including them unequally (Scharpf 2003, Schmidt 2013). Policy entrepreneurs thus may privilege pragmatic approaches over moral values in order to push their pet proposals. This insight raises doubts as to whether policy entrepreneurship should be uncritically embraced as a means to address complex societal challenges. This might be particularly challenging in countries like Kenya where informal incentives and enforcement mechanisms are dominant in governance practice (Mueller 20I I). This situation may create room for process 
manipulation while providing limited accountability mechanisms to curtail pragmatic entrepreneurship.

\section{I.3 Interests, ideas, and institutions: the policymaking context}

This section presents the answer to the second research question: how does the policymaking context influence cross-boundary policy entrepreneurship for climate-smart agriculture?. Below, I characterize the CSA policymaking context in terms of the boundaries entrepreneurs attempt to cross. I furthermore elaborate on how policy entrepreneurs reconfigure the policymaking context and influence the dynamics of the policy process.

First of all, the entrepreneur's interpretation of context rather than a set of objective contextual conditions, determines the entrepreneur's strategies. Entrepreneurs with different interpretations of the policymaking context consequently prefer different strategies. For instance, chapter 3 elaborates how entrepreneurs had different perspectives on policy dynamics and consequently preferred different interventions. One entrepreneur perceived NGOs as having sufficiently overlapping interests and ideas to come under a single organization representing the others, because he feared complexity would bring the process to a halt. The other entrepreneur perceived NGOs as being too varied in their backgrounds and considered the inclusion of the different perspectives essential for support and leverage, and was of the view that some complexity was manageable.

Whereas initially I formulated this question to identify the conditions under which entrepreneurs engage in the crossing of boundaries for CSA, my findings allow for a broader answer. My dissertation has shown that an understanding of CSA policy process also incorporates an account of entrepreneurship influencing the policymaking context. As discussed in section 6.I.I, the policymaking context for CSA consists of two analytical dimensions: an exogenous dimension and the internal policymaking context. The first dimension includes those processes that largely occur alongside, and thus independent of, the policy process under study. These include climatic events, changes in administration, or developments in related multilateral negotiations, including the incorporation of agriculture in the UNFCCC negotiations. The other dimension consists of the policymaking context that entrepreneurship aims to influence. This dimension consists of three interacting and dynamic elements: interests, ideas, and institutions. I identified these elements 
from the application and analysis of the multiple streams, advocacy coalitions, and punctuated equilibrium policy process frameworks in chapter 4 . Below, I elaborate the second dimension as these contextual conditions are central to cross-boundary processes.

The first element, interests, relates to the demands and desires of actors (Hall 1997, May and Jochim 20 I3). Interests in CSA are dynamic and are easily raised through, among other things, framing strategies. Retaining different groups' interest in CSA, however, is more difficult. Differences regarding interests around CSA play out most prominently between businesses and CSOs. Businesses are, simply put, interested in access to markets, profits, and upscaling agricultural production; CSOs are interested in addressing vulnerability and realizing food security while protecting biodiversity and ecosystems. In my cases, trough patchwork framing efforts, CSA initially spoke to the interests of multiple actors. However, the vagueness of CSA and the lack of criteria to define what can and cannot be called CSA forfeited CSA's attractiveness to actors in favour of ecologically and socially viable agriculture. As shown in chapter 3 , in the GACSA policy process, this resulted in frame polarization (see Dewulf and Bouwen 20 I2). Certain actors, mainly CSOs and developing countries, consequently distanced themselves from the process. Thus, whereas policy entrepreneurs aimed to raise different actors' interest in CSA through patchwork framing, because of the vagueness of what is and what is not CSA and the failure to address different interpretations of CSA during negotiations, certain actor groups opted out. Revising CSA's official definition by including mitigation as optional proved to be of no avail.

Ideas form a second element of the policymaking context. Ideas involve norms, principles, ethical ideals, myths, or symbols of (groups of) actors that explain how the world works or should work (May and Jochim 20 I3, Béland 2009). Ideas may also be subject to change over time, but compared to interests they are more resistant to change. Although CSA offers a tool to streamline the debate on climate and agriculture, its vagueness provides limited direction. The major differences in ideas united under the CSA umbrella reflect a long-standing debate between those who promote sustainable intensification and a mere continuation of existing dominant practices, and those who believe in agro-ecology and a need for transformation of existing practices. Although entrepreneurship creates a 'neutral' setting to facilitate learning and information exchange among actors, in both the GACSA case and the Kenya case, learning and exchange of ideas have hardly occurred. 
In Kenya, the limited time frame provided for policy development obstructs idea alignment. In the GACSA case, polarized discussions about conflicting ideas and the interpretation of CSA continue to exist. The National CSA Strategy in Kenya lacks clear guidelines regarding CSA implementation. My dissertation shows that the unwillingness or inability to clarify what CSA entails results in avoiding necessary choices regarding trade-offs and prioritization of directions. Consequently, these choices are postponed until the implementation phase, where CSA's vagueness could facilitate the rebranding of existing practices as climate-smart.

Institutions are a third element codetermining the contours of boundaries. Institutions are arrangements that embody the rules of the game that involved actors generally follow in pursuing their aims (Béland 2009). They structure authority, attention, information, and organizational relationships (Hall 1997). Entities across boundaries are characterized by different levels of authority, differing sources of information, and different relations (May and Jochim 2013). A policymaking context characterized by multiple, overlapping institutions enables entrepreneurs engage in venue shopping to promote their pet ideas. In chapter 3, I discuss how the COMESA entrepreneur promoted CSA at various venues until he managed to organize a series of CSA policy development workshops, which formed the start of the National CSA Strategy. Overarching institutions streamline differences in authority and facilitate trust and information exchange. In both of my cases, policy entrepreneurs set up institutions to bring together actors from differing backgrounds. However, it is challenging to create a true level playing field among actors in a way that satisfies all CSA participants. The platform that was initially established to create GACSA prioritized government's contribution over other actors and excluded various CSOs. In reaction to criticism, meetings were opened up to a wider audience. Participation was, however, still biased, as the physical location of these meetings obstructed participation from less endowed actors. Ultimately, the entrepreneurs organized a series of conference calls to facilitate more equal representation. Institutions are also strategically used by entrepreneurs. In the Kenyan case, at first a CSA taskforce was set up by the COMESA entrepreneur to facilitate learning and policy development among the environment and agriculture ministries. When the agriculture entrepreneur took over leadership, he relocated the process within the Climate Change Unit of the Ministry, which enabled the Ministry of Agriculture to claim leadership over the process. 
Although discussed separately above, interests, ideas, and institutions do not operate independently but are dynamically interrelated. In the GACSA case for instance, there was a certain level of interest in CSA, after which it was possible to create institutions that enabled the exchange of ideas. Differences in ideas eroded interest, thereby diminishing the credibility of the institutions. In the Kenyan case, interest in CSA equally led to the creation of an institution that failed to facilitate idea exchange and proved to lack support from critical interests. Interests, ideas, and institutions thus continuously evolve and can be mutually supporting or destructive.

\section{Reflections on, and contributions to, the existing literature on policy regimes}

The emerging literature on CSA has been largely produced by actors involved in CSA practice (Newell and Taylor 2018). This literature presents CSA as a transformational approach. It focuses mostly on technical discussions around CSA, presenting the crossing of boundaries and the consequent uptake of CSA policy predominantly as a matter of access to resources, strengthened institutions, and participatory decision-making processes (e.g. Lipper et al. 20 I 4, Harvey et al. 20 I4, Steenwerth et al. 2014, Dinesh et al. 20 I8). Only recently has the literature on CSA started to engage more critically in debates on CSA. The more recent literature highlights how CSA is used by dominant forces in the food regime to secure their agenda and consolidate the dominant neoliberal food regime, without any actual changes (Clapp, Newell, and Brent 2018, Newell and Taylor 2018, Taylor 2018). Although these critical publications provide useful insights into the interests and power relations involved in the push for CSA, they paint a rather pessimistic picture of the agriculture - climate regime's present and future.

My dissertation adds a more nuanced perspective to the above-described positions. The development of new CSA policy initiatives does not necessarily require the full alignment of interests, ideas, and institutions. The boundaries of CSA have been deliberately kept vague in order not to exclude entities. Refraining from identifying what is outside the boundaries of CSA creates uncertainty regarding the definition of what CSA is. My findings emphasize that, although CSA has united actors from across boundaries, differences alongside the elements of interests, ideas, and institutions persist, causing certain challenges. Accommodating different interests has eroded support for CSA. The persistence of different ideas under the heading of CSA has relegated the need to refine its meaning to lower government levels and thereby facilitated the rebranding of existing practices as CSA. And although 
designing new institutions facilitated trust and idea exchange, subsequent learning has so far largely failed to occur.

It would, however, be short-sighted to label CSA as either a complete failure or as transformative panacea requiring only a few technical interventions to realize successful implementation. CSA is, in my interpretation, a consensus frame or bridging concept, that accommodates different interests and ideas under a broad umbrella frame (Gamson 1995, Candel et al. 2014, Meadowcroft 2000). Umbrella frames prevent the development of a clear approach and facilitate the rebranding of existing practices, but simultaneously serve to streamline discussions and facilitate the creation of new initiatives (Candel et al. 2014, Meadowcroft 2000). Labelling CSA as 'transformation', as it proponents often do, might not be adequate however (Lipper et al. 2014, Chandra, McNamara, and Dargusch 2018). It is unclear what transformational change in relation to CSA exactly entails. Frequently, transformations are associated with in-depth, large-scale, and rapid change processes. However, this type of change is essentially unrealistic and unfeasible (Termeer, Dewulf, and Biesbroek 2017). Chapter 5 shows that, in Kenya, policies around agriculture and climate change have displayed increasingly integrated policy frames over the past 15 years. This demonstrates that the adoption of a CSA approach has not been in-depth, as limited changes in ideas occurred; and it has not been rapid, as the identification of interlinkages in CSA builds on a longer trajectory. From this point of view, CSA is a gradual continuation of an increasingly complex interpretation of climate change, agriculture, food security, environment, and development, and their interconnections. This makes it likely that the process of addressing complex problems like climate change and poverty evolves on the basis of so-called small wins, which include substantive changes in routines or beliefs, but which are of only moderate importance. CSA does, however, facilitate an acknowledgement of the adverse impacts of agriculture on climate change. Whereas this appears to be a small reconfiguration of existing practices, it may contribute to generating durable and transformational innovations in the longer run (Termeer and Dewulf 20 I8).

My findings contribute to the literature on boundary-spanning policy regimes and the underlying policy regime and political economy literature, by providing insight into how boundary spanning policy regimes evolve. Interests, ideas, and institutions have been identified as central to understanding policy regimes (Hall 1997, May and Jochim 2013 , Clapp, Newell, and Brent 20 I 8). What has been missing from their focus 
is an account of the role of agency, e.g. policy entrepreneurship, in the development of boundary-spanning policy regimes. Understanding how actors create and take advantage of circumstances is clearly important for a fuller picture of regimes (May and Jochim 2013). This dissertation has provided an elaborate account of the role of policy entrepreneurship in fostering the crossing of boundaries between different ideas, interests, and institutions. It has highlighted both the strategies through which entrepreneurs facilitate the spanning of boundaries, including patchwork framing, impartial leadership, and process manipulation, and the conditions that facilitate entrepreneurship to take advantage of the situation, including institutional overlap and a general interest in integrative approaches to related issues.

\subsection{Reflections on research approach, theory, and case studies}

In this section, I reflect on the methodological choices underlying my research. I discuss the implications of my case study approach and the multi-methods research design and elaborate on validity and reliability more generally. Lastly, I reflect on my theoretical choices.

\subsection{Case study design and generalizability}

The larger part of my dissertation is composed of qualitative research based on a case study design, focusing on the development of the GACSA and the National CSA Strategy in Kenya. This approach, like all approaches, has implications regarding the strengths and limitations of my findings.

The case study design provided rich data enabling thick description and helped me to unravel the complex and mutually influencing interactions between policy entrepreneurship and policy process. Case studies enable the production of context-dependent findings. This context specificity is not only useful for understanding the interplay between entrepreneurship and policy process as in my research, but also inevitable in the social sciences at large (Flyvbjerg 2006). Although a case study approach provides great richness in findings, it might be viewed as producing context specific findings that limit generalizability (Flyvbjerg 2006). I have attempted to address context-specificity in various ways. First, I selected the GACSA and Kenya CSA Strategy policy development cases because 
they both provide critical cases of CSA policy development, in the sense that they both display policy processes resulting in the development of CSA policy, with the involvement of policy entrepreneurship. As both cases were expected to involve a high level of cross-boundary entrepreneurship, they were also expected to provide richness in the dynamics and processes of interest (Flyvbjerg 2006). This selection technique is particularly useful when research is explorative, as is the case with cross-boundary entrepreneurship for CSA. Furthermore, the two cases displayed useful variation in the dimensions of theoretical interest, including the type of policy change: a non-binding alliance and a national strategy, and policy level: global and national (Seawright and Gerring 2008). Consequently, the findings from the two cases were likely to be relevant for a number of contexts of CSA policy development. Apart from case selection strategies, I attempted to address generalizability by looking for similar patterns and dynamics in the wider literature. I undertook a systematic literature review involving a variety of empirical settings and topics. This review highlighted some comparable dynamics, for instance regarding strategies deployed and conditions for cross-boundary policy entrepreneurship. The systematic approach adopted in the literature review makes me confident that I have incorporated most of the relevant findings.

The abovementioned measures suggest that my findings are generalizable to policy development processes that require the crossing of boundaries, including but not limited to CSA. However, both cases are characterized by the significant involvement of international organizations such as UN organizations, the World Bank, and CGIAR, which share similar viewpoints and jointly promote a shared interpretation of CSA, supported by relatively high levels of resources. These characteristics obviously influence processes of policy entrepreneurship. For instance, less well-connected and less powerful actors may have to deploy additional strategies to raise resources or to find audiences for their ideas. Hence, my findings are most relevant for situations characterized by similar involvement of bilateral and multilateral donors. My findings might also be generalizable to other processes of entrepreneurship to cross boundaries that involve bilateral and multilateral donors, including pushing for resilience, sustainable development, and sustainable agriculture. What characterizes these concepts is a similar broadness that enables the uniting of a wide variety of actors with differing, possibly conflicting, interpretations of how to achieve these ends (Meadowcroft 2000, Candel et al. 20 I4, De Milliano et al. 20 I5). 


\subsubsection{Validity and reliability}

Internal validity refers to the accuracy of findings, whereas external validity (reliability) entails consistency of research across researchers and projects (Creswell 2014). Validity has been addressed in three ways. First, the multi-methods research design enabled triangulation by relying on various sources including interviews, observation, and document study; and by relying on multiple perspectives through a varied interview sample. This enhanced richness in findings (Creswell 2014). Second, prolonged periods of field work enhance internal validity by realizing an in-depth understanding of the object of research (Creswell 2014). Although a longitudinal involvement with my cases was not possible for practical reasons, I secured engagement in the following ways. For the GACSA case, I visited various global practice conferences and negotiations relating to agriculture and climate, and undertook exploratory interviews with actors participating in these networks to become acquainted with the particular context. Thanks of fieldwork projects in Kenya before I started working on my dissertation, I was already familiar with Kenya's policy context. Furthermore, a scoping visit to Kenya prior to my field work helped me to engage in specific preparation through targeted reading of literature and suggestions of potentially relevant issues. Third, by acknowledging interviewing as an opportunity for the respondent to construct versions of reality in an interactive interplay with the interviewer, I acknowledge the possible subjectivity of the data provided by interviewees (Gubrium and Holstein 200 I, Gill et al. 2008). This has obviously implications for data validity and reliability. To address this, I took various measures that address both internal and external validity. In both cases, I interviewed the majority of actors directly involved in the policy process, actors indirectly involved in the policy process, and actors deliberately not involved in the process. Several checks throughout the process also served to enhance validity. I undertook member checks by sharing draft versions of my papers with various key interviewees. Furthermore, during fieldwork, I discussed preliminary findings and insights with local experts who acted as supervisors during my stay. To ensure the reliability of interpretations of findings, I regularly tested and cross-checked coding schemes with colleagues and supervisors. Apart from the above-described intervention to address external validity, I selected cases that show some variation. Thus, my findings indicate that the results are applicable in a certain variety of situations and contexts. Nevertheless, the external validity (generalizability) of my research could have been strengthened through a comparative cross-country study. Ideally, I would have selected a case similar in most aspects, such as the policy 
entrepreneurs initiating the process, but different in context. I discuss this in more detail in section 6.3. Another limitation refers to the country context of Kenya. Studying a lower-income country like Kenya entails additional challenges. Data collection possibilities in Kenya are rather confined, because there is fairly limited structural documentation and much less is accessible via the internet. This resulted in the omission of certain data sources because they were unavailable.

\subsubsection{Theoretical reflections}

Regarding reflections on my theory, policy entrepreneurship provides a meso-level framework to study a certain component of the policy process. The central focus on policy entrepreneurship in many studies has compromised attention on other factors relevant to the policy process, including contextual conditions. Because the aim in this dissertation has been to understand both entrepreneurial strategies and the policymaking context, the level of depth regarding the individual strategies, including framing or networking, is limited. Whereas a broad approach like entrepreneurship thus enables the capture of a comprehensive insight into the complexity of process dynamics, it simultaneously compromises depth. A more detailed account of the dynamics surrounding the individual strategies built on an elaborate assessment of the literatures on framing (e.g. Dewulf and Bouwen 2012, Lee, McLeod, and Shah 2008, Diez 2010), partnerships (e.g. Bryson, Crosby, and Stone 2015, Babiak and Thibault 2009, Bäckstrand 2006, Googins and Rochlin 2000), or networking (e.g. Stone 2008, Hovik and Hanssen 2015, Klijn and Koppenjan 2016) could provide more depth. Policy entrepreneurship as a field of study is scattered across various disciplines and fields of expertise, as shown in chapter 2 . Whereas this demonstrates the wide interest in entrepreneurship, it risks limiting the accumulation of knowledge because of different interpretations and conceptualizations of entrepreneurship (Petridou 2014). Consequently, entrepreneurship is assigned to a wide variety of actors. Although every actor, both individual and group, in any position, could enact entrepreneurship, each possesses unique actor characteristics. These characteristics inevitably co-shape the entrepreneur's available resources, connections, authority, and hence its room to manoeuvre (Bakir and Jarvis 2017). My research makes limited distinctions between different backgrounds of actors enacting entrepreneurship (see chapter 3). Nevertheless, it was possible to identify certain strategies deployed by different actors in both cases. However, it is self-evident that an actor endowed with strong international connections and a large budget, such as the World Bank, deploys a different set of strategies as compared to a national policymaker in 
Kenya. Moving beyond an identification of possible strategies to an account of the particular strategies required to realize policy development would require a clear distinction among actors and their backgrounds.

The selection of the multiple streams, advocacy coalitions, and punctuated equilibrium policy process frameworks has resulted in the identification of three elements of the policymaking context, namely, interests, ideas, and institutions. This does not mean that these are the only elements comprising the policymaking context and characterizing cross-boundary dynamics. The selection of these frameworks might thus have created a bias in the identification of challenges and dynamics relating to the crossing of boundaries. Different frameworks might enable the identification of additional relevant elements. However, as the triad of interests, ideas, and institutions is acknowledged widely in other literatures (Hall 1997, Hay 2004, Kern 20 I I) and has even been related particularly to the crossing of boundaries (May and Jochim 2013 ), there is reason to assume that these have significant value in themselves.

\subsection{Directions for future research}

In this section, I reflect on two general points arising from my research. For additional recommendations linked to specific research endeavours, please refer to the individual chapters 2-5. Here, I discuss the more significant ones or those relating to multiple chapters.

A first recommendation refers to the causal relation between entrepreneurial strategy and changes in the policymaking context. My findings emphasize the usefulness of distinguishing between strategies on the one hand and elements of the policymaking context (ideas, interests, and institutions) on the other. This distinction provides an initial uncovering of the causal processes underlying policy entrepreneurship as part of policy processes. Whereas entrepreneurship studies initially focused on the what question relating to the kind of strategies deployed by entrepreneurs, my dissertation has started to unravel the how question to identify the causal linkages between strategy and its impact on the policy environment. My case study findings suggest that particular strategies are linked to particular effects. Whereas patchwork framing seems to be undertaken predominantly to change actors' interests across boundaries, leadership strategies and process manipulation 
seem to be related more closely to changes in ideas and institutions. Although have made an important contribution to opening up the black box of strategy, the linkages between strategy and effect could be studied in a more systematic manner, in different contextual settings. Follow-up comparative process tracing research with multiple carefully selected cases or single process-tracing case studies could further this hypothesis by systematically identifying the causal processes that link (observed) causes (policy entrepreneurship) with their effects (policy process change) (Beach 2016, Gerring 2004) and by studying relevant contextual conditions in a more systematic manner. Comparative process tracing enables the singling out of the contextual conditions that codetermine whether a causal process occurs or not (Beach 2016, Collier 201 I). Consequently, qualitative comparative analysis could be helpful to further identify the necessary and/or sufficient requirements of certain strategies for changes in ideas, interests, and institutions to occur (Rihoux 2006, Schneider and Wagemann 20 I0).

A second recommendation for further research would be to engage in action research to identify processes of policy change relating to policy entrepreneurship (Brouwer 2013). Action research refers to the conducting of social research in collaborative ways, whereby rigorous scientific standards are upheld while social change is promoted (Greenwood and Levin 2006, Herr and Anderson 20 I4). Thus, it combines the generation of knowledge and the design of action. This would entail collaboration among policy entrepreneurship researchers and (potential) policy entrepreneurs who could jointly engage in the research and realization of crossboundary policy change processes to address contemporary complex problems in society. This would address the issue of most of the policy entrepreneurship literature (except for some important examples including for instance Mintrom (1997) being based on people's retrospective accounts of change processes, which can be inaccurate and biased due to selective memory. There is limited possibility to verify the reliability of their accounts. Also, this enables a focus on the processual nature of policy processes, as policy change dynamics can be studied and reflected upon in detail (see also McDermott, Coghlan, and Keating 2008). 


\subsection{Policy implications and recommendations}

Although I adopted a theory-heavy approach in this dissertation, the object of study lends itself well to the formulation of recommendations for practitioners and policymakers, particularly related to actions to address problems such as climate change, hunger, and poverty.

First of all, too often CSA policy recommendations are phrased along the lines of 'improved coordination is essential', without acknowledging complexity and political tensions or advising on how to realize the crossing of boundaries (see also Newell and Taylor 2018). Frequently, desired interventions are phrased along the lines of 'additional resources' or 'stakeholder inclusion' (Lipper et al. 20 I 4, Behnassi, Boussaid, and Gopichandran 20 I4, Chandra, McNamara, and Dargusch 20 I8). As shown in this dissertation, policy changes for CSA are complex and tend not to evolve as major transformative disruptions, but are rather developed in the slipstream of calls and trends towards more integrated approaches to climate and agriculture, displaying only small wins rather than radical disruptions (Termeer, Dewulf, and Biesbroek 2017). Actors involved in pushing policy developments should consequently act with prudence towards processes of change and acknowledge and embrace the small changes that they perceive as contributing to moving in the right direction. Policy changes are inherently political processes, involving dynamics regarding interests, ideas, and institutions. These processes take time. That is, although interests might be easily changed to the advantage of the entrepreneur's proposal, they may swiftly change again in a different direction. Ideas take a long time to alter and need to be accompanied by aligned institutional arrangements (Termeer, Dewulf, and Biesbroek 2017, Béland 2009). This process requires an account of the contextual environment in which policy processes are situated and a thorough command of a variety of strategies to reconfigure this context.

CSA on paper acknowledges and addresses context specificity and consequent diversity in reality. Its room for interpretation as required by the context is one of its key selling points. In the practices studied in this dissertation however, it seems as if CSA is rather promoted as an institutional fix, whereby ideas and approaches common and preferred among international donors, international organizations, and research organizations seem to be dominant and in which the particularities of local administrations are overlooked (see also Vink and Schouten 20 I8). These 
actors usually work from a checklist approach that incorporates step-by-step plans based on a checklist of activities to be undertaken and results to be achieved. This is problematic on two accounts: it insufficiently appreciates local interests, ideas, and institutions and fails to create the support required for implementation. As shown in this dissertation, this approach may run up against resistance and opposition from involved actors, who might feel disowned, passed over, or not taken seriously, and might consequently oppose the proposed changes. This compromises the legitimacy of initiatives and entails the risk that policy changes will be no more than paper processes, as almost happened in the case of Kenya's CSA policy development.

Consequently, interventions that focus on linking various actors and institutions, from the global to the local, and from private to public, should be more prudent. I do not recommend simply that the strategies analysed in this dissertation need to be pursued in order to cross boundaries, as this would be too simplistic. I rather acknowledge the complex reality of policy processes around agriculture and climate. Practitioners would profit from sensitivity to local ongoing processes in order to design and implement context-specific interventions, which have to be reassessed and updated on a regular basis to concur with the dynamic policy environment. Acknowledging the constantly changing policy environment, I propose a form of processual diagnostics whereby practitioners first focus on what 'is happening' on the basis of which they can decide what 'ought to happen'. Practitioners seem to grapple with a daily reality that is in constant flux. Whereas at one point in time a small taskforce to design cross-boundary policies might be useful to engage in efficient negotiation, later this might raise opposition from those excluded, and subsequently those involved in the taskforce might lose interest because of negotiations in a different forum (for instance the UNFCCC process). This does not allow for reflection from a distance on the complexity of the situation (Aligica 2007, Bourdieu 1990, Zhang 2017), but requires absorption in the situation to anticipate the unfolding of events. A predefined ideal course of events is useless from this perspective, as the policy process is codetermined by much more than entrepreneurial strategy alone (Jullien 1999). Therefore, this dissertation provides an account of the strategies that may be used to cross boundaries, but it is up to the actor acting as entrepreneur to select and deploy strategies following its interpretation of the surrounding policymaking context. To achieve this, actors should be trained to master a variety of strategies that can be used as a toolkit from which they can draw at their own discretion while engaging in policy change 
processes. However, my dissertation has also demonstrated that entrepreneurship in certain circumstances might undermine institutions and processes (Currie et al. 2008, Brouwer 2013). This is what I have referred to as process manipulation: excluding participants from policy processes while pretending to include them, while deriving legitimacy from the 'paper inclusion' of these participants, as with civil society (organizations) in both my case studies. This risks putting power in the hands of external actors who possess the knowledge and financial resources that trigger the interests of policymakers but compromise the rights and position of less powerful actors in society (see also Alila and Atieno 2006, O'Brien and Ryan 1999). Policy entrepreneurship thus puts power in the hands of mostly external actors, and this might undermine legitimacy.

\subsection{Conclusions}

The overall aim of this dissertation was to enhance the understanding of crossboundary policy entrepreneurship for climate-smart agriculture. The conclusions of this dissertation are summarized below.

First, my dissertation has produced a conceptual framework to display the factors relevant for understanding cross-boundary policy entrepreneurship, and their mutual linkages. It highlights cross-boundary policy entrepreneurship as a complex process that interplays with the policymaking context. I refer to this process as strategizing, the process of entrepreneurship interpreting and acting upon the policymaking context in order to reconfigure the policy process, with both intended and unintended effects. The building blocks of the strategizing framework thus entail starting conditions as part of the policymaking context, strategies as actions of entrepreneurs, and implications as the influence of strategies on the policymaking context. Strategizing can be seen as an ongoing process that plays out in different rounds.

Entrepreneurs deploy the following strategies to cross boundaries: patchwork framing, impartial leadership, and process manipulation. Patchwork framing refers to deploying different, conflicting, frames to different audiences in order to raise diverse interest in CSA, resulting in negotiations based on different interpretations of CSA. Impartial leadership refers to creating a neutral work environment, to 
forestall suspicion and distrust. However, creating a level playing field among such diverse actors is difficult, and hence the ground for mutual learning appears shaky. Process manipulation refers to the bypassing of existing institutions to facilitate progress, and this erodes the support and legitimacy of policy initiatives.

My dissertation has demonstrated that the complexity of the boundary-crossing process is characterized by differences regarding ideas, institutions, and interests that characterize levels, domains and organizations across boundaries. Through strategizing, entrepreneurs target differing interests, ideas, and institutions. Although all strategies could contribute to all components of interests, ideas, and institutions, my findings show that patchwork framing is most closely associated with adapting interests, whereas impartial leadership and process manipulation seem to be predominantly linked to altering ideas and institutions. Thus, entrepreneurs continuously engage in co-defining, erasing, redrawing, and moving boundaries around CSA. They deliberately keep the boundaries of CSA vague in order to accommodate different interests, ideas, and institutions. Despite the resulting challenges regarding accommodating different interests, facilitating the exchange of ideas in a context of distrust, and the eroding support for initiatives, the entrepreneurs in both cases managed to realize CSA policy development. Full alignment of interests, ideas, and institutions is thus no a prerequisite for policy development for CSA. Rather, CSA serves as a bridging concept to accommodate different interests and ideas, to streamline discussions, and to create new initiatives, alongside the inevitable rebranding of existing practices. However, CSA is thus not necessarily a radical transformation, as is often argued, but rather a small but significant reconfiguration of existing practices. 


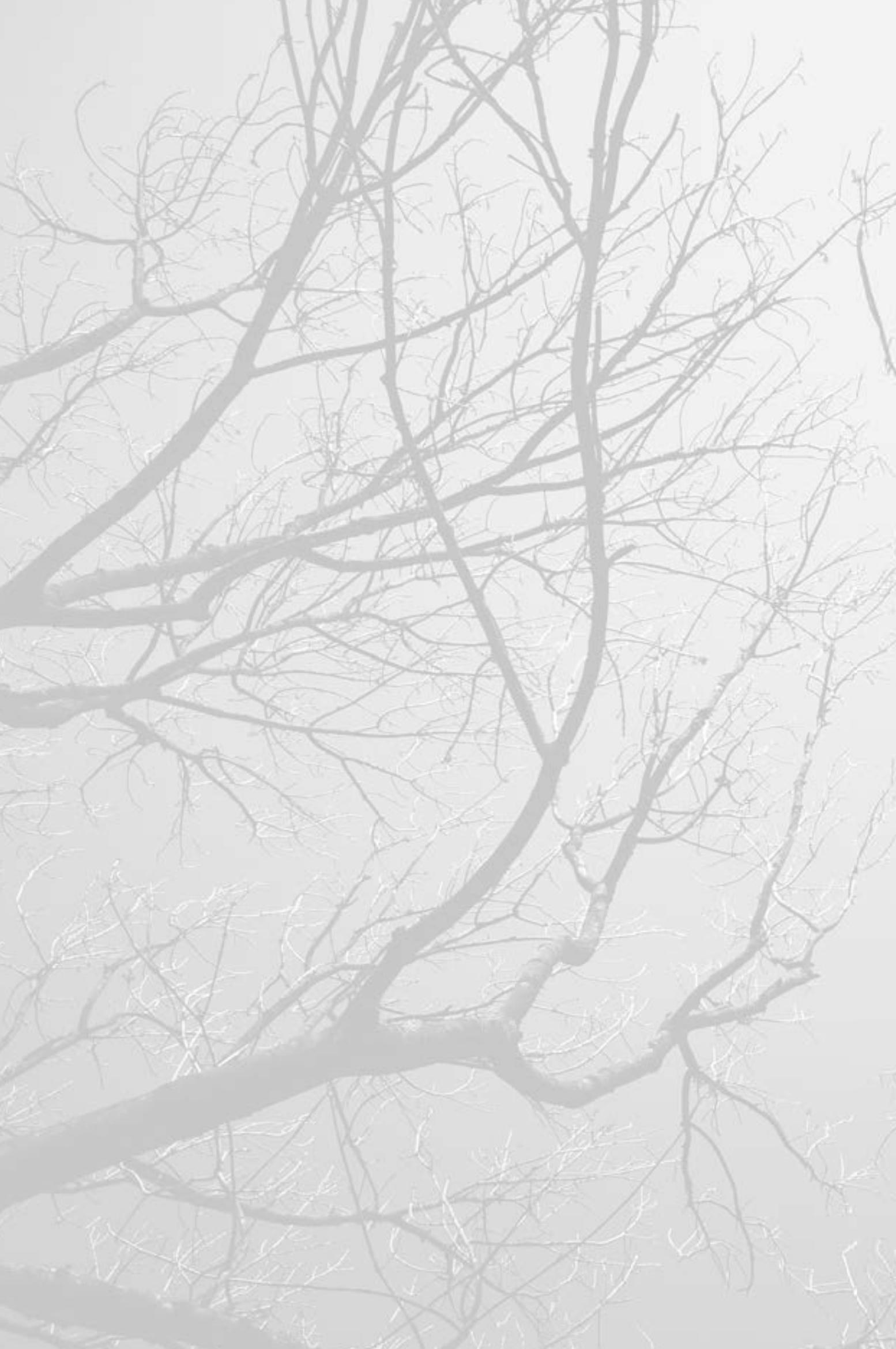





\section{References}

Abbott, A. 1995. “Things of boundairies.” Social research 62 (4):857-882.

Ackrill, R, and A Kay. 20II. "Multiple streams in EU policy-making: the case of the 2005 sugar reform." Journal of European Public Policy 18 (1):72-89.

Ackrill, R, A Kay, and N Zahariadis. 2013 . "Ambiguity, multiple streams, and EU policy." Journal of European Public Policy 20 (6):87|-887.

ActionAid International. 2014. Clever name, losing game: how climate-smart agriculture is sowing confusion in the food movement.

Aligica, PD. 2007. "Efficacy, East and West: François Jullien's explorations in strategy." Comparative Strategy 26 (4):325-337.

Alila, PO, and R Atieno. 2006. "Agricultural policy in Kenya: issues and processes." A paper for the future agricultures consortium workshop, institute of development studies, Nairobi, 20-22 March.

Alimi, D. 2015. "'Going global': Policy entrepreneurship of the global commission on drug policy." Public Administration 93 (4):874-889. doi: | 0. I | | |/padm. 12 | 87.

AMCEN, UNEP;. 2012. Arusha Declaration on Africa's post Rio+20 strategy for sustainable development. In KI 282895, edited by UNEP. Arusha, Tanzania: AMCEN.

Ansell, C, and A Gash. 2008. "Collaborative governance in theory and practice." Journal of public administration research and theory 18 (4):543-57|.

Arieli, T, and N Cohen. 20 I3. "Policy entrepreneurs and post-conflict cross-border cooperation: a conceptual framework and the Israeli-Jordanian case." Policy Sciences 46 (3):237-256.

Atela, J. 2012. The politics of agricultural carbon finance: the case of the Kenya Agricultural Carbon Project. In Steps Working Paper, edited by STEPS Centre. Brighton: STEPS Centre.

Babiak, K, and L Thibault. 2009. "Challenges in multiple cross-sector partnerships." Nonprofit and Voluntary Sector Quarterly 38 ( I): 1 17-143.

Bäckstrand, K. 2006. "Multi-stakeholder partnerships for sustainable development: rethinking legitimacy, accountability and effectiveness." Environmental Policy and Governance 16 (5):290-306.

Bakir, C, and DSL Jarvis. 20 I7."Contextualising the context in policy entrepreneurship and institutional change." Policy and Society 36 (4):465-478.

Bates, RH. 2005. Beyond the miracle of the market: The political economy of agrarian development in Kenya. Cambridge: Cambridge University Press.

Baumgartner, FR, and BD Jones. 1993. Agendas and instability in American politics. Chicago: University of Chicago Press.

Beach, D. 2016 . "It's all about mechanisms: what process-tracing case studies should be tracing." New Political Economy 2 I (5):463-472.

Beach, D, and RB Pedersen. 20 I 6. Causal case study methods: foundations and guidelines for comparing, matching, and tracing. Ann Arbor: University of Michigan Press.

Behnassi, M, M Boussaid, and R Gopichandran. 2014. "Achieving food security in a changing climate: the potential of climate-smart agriculture." In Environmental cost and face of agriculture in the Gulf Cooperation Council Countries: fostering agriculture in the context of climate change, edited by SA Shahid and M Ahmed, 27-42. Cambridge: Gulf Research Centre.

Béland, D. 2009. "Ideas, institutions, and policy change." Journal of European Public Policy I6 (5):70 I-7| 8.

Bennett, A, and JT Checkel, eds. 20 I4. Process tracing: From metaphor to analytic tool. Cambridge: Cambridge University Press.

Berg-Schlosser, D, G De Meur, B Rihoux, and CC Ragin. 2009. "Qualitative comparative analysis (QCA) as an approach." In Configurational comparative methods: qualitative comparative analysis (QCA) and related techniques, edited by B Rihoux and CC Ragin, I- 19. London: Sage.

Berkes, F. 2002. "Cross-scale institutional linkages: perspectives from the bottom up." In The drama of the commons, edited by E Ostrom,T Dietz, N Dolsak, P Stern, S Stonich and EUWeber, 293-32I. Washington DC: National Academy of Sciences.

Berkes, F. 2009. "Evolution of co-management: role of knowledge generation, bridging organizations and social learning." Journal of Environmental Management 90 (5): 1692-1702. 
Bertilsson,TM. 2004." "The elementary forms of pragmatism: on different types of abduction." European Journal of Social Theory 7 (3):37I-389.

Beunen, R, and JJ Patterson. 2017. "Analysing institutional change in environmental governance: exploring the concept of 'institutional work'.' Journal of Environmental Planning and Management:1-18. doi: 10.1080/09640568.2016.1257423.

Bhaskar, R. 1998. The possibility of naturalism: a philosophical critique of the contemporary human sciences (third edition). Oxon: Routledge.

Biermann, F, O Davies, and N van der Grijp. 2009. "Environmental policy integration and the architecture of global environmental governance." International Environmental Agreements: Politics, Law and Economics 9 (4):35 I. doi: |0. I007/s |0784-009-9 | | |-0.

Biermann, F, P Pattberg, H van Asselt, and F Zelli. 2009." "The fragmentation of global governance architectures: a framework for analysis." Global Environmental Politics 9 (4): I 4-40. doi: I0.1 I 62/glep.2009.9.4. I4.

Bjorkdahl, A. 2013. "Ideas and Norms in Swedish Peace Policy." Swiss Political Science Review 19 (3):322-337. doi: | 0.1 | | | |/spsr. 12046.

Black, L, and YJ Hwang. 20 I2. "China and Japan's quest for great power status: norm entrepreneurship in antipiracy responses." International Relations 26 (4):43I-45I.

Blavoukos, S, and D Bourantonis. 201 I. "Chairs as policy entrepreneurs in multilateral negotiations." Review of International Studies 37 (02):653-672.

Boasson, E. L., and J. Wettestad. 2014. "Policy invention and entrepreneurship: Bankrolling the burying of carbon in the EU." Global Environmental Change-Human and Policy Dimensions 29:404-4 I2. doi: I0. 101 6/j. gloenvcha.2014.09.010.

Boasson, EL. 2018. "Entrepreneurship: a key driver of polycentric governance?" In Governing climate change: polycentricity in action?, edited by A Jordan, D Huitema, $\mathrm{H}$ van Asselt and J Forster, I I 7- I 34. Cambridge: Cambridge University Press.

Boasson, EL, and D Huitema. 2017. "Climate governance entrepreneurship: emerging findings and a new research agenda." Environment and Planning C: Politics and Space 35 (8): I343-1361.

Boekhorst, DGJT, TJM Smits, XB Yu, LF Li, G. Lei, and C. Zhang. 2010 . "Implementing Integrated River Basin Management in China." Ecology and Society I5 (2).

Boezeman, DF. 2015. "Transforming adaptation. Authoritative knowledge for climate change governance." doctoral degree, Radboud University.

Boin, A, and M Lodge. 2016. "Designing resilient institutions for transboundary crisis management: a time for public administration." Public Administration 94 (2):289-298.

Bourdieu, P. 1990. The logic of practice. Stanford: Stanford University Press.

Braithwaite, J, and P Drahos. 2000. Global business regulation. Cambridge: Cambridge University Press.

Briassoulis, H. 2004. "Policy integration for complex policy problems: what, why and how." Berlin Conference 'Greening of Policies: Interlinkages and Policy Integration', Berlin, 3-4 December

Briassoulis, H. 20I I. "Governing desertification in Mediterranean Europe: the challenge of environmental policy integration in multi-level governance contexts." Land Degradation \& Development 22 (3):313-325.

Brinkerhoff, JM. 2015. "Agency in institutional reform: creating the Ethiopia Commodities Exchange." Public Administration and Development 35 (4):30 I-3/4.

Brouwer, S. 2013. "Policy entrepreneurs and strategies for change: the case of water management in the Netherlands." PhD, Vrije Universiteit Amsterdam.

Brouwer, S. 20 I 5. Policy entrepreneurs in water governance: strategies for change. London: Springer.

Brouwer, S, and F Biermann. 20II. "Towards adaptive management: examining the strategies of policy entrepreneurs in Dutch water management." Ecology and Society 16 (4):5.

Brouwer, S, and D Huitema. 2018. "Policy entrepreneurs and strategies for change." Regional Environmental Change I8 (5): 1259- 1272.

Brown, ME, and CC Funk. 2008. "Food security under climate change." Nature Climate Change 31 9:580-58I.

Bryan, E, C Ringler, B Okoba, J Koo, M Herrero, and S Silvestri. 2013. "Can agriculture support climate change adaptation, greenhouse gas mitigation and rural livelihoods? Insights from Kenya." Climatic Change I 8 (2): $151-165$.

Bryan, E, C Ringler, B Okoba, C Roncoli, S Silvestri, and M Herrero. 20I 3. "Adapting agriculture to climate change in Kenya: household strategies and determinants." Journal of Environmental Management I | 4:26-35. 
Bryson, JM, BC Crosby, and MM Stone. 20 I 5. “Designing and implementing cross-sector collaborations: needed and challenging." Public Administration Review 75 (5):647-663.

Budabin, AC. 2015. "Celebrities as norm entrepreneurs in international politics: Mia Farrow and the 'Genocide Olympics' campaign." Celebrity Studies 6 (4):399-4I3.

Cairney, P. 201 I. Understanding public policy: theories and issues. London: Palgrave Macmillan.

Cairney, P. 2013. "Standing on the shoulders of giants: how do we combine the insights of multiple theories in public policy studies?" Policy Studies Journal 4I (I): I-2I.

Cairney, P, and T Heikkila. 20 17. "A comparison of theories of the policy process." In Theories of the policy process. New York: Routledge.

Cairney, P, and MD Jones. 2016. "Kingdon's multiple streams approach: what is the empirical impact of this universal theory?" Policy Studies Journal 44 ( I):37-58.

Candel, JJL, and R Biesbroek. 2016. "Toward a processual understanding of policy integration.” Policy Sciences 49 (3):2 I I-23।. doi: 10. 1007/s I I077-0 I 6-9248-y.

Candel, JJL, and L Pereira. 2017. "Towards integrated food policy: main challenges and steps ahead." Environmental Science \& Policy 73:89-92.

Candel, JL, and R Biesbroek. 2018. "Policy integration in the EU governance of global food security." Food Security $10(1): 195-209$.

Candel, JL, GE Breeman, SJ Stiller, and CJAM Termeer. 2014. "Disentangling the consensus frame of food security: the case of the EU Common Agricultural Policy reform debate." Food Policy 44:47-58.

Capano, G. 2009. "Understanding policy change as an epistemological and theoretical problem." Journal of Comparative Policy Analysis II ( I):7-31.

Carter, B, and C New. 2004. "Introduction: realist social theory and empirical research." In Making realism work: realist social theory and empirical research, edited by B Carter and C New, I-20. London: Routledge.

Carter, N, and M Jacobs. 2014. "Explaining radical policy change:The case of climate change and energy policy under the British labour government 2006- I0." Public Administration 92 ( I): | 25- |4|.

Cejudo, GM, and CL Michel. 2017. "Addressing fragmented government action: coordination, coherence, and integration." Policy Sciences 50 (4):745-767.

Chandra, A, KE McNamara, and P Dargusch. 2018. "Climate-smart agriculture: perspectives and framings.' Climate Policy 18 (4):526-54I.

Clapp, J, P Newell, and ZW Brent. 2018. "The global political economy of climate change, agriculture and food systems." The Journal of Peasant Studies 45 ( I ):80-88.

Cohen, MD, JG March, and JP Olsen. 1972. "A garbage can model of organizational choice." Administrative science quarterly $17(\mathrm{I}): \mathrm{I}-25$.

Collier, D. 201 I. "Understanding process tracing." Political Science \& Politics 44 (4):823-830.

Cornforth, C, JP Hayes, and S Vangen. 2015. "Nonprofit-public collaborations: understanding governance dynamics." Nonprofit and Voluntary Sector Quarterly 44 (4):775-795.

Creswell, JW. 2014. Research design: qualitative, quantitative and mixed methods approaches 4 ed. Thousand Oaks: Sage.

Crosby, BC, P 't Hart, and J Torfing. 2017. "Public value creation through collaborative innovation." Public Management Review 19 (5):655-669.

Crosby, BC, and JM Bryson. 2005. Leadership for the common good: tackling public problems in a shared-power world. 2nd edition ed. San Fransisco: Jossey-Bas.

Crosby, BC, and JM Bryson. 2010. "Integrative leadership and the creation and maintenance of cross-sector collaborations." The Leadership Quarterly 21 (2):21 I-230.

Crouch, L, D Lapidus, R Beach, D Birur, M Moussavi, and ETurner. 20 17. Developing climate-smart agriculture policies: the role of economic modeling. In RTI Press PUblication edited by RTI. Research Triangle Park, NC: RTI Press.

Crowley, K, and BW Head. 2017. "The enduring challenge of 'wicked problems': revisiting Rittel and Webber." Policy Sciences 50 (4):539-547.

Currie, G, M Humphreys, D Ucbasaran, and S McManus. 2008. "Entrepreneurial leadership in the English public sector: paradox or possibility?" Public Administration 86 (4):987- 1008.

Dahl, RA. 2005. Who governs? Democracy and power in an American city. New Haven:Yale University Press. 
Danermark, B, M Eckström, L Jakobsen, and JC Karlsson. 2002. Explaining society: an introduction to critical realism in the social sciences. London: Routledge.

David, CC, JMAtun, E Fille, and C Monterola. 20I I. "Finding frames: comparing two methods of frame analysis." Communication Methods and Measures 5 (4):329-351.

De Franco, C, CO Meyer, and KE Smith. 20 I 5." 'Living by example?'The European Union and the implementation of the Responsibility to Protect (R2P)." JCMS: Journal of Common Market Studies 53 (5):994- 1009.

De Milliano, C, M Faling, A Clark-Ginsberg, D Crowley, and P Gibbons. 20 I5. "Resilience:The Holy Grail or yet another hype?" In The Humanitarian Challenge, edited by P Gibbons and HJ Heintze, 17-30. Switzerland: Springer International

De Rynck, S. 2016. "Banking on a union: the politics of changing eurozone banking supervision." Journal of European Public Policy 23 ( I): I 19- 135.

Dekker, R. 2017. “Frame ambiguity in policy controversies: critical frame analysis of migrant integration policies in Antwerp and Rotterdam." Critical Policy Studies I I (2): I 27- 45.

Dewulf, A, and R Bouwen. 2012. "Issue framing in conversations for change: discursive interaction strategies for 'doing differences'.' The Journal of Applied Behavioral Science 48 (2): I 68-193.

Dewulf,A, M Craps, R Bouwen,TTaillieu, and C Pahl-Wostl. 2005. "Integrated management of natural resources: dealing with ambiguous issues, multiple actors and diverging frames." Water Science and Technology 52 (6): $115-124$.

Diez, J. 2010 . "The importance of policy frames in contentious politics." Latin American Research Review 45 ( 1 ):33-54.

DiMaggio, P. 1988. "Interest and Agency in Institutional Theory." In Institutional Patterns and Culture, edited by L. Zucker, 3-22. Cambridge: MA: Ballinger Publishing Company.

Dinesh, D, R Zougmore, JVervoort, E Totin, PThornton, D Solomon, P Shirsath, V Pede, I Lopez Noriega, and P Läderach. 2018. "Facilitating change for climate-smart agriculture through science-policy engagement." Sustainability 10 (8):2616. doi: 10.3390/sul0082616.

Dixon-Woods, M, S Agarwal, D Jones, B Young, and A Sutton. 2005. "Synthesising qualitative and quantitative evidence: a review of possible methods." Journal of Health Services Research \& Policy 10 ( I):45-53.

Douglas, JW, R Raudla, and RE Hartley. 2015. "Shifting constellations of actors and their influence on policy diffusion: a study of the diffusion of drug courts." Policy Studies Journal 43 (4):484-5I I.

EDRI. 2010. Africa, Forests and the Global Negotiations on Climate Change. In African Regional Dialogue on Forests, Governance \& Climate Change. Addis Abeba, Ethiopia: EDRl; Rights and Resources; .

Entman, RM. 1993. "Framing: toward clarification of a fractured paradigm." Journal of Communication 43 (4):5 I 58.

Falagas, ME, El Pitsouni, GA Malietzis, and G Pappas. 2008. "Comparison of PubMed, Scopus, Web of Science. and Google scholar: strengths and weaknesses." The FASEB journal 22 (2):338-342.

Faling, M, R Biesbroek, S Karlsson-Vinkhuyzen, and KTermeer. 20 I 8. "Policy entrepreneurship across boundaries: a systematic literature review." Journal of Public Policy: I-30. doi: I0. I0 I7/S0 I 438 I 4X I8000053.

Faling, M, R Biesbroek, and S Karlsson-Vinkhuyzen. 20I 8. "The strategizing of policy entrepreneurs towards the Global Alliance for Climate-Smart Agriculture." Global Policy I5 (2):408-419.

Falleti, TG, and JF Lynch. 2009. "Context and causal mechanisms in political analysis.” Comparative Political Studies 42 (9): | | 43- | | 66.

FAO. 2009. "Draft Declaration of the World Summit on Food Security." World Summit on Food Security, Rome, Italy, I6-I 8 November 2009.

FAO. 2010. Climate-Smart agriculture: policies, practice and financing for food security, adaptation and mitigation. Rome, Italy: FAO.

FAO. 20 I5. "Regional CSA Alliances and platforms: Information sheet." Accessed 27 - 10. http://www.fao. org/3/a-bl862e.pdf.

Field, A. 2009. Discovering statistics using SPSS. London: Sage Publications.

Fiss, PC, and PM Hirsch. 2005. "The discourse of globalization: Framing and sensemaking of an emerging concept." American Sociological Review 70 ( I):29-52.

Fletcher, AJ. 2017. "Applying critical realism in qualitative research: methodology meets method." International Journal of Social Research Methodology 20 (2): I 81 - 194. 
Flyvbjerg, B. 2006. "Five misunderstandings about case-study research." Qualitative Inquiry 12 (2):219-245.

Font, N, and J Subirats. 2010 . "Water management in Spain: the role of policy entrepreneurs in shaping change." Ecology and Society 15 (2):25.

Forbes, T. 2012. "Institutional entrepreneurship in hostile settings: health and social care partnerships in Scotland, 2002-05." Environment and Planning C: Government and Policy 30 (6): I I $00-$ I I I 5.

GACSA. 2014. Agriculture: Global Alliance for Climate-Smart Agriculture Action Plan. New York, USA: UN Climate Summit 2014.

Galanti, MT, and G Capano. 2015. "Brokers, entrepreneurs and leaders in policy dynamics: from individual actors to types of agency." ECPR General Conference, Montreal, 27-29 August.

Gamson,WA. 1995. "Constructing social protest." Social Movements and Culture 4:85- 106.

Garud, R, C Hardy, and S Maguire. 2007." "Institutional entrepreneurship as embedded agency: an introduction to the special issue." Organization Studies 28 (7):957-969.

Geertz, C. 2008. “Thick description: toward an interpretive theory of culture." In The Cultural Geography Reader, 4I-5I. London: Routledge.

Gerring, J. 2004. "What is a case study and what is it good for?" American Political Science Review 98 (2):341354.

Gill, P, K Stewart, E Treasure, and B Chadwick. 2008. "Methods of data collection in qualitative research: interviews and focus groups." British Dental Journal 204 (6):29I-295.

Global Conference. 2010 . "The Hague Conference on Agriculture, Food Security and Climate Change: Chair's Summary and Roadmap for Action." Global Conference on Agriculture, Food Security and Climate Change, The Hague, The Netherlands, 3 I October - 5 November 20 I 0.

Godfray, HCJ, JR Beddington, IR Crute, L Haddad, D Lawrence, JF Muir, J Pretty, S Robinson, SM Thomas, and CToulmin. 20 10. "Food security: the challenge of feeding 9 billion people." Science 327 (5967):812-8I8.

Goggin, Malcolm L. 1986. "The" too few cases/too many variables" problem in implementation research." Western Political Quarterly 39 (2):328-347.

Googins, BK, and SA Rochlin. 2000." "Creating the partnership society: understanding the rhetoric and reality of cross-sectoral partnerships." Business and Society Review I05 (I): I27-I 44.

Gorton, M, P Lowe, and A Zellei. 2005. "Pre-accession Europeanisation: the strategic realignment of the environmental policy systems of Lithuania, Poland and Slovakia towards agricultural pollution in preparation for EU membership." Sociologia Ruralis 45 (3):202-223.

Gough, D, S Oliver, and J Thomas. 20 I2. An introduction to systematic reviews. London: Sage.

Government, National. 20 I3. Dijksma en Clinton werken samen aan meer voedselzekerheid.

Gow, J, and K Parton. 1995. "Evolution of Kenyan agricultural policy." Development Southern Africa I2 (4):467479.

Green, JF. 2017." Policy entrepreneurship in climate governance: toward a comparative approach." Environment and Planning C: Politics and Space 35 (8): 147| - 1482.

Greenwood, DJ, and M Levin. 2006. Introduction to action research: Social research for social change. London: Sage.

Grint, K. 20I I. "A history of leadership." In The SAGE handbook of leadership, edited by A Bryman, D Collinson, K Grint, B Jackson and M Uhl-Bien, 3- I4. London: Sage

Gubrium, JF, and JA Holstein. 200 I. Handbook of interview research: context and method. London: Sage.

Hajer, M, M Nilsson, K Raworth, P Bakker, F Berkhout, Y de Boer, J Rockström, K Ludwig, and M Kok. 2015. "Beyond cockpit-ism: four insights to enhance the transformative potential of the sustainable development goals." Sustainability 7 (2): 1651 - 1660.

Hajer, Maarten A. 1995. The politics of environmental discourse: ecological modernization and the policy process: Clarendon Press Oxford.

Hall, PA. 1993. "Policy paradigms, social learning, and the state: the case of economic policymaking in Britain." Comparative Politics 25 (3):275-296.

Hall, PA. 1997. "The role of interests, institutions, and ideas in the comparative political economy of the industrialized nations." In Comparative politics: rationality, culture, and structure, edited by MI Lichbach and AS Zuckerman, 174-207. Cambridge: Cambridge University Press.

Harting, J, AE Kunst, A Kwan, and K Stronks. 20 I 0. "A 'health broker' role as a catalyst of change to promote health: an experiment in deprived Dutch neighbourhoods." Health Promotion International 26 (I):65-8I. 
Harvey, CA, M Chacón, Cl Donatti, E Garen, L Hannah, A Andrade, L Bede, D Brown, A Calle, and J Chara. 2014. "Climate-smart landscapes: opportunities and challenges for integrating adaptation and mitigation in tropical agriculture." Conservation Letters 7 (2):77-90.

Hay, C. 2004. "Ideas, interests and institutions in the comparative political economy of great transformations." Review of International Political Economy II ( I):204-226.

Head, BW, and J Alford. 201 5. "Wicked problems: implications for public policy and management." Administration \& Society $47(6): 711-739$

Heclo, H. 1978. "Issue networks and the executive establishment." Public Adm. Concepts Cases 41 3:46-57.

Heinze, KL, J Banaszak-Holl, and K Babiak. 2016. "Social entrepreneurship in communities." Nonprofit Management and Leadership 26 (3):313-330.

Hermansen, EAT. 2015. "Policy window entrepreneurship: the backstage of the world's largest REDD+ initiative." Environmental Politics 24 (6):932-950.

Herr, K, and GL Anderson. 2014. The action research dissertation: a guide for students and faculty. London: Sage.

Hertin, J, and F Berkhout. 2003. "Analysing institutional strategies for environmental policy integration: the case of EU enterprise policy." Journal of Environmental Policy \& Planning 5 ( I ):39-56.

Hooghe, L, G Marks, and GW Marks. 200 I. Multi-level governance and European integration. Oxford: Rowman \& Littlefield.

Hovik, S, and GS Hanssen. 2015. "The impact of network management and complexity on multi-level coordination." Public Administration 93 (2):506-523. doi: I0. I I I I/padm. 12 I 35.

Huitema, D, EL Boasson, and R Beunen. 20 I 8. “Entrepreneurship in climate governance at the local and regional levels: concepts, methods, patterns, and effects." Regional Environmental Change I 8 (5): I 247- I 257.

Huitema, D, and S Meijerink, eds. 2009. Water policy entrepreneurs: a research companion to water transitions around the globe. Cheltenham: Edward Elgar.

Huitema, D, and S Meijerink. 20 I0. "Realizing water transitions: the role of policy entrepreneurs in water policy change." Ecology and Society 15 (2):26.

Hyett, N, A Kenny, and V Dickson-Swift. 2014. "Methodology or method? A critical review of qualitative case study reports." International Journal of Qualitative Studies on Health and Well-Being 9 ( I):23606. doi: http://dx.doi.org/| 0.3402/qhw.v9.23606.

Intindola, M, JWeisinger, and C Gomez. 20 I6. "With a little help from my friends: Multi-sector collaboration and strategic decision-making." Management Decision 54 ( I 0):2562-2586.

IPCC, Intergovernmental Panel on Climate Change. 2007. Climate Change 2007-Mitigation of Climate Change: Working Group III Contribution to the Fourth Assessment Report of the IPCC. Cambridge: Cambridge University Press.

Jenkins-Smith, HC, D Nohrstedt, CM Weible, and PA Sabatier. 2014. "The advocacy coalition framework: foundations, evolution, and ongoing research." In Theories of the policy process, edited by PA Sabatier, 183 224. Boulder: Westview Press.

Jochim, AE, and PJ May. 20 I0. "Beyond subsystems: Policy regimes and governance." Policy Studies Journal 38 (2):303-327.

Johansson, KM. 1999. "Tracing the employment title in the Amsterdam treaty: uncovering transnational coalitions." Journal of European Public Policy 6 ( I):85- 101.

John, P. 2003. "Is there life after policy streams, advocacy coalitions, and punctuations: Using evolutionary theory to explain policy change?" Policy Studies Journal 31 (4):48I-498.

John, P. 20 I8. "Theories of policy change and variation reconsidered: a prospectus for the political economy of public policy." Policy Sciences 5 I ( I): I - I6.

Jones, MD, and HC Jenkins-Smith. 2009. "Trans-subsystem dynamics: policy topography, mass opinion, and policy change." Policy Studies Journal 37 ( I):37-58.

Jordan, A, D Huitema, H van Asselt, and J Forster. 2018. Governing Climate Change: Polycentricity in Action? Cambridge: Cambridge University Press.

Jordan, A, and A Lenschow. 20 I0. "Environmental policy integration: a state of the art review." Environmental Policy and Governance 20 (3): I47- 158.

Jullien, F. 1999. The propensity of things: toward a history of efficacy in China. New York: Zone Books.

Karlsson, L, LO Naess, A Nightingale, and JThompson. 20I 8. “'Triple wins' or 'triple faults'? Analysing the equity implications of policy discourses on climate-smart agriculture (CSA)."' The Journal of Peasant Studies 45 (I): I50- 174 . 
Karlsson, T, and KW Middleton. 2015. "Strategies for creating new venture legitimacy." Industry and Higher Education 29 (6):469-479.

Kenya, Republic of. 20 16. Climate Change Act Nairobi: National Council for Law Reporting.

Kern, F. 20I I. 'Ideas, institutions, and interests: explaining policy divergence in fostering 'system innovations' towards sustainability." Environment and Planning C: Government and Policy 29 (6): I | | 6- I I 34.

Kettl, DF. 2006. "Managing boundaries in American administration: the collaboration imperative." Public Administration Review 66 (sI): 10-19.

Khan, FR, KA Munir, and H Willmott. 2007. "A dark side of institutional entrepreneurship: soccer balls, child labour and postcolonial impoverishment." Organization Studies 28 (7): I 055- 1077.

King, G, RO Keohane, and S Verba. 1994. Designing social inquiry: scientific inference in qualitative research. Princeton: Princeton University Press.

Kingdon, JW. 1995. Agendas, alternatives, and public policies. 2 ed. New York: HarperCollins.

Klijn, EH, and J Koppenjan. 20 16. Governance networks in the public sector. London: Routledge.

Knill, C, and J Tosun. 20 I2. Public policy: a new introduction. London: Palgrave Macmillan.

Koebele, E. 2016. "Using the Advocacy Coalition Framework to understand collaborative policy processes." Western Political Science Association Conference, San Diego, California, 24-26 March.

Köhler, G. 20I I. The challenges of Delivering as One: Overcoming fragmentation and moving towards policy coherence. In Working Paper, edited by International Labour Organization. Geneva: ILO.

Koppenjan, JFM, and EH Klijn. 2004a. Managing uncertainties in networks: a network approach to problem solving and decision making. London: Routledge.

Koppenjan, JFM, and EH Klijn. 2004b. Managing uncertainties in networks: a network approach to problem solving and decision making: Psychology Press.

Kugelberg, S, K Jönsson, and A Yngve. 2012. "Understanding the process of establishing a food and nutrition policy: the case of Slovenia." Health Policy 107 ( I):91-97.

Lee, NJ, DM McLeod, and DV Shah. 2008. "Framing policy debates: issue dualism, journalistic frames, and opinions on controversial policy issues." Communication Research 35 (5):695-718.

Lenschow, A, ed. 2002. Environmental policy integration: greening sectoral policies in Europe. London: Earthscan Publications.

Lipper, L, N McCarthy, D Zilberman, S Asfaw, and G Branca, eds. 20 I 8. Climate Smart Agriculture: building resilience to climate change. Edited by D Zilberman, R Goetz and A Garrido, Natural Resource Management and Policy. Cham: Springer.

Lipper, L, P Thornton, BM Campbell, T Baedeker, A Braimoh, M Bwalya, P Caron, A Cattaneo, D Garrity, and K Henry. 20 I4. "Climate-smart agriculture for food security." Nature Climate Change 4 ( I 2): I 068- 1072.

Lober, DJ. 1997. "Explaining the formation of business-environmentalist collaborations: collaborative windows and the Paper Task Force." Policy Sciences 30 (I): I-24.

Long, JC, FC Cunningham, and J Braithwaite. 20I3. "Bridges, brokers and boundary spanners in collaborative networks: a systematic review." BMC Health Services Research I3 (I): 158.

Lounsbury, M, and MA Glynn. 2001. "Cultural entrepreneurship: stories, legitimacy, and the acquisition of resources." Strategic Management Journal 22 (6-7):545-564.

Mahoney, J, and K Thelen. 2010. "A theory of gradual institutional change." In Explaining institutional change: Ambiguity, agency, and power, edited by J Mahoney and KThelen, I-38. Cambridge: Camrbidge University Press.

Maina, I, A Newsham, and M Okoti. 2013. Agriculture and climate change in Kenya: climate chaos, policy dilemmas. In Working Paper. Future Agricultures.

MALF. 20 17. Kenya Climate Smart Agriculture Strategy 20 17-2026. edited by Livestock and Fisheries Ministry of Agriculture. Nairobi, Kenya: Republic of Kenya.

Maltby, T. 2013. "European Union energy policy integration: a case of European Commission policy entrepreneurship and increasing supranationalism." Energy Policy 55:435-444.

Margerum, RD, and CJ Robinson, eds. 2016. The challenges of collaboration in environmental governance: barriers and responses. Cheltenham: Edward Elgar Publishing.

Marks, G, L Hooghe, and K Blank. 1996. "European integration from the 1980s: state-centric v. multi-level governance." Journal of Common Market Studies 34 (3):34I-378. 
Massey, E, R Biesbroek, D Huitema, and A Jordan. 2014. "Climate policy innovation: the adoption and diffusion of adaptation policies across Europe." Global Environmental Change 29:434-443.

Mattli,W, and J Seddon. 20 I5. "New organizational leadership: nonstate actors in global economic governance." Global Policy 6 (3):266-276.

May, PJ, and AE Jochim. 20 I3. "Policy regime perspectives: policies, politics, and governing." Policy Studies Journal 4 ( (3):426-452.

May, PJ, and SC Winter. 2009. "Politicians, managers, and street-level bureaucrats: influences on policy implementation." Journal of Public Administration Research and Theory 19 (3):453-476. doi: I0. I093/jopart/ mum030

McConnell, A. 20 I 0. "Policy success, policy failure and grey areas in-between." Journal of Public Policy 30 (3):345362.

McDermott, A, D Coghlan, and MA Keating. 2008. "Research for action and research in action: processual and action research in dialogue?" Irish Journal of Management 29 (I): I - I 8.

McNamara, MW. 2014. "Collaborative windows, entrepreneurs, and subsystems: setting the stage for partnership to rebuild Louisiana's coast." Journal for Nonprofit Management:42-65.

Meadowcroft, J. 2000. "Sustainable development: a new (ish) idea for a new century?" Political Studies 48 (2):370-387.

Meadowcroft, J. 201 I. "Engaging with the politics of sustainability transitions." Environmental Innovation and Societal Transitions I ( ):70-75

Meijerink, S, and D Huitema. 2010. "Policy entrepreneurs and change strategies: lessons from sixteen case studies of water transitions around the globe." Ecology and Society I 5 (2):2I.

Meijerink, S, and S Stiller. 2013. "What kind of leadership do we need for climate adaptation? A framework for analyzing leadership objectives, functions, and tasks in climate change adaptation." Environment and Planning C: Government and Policy 3 I (2):240-256.

Meijerink, S, and M Wiering. 2009. "River basin management in Europe:The 'up-and downloading'of a new policy discourse." In The disoriented state: shifts in governmentality, territoriality and governance, edited by B Arts, A Lagendijk and H Houtum, I 8 I-200. Dordrecht: Springer.

Mintrom, M. 1997. "Policy entrepreneurs and the diffusion of innovation." American Journal of Political Science 4 I (3):738-770.

Mintrom, M. 2000. Policy entrepreneurs and school choice. Washington: Georgetown University Press.

Mintrom, M. 2013. "Policy entrepreneurs and controversial science: governing human embryonic stem cell research." Journal of European Public Policy 20 (3):442-457.

Mintrom, M, and J Luetjens. 2017. "Policy entrepreneurs and problem framing: the case of climate change." Environment and Planning C: Politics and Space 35 (8): I 362- 1377.

Mintrom, M, and P Norman. 2009. "Policy entrepreneurship and policy change." Policy Studies Journal 37 (4):649-667. doi: 10.1 I I I/j. I54 I-0072.2009.00329.x.

Mintrom, M, and MThomas. 20 8 . "Policy entrepreneurs and collaborative action: pursuit of the sustainable development goals." International Journal of Entrepreneurial Venturing 10 (2): I53- I7।.

Mintrom, M, and SVergari. 1996. "Advocacy coalitions, policy entrepreneurs, and policy change." Policy Studies Journal 24 (3):420-434.

Miskel, C, and M Song. 2004. "Passing reading first: prominence and processes in an elite policy network." Educational Evaluation and Policy Analysis 26 (2):89- 109.

Mitchell, SM, and SM Shortell. 2000. "The governance and management of effective community health partnerships: a typology for research, policy, and practice." The Milbank Quarterly 78 (2):24I-289.

Moher, D, A Liberati, J Tetzlaff, and DG Altman. 2009. "Preferred reporting items for systematic reviews and meta-analyses: the PRISMA statement.” PLoS Medicine 6 (7):el 000097.

Moomaw, WR, RR Bhandary, L Kuhl, and PVerkooijen. 20 17. "Sustainable development diplomacy: diagnostics for the negotiation and implementation of sustainable development." Global Policy 8 ( I):73-81.

Mueller, SD. 201 I. "Dying to win: elections, political violence, and institutional decay in Kenya." Journal of Contemporary African Studies 29 ( I):99- 117.

Mukhtarov, F.,A. Brock, S. Janssen, and A. Guignier. 20 I 3. "Actors and strategies in translating global conservation narratives to Vietnam: An agency perspective." Policy and Society 32 (2):113-124. doi: 10.1016/j. polsoc.2013.05.006. 
Muldowney, J, J Mounsey, and L Kinsella. 2013. "Agriculture in the climate change negotiations; ensuring that food production is not threatened." Animal 7 (s2):206-21 I.

Nations, United. 2015a. Policy integration in government in pursuit of the sustainable development goals. edited by Department of Economic and Social Affairs. New York: United Nations.

Nations, United. 2015b. Transforming our world: the 2030 agenda for sustainable development. In Resolution adopted by the General Assembly, edited by United Nations.

Negra, C. 2014. Integrated national policy approaches to climate-smart agriculture. Insights from Brazil, Ethiopia, and New Zealand. In CCAFS Report, edited by CGIAR-CCAFS. Copenhagen: CCAFS.

Neufeldt, H, M Jahn, BM Campbell, JR Beddington, F DeClerck, A De Pinto, J Gulledge, J Hellin, M Herrero, and A Jarvis. 2013. "Beyond climate-smart agriculture: toward safe operating spaces for global food systems." Agriculture \& Food Security 2 ( I): 12.

Newell, P, and OTaylor. 2018 . "Contested landscapes: the global political economy of climate-smart agriculture." The Journal of Peasant Studies 45 ( I): I08- 129.

Newman, AL. 2008. "Building transnational civil liberties: transgovernmental entrepreneurs and the European Data Privacy Directive." International Organization 62 (0I): I03-130.

Nilsson, M. 2005. "Learning, frames, and environmental policy integration: the case of Swedish energy policy." Environment and Planning C: Government and policy 23 (2):207-226.

Njoroge, JM, BMW Ratter, and L Atieno. 2017. "Climate change policy-making process in Kenya: deliberative inclusionary processes in play." International Journal of Climate Change Strategies and Management 9 (4):535-554.

NL Ministry of Economic Affairs. 20 13. Rijksjaarverslag 2013. edited by Landbouw en Innovatie Ministerie van Economische Zaken. The Hague: Ministry of Economic Affairs.

Noble, G, and R Jones. 2006. "The role of boundary-spanning managers in the establishment of public-private partnerships." Public Administration 84 (4):891-917.

Nohrstedt, D. 201 I. "Shifting resources and venues producing policy change in contested subsystems: a case study of Swedish signals intelligence policy." Policy Studies Journal 39 (3):46I-484.

Nohrstedt, D, and K Olofsson. 20 16." A review of applications of the advocacy coalition framework in Swedish policy processes." European Policy Analysis 2 (2): | 8-42.

Nohrstedt, D, and CM Weible. 20I0. "The logic of policy change after crisis: Proximity and subsystem interaction." Risk, Hazards \& Crisis in Public Policy I (2): I-32.

O'Flynn, J, D Blackman, and J Halligan, eds. 2013. Crossing boundaries in public management and policy: the international experience. Vol. I5, Routledge critical studies in public management. London: Routledge.

O'Brien, FS, and TCI Ryan. 1999. Aid and reform in Africa: Kenya case study. In Aid and Reform in Africa Papers, edited by World Bank. Washington, DC: World Bank.

O'Flynn, J. 2013. "Crossing boundaries: the fundamental questions in public management and policy." In Crossing boundaries in public management and policy: the international experience, edited by J O'Flynn, D Blackman and J Halligan, 3 I-64. New York: Routledge.

O'Leary, R, and N Vij. 2012. "Collaborative public management: Where have we been and where are we going?" The American Review of Public Administration 42 (5):507-522.

Oborn, E, M Barrett, and M Exworthy. 20II. "Policy entrepreneurship in the development of public sector strategy: the case of London health reform." Public Administration 89 (2):325-344.

Olsson, P, C Folke, V Galaz, T Hahn, and L Schultz. 2007. "Enhancing the fit through adaptive co-management: creating and maintaining bridging functions for matching scales in the Kristianstads Vattenrike Biosphere Reserve, Sweden." Ecology and Society 12 (I).

Orchard, P, and J Gillies. 2015. "Atypical leadership: the role of the presidency and refugee protection, 1932 1952." Presidential Studies Quarterly 45 (3):490-5 I3.

Ostrom, E. 2007. "Institutional rational choice: an assessment of the institutional analysis and development framework." In Theories of the policy process, edited by P Sabatier, 2 1 -64. Boulder: Westview Press.

Ostrom, E. 2009. "A general framework for analyzing sustainability of social-ecological systems." Science 325 (5939):419-422.

Ostrom, E. 2010. "Polycentric systems for coping with collective action and global environmental change." Global Environmental Change 20 (4):550-557. 
Oxfam Novib. 20 10. Plenary Statement at Ministerial Meeting from Oxfam Novib. Oxfam Novib, on behalf of NGOs.

Palich, LE, and DR Bagby. 1995. "Using cognitive theory to explain entrepreneurial risk-taking: challenging conventional wisdom." Journal of Business Venturing 10 (6):425-438.

Palmer, J. 20 I0. "Stopping the unstoppable? A discursive-institutionalist analysis of renewable transport fuel policy." Environment and Planning C: Government and Policy 28 (6):992- 1010.

Partzsch, L. 2017. "Powerful individuals in a globalized world." Global Policy 8 ( I):5-13.

Paterson, BL, SEThorne, C Canam, and C Jillings. 200 I. Meta-study of qualitative health research: a practical guide to meta-analysis and meta-synthesis. Vol. 3, Methods in nursing research. London: Sage Publications.

Perkmann, M, and A Spicer. 2007. "Healing the scars of history': projects, skills and field strategies in institutional entrepreneurship." Organization Studies 28 (7): I I01-1 122.

Persson, $\AA$, and $\mathrm{H}$ Runhaar. 2018. "Conclusion: drawing lessons for Environmental Policy Integration and prospects for future research." Environmental Science \& Policy 85: | 4 | - | 45.

Peters, B Guy, and Jon Pierre. 20 I6. Comparative governance: Rediscovering the functional dimension of governing: Cambridge University Press.

Peters, BG. 20 I5. Pursuing horizontal management: the politics of public sector coordination. Kansas: University Press of Canvas.

Petridou, E. 2017." Political entrepreneurship in Swedish: towards a (re) theorization of entrepreneurial agency." Mid Sweden University.

Petridou, E, I Narbutaité Aflaki, and L Miles. 20 I 5. "Unpacking the theoretical boxes of political entrepreneurship." In Entrepreneurship in the polis: understanding political entrepreneurship, edited by I Narbutaité Aflaki, E Petridou and L Miles, I- 16. London: Routledge.

Petridou, E. 2014. "Theories of the policy process: Contemporary scholarship and future directions." Policy Studies Journal 42 (SI):SI 2-S32. doi: I 0. I I I I/psj. 12054.

Petticrew, M, and H Roberts. 2008. Systematic reviews in the social sciences: a practical guide. Oxford: Plackwell Publishing.

Pettigrew, AM. 1990. "Longitudinal field research on change: theory and practice." Organization Science I (3):267-292.

Pettigrew, AM. 1997. "What is a processual analysis?" Scandinavian Journal of Management I 3 (4):337-348.

Phillips, N, and PTracey. 2007. "Opportunity recognition, entrepreneurial capabilities and bricolage: connecting institutional theory and entrepreneurship in strategic organization." Strategic Organization 5 (3):3 I 3.

Polsby, NW. 1985. Political innovation in America: the politics of policy initiation. New Haven:Yale University Press.

Poulton, C, and K Kanyinga. 20 14. "The politics of revitalising agriculture in Kenya." Development Policy Review $32($ s2):s $|5|-s \mid 72$

Prakash, A, A Héritier, B Koremenos, and E Brousseau. 2015. "Organizational leadership and collective action in international governance: an introduction." Global Policy 6 (3):234-236.

Pralle, S. 2006. "The "mouse that roared": agenda setting in Canadian pesticides politics." Policy Studies Journal 34 (2): $171-194$.

Pralle, SB. 2003b. "Venue shopping, political strategy, and policy change: the internationalization of Canadian forest advocacy." Journal of Public Policy 23 (3):233-260.

Princen, S. 2013 . "Punctuated equilibrium theory and the European Union." Journal of European Public Policy 20 (6):854-870.

Pump, B. 201 I. "Beyond metaphors: new research on agendas in the policy process." Policy Studies Journal 39 $(\mathrm{s} I): I-12$.

Quick, KS, and MS Feldman. 2014. "Boundaries as junctures: collaborative boundary work for building efficient resilience." Journal of Public Administration Research and Theory 24 (3):673-695.

Rein, M, and D Schon. 1977. "Problem setting in policy research." Using Social Research in Public Policy Making | 1:235.

Reus-Smit, C, and D Snidal. 2010. The Oxford handbook of international relations. Oxford: Oxford University Press.

Rihoux, B. 2006. "Qualitative comparative analysis (QCA) and related systematic comparative methods: recent advances and remaining challenges for social science research." International Sociology 2 I (5):679-706. 
Ringler, C, A Bhaduri, and R Lawford. 20 I3. "The nexus across water, energy, land and food (WELF): potential for improved resource use efficiency?" Current Opinion in Environmental Sustainability 5 (6):617-624.

Rittel, HWJ, and MMWebber. 1973. "Dilemmas in a general theory of planning." Policy Sciences 4 (2): I 55- 169.

Roberts, NC. 1992. "Public entrepreneurship and innovation." Review of Policy Research I I ( I):55-74.

Roberts, NC. 2006. "Public entrepreneurship as social creativity." World Futures 62 (8):595-609.

Roberts, NC, and PJ King. 1991. "Policy entrepreneurs: their activity structure and function in the policy process." Journal of Public Administration Research and Theory I (2): I 47- I 75.

Roberts, NC, and PJ King. 1996. Transforming public policy: dynamics of policy entrepreneurship and innovation. San Fransisco: Jossey-Bass Publishers.

Rosen, F, and P Olsson. 20 I3. "Institutional entrepreneurs, global networks, and the emergence of international institutions for ecosystem-based management:The Coral Triangle Initiative." Marine Policy 38:195-204.

Rosenzweig, C, and D Hillel. 1998. Climate change and the global harvest: potential impacts of the greenhouse effect on agriculture. New York: Oxford University Press.

Sabatier, P. 2014. "The need for better theories." In Theories of the policy process, edited by P Sabatier and C Weible, 3-17. Boulder: Westview Press.

Sabatier, PA. 1988. "An advocacy coalition framework of policy change and the role of policy-oriented learning therein." Policy Sciences 21 (2): I29- 168.

Sabatier, PA, and HC Jenkins-Smith. 1996. "The advocacy coalition framework: an assessment "Annual Meeting of the American Political Science Association.

Sabatier, PA, WD Leach, M Lubell, and NW Pelkey. 2005. "Theoretical frameworks explaining partnership success." In Swimming upstream: Collaborative approaches to watershed management, edited by PA Sabatier, W Focht, M Lubell, ZTrachtenberg, A Vedlitz and M Matlock, 173-200. Cambridge: MIT Press.

Sabatier, PA, and CWeible. 2014. Theories of the policy process. Boulder:Westview Press.

Sabatier, PA, and CM Weible. 2007. "The advocacy coalition framework: innovations and clarifications." In Theories of the policy process, edited by PA Sabatier and CM Weible, 189-217. Boulder: Westview Press.

Saz-Carranza, A. 20 I 5. "Agents as brokers: leadership in multilateral organizations." Global Policy 6 (3):277-289.

Schaltegger, S, M Beckmann, and K Hockerts. 20 I 8. "Collaborative entrepreneurship for sustainability. Creating solutions in light of the UN sustainable development goals." International Journal of Entrepreneurial Venturing $10(2): 131-152$.

Scharpf, FW. 1991. "Games real actors could play: the challenge of complexity." Journal of Theoretical Politics 3 (3):277-304.

Scharpf, FW. 2003. Problem-solving Effectiveness and Democratic Accountability in the EU. In MPIfG working paper. Köln: Max-Planck-Institut für Gesellschaftsforschung.

Schattschneider, EE. 1960. The semisovereign people: a realist's view of democracy in America. New York: Holt, Rinehart and Winston.

Scherr, SJ, S Shames, and R Friedman. 2012. "From climate-smart agriculture to climate-smart landscapes." Agriculture \& Food Security I (I): 12.

Schlager, E. 1999. "A comparison of frameworks, theories, and models of policy processes." In Theories of the policy process, 233-260. Boulder:Westview Press.

Schmidt,VA. 2013. “Democracy and legitimacy in the European Union revisited: Input, output and 'throughput'." Political Studies 6 I ( I):2-22

Schneider, CQ, and CWagemann. 2010."Standards of good practice in qualitative comparative analysis (QCA) and fuzzy-sets." Comparative Sociology 9 (3):397-4I8.

Schneider, M, and P Teske. 1992. "Toward a theory of the political entrepreneur: evidence from local government." American Political Science Review 86 (03):737-747.

Schon, DA, and M Rein. 1995. Frame reflection: toward the resolution of intractrable policy controversies. New York: Basic Books.

Schoorl, E. 20 I2. Jean-Baptiste Say: Revolutionary, Entrepreneur, Economist. London: Routledge.

Scott,WR. 2008. Institutions and organizations: ideas and interests. Thousand Oaks: Sage.

Seawright, J, and J Gerring. 2008. "Case selection techniques in case study research: a menu of qualitative and quantitative options." Political Research Quarterly 61 (2):294-308. 
Selznick, P. 20I I. Leadership in administration: a sociological interpretation, Classics of social sciences series. New Orleans: Quid Pro Books.

Sénit, CA, F Biermann, and A Kalfagianni. 2017. "The representativeness of global deliberation: a critical assessment of civil society consultations for sustainable development." Global Policy 8 ( 1):62-72.

Shane, S, EA Locke, and CJ Collins. 2003. “Entrepreneurial motivation.” Human Resource Management Review 13 (2):257-279.

Shannon, MA, and CH Schmidt. 2002. "Theoretical approaches to understanding intersectoral policy integration." Cross-Sectoral Policy Impacts on Forests 46: I 5-26.

Sibanda, LM, SN Mwamakamba, M Mentz, and T Mthunzi. 2017. Policies and Practices for Climate-Smart Agriculture in Sub-Saharan Africa: A Comparative Assessment of Challenges and Opportunities across I 5 Countries. Pretoria: Food, Agric ulture and Natural Resource Policy Analysis Network (FANRPAN).

Smith, KE, G Fooks, AB Gilmore, J Collin, and H Weishaar. 20I5. "Corporate coalitions and policy making in the European Union: how and why British American Tobacco promoted "Better Regulation".' Journal of Health Politics, Policy and Law 40 (2):325-372.

Smith, L, S Jones, and S Karuga. 2004. Agriculture in Kenya: what shapes the policy environment? Nairobi: Oxford Policy Management.

Sørensen, E. 2007. “Local politicians and administrators as metagovernors." In Democratic network governance in Europe, edited by M Marcussen and J Torfing, 89- 108. London: Palgrave Macmillan.

Stafford-Smith, M, D Griggs, O Gaffney, F Ullah, B Reyers, N Kanie, B Stigson, P Shrivastava, M Leach, and D O'Connell. 2017."Integration: the key to implementing the Sustainable Development Goals." Sustainability Science 12 (6):911-919.

Steensland, B. 2008. "Why do policy frames change? Actor-idea coevolution in debates over welfare reform." Social Forces 86 (3): I027- 1054.

Steenwerth, KL, AK Hodson, AJ Bloom, MR Carter, A Cattaneo, CJ Chartres, JL Hatfield, K Henry, JW Hopmans, and WR Horwath. 2014. "Climate-smart agriculture global research agenda: scientific basis for action." Agriculture \& Food Security 3 ( I): I I. doi: I0. I |86/2048-70 I0-3- I I.

Stone, D. 2008. "Global public policy, transnational policy communities, and their networks." Policy Studies Journal 36 ( I): 19-38. doi: 10.1 I I I/j. I54 I-0072.2007.0025 I.x.

Stone, D, and S Ladi. 20I5. "Global public policy and transnational administration." Public Administration 93 (4):839-855.

Stone, DA. 1989. "Causal stories and the formation of policy agendas." Political Science Quarterly I04 (2):28I 300.

Stone, DA. 2002. Policy paradox: the art of political decision making. New York: Norton

Strohmaier, R, J Rioux, A Seggel, A Meybeck, M Bernoux, M Salvatore, J Miranda, and A Agostini. 20 I6. The Agriculture Sectors in the Intended Nationally Determined Contributions: Analysis. In Environment and Natural Resources Management Working Paper, edited by FAO. Rome: FAO.

Takahashi, LM, and G Smutny. 2002. "Collaborative windows and organizational governance: exploring the formation and demise of social service partnerships." Nonprofit and Voluntary Sector Quarterly 3 I (2): I 65 185.

Taylor, M. 20 I 8. "Climate-smart agriculture: what is it good for?" The Journal of Peasant Studies 45 ( I ):89- 107.

Teisman, GR. 2000. "Models for research into decision-making processes: on phases, streams and decisionmaking rounds." Public Administration 78 (4):937-956.

Termeer, CJAM, and A Bruinsma. 2016. "ICT-enabled boundary spanning arrangements in collaborative sustainability governance." Current Opinion in Environmental Sustainability | 8:9|-98.

Termeer, CJAM, and A Dewulf. 2018. "A small wins framework to overcome the evaluation paradox of governing wicked problems." Policy and Society. doi: I0. I080/| 4494035.20 I 8. 1497933.

Termeer, CJAM, A Dewulf, and GR Biesbroek. 2017. "Transformational change: governance interventions for climate change adaptation from a continuous change perspective." Journal of Environmental Planning and Management 60 (4):558-576.

Tomlins, R. 1997. "Officer discretion and minority ethnic housing provision." Journal of Housing and the Built Environment 12 (2): $179-197$.

Torfing, J. 2012. Interactive governance: advancing the paradigm. Oxford: Oxford University Press.

Tosun, J, and A Lang. 2017. "Policy integration: mapping the different concepts." Policy Studies 38 (6):553-570. 
Trampusch, C, and B Palier. 20 I6. "Between $\mathrm{X}$ and Y: how process tracing contributes to opening the black box of causality." New Political Economy 2 I (5):437-454.

Tversky, A, and D Kahneman. 1981. "The framing of decisions and the psychology of choice." Science 21 I (448I):453-458.

Uittenbroek, Caroline J, Leonie B Janssen-Jansen, and Hens AC Runhaar. 2016 . "Stimuli for climate adaptation in cities: insights from Philadelphia-an early adapter." International Journal of Climate Change Strategies and Management 8 ( I):38-56.

UN ECOSOC, African Union. 2009. Report on the Seventeenth Session. edited by Economic and Social Council Commission on Sustainable Development. New York, USA: United Nations.

van Broekhoven, S, F Boons, A van Buuren, and GTeisman. 20 I5. "Boundaries in action: a framework to analyse boundary actions in multifunctional land-use developments." Environment and Planning C: Government and Policy 33 (5): I 005- 1023.

van Meerkerk, I, and J Edelenbos. 2018. Boundary spanners in public management and governance: an interdisciplinary assessment. Cheltenham: Edward Elgar.

Vandenbussche, L, J Edelenbos, and J Eshuis. 20I8. "Plunging into the process: methodological reflections on a process-oriented study of stakeholders' relating dynamics." Critical Policy Studies: I-20. doi: https://doi. org/ / 0. I 080/19460 I 71.2018.1488596.

Varone, Frederic, Stephane Nahrath, David Aubin, and Jean-David Gerber. 20 I 3. "Functional regulatory spaces." Policy Sciences 46 (4):3 I I-333.

Verger,Antoni. 2012 ." "Framing and selling global education policy: the promotion of public-private partnerships for education in low-income contexts." Journal of Education Policy 27 ( I): I09- 130.

Vij, S, R Biesbroek, A Groot, and KTermeer. 20 I 8. "Changing climate policy paradigms in Bangladesh and Nepal.' Environmental Science \& Policy 81:77-85.

Vink, M, and G Schouten. 20 I 8. "Foreign-funded adaptation to climate change in Africa: mirroring administrative traditions or traditions of administrative blueprinting?" Review of Policy Research. doi: https://doi. org/| 0. I | | |/ropr. |229|.

von Heland, F, J Clifton, and P Olsson. 2014. "Improving stewardship of marine resources: linking strategy to opportunity." Sustainability 6 (7):4470-4496.

Wamicha, WN, and II Mwanje. 2000. Environmental Management in Kenya: Have the National Conservation Plans Worked? In Environmental Forum Publications Series, edited by OSSREA. Ethiopia: OSSREA.

Warutere, P. 201।. "Triple win of climate-smart agriculture put into practice." World Bank Accessed 17-03. http://www.worldbank.org/en/news/feature/20 I I/03/08/triple-win-climate-smartagriculture-put-into-practice.

Weible, CM, PA Sabatier, and K McQueen. 2009."Themes and variations:Taking stock of the advocacy coalition framework." Policy Studies Journal 37 ( I): | 2 | - | 40.

Wellstead, A. 2017. "Plus ça Change, Plus C'est La Même Chose? A review of Paul Sabatier's "An advocacy coalition framework of policy change and the role of policy-oriented learning therein"." Policy Sciences 50 (4):549-56I.

Wernham, R. 1985. "Obstacles to Strategy Implementation in a Nationalized Industry " Journal of Management Studies 22 (6):632-648.

Westerink, J. 2016. “Making a difference: boundary management in spatial governance.'Doctoral dissertation, Wageningen University.

Wheeler, T, and JVon Braun. 2013. "Climate change impacts on global food security." Science 34I (6I45):508 513.

Whittington, R. 2003. "The work of strategizing and organizing: for a practice perspective." Strategic organization I (I):1 $17-126$

Widmer, A. 2018. "Mainstreaming climate adaptation in Switzerland: How the national adaptation strategy is implemented differently across sectors." Environmental Science \& Policy 82:7।-78.

Williams, P. 2002. "The competent boundary spanner." Public administration 80 ( I): I03- 124.

Wynn, D , and CKWilliams. 2012. "Principles for conducting critical realist case study research in information systems." MIS quarterly:787-8I0.

Yanow, D. 1996. How does a policy mean?: Interpreting policy and organizational actions: Georgetown University Press. 
Yin, RK. 2003. Case study research: design and methods. Los Angeles: Sage.

Yow,VR. 20 I4. Recording oral history: A guide for the humanities and social sciences. Lanham: Rowman \& Littlefield.

Zahariadis, N. 2008. "Ambiguity and choice in European public policy." Journal of European Public Policy I5 (4):5।4-530.

Zahariadis, N, and T Exadaktylos. 2016. "Policies that Succeed and Programs that Fail: Ambiguity, Conflict, and Crisis in Greek Higher Education." Policy Studies Journal 44 ( I ):59-82.

Zaun, N, C Roos, and F Gülzau. 2016. "Circumventing deadlock through venue-shopping: why there is more than just talk in US immigration politics in times of economic crisis." Journal of Ethnic and Migration Studies 42 (10): 1590-1609.

Zelli, F, and H Van Asselt. 2013. "Introduction: The institutional fragmentation of global environmental governance: Causes, consequences, and responses." Global Environmental Politics I3 (3): I- I 3.

Zhang, H. 2017. "Complexity absorption: a processual strategic approach to corporate entrepreneurship strategy." Frontiers of Business Research in China | | ( I): | 3. doi: | 0. I | 86/s | | 782-0 I 7-00 I 5-5.

Zito, AR. 200I. "Epistemic communities, collective entrepreneurship and European integration." Journal of European public policy 8 (4):585-603.

Zito, AR. 20 I 3. Learning and governance in the EU policy making process: Routledge.

Zohlnhöfer, R. 201 6. "Putting Together the Pieces of the Puzzle: Explaining German Labor Market Reforms with a Modified Multiple-Streams Approach." Policy Studies Journal 44 ( I):83- 107. 


\section{Annexes}

\section{Annex I (belonging to chapter 2)}

\section{Supplementary materials}

Supplementary material 'Policy entrepreneurship across boundaries: a systematic literature review'

\section{Selected key words and search terms}

\begin{tabular}{|c|c|c|c|c|c|c|}
\hline $\begin{array}{l}\text { Policy entrepreneur } \\
\text { "entrepreneur*" }\end{array}$ & AND & 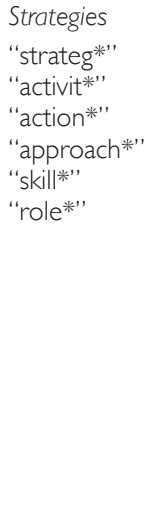 & AND & $\begin{array}{l}\text { Policy } \\
\text { "policy" } \\
\text { "policies" }\end{array}$ & AND NOT & 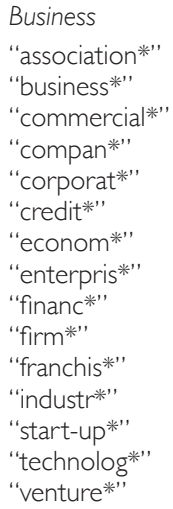 \\
\hline
\end{tabular}

\section{2. search string}

( (TITLE-ABS-KEY ("entrepreneur*") ) AND (TITLE-ABS-KEY ("strateg*" OR "activit*" OR "action*" OR "approach*" OR "skill*" OR "role*") ) AND ( ( TITLE-ABS-KEY ("policy*") OR TITLE-ABS-KEY ("policies" ) ) ) ) AND NOT ( ( TITLE-ABS-KEY ( "association*") OR TITLE-ABS-KEY ("business*") OR TITLE-ABS-KEY ("commercial*") OR TITLE-ABS-KEY ("compan*") ORTITLEABS-KEY ("corporat*") OR TITLE-ABS-KEY ("credit*") OR TITLE-ABS-KEY ( "econom*") OR TITLE-ABS-KEY ("enterpris*") OR TITLE-ABS-KEY ("financ*" ) OR TITLE-ABS-KEY ("firm*") OR TITLE-ABS-KEY ("franchis*") OR TITLEABS-KEY ("industr*") OR TITLE-ABS-KEY ("start-up*") OR TITLE-ABS-KEY ( "technolog*") OR TITLE-ABS-KEY ("venture*") )) AND (LIMIT-TO (DOCTYPE ,"ar"))\} 


\section{Coding instructions}

\section{Bibliographic information}
A. Document number
B. Document title
C. Year of publication
D. Journal

\section{Entrepreneur as actor}

E. Adjective entrepreneur (e.g. policy, norm, institutional)

F. Entity

- Individual

- Institution

- Joint

G. Type of actor

- inside government

i. political (president, presidential staff, political appointees)

ii. administration (bureaucrats, non-elected staff)

- outside government

i. NGO (non-profit organizations operating independently of government, whose objective is to address social or political issue)

ii. private (under no state control, seeking profit)

iii. research (academics, researchers, consultants)

iv. CSO (local organization that manifests and represents interest and will citizens)

v. Citizen (non-organized local, not representative of larger group)

H. Type of actor - specific [open coding] (e.g. EU Trade Commissioner Lamy, NGO Friends of the Earth)

\section{Focus and locus study}

I. Focus of the study [open coding] (e.g. EU, Israel, USA, Vietnam)

J. Locus of the study

- Global

- Supranational 
- National

- Subnational

K. Topic [open coding]

L. Discipline journal - based on ISI Web of Knowledge Journal Citation Report

\section{Cross-boundary strategies}

M. Conditions, [open coding] "a premise upon which the appearance, occurrence and/or manifestation of the cross-boundary strategizing depends"

N. Type of strategy, "(a set of) activities, manoeuvres, or actions of a particular kind and for a particular purpose, available to the actor" to be recognized by an active verb (to undertake, to do, to go etc)

- 'Issue promotion', actions of policy entrepreneurs that contribute to issue visibility, including publishing papers, giving speeches, voicing ideas in discussions, and advising other stakeholders across boundaries

- 'Coalition building', identifying contacts, building teams and points for cooperation and forming coalitions across the boundaries of levels and/or domains

- 'Transforming institutions', the actions of policy entrepreneurs to alter the distribution of authority and power and/or transform existing institutions

- ' 'Issue framing', the use of narratives and stories to make sense of an issue by selecting particular relevant aspects, connecting them into a sensible whole, and delineating issue boundaries

- $\quad$ 'Leading by example', the undertaking of pilot programs, the using of exemplar policy, or the testing of preferred policy change

O. Directions of cross-boundary strategies

- 'Vertical', crosscutting the boundaries between different policy levels

- 'Horizontal', crosscutting the boundaries between different policy domains

- 'Diagonal', crosscutting the boundaries of policy domains and levels simultaneously

P. Functions of cross-boundary strategies

- 'Expanding' the issue arena, involving an additional level and/or domain

- 'Shifting' the issue arena, moving the issue from the traditional arena 
in which it was discussed to a different level/domain. Also referred to as venue-shopping

- 'Integrating' issue arenas, including additional domains/levels into original issue arena or into a new institution

Q. Implications, [open coding], "apart from increase in resources or successful policy change, the consequences following from and directly dependent on the cross-boundary strategies of the entrepreneur".

\section{PRISMA-P checklist}

(Preferred Reporting Items for Systematic review and Meta-Analysis Protocols) (based on Moher et al. 2009, de Vries et al 2015)

NOTE: some checks are not applicable as they are meant for meta-analysis or more quantitative systematic reviews

\begin{tabular}{|c|c|c|c|}
\hline TITLE & & & \\
\hline Title & I. & Identify the research as systematic review & p. 1 \\
\hline \multicolumn{4}{|l|}{ ABSTRACT } \\
\hline Structured summary & 2. & $\begin{array}{l}\text { Provide a structured summary including (as applicable): background; } \\
\text { objectives; data sources; study eligibility criteria, participants, and } \\
\text { interventions; study appraisal and synthesis methods; results; } \\
\text { limitations; conclusions and implications of key findings; systematic } \\
\text { review registration number. }\end{array}$ & p. 1 \\
\hline \multicolumn{4}{|l|}{ INTRODUCTION } \\
\hline Rationale & 3. & $\begin{array}{l}\text { Describe the rationale for the review in the context of what is } \\
\text { already known. }\end{array}$ & p. $1-4$ \\
\hline Objectives & 4. & $\begin{array}{l}\text { Provide an explicit statement of questions being addressed with } \\
\text { reference to participants, interventions, comparisons, outcomes } \\
\text { and study design. }\end{array}$ & p. 3-4 \\
\hline \multicolumn{4}{|l|}{ METHODS } \\
\hline $\begin{array}{l}\text { Protocol and } \\
\text { registration }\end{array}$ & 5. & $\begin{array}{l}\text { Indicate if a review protocol exists, if and where it can be accessed } \\
\text { (e.g. Web address) and, if available, provide registration information } \\
\text { including registration number. }\end{array}$ & Annex \\
\hline Eligibility criteria & 6. & $\begin{array}{l}\text { Specify study characteristics and report characteristics (e.g. years } \\
\text { considered, language, publication status) used as criteria for } \\
\text { eligibility, giving rationale. }\end{array}$ & \\
\hline Information sources & 7. & $\begin{array}{l}\text { Describe all information sources (e.g. databases with dates of } \\
\text { coverage, contact with study authors to identify additional studies) } \\
\text { in the search and date last searched. }\end{array}$ & p. 5 \\
\hline Search strategy & 8. & $\begin{array}{l}\text { Present full electronic search strategy for at least one database, } \\
\text { including any limits used, such that it could be repeated. }\end{array}$ & $\begin{array}{l}\text { p. } 5+ \\
\text { annex }\end{array}$ \\
\hline Study selection & 9. & $\begin{array}{l}\text { State the process for selecting studies (i.e. screening, eligibility, } \\
\text { included in systematic review, and, if applicable, included in the } \\
\text { meta-analysis). }\end{array}$ & p. 4-5 \\
\hline $\begin{array}{l}\text { Data collection } \\
\text { process }\end{array}$ & 10 & $\begin{array}{l}\text { Describe method of data extraction from reports (e.g. piloted } \\
\text { forms, independently, in duplicate) and any processes for obtaining } \\
\text { and confirming data from investigators. }\end{array}$ & p. 5-6 \\
\hline
\end{tabular}


Appendix

Data items

Risk of bias in

individual studies

Summary measures

Synthesis results

Risk of bias across studies

Additional analyses

\section{RESULTS}

Study selection

Study characteristics

Synthesis results

Risk of bias across studies

Additional analysis
II. List and define all variables/categories for which data were p.7 sought (e.g. PICOS, funding sources) and any assumptions and simplifications made.

12. Describe methods used for assessing risk of bias in individual N/A studies (including specification of whether this was done at the study or outcome level), and how this information is to be used in any data synthesis.

13. State the principal summary measures (e.g. risk ratio, difference in N/A means).

14. Describe the methods for handling data and combining results of p. 7-8 studies, if done, including measures of consistency (e.g. I) for each meta-analysis.

15. Specify any assessment of risk of bias that may affect the cumulative p. 8 evidence (e.g. publication bias, selective reporting within studies).

16. Describe methods of additional analyses (e.g. sensitivity or N/A subgroup analyses, meta-regression), if done, indicating which were pre-specified.

\section{DISCUSSION}

Summary of evidence 22. Summarize the main findings including the strength of evidence for p. 21-25 each main outcome; consider their relevance to key groups (e.g. healthcare providers, users, and policy makers).

Limitations

23. Discuss limitations at study and outcome level (e.g. risk of bias), p. 25 and at review-level (e.g., incomplete retrieval of identified research, reporting bias).

Conclusions

24. Provide a general interpretation of the results in context of other p. 23-26 evidence, and implications for future research

\section{FUNDING}

Funding

25. Describe sources of funding for the systematic review and other $N / A$ support (e.g., supply of data); role of funders for the systematic review 


\section{References}

Moher, D., A. Liberati, J.Tetzlaff and D.G. Altman. 2009.'Preferred Reporting Items for Systematic Reviews and Meta-Analyses: The PRISMA Statement', Annals of Internal Medicine, I5I, 4, 264-69.

DeVries, H.,V. Bekkers and L. Tummers. 20 I5. Innovation in the Public Sector: a Systematic Review and Future Research Agenda', Public Administration 94, I, 146- 166. 
5. Data extraction table I: general description literature

\begin{tabular}{|c|c|c|c|c|c|}
\hline \# & $\begin{array}{l}\text { author, } \\
\text { year }\end{array}$ & Methods & Entrepreneur & $\begin{array}{l}\text { Level, locus, } \\
\text { topic }\end{array}$ & Condition \\
\hline $\begin{array}{l}\text { I. } \\
\text { (I) }\end{array}$ & Ackrill, 201। & $\begin{array}{l}\text { I sentence in } \\
\text { intro collection: } \\
\text { 'elite interviews' }\end{array}$ & $\begin{array}{l}\text { EUTrade } \\
\text { Commissioner } \\
\text { Trade Lamy } \\
\text { (political) }\end{array}$ & $\begin{array}{l}\text { supranational, } \\
\text { global; EU; sugar } \\
\text { reform }\end{array}$ & $\begin{array}{l}\text { Ambiguous hierarchical structure of authority } \\
\text { between different DGs, some policy issues } \\
\text { occupy policy arena of different DGs, such as } \\
\text { sugar - policy issue located across multiple } \\
\text { institutionally connected EU arenas. } \\
\text { He wanted to put pressure on DG-AGRI }\end{array}$ \\
\hline $\begin{array}{l}2 . \\
(7)\end{array}$ & Arieli, 2013 & $\begin{array}{l}\text { Paragraph in } \\
\text { intro: collection: } \\
\text { systematic } \\
\text { review } \\
\text { literature (?), } \\
28 \text { interviews, } \\
\text { using snowball } \\
\text { sampling }\end{array}$ & $\begin{array}{l}\text { Aqaba-Eilat } \\
\text { municipal } \\
\text { cooperative } \\
\text { committees } \\
\text { (administration) }\end{array}$ & $\begin{array}{l}\text { subnational, } \\
\text { national; } \\
\text { Israel-Jordan; } \\
\text { post-conflict } \\
\text { cross-border } \\
\text { cooperation }\end{array}$ & $\begin{array}{l}\text { General lack of trust, authority and support } \\
\text { among communities at different sides of the } \\
\text { border }\end{array}$ \\
\hline $\begin{array}{l}3 . \\
\text { (i8) }\end{array}$ & Black, 2012 & No & $\begin{array}{l}\text { Chinese and } \\
\text { Japanese } \\
\text { policymakers } \\
\text { (political) }\end{array}$ & $\begin{array}{l}\text { global, national; } \\
\text { China, Japan; } \\
\text { anti-piracy } \\
\text { responses }\end{array}$ & $\begin{array}{l}\text { Piracy in Gulf provides space for powers to } \\
\text { demonstrate their power - as issue is new } \\
\text { and authority is unclear }\end{array}$ \\
\hline $\begin{array}{l}4 . \\
(20)\end{array}$ & $\begin{array}{l}\text { Blavoukos, } \\
2012\end{array}$ & No & $\begin{array}{l}\text { prime minister } \\
\text { C. Simitis, } \\
\text { foreign affairs } \\
\text { minister G.A. } \\
\text { Papandreou } \\
\text { (political) }\end{array}$ & $\begin{array}{l}\text { Supranational; } \\
\text { EU; Greek- } \\
\text { Turkish } \\
\text { rapprochment } \\
\text { (and Greek } \\
\text { foreign policy } \\
\text { shift towards } \\
\text { Turkish inclusion } \\
\text { in EU) }\end{array}$ & $\begin{array}{l}\text { Level of entry barriers facilitates or frustrates } \\
\text { entrepreneurs in any given policy arena. This } \\
\text { dictates the amount of resources needed } \\
\text { to realize policy change. at same time, too } \\
\text { low barriers may discourage activities, as } \\
\text { any return may well be rapidly decreased } \\
\text { by competition from future newcomers } \\
\text { (curvilinear relationship). } \\
\text { Turmoil in Balkan posed security challenges } \\
\text { to Greece. Plus end of bipolarity loosened } \\
\text { NATO constraints over Turkey. Greece for } \\
\text { security reasons felt it should change its } \\
\text { stance. Also EU-enlargement policy became } \\
\text { more welcoming towards Turkey }\end{array}$ \\
\hline $\begin{array}{l}5 . \\
\text { (23) }\end{array}$ & $\begin{array}{l}\text { Boasson, } \\
2014\end{array}$ & $\begin{array}{l}\text { Half section. } \\
\text { Collection: } \\
\text { Document } \\
\text { review, } 26 \\
\text { interviews. } \\
\text { Analysis: } \\
\text { nothing }\end{array}$ & $\begin{array}{l}\text { EU DGs for } \\
\text { environment, } \\
\text { research } \\
\text { (administration) }\end{array}$ & $\begin{array}{l}\text { Supranational; } \\
\text { EU; adoption } \\
\text { of Carbon } \\
\text { Capture and } \\
\text { Storage policy } \\
\text { with NER300 } \\
\text { funding }\end{array}$ & $\begin{array}{l}\text { Signing of Kyoto protocol required coming up } \\
\text { with climate measures. } \\
\text { Commission also shifted attitude in reaction to } \\
\text { growing concern over energy security. }\end{array}$ \\
\hline
\end{tabular}




\section{Strategy}

Trade commissioner Lamy proposed duty-free quota-free policy for Least Developed Countries, EBA, to include sugar. Unrestricted sugar exports would undermine protected, high-priced, EU market regime. Lamy was fully aware of this and used it to put pressure on DG-AGRI

Therefore entrepreneurs engage in coalition building on two spheres: horizontal and vertical. Horizontal: identify cross-border contacts for cooperation in parallel organizations and functions to serve personal and/or organizational interests. Vertically: seek authorization and support from higher level politicians and bureaucrats for cross-border aspects of their local activity.

Organized initiative to facilitate communication between mayors of neighbouring communities and local public. Participated in seminars and outings to indicate needs

Both China and Japan took opportunity to spread certain idea about them as great powers, with different frames

Papandreou gave speech in september 1999 in UN General Assembly to enhance Greek-Turkish relations, because of underlying assumptions that closer entanglement within EU would bring forward series of reforms in Turkey that would eventually necessitate abandonment of aggression in bilateral relationship

Approaching Copenhagen summit and energy security issue used by entrepreneurs to create sense of urgency and frame CCS as solution to these problems.

Linking CCS to renewable energy in the funding mechanism, in order to gain support from CCS sceptics

Touring capitals of EU member states to promote the parliaments amendments to the CCS to create leverage for ideas

\section{Implications \\ Type}

Policy subject (sugar)

Policy entrepreneur subject to decisionmaking in one area may affect causally decisions on that issue in other arenas

Resulted in Policy entrepreneur cooperation and

increased levels of trust
Norm

entrepreneur 
Appendix

5. Data extraction table I: continued

\begin{tabular}{|c|c|c|c|c|c|}
\hline$\#$ & $\begin{array}{l}\text { author, } \\
\text { year }\end{array}$ & Methods & Entrepreneur & $\begin{array}{l}\text { Level, locus, } \\
\text { topic }\end{array}$ & Condition \\
\hline $\begin{array}{l}6 . \\
(24)\end{array}$ & $\begin{array}{l}\text { Boekhorst, } \\
2010\end{array}$ & No & $\begin{array}{l}\text { World Wildlife } \\
\text { Fund for } \\
\text { Nature China } \\
\text { (international } \\
\text { NGO, } \\
\text { subdivision in } \\
\text { China, but not } \\
\text { registered as } \\
\text { Chinese NGO) } \\
\text { (NGO) }\end{array}$ & $\begin{array}{l}\text { subnational, } \\
\text { National, global; } \\
\text { China, Yangtze } \\
\text { River Basin; } \\
\text { Integrated } \\
\text { river basin } \\
\text { management }\end{array}$ & $\begin{array}{l}\text { Difficult to collaborate with national } \\
\text { government and place issues on the agenda, as } \\
\text { in China agenda-setting is limited mainly to the } \\
\text { central government. } \\
\text { I } 998 \text { flood created attention to river } \\
\text { management, and created room for WWF to } \\
\text { act again. }\end{array}$ \\
\hline $\begin{array}{l}7 . \\
(27)\end{array}$ & $\begin{array}{l}\text { Bourblanc, } \\
2014\end{array}$ & No. & $\begin{array}{l}\text { Environmental } \\
\text { Movement } \\
\text { Organization, } \\
\text { ERB (d'eau } \\
\text { et rivieres } \\
\text { de bretagne) } \\
\text { (NGO) }\end{array}$ & $\begin{array}{l}\text { Subnational, } \\
\text { national; } \\
\text { Brittany, France; } \\
\text { Water pollution } \\
\text { (from intensive } \\
\text { agriculture) }\end{array}$ & $\begin{array}{l}\text { Initially, agriculture perceived as very important } \\
\text { sector for regional development, therefore } \\
\text { ERB was hesitant to point to the source for } \\
\text { water pollution (intensive agriculture) and } \\
\text { instead focused primarily on consequence of } \\
\text { water pollution. } \\
\text { But after } 1980 \text { s changed and ERB started } \\
\text { opposing intensive agriculture system. }\end{array}$ \\
\hline
\end{tabular}


WWF used its national and international network to stimulate acceptance and application of IRBM.

Built coalition with Chinese Academy of Sciences and State Forestry Administration. Led to staff training and site listing for protection, but not much impact.

Built coalitions as well with local stakeholders and governments in the river basin. Led to discovery of experts and funding necessary for launching the Living River Program.

Moreover,WWF also established networks internationally by linking up with the CCICED. WWF provided secretariat for IRBM Task Force (which was jointly established with CCICED) WWF managed to incorporate their approach in CCICED recommendations. Also, WWF through its coalition could deliver recommendations to the premier of the state council (without having to pass through ministerial levels).

In parallel, it held close contacts with academic field, led to media coverage in form of special issue in National Chinese Geographic, and articles in China Daily Newspaper, creating awareness in and outside of China.

First brought it to higher administrative levels by bringing criminal charges against leaders of intensive agriculture (and not smaller agriculture actors), and subsequently involving the Dept of Agriculture. DoA drew up first programme to deal with pollution caused by agriculture. but since program did not challenge intensive mode of production, further protest from ERB.

ERB started a juridical battle to try to force the French administration to transpose European legislation into French law.

To keep problem on agenda, ERB started to frame water pollution in terms of nitrate concentration in drinking water and the impact on human health (e.g. in its columns).

ERB appealed to EU authorities to have France's failure to implement binding European legislation (European Directive on to regulate use drinking water from surface water courses in which nitrates exceed certain percentage) condemned. French government convicted in 2001 and 2007, resulting in major pressure from EU to implement substantial changes in agricultural practices.

Since ERB wanted to place blame on Agriculture sector it did not support other local NGO collective (CEP) in their campaign to protest against water delivery services re. nitrates in drinking water, as this would shift attention away from ag sector (as focus on drinking water, not water resources), and towards water service authorities and municipal authorities.

Informed politicians at all levels through field visits, conferences, lectures etcetera to create support and inform stakeholders.

Started pilot projects in local areas who were willing to get along with WWF (because it raised living conditions local inhabitants). WWF organized meetings with local people to explain them about functioning river system (awareness sessions). Organized workshops to come up with alternative income generating activities. Created public support (especially because average household income rose exponentially). China Council for International Cooperation on Environment and Development (CCICED) devoted special taskforce to IRBM,WWF linked up with institution to include recommendations.

Site visits, international conference, publications created visibility and impact.
Led to successful policy Policy entrepreneur change

Policy entrepreneur 
Appendix

5. Data extraction table I: continued

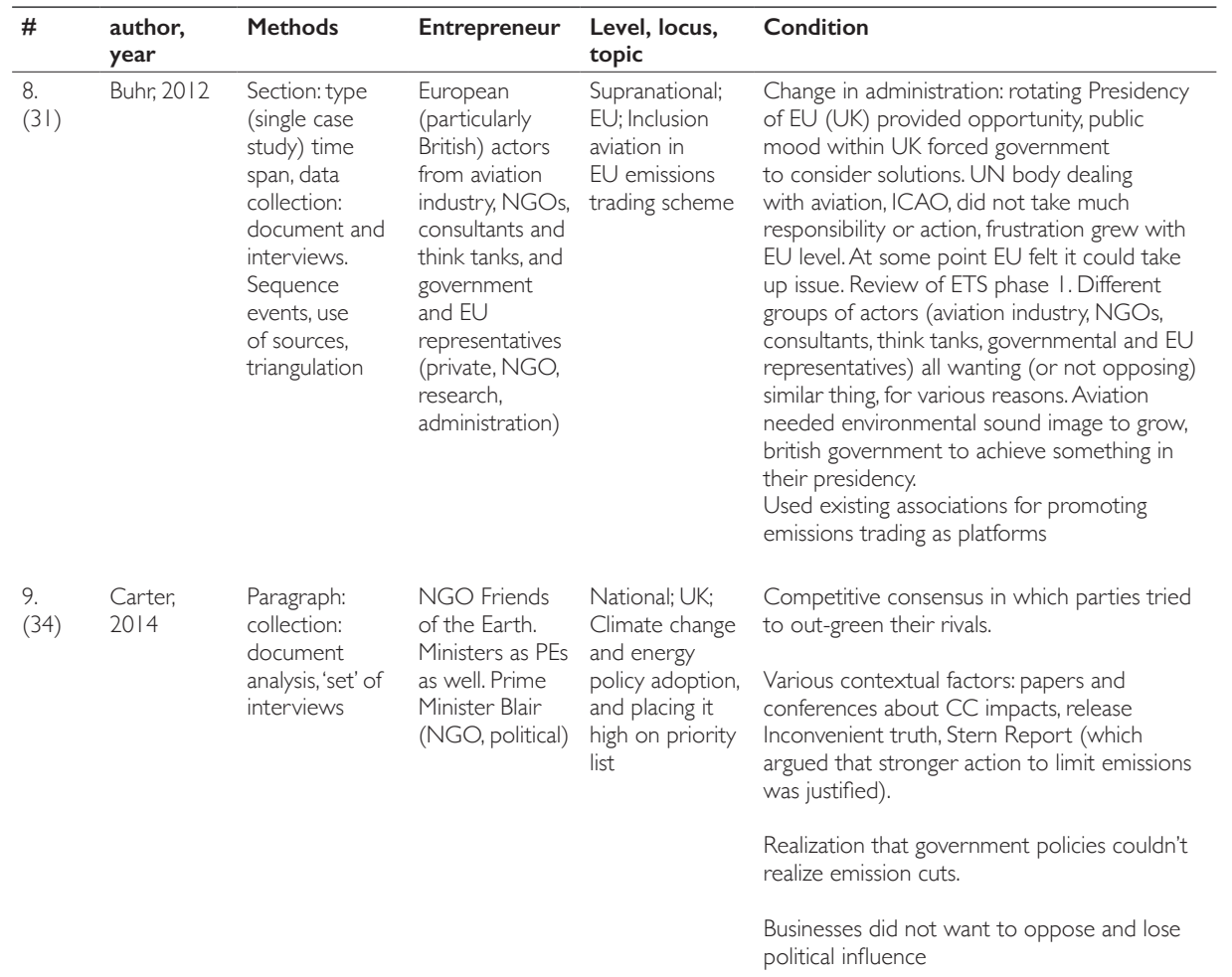


British institutional entrepreneurs used rotating presidency of EU to come up Institutional with policy proposal, and emissions trading was also something the aviation entrepreneur industry could live with.

Entrepreneurs behind proposal linked arguments about emissions trading to norms and values in institutional context to promote preferred policy proposal.

Checked with different actors and felt little/no resistance to plan of emissions trading scheme.

Aviation industry, also as entrepreneur, initially developed proposal for ETS. This was initially developed at UK level and then brought to EU level. Used EU level to gain broader support from wider industry (their growth prospects were partly dependent on environmentally responsible image)

FotE identified the government's failure to deliver emissions reduction targets, Institutional defined a solution in the form of a climate change bill, took Cameron for visit entrepreneurs to Arctic to see impacts of climate change, and eventually won cross-party political support for it.

Tony Blair pushed climate change onto international agenda already before FoE took it up. (G8 and EU presidencies). through Stern report other parties began promoting and framing low carbo economy as opportunity for business.

David Miliband (Secretary of State at DEFRA) created new government institution, Inter Departmental office for Climate Change (OCC) that represented all main departments affecting GHG emissions, including environment, energy, transport, business, overseas development, foreign office, cabinet office, treasury. Was given responsibility for developing and passing climate change bill (which would normally have been undertaken by internal DEFRA team). As such different (conflicting) interests together to generate consensus. Effect was noticeable undermining of treasury's formerly influence

David Miliband took issue of EU ETS cap and turned it into major symbolic battle within cabinet on governments environmental credentials

The third venue shift was the creation of a new ministry, the Department for Energy and

Climate Change (DECC), in October 2008. It combined the energy and climate portfolios

previously split between the DTI (renamed the Department for Business, Enterprise and

Regulatory Reform (BERR)) and DEFRA, with the aim of institutionalizing a coordinated approach to CCEP. Under an energetic Secretary of State, Ed Miliband, DECC quickly

adopted ambitious emissions reductions at home and abroad as its main priority and

began to develop the policies required by the EU and CCA targets. 
Appendix

5. Data extraction table I: continued

\begin{tabular}{|c|c|c|c|c|c|}
\hline$\#$ & $\begin{array}{l}\text { author, } \\
\text { year }\end{array}$ & Methods & Entrepreneur & $\begin{array}{l}\text { Level, locus, } \\
\text { topic }\end{array}$ & Condition \\
\hline $\begin{array}{l}10 . \\
(62)\end{array}$ & Diez, 2010 & $\begin{array}{l}\text { Paragraph } \\
\text { in intro: } \\
\text { interviews, type, } \\
\text { number }\end{array}$ & $\begin{array}{l}\text { Advocates of } \\
\text { sexual minority } \\
\text { rights. } 3 \\
\text { individuals in } 2 \\
\text { federal agencies. } \\
\text { Saavedra, } \\
\text { director } \\
\text { National } \\
\text { Center } \\
\text { Prevention } \\
\text { Control HIV/ } \\
\text { AlDS (part } \\
\text { ministry health), } \\
\text { Frenk, Minister } \\
\text { of Health. } \\
\text { Frend and } \\
\text { Saveedra knew } \\
\text { each other well. } \\
\text { Betancourt, } \\
\text { Espindola were } \\
\text { recruited into } \\
\text { senior positions } \\
\text { council. (CSO, } \\
\text { administration) }\end{array}$ & $\begin{array}{l}\text { National, } \\
\text { global; Mexico; } \\
\text { National Anti- } \\
\text { homophobia } \\
\text { Campaign }\end{array}$ & $\begin{array}{l}\text { Public mood: broader, structural social changes } \\
\text { (secularization). Other (non-elected) political } \\
\text { party brought up issue of sexual minorities } \\
\text { in public debate. also human rights part of } \\
\text { the broader issue of human rights, central to } \\
\text { elections. } \\
\text { Also opening up to civil society actors through } \\
\text { democratization. } \\
\text { Presidency of Fox, and resulting opening-up of } \\
\text { policy-making process. Policy entrepreneurs } \\
\text { (who were from civil society previously) } \\
\text { assumed important positions in } 2 \text { federal } \\
\text { agencies. }\end{array}$ \\
\hline $\begin{array}{l}11 . \\
(71)\end{array}$ & Font, 2010 & $\begin{array}{l}\text { Paragraph: } \\
\text { qualitative } \\
\text { design, based } \\
\text { on document } \\
\text { analysis and } \\
\text { interviews } \\
\text { (types } \\
\text { interviewees). }\end{array}$ & $\begin{array}{l}\text { Greenpeace, } \\
\text { WWF-Spain, } \\
\text { SEO/BirdLife, } \\
\text { and the } \\
\text { Confederation } \\
\text { of } \\
\text { Organizations } \\
\text { for } \\
\text { Environmental } \\
\text { Protection } \\
\text { (CODA), } \\
\text { which was in } \\
\text { turn integrated } \\
\text { into the New } \\
\text { Water Culture } \\
\text { Foundation, the } \\
\text { Association of } \\
\text { People Affected } \\
\text { by Large Dams } \\
\text { (COAGRET), } \\
\text { and territorially- } \\
\text { based social } \\
\text { movements } \\
\text { such as the } \\
\text { Association for } \\
\text { the Defense of } \\
\text { the Ebro River. } \\
\text { (NGO) }\end{array}$ & $\begin{array}{l}\text { National; Spain; } \\
\text { Water policy } \\
\text { change }\end{array}$ & $\begin{array}{l}\text { Government turnover gave way to new } \\
\text { policy proposals. Water Framework Directive } \\
\text { requirements (at EU level) and need to } \\
\text { comply with them. } \\
\text { Persistence has been central in putting } \\
\text { forward alternative ideas. } \\
\text { Multiple venues allows for shopping as way of } \\
\text { amplifying concerns and finding institutional } \\
\text { alliances. EU has provided WFD requirements } \\
\text { and complaints system, regularly used by PEs } \\
\text { in water sector. } \\
\text { Different PEs pooled resources in order to } \\
\text { maximize their efforts. }\end{array}$ \\
\hline
\end{tabular}


Official launch of campaign at UN office Mexico, with presence various $\mathrm{NGOs}$, IOs, CSOs by government (promoting)

As a reaction to the debate and to counter opposition to their campaign, entrepreneurs decided to pursue 2 strategies: first, expand alliance they had formed in favour of campaign, by integrating international actors ( $\mathrm{PHO}$ and UNAIDS). Asked them to sign onto the initiative to allow them to present the campaign as a collective initiative. 2 orgs started stating that Mexico had to abide by international recommendations to fight homophobia. (networking, institution)

Assembly held series of consultations, regional fora, and meetings with experts and members of civil society at large. After consultations published report in which members presented antidiscrimination draft bill and recommended establishment of national council tasked with 2 main objectives: ensuring that such law be implemented and promoting more generally a culture of tolerance in the country.

Report was taken over by Fox and sent to Congress without changes

Alliance developed arguments counter opposition and convince government actors and public at large of need campaign, based on 2 frames: 1) homophobia as obstacle to fight aids (based on scientific data) thus involving public health; 2) human rights: prohibited discrimination against homosexuals

Entrepreneurs participated in technical meeting hosted by European Commission

Group of entrepreneurs also frequently provided info and lodged complaints to the European Commission. Also presented petitions and questions to European Parliament, all of which alleged that National Water Plan went against several EU environmental directives (Environmental groups considered that the large-scale infrastructure proposed in the Plan, in particular the Ebro diversion, had negative effects on Special Areas of Conservation and Special Protection Areas that constituted the Natura 2000 Network, and that it would have severe consequences for most water ecosystems).

Variety of social organizations launched intensive networking campaign in Brussels in order to sell ideas opposed to EU financing of the work that was projected in the National Water Plan. These activities led to European Commission contacting Spain's Ministry of Environment to obtain information to decide on its own position. Thereafter send a letter to ministry to express their concern. Thereafter recommended it to produce strategic impact assessment

In 200 I entrepreneurs participated in Blue March to Brussels, where they lodged complaints about the NWP to the European Commission and European Parliament $\rightarrow$ gained media attention $\rightarrow$ to activate resources and gain support

To put pressure on the government of Spain to withdraw the 200 I National Water Plan, different entrepreneurs, Greenpeace, WWF-Spain, SEO/Birdlife, and social movements, launched national and supra-national campaigns that condemned social, economic, and environmental consequences of the plan

Scientific actors as entrepreneurs undertook studies that questioned the Plan, and adviced the European Commission on the plan, including strategic impact assessment, and socio-economic assessment of transfer projects included in plan, to transform dominant policy image. WWF Spain for instance produced environmental assessment for impact projected dams and water transfers and their impact on Natura 2000 sites.

Fierce opposition in first instance from several actors, including US conservative NGO and Catholic Church.

However PEs have not demonstrated sufficient capacities to significantly advance completion water transition. With subsuming ministry environment into ministry ag, other water schemes were introduced and this initiative overshadowed
Policy

entrepreneurs 
Appendix

5. Data extraction table I: continued

\begin{tabular}{|c|c|c|c|c|c|}
\hline \# & $\begin{array}{l}\text { author, } \\
\text { year }\end{array}$ & Methods & Entrepreneur & $\begin{array}{l}\text { Level, locus, } \\
\text { topic }\end{array}$ & Condition \\
\hline $\begin{array}{l}12 . \\
(72)\end{array}$ & $\begin{array}{l}\text { Forbes, } \\
2012\end{array}$ & $\begin{array}{l}\text { Section: } \\
\text { qualitative } \\
\text { methodology, } \\
\text { document } \\
\text { analysis, } \\
\text { interviews. } \\
\text { Analysis: } \\
\text { iterative coding. }\end{array}$ & $\begin{array}{l}\text { senior } \\
\text { managers, } \\
\text { chairs directors } \\
\text { of NHS and } \\
\mathrm{CHSCP} \text { in } \\
\text { Scotland } \\
\text { (administration) }\end{array}$ & $\begin{array}{l}\text { National; } \\
\text { Scotland; Health } \\
\text { and social care } \\
\text { partnerships }\end{array}$ & $\begin{array}{l}\text { Devolution and institutional redesign led } \\
\text { to creation multilevel institutions that have } \\
\text { provided the opportunity for local actors to } \\
\text { influence policy }\end{array}$ \\
\hline
\end{tabular}

\begin{tabular}{|c|c|c|c|c|}
\hline $\begin{array}{l}13 . \\
(75)\end{array}$ & $\begin{array}{l}\text { Gorton, } \\
2005\end{array}$ & $\begin{array}{l}\text { Footnote: } \\
\text { collection: } \\
\text { interviews, } \\
\text { documentation, } \\
\text { learning } \\
\text { workshop and } \\
\text { for what data. } \\
\text { Reference } \\
\text { to other } \\
\text { publication with } \\
\text { more info. }\end{array}$ & $\begin{array}{l}\text { selected } \\
\text { number of } \\
\text { actors from } \\
\text { Ministries, } \\
\text { NGOs, and } \\
\text { academia } \\
\text { became part } \\
\text { of elite int. } \\
\text { networks. } \\
\text { Almonas } \\
\text { Gukauskas } \\
\text { from agriculture } \\
\text { ministry. } \\
\text { professor } \\
\text { Sapek in Poland. } \\
\text { (Political, NGO, } \\
\text { research, } \\
\text { administration) }\end{array}$ & $\begin{array}{l}\text { National, } \\
\text { supranational; } \\
\text { CEEC: Lithuania } \\
\text { (Northern } \\
\text { Lithuanian Karst } \\
\text { region), Poland } \\
\text { (Ostroleka } \\
\text { county), } \\
\text { Slovakia (Corn } \\
\text { Island); Strategic } \\
\text { realignment of } \\
\text { environmental } \\
\text { policy systems } \\
\text { (agriculture } \\
\text { induced water } \\
\text { pollution) }\end{array}$ \\
\hline $\begin{array}{l}14 . \\
(77)\end{array}$ & $\begin{array}{l}\text { Grinstein, } \\
2009\end{array}$ & $\begin{array}{l}\text { Section. Case } \\
\text { study approach. } \\
\text { (?) Interviews } \\
\text { and survey. } \\
\text { Use of sources. } \\
\text { Analysis: } \\
\text { iterative } \\
\text { process, } \\
\text { descriptive } \\
\text { statistics. }\end{array}$ & $\begin{array}{l}\text { Michael } \\
\text { Sherraden, } \\
\text { author; Robert } \\
\text { Friedman, } \\
\text { founder } \\
\text { Corporation } \\
\text { for Enterprise } \\
\text { Development } \\
\text { (CFED), Ray } \\
\text { Boshara, } \\
\text { crafter original } \\
\text { legislation IDA } \\
\text { (administration, } \\
\text { private) }\end{array}$ & $\begin{array}{l}\text { National; USA; } \\
\text { Individual } \\
\text { Development } \\
\text { Accounts } \\
\text { (IDA) - to } \\
\text { promote social } \\
\text { and economic } \\
\text { development } \\
\text { among } \\
\text { economically } \\
\text { disadvantaged } \\
\text { populations }\end{array}$ \\
\hline
\end{tabular}


Conceptual: spanning levels is required to realise change. 'boundary bridging' as adjacent fields influencing each other through alternative viewpoints and practices. Need for actors to pass on these ideas - entrepreneurs.

I) microlevel institutional work: opportunity recognition: reframing of health issues as stemming from socio-economic inequalities, making it a social issue as well. As such, integration was encouraged and current policy framed as failure. Entrepreneurs were also within institutions (NHS board, city council). agreed that integration would address problems, only however not sure what it should look like.

2) mesolevel inst work: designing new inst field: design to make NHS and city council work on an equal basis.

3) macro-level inst work: legitimizing new institutional field: at 2 levels, locally w/ city NHS members and professions, and nationally w/ executive civil servants and ministers. had to negotiate and discuss a lot to convince people of added value

Gutkauskas (Lithuania) worked for min ag and dept land use and reclamation, and brought together scientists to prepare programme on groundwater protection and sustainable agriculture, program accepted and funded by government in 1993

Also founded NGO Tatula Fund, which he used to address conferences and meetings, also internationally, and in EU-context. This internationalized local problems.

In Poland, research carried out by Institute for Land Reclamation and Grassland Farming (IMUZ), funded by US Environmental Protection Agency, under leadership of PE Sapek. Findings were framed as threat to human health, requiring investments for improvement animal waste management. This led to many funds coming in

Entrepreneurs started short-term demonstration project in 3 states, to overcome reluctance from public welfare policy (demonstrating, support)

Efforts of non-profit orgs were critical in moving IDA policy dialogue to national level, by using national platforms at conferences, web sites, networking expertise to disseminate pivotal research findings emerging from American Dream Policy Demonstration (ADD), a large-scale multi-site IDA demonstration project. (networking/promoting, support)

\section{Creation new} institution, the CHSCP which crossed both institutions, which at first was difficult due to competition and leadership issues but was overcome through legitimating CHSCP with executive ministers
Institutiona

entrepreneurship 
5. Data extraction table I: continued

\begin{tabular}{|c|c|c|c|c|c|}
\hline$\#$ & $\begin{array}{l}\text { author, } \\
\text { year }\end{array}$ & Methods & Entrepreneur & $\begin{array}{l}\text { Level, locus, } \\
\text { topic }\end{array}$ & Condition \\
\hline $\begin{array}{l}15 . \\
(82)\end{array}$ & $\begin{array}{l}\text { Hammond, } \\
2013\end{array}$ & $\begin{array}{l}\text { Section. Single } \\
\text { case study. } \\
\text { Collection: } \\
\text { document and } \\
\text { interviews. } \\
\text { Identification } \\
\text { interviewees, } \\
21 \text { interviews, } \\
100 \text { docs. } \\
\text { Analysis: coding } \\
\text { (deductive, but } \\
\text { iterative) }\end{array}$ & $\begin{array}{l}\text { Minister Duoji } \\
\text { Cairan from } \\
\text { Civil Affairs } \\
\text { (political) }\end{array}$ & $\begin{array}{l}\text { Subnational, } \\
\text { national; China; } \\
\text { Minimum } \\
\text { livelihood } \\
\text { guarantee } \\
\text { system }\end{array}$ & $\begin{array}{l}\text { As Minister Duoji was not in position to } \\
\text { provide legislative or fiscal support, hence had } \\
\text { to stimulate other institutions to do so. } \\
\text { Chinese system is fragmented which provides } \\
\text { opportunities for bureaucracy at different } \\
\text { levels, to influence policy }\end{array}$ \\
\hline $\begin{array}{l}16 . \\
(95)\end{array}$ & $\begin{array}{l}\text { lusmen, } \\
2012\end{array}$ & $\begin{array}{l}\text { Several } \\
\text { sentences: } \\
\text { qualitative } \\
\text { interviews, } \\
\text { documentary } \\
\text { analysis, } \\
\text { analysis policy } \\
\text { instruments }\end{array}$ & $\begin{array}{l}\text { Franco Frattini, } \\
\text { then EU } \\
\text { Commissioner } \\
\text { for Justice, } \\
\text { Freedom } \\
\text { and Security. } \\
\text { (political) }\end{array}$ & $\begin{array}{l}\text { Supranational; } \\
\text { EU; Children's } \\
\text { rights }\end{array}$ & $\begin{array}{l}\text { Vacuum in EU internal dimension on } \\
\text { children's rights, applied it to Romanian level. } \\
\text { This feedbacked on EU level, causing an } \\
\text { incremental and slow-moving policy evolution } \\
\text { of children's rights at EU-level. Which was } \\
\text { promoted by Commissioner for Justice. } \\
\text { PE learned from Romania, and used that for } \\
\text { EU }\end{array}$ \\
\hline $\begin{array}{l}17 . \\
(105)\end{array}$ & $\begin{array}{l}\text { Kugelberg, } \\
2012\end{array}$ & $\begin{array}{l}\text { Section: } \\
\text { Qualitative: } \\
\text { collection: } 18 \\
\text { interviews, } \\
\text { scientific docs, } \\
\text { policy docs. } \\
\text { Analysis: coding. } \\
\text { Triangulation } \\
\text { and validation }\end{array}$ & Any & $\begin{array}{l}\text { National; } \\
\text { Slovenia; Food } \\
\text { and nutrition } \\
\text { policy }\end{array}$ & \\
\hline $\begin{array}{l}18 . \\
(117)\end{array}$ & $\begin{array}{l}\text { Maltby, } \\
2013\end{array}$ & $\begin{array}{l}\text { Several } \\
\text { sentences: } \\
\text { collection: } \\
\text { scientific docs, } \\
16 \text { interviews, } \\
\text { policy docs. }\end{array}$ & $\begin{array}{l}\text { EU European } \\
\text { Commission } \\
\text { (administration) }\end{array}$ & $\begin{array}{l}\text { Supranational; } \\
\text { EU; EU energy } \\
\text { security policy } \\
\text { (integration) }\end{array}$ & $\begin{array}{l}\text { (I) a trend of increasing energy import } \\
\text { dependence; } \\
\text { (2) increasing prices; (3) EU enlargement } \\
\text { and (a) historical relations with Russia/USSR } \\
\text { and, (b) relatively higher energy import } \\
\text { dependence; } \\
\text { (4) gas supply disruptions, leading to } \\
\text { undermining of EU energy security, possibilities } \\
\text { for European Commission } \\
\text { Conceptual: while each Commission DG has } \\
\text { own owrlapping, but distinct purview within } \\
\text { Council's often general aims and direction, in } \\
\text { this case there are synergies between DGs } \\
\text { trade, External Relations, Energy, and Climate } \\
\text { on interlinking issues related to energy. } \\
\text { Strategically minded actors frame initiatives to } \\
\text { fit with certain institutional venues. Different } \\
\text { venues may have different priorities and } \\
\text { perceive EU concern differently, yet solutions } \\
\text { need not be mutually exclusive. } \\
\text { Commission is on path-dependent pro- } \\
\text { integration mission }\end{array}$ \\
\hline
\end{tabular}


Meanwhile, he also intervened in the development of the policy in the province. He suggested the city of Dalian establish an MLG system to provide an example - which happened. Dalian served as an example for other cities throughout China. Through example served to expand the experience, methods and support that could be drawn upon.

Duoji shifted policy onto national agenda and pushed for implementation, by mentioning it in speech at Tenth National Civil Affairs Congress (because, according to the author, he as a minister was unable to provide legislative or fiscal support for the policy)

Commission officials in DG ELARG highlighted how the Romanian case has provided them with knowledge and expertise in key principles and implementation mechanisms underlying the UNCRC (demonstrate resources)

Frattini used the example of Romania and its child-rights policy (which provided knowledge and expertise) to find support for an EU-wide policy on children's rights (demonstrating - support)

Aileen Robertson, (state secretary for public health) individual responsible for advising countries within WHO European Region on public health and national nutrition policy, proposed to undertake Health Impact Assessment from the CAP (EU) to convince the Ministry of Agriculture, Food and Forestry to support the food and nutrition plan, and eventually brought together ministry health and ministry agriculture, food, forestry because their objectives were met and CAP could fund (resources - institution/ networking)

Conceptual: while each Commission DG has own overlapping, but distinct purview within Council's often general aims and direction, in this case there are synergies between DGs trade, External Relations, Energy, and Climate on interlinking issues related to energy. Strategically minded actors frame initiatives to fit with certain institutional venues. Different venues may have different priorities and perceive EU concern differently, yet solutions need not be mutually exclusive.

In its communications the Commission increasingly referred to energy security as supranational issue to be solved at Commission level

UK's EU presidency study concluded that stronger EU energy policy cooperation was necessary to improve security of supplies. This was to secure national gas security, as UK had always been exporter but then became net importer of gas (resources) - whereas UK had been one of most important opposers of joint policy

Commission has created multiple different policy frames to make energy legislation at supranational level viable and enhance support for a common energy policy: security, environmental protection (framing - institution/ support)

Identification surpranational scale of energy governance as necessary solution to policy problem is one which is socially constructed.

Commission utilized expert studies to establish knowledge-based authority on the issue of energy
Would it have stayed

a local experiment,

MLG would have never

become widespread acknowledged
Policy

entrepreneurs 
5. Data extraction table I: continued

\begin{tabular}{|c|c|c|c|c|c|}
\hline \# & $\begin{array}{l}\text { author, } \\
\text { year }\end{array}$ & Methods & Entrepreneur & $\begin{array}{l}\text { Level, locus, } \\
\text { topic }\end{array}$ & Condition \\
\hline $\begin{array}{l}19 . \\
(122)\end{array}$ & $\begin{array}{l}\text { Meijerink, } \\
2010\end{array}$ & $\begin{array}{l}\text { Some } \\
\text { sentences: } \\
\text { comparative } \\
\text { case study, } \\
\text { document } \\
\text { analysis and } \\
\text { interviews }\end{array}$ & Various & $\begin{array}{l}\text { Various; Various; } \\
\text { water policy } \\
\text { transitions }\end{array}$ & $\begin{array}{l}\text { Complex decision-making processes in } \\
\text { which many different parties and levels of } \\
\text { government are involved usually feature a } \\
\text { wide range of venues where change agents } \\
\text { may place their issue on the agenda or seek } \\
\text { support for their ideas. Institutional complexity } \\
\text { and redundancy is not dysfunctional. Provides } \\
\text { alternative platforms for deliberation and } \\
\text { policy influence at multiple levels. More } \\
\text { centralized and less democratic government } \\
\text { systems offer other opportunities. Once PEs } \\
\text { have managed to gain access to and support } \\
\text { from central decision-makers, they may be } \\
\text { quite effective realizing policy change in such } \\
\text { systems. }\end{array}$ \\
\hline $\begin{array}{l}20 . \\
(13 \mid)\end{array}$ & $\begin{array}{l}\text { Mintrom, } \\
1997\end{array}$ & $\begin{array}{l}\text { Section: } \\
\text { collection, } \\
\text { analysis. Event } \\
\text { history analysis, } \\
\text { survey and } \\
\text { statistics }\end{array}$ & $\begin{array}{l}6 \text { policy think } \\
\text { tank, } 3 \text { business, } \\
5 \text { teaching, } \\
2 \text { grassroots } \\
\text { groups, } 3 \\
\text { governors, } 7 \\
\text { state legislator } \\
\text { (Research } \\
\text { Private } \\
\text { Political } \\
\text { Administration } \\
\text { NGO) }\end{array}$ & $\begin{array}{l}\text { National; USA; } \\
\text { state legislative } \\
\text { consideration } \\
\text { and approval of } \\
\text { school choice } \\
\text { (educational } \\
\text { reform). }\end{array}$ & \\
\hline $\begin{array}{l}21 \\
(134)\end{array}$ & Miskel, 2004 & $\begin{array}{l}\text { Section. } \\
\text { Collection, } \\
\text { Interviews, } \\
\text { archival docs. } \\
\text { Analysis: social } \\
\text { network } \\
\text { analysis, content } \\
\text { analysis }\end{array}$ & $\begin{array}{l}\text { National } \\
\text { Research } \\
\text { Council, } \\
\text { Learning } \\
\text { First Alliance, } \\
\text { American } \\
\text { federation } \\
\text { Teachers, } \\
\text { National } \\
\text { Reading Panel. } \\
\text { I powerful } \\
\text { representatives } \\
\text { Lyon, chief } \\
\text { in National } \\
\text { Institute for } \\
\text { Child Health } \\
\text { and Human } \\
\text { Development, } \\
\text { Congressman } \\
\text { Goodling. } \\
\text { (administration) }\end{array}$ & $\begin{array}{l}\text { National; USA; } \\
\text { Reading First } \\
\text { initiative in the } \\
\text { US in } 2001, \text { to } \\
\text { raise reading } \\
\text { achievement }\end{array}$ & $\begin{array}{l}\text { New staff is new opportunities for new } \\
\text { policies. What enabled the promotion of } \\
\text { reading policies was that traditional interests } \\
\text { granted the new government a so-called } \\
\text { 'honeymoon period'; moreover, president and } \\
\text { staff already had experience, commitment } \\
\text { and success with the initiative by running } \\
\text { trial in Texas; strong desire by congressional } \\
\text { leaders to reverse their failures and actually } \\
\text { reauthorize ESEA. } \\
\text { However possible downside is that ideas } \\
\text { developed in small leadership arena violates } \\
\text { expectations for involvement and undermines } \\
\text { implementation efforts of new policy }\end{array}$ \\
\hline
\end{tabular}


Example smaller scale implementation to gain experience with the proposed policy and demonstrate feasibility and benefits of newly proposed approaches (such as Plan Stork in the Netherlands or floodplain restoration in Bodrogköz area before it was adopted at the national level)

a minister in Indonesia purposefully moved a specific department from one ministry to another in order to minimize the influence of the conservative old guard to enable smoother processes.

Donor organizations are in position to impose change through formulation of conditions to funding.

WWF in China managed to gain support for ecosystem restoration projects by addressing economic needs of the local population at the same time.

Manipulating venues to have their own ideas or their coalition represented where policy-relevant issues are discussed, and bypass those who resist the change proposed.

Venue-shopping: for local initiatives to be scaled up, they need to be linked to higher level

Networking across state lines for I) learning about details of innovations elsewhere (and gain expertise) this can increase the credibility of the entrepreneur, because they can more readily give authoritative-sounding responses to questions or objections raised concerning proposed policy innovation; 2) draw upon experts from other states to give testimony on earlier experiences with policy innovation; 3) what strategies are successful in other states for selling particular innovation

Bush and his team used their experience from implementing a reading first initiative in Texas to claim the attention of Congress, with well-developed ideas for education
Policy

entrepreneurs

Policy

entrepreneurs
Involving multiple arenas in large networks sometimes may be too cumbersome and overloaded for collective policy actions. Small leadership arenas or circles within larger networks may attain desired policy objectives in a more effective and efficient manner 
Appendix

5. Data extraction table I: continued

\begin{tabular}{|c|c|c|c|c|c|}
\hline$\#$ & $\begin{array}{l}\text { author, } \\
\text { year }\end{array}$ & Methods & Entrepreneur & $\begin{array}{l}\text { Level, locus, } \\
\text { topic }\end{array}$ & Condition \\
\hline $\begin{array}{l}22 . \\
(136)\end{array}$ & $\begin{array}{l}\text { Mukhtarov, } \\
2013\end{array}$ & $\begin{array}{l}\text { Subsection: } \\
\text { case study. } \\
\text { Collection: } \\
64 \text { qualitative } \\
\text { interviews, } \\
\text { secondary } \\
\text { sources. }\end{array}$ & $\begin{array}{l}4 \text { major } \\
\text { groups: I) local } \\
\text { communities; } \\
\text { 2) government } \\
\text { agencie; 3) } \\
\text { transnational } \\
\text { actors; 4) } \\
\text { regional and } \\
\text { national level } \\
\text { civil society } \\
\text { orgs. UNDP. } \\
\text { GEF, IUCN. } \\
\text { (CSO } \\
\text { Citizens } \\
\text { administration) }\end{array}$ & $\begin{array}{l}\text { Subnational; } \\
\text { Vietnam, Ba Be } \\
\text { and Na Hang } \\
\text { areas; neoliberal } \\
\text { discourses } \\
\text { of water } \\
\text { management, } \\
\text { integration } \\
\text { Ba BE and } \\
\text { Na Hang into } \\
\text { single nature } \\
\text { conservation } \\
\text { complex }\end{array}$ & \\
\hline
\end{tabular}


Conceptual: identify (I) scale-based strategies, emphasize importance to target narratives at multiple venues across scales of governance, construct problems and solutions as pertinent to certain geographical scale, engage in networking and coalition-building that span scales of governance. (2) meaning-based strategies, underline importance of developing ideas and linking them to narratives and dominant ideas in policy setting in quest for legitimacy, and presenting them in politically palatable way. (3) context-based strategies, imply necessity to understand context $n$ which narratives are advanced and may involve enrolling some actors in coalitions while excluding others, and keeping alert to opportunities to advance opportunities at particular time and place

Managing director of PARC project Fernando Potess established links with government agencies, provincial departments, as well as international NGOs (IUCN) to secure a broad base of supporters for the project $\rightarrow$ resulted in establishment of management board for BA BE and $\mathrm{Na} \mathrm{Hang}$, and $\rightarrow$ numerous pilot projects introducing agro-forestry, community-based resource planning and the basic PA infrastructure investment.

(framing) PARC proposed to approach the 2 protected sites as an integrated national park, however this was met with reluctance from the provincial authorities who did not want to share authority. Also competition between which level would get authority over certain jurisdiction (thus not successful!)

Link with IUCN $\rightarrow$ recommend implementation at UNESCO World Heritage (support)
Working in a different arena, such as implementing PES in

Vietnam local area, provides constraints because different context gives different understanding to concept. The accountability of the coalition of transnational policy entrepreneurs and the national government may raise questions, and neither international nor Vietnamese civil society organizations provide sufficient scrutiny to their work.

Trust

The proposal to integrate two different protected sites into one was met with reluctance and fear of losing turf. Hence did not make it.

Linking together 2 government agencies involved with responsibilities environmenta protection and forestry respectively created institutional confusion in joint management.

Implementing international approach in local context means adapting it to local specificities. In the context of Vietnam this meant that the program was tailored to fit. That is, where PES is considered voluntary mechanism, it was presented as mandatory instrument to raise additional finances. Moreover, level of payment was prescribed by government, whereas it should be determined by market
Policy

entrepreneurs 
Appendix

5. Data extraction table I: continued

\begin{tabular}{|c|c|c|c|c|c|}
\hline$\#$ & $\begin{array}{l}\text { author, } \\
\text { year }\end{array}$ & Methods & Entrepreneur & $\begin{array}{l}\text { Level, locus, } \\
\text { topic }\end{array}$ & Condition \\
\hline $\begin{array}{l}23 . \\
(143)\end{array}$ & $\begin{array}{l}\text { Newman, } \\
2008\end{array}$ & $\begin{array}{l}\text { No. Process- } \\
\text { tracing } \\
\text { mentioned. }\end{array}$ & $\begin{array}{l}\text { National } \\
\text { data privacy } \\
\text { authorities } \\
\text { (created by } \\
\text { earlier domestic } \\
\text { legislation) } \\
\text { (administration) }\end{array}$ & $\begin{array}{l}\text { Supranational, } \\
\text { national; EU; } \\
\text { EU manage } \\
\text { transnational } \\
\text { civil liberties } \\
\text { by adopting } \\
\text { data privacy } \\
\text { directive I995 } \\
\text { (and how issue } \\
\text { transferred } \\
\text { from domestic } \\
\text { to supranational } \\
\text { level) }\end{array}$ & $\begin{array}{l}\text { Fear with national privacy authorities that } \\
\text { transnational data flows would harm privacy } \\
\text { citizens. If subset of EU countries did not pass } \\
\text { data privacy rules, underregulated nations } \\
\text { could potentially become data havens, with } \\
\text { firms circumventing national stricter rules. } \\
\text { Lack of knowledge with the EU (and member } \\
\text { states), due to severe budget constraints, } \\
\text { provided opportunity for transnational actors } \\
\text { to jump in and influence the debate. } \\
\text { Authority within the European Union is } \\
\text { distributed simultaneously across a number of } \\
\text { overlapping institutional jurisdictions. Power } \\
\text { relations among levels are not necessarily } \\
\text { discrete or subordinate. This structure of the } \\
\text { European Union opens up access points for } \\
\text { policy entrepreneurs. } \\
\text { Network power derived from patterns } \\
\text { of information flows and delegated } \\
\text { authority within network, as well as from } \\
\text { legitimacy network enjoys by creating ties to } \\
\text { constituencies and other organizations. }\end{array}$ \\
\hline
\end{tabular}

Moreover, horizontal networks amplify effect both information asymmetries and domestic delegation. Much larger framing effect in european network of commissions than e.g. commission of spain.

Vertical ties solidify importance of particular information advantage. Enhance ability transgovernmental actors to make their preferences known and control agenda formation.

Level of issue complexity will affect the ability of well-resourced transgovernmental actors to play an active role in agenda setting and policy mediation - when issue highly complex, transgovernmental actors well-positioned to use their expertise and information advantage to define and frame terms of the policy agenda. In less technical fields, policymakers less willing to listen to transgovernmental actors. 


\begin{tabular}{lll}
\hline Strategy & Implications & Type \\
\hline National privacy experts lobbied European Commission, little success. & $\begin{array}{l}\text { Trans-governmental } \\
\text { actors rarely have } \\
\text { formal power in } \\
\text { supranational decision- } \\
\text { making process. They } \\
\begin{array}{l}\text { Only when they became institutionalized groups of sub-state actors with } \\
\text { domestic authority }\end{array}\end{array}$ & $\begin{array}{l}\text { must rely on informal } \\
\text { tools to shape agendas, } \\
\text { German data privacy agency organized conference for data privacy }\end{array}$ \\
$\begin{array}{l}\text { commissioners in Europe } \rightarrow \text { debating pressing issues, share information, } \\
\text { discuss best practices, release joint resolutions } \rightarrow \text { establish working groups } \\
\text { develop collaborative policy initiatives; formulated proposal for EU reform }\end{array}$ & $\begin{array}{l}\text { mobilize support for } \\
\text { their interests. Use } \\
\begin{array}{l}\text { Trans-governmental network of data privacy authorities framed issue of } \\
\text { supranational data privacy protection as prerequisite for further market } \\
\text { and administrative integration in Europe to get their support (and making it } \\
\text { transnational instead of domestic issue). They played on symbolic importance } \\
\text { of the single market to both Commission and single member states }\end{array} \\
\text { delegated authority, } \\
\text { network ties }\end{array}$ \\
$\begin{array}{l}\text { Trust } \\
\end{array}$
\end{tabular}

Data authorities threatened to block trans-border data flows, changing the regulatory reversion point (that is, changing regulatory status-quo that would exist in absence supranational legislation, altering cost-benefit to other policymakers of inaction) to create support for their proposals 
Appendix

5. Data extraction table I: continued

\begin{tabular}{|c|c|c|c|c|c|}
\hline$\#$ & $\begin{array}{l}\text { author, } \\
\text { year }\end{array}$ & Methods & Entrepreneur & $\begin{array}{l}\text { Level, locus, } \\
\text { topic }\end{array}$ & Condition \\
\hline $\begin{array}{l}24 . \\
(148)\end{array}$ & $\begin{array}{l}\text { Palmer, } \\
2015\end{array}$ & $\begin{array}{l}\text { Subsection: } \\
\text { collection: } 33 \\
\text { interviews }\end{array}$ & $\begin{array}{l}\text { Policy official X } \\
\text { (administration) }\end{array}$ & $\begin{array}{l}\text { Supranational; } \\
\text { EU; EU } \\
\text { transport } \\
\text { biofuels policy } \\
\text { (Biofuels } \\
\text { Directive } 2003 \\
\text { and Renewable } \\
\text { Energy } \\
\text { Directive 2009) }\end{array}$ & \\
\hline $\begin{array}{l}25 . \\
(149)\end{array}$ & $\begin{array}{l}\text { Perkmann, } \\
2007\end{array}$ & $\begin{array}{l}\text { Section. Case } \\
\text { study, collection: } \\
23 \text { interviews, } \\
\text { historic } \\
\text { accounts, policy } \\
\text { documentation. } \\
\text { Analysis: } \\
\text { narrative } \\
\text { account, coding, } \\
\text { periodization } \\
\text { technique. }\end{array}$ & $\begin{array}{l}\text { Euroregions. } \\
\text { (for } \\
\text { coordinating } \\
\text { policies with } \\
\text { counterparts } \\
\text { across the } \\
\text { borders). } \\
\text { (administration) }\end{array}$ & $\begin{array}{l}\text { supranational, } \\
\text { national; EU; } \\
\text { establishing } \\
\text { Euroregions }\end{array}$ & $\begin{array}{l}\text { Emerging fields offer scope for institutional } \\
\text { entrepreneurship (transnational, CoE, EU). } \\
\text { Maturing fields place limits on PEship. } \\
\text { They engaged in cross-border collaboration } \\
\text { to improve their advocacy impact on central } \\
\text { government and european agencies. } \\
\text { Findings suggest that emerging fields } \\
\text { offer considerable scope for institutional } \\
\text { entrepreneurship, therefore entrepreneurs } \\
\text { shifted focus from intergove, to CoE to EU } \\
\text { as a new emerging field would occur. Field } \\
\text { switching as solution }\end{array}$ \\
\hline
\end{tabular}


European Commission encouraged use of biofuels by linking it to existing problems within European Union, in tripod style approach: said that biofuels production may be of particular interest under CAP for creating new economic resources and preserving employment in agricultural community; in addition to mitigating GHGs and enhance energy security.

Depicted biofuels as only readily available means of reducing road transport GHG emissions, and depicting reduction of road transport GHG emissions extremely difficult without biofuels (whereas in reality alternative means were available)

Official X criticized studies that showed effects on land-use as poor quality

EUREGIO actors engaged in various strategies: ( I ) interactional projects aimed at bringing together actors previously not connected, from different municipalities, with objective of mobilizing resources from external agencies such as national governments.

(2) AEBR presented its case of cross-border collaboration to politicians in the European Parliament by framing Euregions within wider discourse of European integration: euregions as constituting integration on small scale and building europe from below $\rightarrow$ border regions explicitly mentioned in European Constitutional Treaty.

(3) also target local politicians and civil servants. Installed 'observatory' with branches at various european locations, and sought out speaking and consulting engagements actoss europe: 80 workshops held, 60 reports published - all framing euregion as european integration.

Thus addressed 3 different fields: intergovernmental relationships: germany netherlands; CoE and EU. All have different characteristics
Biofuels have proven

attractive at eu

level through their

purported ability to

reduce $\mathrm{GHG}$ s, enhance

energy security,

and stimulate rural

development.

But then realization

that biofuels had

negative side effects,

for instance in indirect

land use change

(ILUC).

Institutional

entrepreneur 
Appendix

5. Data extraction table I: continued

\begin{tabular}{|c|c|c|c|c|c|}
\hline$\#$ & $\begin{array}{l}\text { author, } \\
\text { year }\end{array}$ & Methods & Entrepreneur & $\begin{array}{l}\text { Level, locus, } \\
\text { topic }\end{array}$ & Condition \\
\hline $\begin{array}{l}26 . \\
(150)\end{array}$ & Pralle, 2006 & $\begin{array}{l}\text { Few sentences. } \\
\text { Case study, } \\
\text { scientific } \\
\text { literature, } \\
\text { examination } \\
\text { media coverage, } \\
\text { government } \\
\text { docs, interviews }\end{array}$ & $\begin{array}{l}\text { No definition } \\
\text { nor description }\end{array}$ & $\begin{array}{l}\text { National, } \\
\text { subnational; } \\
\text { Canada, } \\
\text { Hudson, } \\
\text { Quebec; passing } \\
\text { bylaw to restrict } \\
\text { the nonessential } \\
\text { use of lawn } \\
\text { and garden } \\
\text { pesticides as } \\
\text { precautionary } \\
\text { principle } \\
\text { in Hudson, } \\
\text { Canada }\end{array}$ & $\begin{array}{l}\text { Mistakes of one side may create opportunities } \\
\text { for others. } \\
\text { Venue shopping not always rational, some also } \\
\text { do not see opportunities or do not want to } \\
\text { go into certain policy arenas. } \\
\text { Different political systems offer different } \\
\text { opportunities for venue shopping. Canada, } \\
\text { with mixed system of parliamentary } \\
\text { government and federa structure has limited } \\
\text { opportunities to shop venues horizontally, } \\
\text { because of dominance executive branch and } \\
\text { relatively weak judiciary. }\end{array}$ \\
\hline
\end{tabular}

Might provide opportunities for vertical venue shopping, play different levels of government.

Schattsneider: one of most remarkable developments in recent american politics is extent to which federal, state and local governments have become involved in doing same kinds of things in large areas of public policy, so that it is possible for contestants to move freely from one level of government to another in an attempt to find level at which they might try most advantageously to get what they want 


\begin{abstract}
Strategy
Conceptual: Issue redefinition: shifting not only image of issue but also the basis for considering those issues - what I call policy principles: core values, beliefs, or guidelines attached to policies that help direct decision-making. Venue shopping searching for alternative policy arenas and efforts to move decision-making authority to new venues. Keeping issues out of venues they would rather not participate in as well as move decision-making to new arenas. Successful entrepreneurs may force opponents to compete in arenas where opponents are at disadvantage or to expend resources waging battles in multiple venues when they would prefer to concentrate on just one.
\end{abstract}

Issue definition and venue shopping often go hand in hand.

PEs might try and redefine an issue to move consideration of it into new policy venue, where decisions, rules, norms, procedures differ. Moving seemingly local issue to international policy arena, for example, requires redefining issue to emphasize global implications and importance.

Cities are sensitive to what other cities do. Advocacy groups in cities must form national networks to take advantage of openness provided by federal structures; sharing of info and campaign expertise among cities facilitates diffusion of progressive policies.

Different environmental organizations, both regional and national united and launched Campaign for Pesticides Reduction (CPR). Shared resources and info about campaigns through internet, email and person.

Also environmental, labour and health organizations linked up to map the various risks of the use of pesticides.

Redefined use of lawn and garden pesticides in 3 ways: ( 1 ) challenged ideal of entirely weed-free near-perfect lawn - "dandelions are your friend". (2) argument about negative impact of lawn chemicals on children's health sparked chord with general public and were key factor gaining attention to issue; focusing on children to mobilize large segments of population, and because children are positively constructed target populations policymakers often feel pressure to direct policy to them. Trade-off children;'s health and weed-free lawn became powerful frame for rallying public behind bylaws.

(3) involving precautionary principle in debate: policymakers should act to protect human health and environment even in the face of scientific uncertainty.

Hudson, town in Canada, first to assert its jurisdiction over issue of pesticides, functioned as example for activists, who subsequently put issue on other municipal agendas, in addition to the national venue where they were pushing (venue adding instead of venue shopping) pro was that companies were not prepared to fight battle at hundreds of city councils around Canada (and because multiple-level coalition was also at local, this was easy for activists, also they had better access to local politicians)
Implications

Changing definition

issue requires

mobilization of

previously uninterested,

something which is

difficult for small or

resource-poor interest

groups. Savvy groups

will suffer

Court confirmed authority of local governments to pass laws to secure peace, order, good government, health and general welfare in territory municipality, based on idea that policymakers should act to protect human health and environment even in face of scientific uncertainty. This encouraged spread of pesticides bylaws to other municipalities by giving localities green light to regulate in area.

Shifting venues may sometimes backfire on entrepreneurs, e.g. increasing opposition, trigger effective counter mobilization, leading to stalemate and stability.

Sometimes I frame does not replace but complements other, so that mood swings from one to another: e.g. pesticides as threat to health vs pesticides as necessary tool in agricultural production. When new principles are introduced to guide policymaking chance of success is bigger.

Linking of different organizations through network helped to create benefit of broader knowledge, experience and expertise sharing, without which movement would have remained fragmented and small.

\section{Type}

Policy

entrepreneurs 
Appendix

5. Data extraction table I: continued

\begin{tabular}{|c|c|c|c|c|c|}
\hline \# & $\begin{array}{l}\text { author, } \\
\text { year }\end{array}$ & Methods & Entrepreneur & $\begin{array}{l}\text { Level, locus, } \\
\text { topic }\end{array}$ & Condition \\
\hline $\begin{array}{l}27 . \\
(170)\end{array}$ & $\begin{array}{l}\text { Verger, } \\
2012\end{array}$ & $\begin{array}{l}\text { Subsection. } \\
\text { Collection: } \\
\text { Case study, } \\
\text { document } \\
\text { analysis reports, } \\
\text { IO interviews, } \\
\text { observation. }\end{array}$ & $\begin{array}{l}\text { transnational } \\
\text { policy network } \\
\text { of education } \\
\text { experts } \\
\text { strategically } \\
\text { placed in } \\
\text { influential } \\
\text { organizations } \\
\text { (international } \\
\text { orgs, think tanks, } \\
\text { universities, } \\
\text { consultancy } \\
\text { firms - at } \\
\text { interstices } \\
\text { business- } \\
\text { govment- } \\
\text { academia). } \\
\text { located at } \\
\text { interstices } \\
\text { range int. orgs } \\
\text { such as WB, } \\
\text { ADB, IFC, } \\
\text { CfBT. came } \\
\text { together in } \\
\text { WB Economics } \\
\text { of Education } \\
\text { Thematic } \\
\text { Group. (NGO } \\
\text { Research } \\
\text { Private) }\end{array}$ & $\begin{array}{l}\text { Global; global; } \\
\text { promotion } \\
\text { public-private- } \\
\text { partnerships } \\
\text { for education } \\
\text { in low income } \\
\text { countries }\end{array}$ & $\begin{array}{l}\text { (institutional explanation) multi-scalar } \\
\text { approach is required as in globalization era, } \\
\text { agenda setting happens more frequently at } \\
\text { supranational scale, whereas final decisions } \\
\text { re adoption and translation new agendas } \\
\text { in particular contexts are usually taken at } \\
\text { national or subnational scale }\end{array}$ \\
\hline $\begin{array}{l}28 . \\
(17 \mid)\end{array}$ & $\begin{array}{l}\text { Von Heland, } \\
2014\end{array}$ & $\begin{array}{l}\text { Section. } \\
\text { Case study. } \\
\text { Collection: } 50 \\
\text { interviews. } \\
\text { Observation. }\end{array}$ & $\begin{array}{l}\text { I entrepreneur } \\
\text { highlighted } \\
\text { (because } \\
\text { identified } \\
\text { as being } \\
\text { instrumental in } \\
\text { changes by all } \\
\text { interviewees), } \\
\text { locally elected } \\
\text { politician and } \\
\text { community } \\
\text { leader Adhi. } \\
\text { also IE found } \\
\text { in WWF, } \\
\text { TNC, USAID. } \\
\text { (political) }\end{array}$ & $\begin{array}{l}\text { Subnational, } \\
\text { national global; } \\
\text { Wakatobi } \\
\text { national park, } \\
\text { Southeast } \\
\text { Sulawesi, } \\
\text { Indonesia; } \\
\text { Coastal } \\
\text { and marine } \\
\text { resources } \\
\text { stewardship } \\
\text { in Wakatobi } \\
\text { National Park }\end{array}$ & $\begin{array}{l}\text { New decentralization act created vacuum that } \\
\text { NGOs could fill. Their support was critical to } \\
\text { district's ability to pursue strategies. } \\
\text { Yet, sensitivity to context means that the } \\
\text { strategies of institutional entrepreneurs must } \\
\text { be culturally } \\
\text { embedded and address emotional and } \\
\text { spiritual aspects of people's lives. } \\
\text { Citizens were not responsive to idea of MPA } \\
\text { management, hence there was a need to } \\
\text { convince them of pride to be taken in marine } \\
\text { resources, and receive economic benefits in } \\
\text { return for protecting marine resources. }\end{array}$ \\
\hline
\end{tabular}

Moreover, little tourism, which Adhi wanted to increase 
Coalition/network of policy entrepreneurs, strategically placed in influential international organizations, advocate for privatization and ePPP through scientific and technical style.

Policy prescriptions, beyond blueprints, need to inform policymakers about necessary conditions (contextual, material, regulatory etc). this is certainly most challenging aspect for policy entrepreneurs who aspire to prescribe policies aimed at fitting in a broad range of time-place situations

Establishment school for marine conservation, collaborative investment between district government and Ministry of Marine Affairs and Fisheries (again, example of teaming up entrepreneurs for different purposes: whereas the national government used this as a strategy to overcome lack of trained staff to deal with MPAs, for Adhi this was a strategy to ensure the long-term perspective, beyond the electoral interests of politicians. Moreover, school also was a long-term strategy to promote cultural change among not only government institutions but also coastal communities. On top, from national perspective school links to broader national strategy to position Indonesia as leader in ocean issues (president Yudhoyono to initiate CTI, hosting world ocean conference 2009, world coral reef conference 2013)

Adhi and colleagues worked with "Hoga marine research centre" (comanaged by essex university and Operation Wallacea - british ecosystem

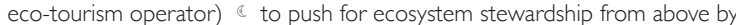
organizations that can inspire and put pressure on local authorities.

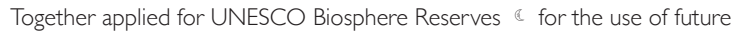
conservation and fund raising activities, and also help institutionalize MPA management and ensure that marine environment remains prioritized by politicians $\mathbb{a}$ and hope that will attract more researchers and improve collaboration with central government.

Adhi from district government partnered with two major NGOs (WWF and TNC) not only to improve park management but also to promote dive tourism, which would be a strong tool to enhance the government's and the public's appreciation of marine biodiversity. Partnership $\mathbb{a}$ also led to investment of money by NGOs in the site
Cosidering Wakatobi's remote location and little political significance in national context, relationship between district and central government is of vital importance for potential to go to scale and influence financial flows and political priorities beyond local. The strategy to form the School for Marine Conservation helped in this regard.
Institutional entrepreneur 
Appendix

5. Data extraction table I: continued

\begin{tabular}{|c|c|c|c|c|c|}
\hline$\#$ & $\begin{array}{l}\text { author, } \\
\text { year }\end{array}$ & Methods & Entrepreneur & $\begin{array}{l}\text { Level, locus, } \\
\text { topic }\end{array}$ & Condition \\
\hline $\begin{array}{l}29 . \\
(172)\end{array}$ & Wejs, 2014 & $\begin{array}{l}\text { Section. } \\
\text { Comparative } \\
\text { case study. } \\
\text { interviews, } \\
\text { document } \\
\text { study. }\end{array}$ & $\begin{array}{l}\text { In one instance } \\
\text { this was } \\
\text { environmental } \\
\text { officer (who } \\
\text { saw strategy } \\
\text { as solution to } \\
\text { harsh climate), } \\
\text { in other this } \\
\text { was employee } \\
\text { in development } \\
\text { and business } \\
\text { unit (who saw } \\
\text { CC in terms } \\
\text { of business } \\
\text { strategy) } \\
\text { (administration) }\end{array}$ & $\begin{array}{l}\text { Subnational; } \\
\text { Norway, } \\
\text { Denmark; local } \\
\text { strategies for } \\
\text { adaptation to } \\
\text { climate change } \\
\text { in Denmark and } \\
\text { Norway }\end{array}$ & $\begin{array}{l}\text { In Denmark, municipal councils in charge } \\
\text { of spatial planning and sector plans, many } \\
\text { opportunities for CCA. In Norway also power } \\
\text { for municipal government to address CCA. } \\
\text { Local governments operate in an institutional } \\
\text { void, as they are not supported or backed } \\
\text { by central government (vertical networks) } \\
\text { for CCA measures. Therefore they call in } \\
\text { expertise from other institutions such as } \\
\text { research centres, universities etc. opening up } \\
\text { possibilities for PEs. } \\
\text { In both municipalities A and C, the importance } \\
\text { of network engagement and, } \\
\text { through these, accessing knowledge and } \\
\text { resources is clear. When the hierarchical } \\
\text { structure is weak, horizontal networks } \\
\text { become increasingly important. } \\
\text { Search for adaptation solutions required } \\
\text { additional financial and/or human resources. } \\
\text { therefore entrepreneurs went looking for } \\
\text { external support. }\end{array}$ \\
\hline $\begin{array}{l}30 . \\
(173)\end{array}$ & Wigell, 2013 & $\begin{array}{l}\text { Few sentences: } \\
\text { interviews }\end{array}$ & $\begin{array}{l}\text { Aland, Finland } \\
\text { (political) }\end{array}$ & $\begin{array}{l}\text { Subnational, } \\
\text { national, } \\
\text { global; Finland, } \\
\text { Aland; Security, } \\
\text { solutions to } \\
\text { ethno-territorial } \\
\text { disputes, } \\
\text { demilitarization, } \\
\text { neutralization }\end{array}$ & $\begin{array}{l}\text { Strategy to gain influence in international } \\
\text { society often used by actors with limited } \\
\text { traditional power resources; 'nche } \\
\text { diplomacy' whereby small powers, unable to } \\
\text { exercise influence across the board, make } \\
\text { themselves relevant on international stage by } \\
\text { concentrating their efforts in certain key areas. } \\
\text { International promotion of Aland case is also } \\
\text { to preserve and maintain semi-sovereign and } \\
\text { autonomous status, and thus serves self- } \\
\text { interest }\end{array}$ \\
\hline
\end{tabular}


Necessary for entrepreneurs to build legitimacy for adaptation plans. Used Institutional vulnerability as frame to do so

Recruit external expertise and secure funding for work towards climatechange adaptation in municipality, through externally funded research projects and networks, which provided direct contact to climate researchers, whom PE could ask for downscaled scenarios on issues considered important in local context. Also access to northern coastal municipalities with engagement in international network for downscaling solutions (network, contacts $\mathbb{e}$ expertise and funding)

Sought access to regional development funding from EU and Danish regional authority, to create large projects, which gather knowledge resources from different partners worldwide (universities, research institutes, large companies)

Recruit external expertise and secure funding for work towards climatechange adaptation in municipality, through externally funded research projects and networks, which provided direct contact to climate researchers, whom PE could ask for downscaled scenarios on issues considered important in local context. Also access to northern coastal municipalities with engagement in international network for downscaling solutions (network, contacts $\mathbb{e}$ expertise and funding)

Aland lobbied with national government finland to establish co-operative forum between aland and ministry foreign affairs. Contact group started working: mapping out conflict zones where aland could serve as example, international study visits and research about Aland. Group discusses current developments affecting Aland and initiatives regarding promotion Aland

Aland (island) upholds interstate contacts with various states and has representation in Nordic council to promote itself as an example.

Aland Islands Peace Institute (AIPI) an NGO has been active in disseminating idea about Aland Example by organizing events and hosting number of foreign groups (among whom Armenia, Nagorno-Karabakh, Azerbaijan) who came together for peace talks. This all to influence its domestic relations with Finnish government.

Finland (MoFA) organized and sponsored seminars and panels in places such as New York, Brussels, Geneva with aim of bringing Aland under attention of key orgs such as UN as well as broader diplomatic community. And brings Aland up in several other activities such as Ireland Peace talks, OSCE Parliamentary Assembly Team on Moldova etc. talked about as inspiration for constructive discussions and resource for Finnish public diplomacy and brand-building 
5. Data extraction table I: continued

\begin{tabular}{|c|c|c|c|c|c|}
\hline$\#$ & $\begin{array}{l}\text { author, } \\
\text { year }\end{array}$ & Methods & Entrepreneur & $\begin{array}{l}\text { Level, locus, } \\
\text { topic }\end{array}$ & Condition \\
\hline $\begin{array}{l}31 . \\
(178)\end{array}$ & Zhu, 2012 & $\begin{array}{l}\text { Some } \\
\text { sentences. } \\
\text { Interviews, } \\
\text { government } \\
\text { docs, } \\
\text { newspaper } \\
\text { articles }\end{array}$ & $\begin{array}{l}\text { Government } \\
\text { officials } \\
\text { as policy } \\
\text { entrepreneurs. } \\
\text { Guo Shuqing, } \\
\text { the main } \\
\text { designer of } \\
\text { the Guizhou } \\
\text { housing } \\
\text { model as vice } \\
\text { governor in } \\
\text { charge of } \\
\text { housing reform } \\
\text { (political) }\end{array}$ & $\begin{array}{l}\text { Subnational, } \\
\text { national; } \\
\text { Guizhou } \\
\text { province, China; } \\
\text { local policy } \\
\text { innovations } \\
\text { in housing } \\
\text { monetarization } \\
\text { reform in } \\
\text { Guizhou } \\
\text { province, China } \\
\text { at two levels: } \\
\text { provincial and } \\
\text { prefectural. } \\
\text { From heavily } \\
\text { subsidized } \\
\text { state housing } \\
\text { provision } \\
\text { system into a } \\
\text { market oriented } \\
\text { one }\end{array}$ & $\begin{array}{l}\text { Introduction housing monetarization reform } \\
\text { by central government provided Window of } \\
\text { Opportunity for provincial level. } \\
\text { Given authoritarian nature China's political } \\
\text { regime, key figures within government still } \\
\text { exercise crucial influence over policymaking } \\
\text { PEs increased role in the policy process has } \\
\text { been } \\
\text { recognised as the Chinese political system has } \\
\text { become more pluralistic or transformed into } \\
\text { a so-called 'fragmented authoritarianism } 2.0 \text { ' } \\
\text { (Mertha } 2009 \text { ). Barriers to political } \\
\text { participation have been lowered and } \\
\text { previously excluded actors have successfully } \\
\text { penetrated the } \\
\text { system and exerted an increasingly influential } \\
\text { role in the policy process. } \\
\text { Setting example to reduce political opposition } \\
\text { and demonstrate soundness of the plan and } \\
\text { market ideas amongst potential supporters. } \\
\text { As the reform plan concerned or even } \\
\text { harmed interests of many cadres (harde } \\
\text { kern) but favoured ordinary employees, policy } \\
\text { entrepreneurs strived to mobilize ordinary } \\
\text { citizens to become involved and strengthen } \\
\text { legitimacy and popularity of reform process }\end{array}$ \\
\hline $\begin{array}{l}32 . \\
(179)\end{array}$ & Zito, 200I & No. & $\begin{array}{l}\text { epistemic } \\
\text { community } \\
\text { as network of } \\
\text { professionals } \\
\text { sharing } \\
\text { common } \\
\text { worldview } \\
\text { (research) }\end{array}$ & $\begin{array}{l}\text { Supranational; } \\
\text { EU, acid rain } \\
\text { policy adoption }\end{array}$ & $\begin{array}{l}\text { Lack of strong EU-wide political parties, } \\
\text { existence of numerous access points into } \\
\text { institutional process, large number of officials } \\
\text { and organizations that have role in the } \\
\text { process, many policy options, all suggest EU- } \\
\text { process open to agenda change. } \\
\text { But EU also constrains entrepreneurs' ability } \\
\text { to alter status quo: EU as chain of institutions, } \\
\text { each institution within chain acts as veto } \\
\text { point, with its actors potentially blocking any } \\
\text { agreement on proposal. System's intricacy and } \\
\text { fragmentation hinders entrepreneurship as } \\
\text { it gives multiple opportunities for opposing } \\
\text { perspectives to exert influence and requires } \\
\text { consensus within and across institutions. } \\
\text { Hence, to succeed within daily EU decision- } \\
\text { making, must persuade coalitions of actors } \\
\text { across all potential EU veto points. Thus: } \\
\text { collective entrepreneurship } \\
\text { When issues are complex, new or involve } \\
\text { issue uncertainty, epistemic community } \\
\text { entrepreneurship will be more effective. }\end{array}$ \\
\hline
\end{tabular}


Strategy

To reduce the perception of risk among decision-makers: conducting pilot reforms or leading by example can reduce political opposition and demonstrate the soundness of the plan and also market the ideas amongst potential supporters. In Guizhou, provincial guiding program set prototype for process of innovation. Guiyang Municipal Housing Reform Office together with provincial and municipal housing authorities worked together and implemented reform. Reported success helped silence opposition in Guizhou and drew positive attention from all over the country. Demonstrated by Guiyang city, approach extended to entire province, and then nationwide. Example $\mathbb{e}$ silence opposition

Created support among local community through media coverage and informing them and seeking their input. Thereby the provincial government did not dare to change the policy direction that was set in, and had to continue after the PE left the province.

To increase legitimacy and support, and given the significance of work units in the implementation of housing reform, dozens of consultation meetings were held in different government depts, research institutes and enterprises to get feedback and support from employees across wide range of social strata.
Implications

Wide engagement led to wide support as well, and pressed provincial government to continue after Guo left Guizhou. Even losers accepted reform as they saw how many benefited

\section{Type}

\section{Policy}

entrepreneurs

Scandinavian experts defined problem of acid rain as transnational, product of long-range air pollution emissions from other European countries, strove to get issue identified as serious in European Community and other IOs.

UN Economic Commission for Europe (UN/ECE) was interested, created Convention on Long-Range Transboundary Air Pollution (LTRAP) which provided policy framework for exchanging technical info between member states.

Collective entrepreneurship 
Appendix

5. Data extraction table I: continued

\begin{tabular}{|c|c|c|c|c|c|}
\hline$\#$ & $\begin{array}{l}\text { author, } \\
\text { year }\end{array}$ & Methods & Entrepreneur & $\begin{array}{l}\text { Level, locus, } \\
\text { topic }\end{array}$ & Condition \\
\hline $\begin{array}{l}33 . \\
(182)\end{array}$ & $\begin{array}{l}\text { Bjorkdahl, } \\
2014\end{array}$ & No. & $\begin{array}{l}\text { Sweden } \\
\text { (country) } \\
\text { (political) }\end{array}$ & $\begin{array}{l}\text { Supranational, } \\
\text { global; EU, } \\
\text { UN; inclusion } \\
\text { of conflict } \\
\text { prevention } \\
\text { in security } \\
\text { approach UN } \\
\text { and EU }\end{array}$ & $\begin{array}{l}\text { Shared core values among EU partially explain } \\
\text { success norm entrepreneurship. } \\
\text { Prevention fitted well with normative power } \\
\text { image EU and UN. } \\
\text { Small states particularly rely on international } \\
\text { institutions for the promotion of their norms, } \\
\text { and Sweden believed their norm would } \\
\text { resonate with normative contexts of both } \\
\text { UN and EU. }\end{array}$ \\
\hline
\end{tabular}

When Sweden was elected as non-permanent member of UN security Council it made attempts to include conflict prevention on agenda Council, but with little success 
When selected as non-permanent member of Security Council, Sweden draw the Presidential conclusions wherein it linked conflict prevention and peacekeeping. Worked to keep conflict prevention on UN agenda, by linking it to R2P, because this was UN adopted doctrine

Sweden attempted to build support by approaching likeminded countries bilaterally for informal meetings and interpersonal and argumentative persuasion

Established 'Group of Friends for Conflict prevention' and various ad hoc coalitions with members of security council, to mobilize support for their ideas.

Diplomatic tactics and persuasion kept conflict prevention on the EU agenda in times when support for crisis management grew strong. By occupying the rotating presidency of the EU in 200 I, Sweden enjoyed privileged control over procedures, and normative influence was enhanced.

Norm entrepreneurship is about building winning coalitions. Swedish representatives

attempted to mobilise support for the idea of conflict prevention within the $\mathrm{UN}$ as well as in the EU, using informal meetings for interpersonal and argumentative persuasion.

Countries identified as likeminded or crucial to the success of the norm entrepreneurial activities were approached bilaterally to build a critical mass (Bjorkdahl 2002a). 
5. Data extraction table I: continued

\begin{tabular}{|c|c|c|c|c|c|}
\hline$\#$ & $\begin{array}{l}\text { author, } \\
\text { year }\end{array}$ & Methods & Entrepreneur & $\begin{array}{l}\text { Level, locus, } \\
\text { topic }\end{array}$ & Condition \\
\hline $\begin{array}{l}34 . \\
(199)\end{array}$ & Rosen, 2013 & $\begin{array}{l}\text { Section. } \\
\text { Case study. } \\
\text { Collection: } \\
\text { interviews. }\end{array}$ & $\begin{array}{l}\text { IEs from inside } \\
\text { and outside } \\
\text { region and } \\
\text { primarily from } \\
\text { conservation } \\
\text { NGOs with } \\
\text { long history } \\
\text { flobbying } \\
\text { for marine } \\
\text { conservation. } \\
\text { long experience } \\
\text { with } \\
\text { transboundary } \\
\text { resource } \\
\text { dilemmas or } \\
\text { with bringing } \\
\text { government } \\
\text { and non-state } \\
\text { actors together } \\
\text { (NGO) }\end{array}$ & $\begin{array}{l}\text { Supranational, } \\
\text { global; Coral } \\
\text { Triangle, Asia; } \\
\text { international } \\
\text { agreement } \\
\text { to radically } \\
\text { transform } \\
\text { management } \\
\text { of coastal } \\
\text { and marine } \\
\text { resources in the } \\
\text { Coral Triangle } \\
\text { litiative (CTI) }\end{array}$ & $\begin{array}{l}\text { This situation [of marine environmental } \\
\text { degradation] calls for a fundamental shift in } \\
\text { institutions. New } \\
\text { integrated management approaches like } \\
\text { ecosystem-based management, which } \\
\text { recognize the full array of interactions within } \\
\text { an ecosystem, are needed to promote } \\
\text { active stewards and restore the resilience } \\
\text { of the Earth's ecosystems [6,7]. Integrated } \\
\text { approaches are especially important since } \\
\text { many marine resources and ecological } \\
\text { processes supporting human wellbeing know } \\
\text { no political boundaries, and the drivers of } \\
\text { their degradation often transcend both } \\
\text { policy sectors and nation-states. Yet marine } \\
\text { governance is often fragmented and poorly } \\
\text { coordinated to deal with dynamic ecosystems } \\
\text { and cross-scale drivers of change [8,9]. There } \\
\text { is also } \\
\text { a lack of institutional support for integrated } \\
\text { approaches for } \\
\text { managing and governing marine resources at } \\
\text { the regional and } \\
\text { international level [2, I0- } 12] \text {. Such piecemeal } \\
\text { governance and the tendency to apply simple } \\
\text { solutions to complex problems seriously } \\
\text { threaten the ability of the oceans to continue } \\
\text { to support } \\
\text { humans with critical ecosystem services }\end{array}$ \\
\hline
\end{tabular}

Number of factors triggering action. These include demands for social and economic development, concerns about political stability and national security, and rapid loss of biodiversity (especially of commercially important species). Together they created opportunity context for emergence ecosystem-based management.

Introduction CTI coincided with increasing interest in assisting small island states in protecting marine ecosystems.

Moreover, institutions had been working with each other before, hence there was quite some social capital to draw on

Alimi, 2015 Few sentences. Global Observation, interviews,

\section{Commission}

on Drug Policy

(administration)
Supranational, global; Latin America; war on drugs

\section{Went from regional to global to bypass} traditional decision-making authorities which favoured a different (and in their view less successful) approach; namely the war on drugs.

Unlocking new and additional resources.

Allowing for new strategies 
First step for NGO-entrepreneurs was to get president Indonesia, Yudhoyono on board (as Indonesia would host COP), therefore they had to liaison with individuals who could provide access, away from public attention and behind closed doors.

To do so they first looked into what ongoing processes of environmental policy making CTI could be linked to to prove its relevance (such as Yudhoyono's push for impact of climate change on food security)

Established CTI coordination committee, senior officials meetings, national coordination committees, CTI secretariat; to provide opportunity to engage in both domestic and international policymaking; and to raise human, financial resources and institutional capacity (thus targeting international level)

Institutional entrepreneurs (engaged in organizational issues) provided technical support and actively facilitated multilateral negotiations to develop RPOA, develop national agendas, legal and financial arrangements. PEs mobilized travel funds, distributing information, delivering logistical support, drafted documents with right diplomatic wording.

Lack of institutional capacity and resource asymmetries between the 6 countries constituted barrier to change and called for careful facilitation, both in meetings and between meetings, to avoid deadlock

When the idea had been anchored at highest political level in Indonesia, it was critical to communicate about CTI in ways that could secure sufficient outreach and international recognition. Had to seize opportunity provided by string of scheduled international events (COP 8 and APEC meeting) to introduce CTI to international community. Decided to have parallel activities from the side of NGOs at the same time as well. (thus targeting national levels_)

After 9? I I and Bali bombings there was interest from US to invest in Indonesia and reach muslim population, stability in southeast Asia, CTI provided good opportunity to increase political presence in region for USA.

Before the Manado meeting (where CTI would be signed) there was daily contact with entrepreneurs and countries to discuss and prepare for the event.

The impact of institutional entrepreneurship was reinforced by the appointment of a number of 'CTI officials' within the six governments. Simultaneously, with NGO support a person from UN was recruited strengthen the CTI secretariat and regional coordination, and the US government set up the US CTISP to deliver support to the countries and galvanize regional collaboration

Framing -

Widespread social media coverage, outreach campaigns, partnerships.

Joining up with wider community of global drug policy reformers, to enhance legitimacy.

Playing within multiple arenas to link its message to wide range of authorities

Linking global discourse and local (or regional) implementation by organizing tailor-made local programmes and activities

\section{Targeting many}

different countries and levels simultaneously was difficult and agendas individual leaders profoundly influenced what countries hoped to get out of it (entrepreneurs had therefore demonstrate links between national interests and ecosystem-based management, or links between local resource availability and transboundary socioecological processes.

Entrepreneurs could only succeed with help of other leaders, such as president Indonesia
Institutiona

entrepreneurship
More resources needed.

Tailoring different messages to differing audiences.

Issues of legitimacy with other actors not recognizing the local actors moving to global scale
Policy entrepreneurs 
Appendix

5. Data extraction table I: continued

\begin{tabular}{|c|c|c|c|c|c|}
\hline \# & $\begin{array}{l}\text { author, } \\
\text { year }\end{array}$ & Methods & Entrepreneur & $\begin{array}{l}\text { Level, locus, } \\
\text { topic }\end{array}$ & Condition \\
\hline $\begin{array}{l}36 . \\
(202)\end{array}$ & $\begin{array}{l}\text { Brinkerhof, } \\
2015\end{array}$ & No. & $\begin{array}{l}\text { Newai Gebre } \\
\text { (chief economic } \\
\text { advisor); } \\
\text { Gabre-Madhin } \\
\text { (diasporan and } \\
\text { expert); Diwan, } \\
\text { WB; Legesse } \\
\text { (deputy prime- } \\
\text { minister and } \\
\text { later AgMin) } \\
\text { (Administration } \\
\text { CSO) }\end{array}$ & $\begin{array}{l}\text { National; } \\
\text { Ethiopia; } \\
\text { Commodities } \\
\text { exchange } \\
\text { market: } \\
\text { agriculture, } \\
\text { economy }\end{array}$ & $\begin{array}{l}\text { Due to a lack of resources, diasporan and } \\
\text { expert involved 'relevant donors' to persuade } \\
\text { them to participate in a conference. }\end{array}$ \\
\hline $\begin{array}{l}37 . \\
(203)\end{array}$ & $\begin{array}{l}\text { Budabin, } \\
2015\end{array}$ & No. & $\begin{array}{l}\text { Mia Farrow } \\
\text { (citizen) }\end{array}$ & $\begin{array}{l}\text { Global, national; } \\
\text { China, Darfur- } \\
\text { Sudan; Conflict, } \\
\text { genocide, } \\
\text { diplomacy }\end{array}$ & $\begin{array}{l}\text { To receive critical support, one might want to } \\
\text { move issue onto international agenda. }\end{array}$ \\
\hline $\begin{array}{l}38 . \\
(207)\end{array}$ & $\begin{array}{l}\text { Davidson, } \\
2016\end{array}$ & $\begin{array}{l}\text { Section. } \\
\text { Longitudinal } \\
\text { mixed-method } \\
\text { single in-depth } \\
\text { case-study } \\
\text { approach. } \\
\text { Collection: } \\
\text { policy } \\
\text { documentation, } \\
\text { media releases, } \\
\text { interviews, } \\
\text { survey. Analysis } \\
\text { UCINET (no } \\
\text { specification } \\
\text { analysis). }\end{array}$ & $\begin{array}{l}\text { ENGOs and } \\
\text { individuals } \\
\text { within - Rescue } \\
\text { Lake Simcoe } \\
\text { Coalition } \\
\text { (RLSC), } \\
\text { Campaign Lake } \\
\text { Simcoe (CLS), } \\
\text { staff members } \\
\text { and president } \\
\text { of RLSC, Ladies } \\
\text { of the Lake } \\
\text { (LofL), co- } \\
\text { founder LofL } \\
\text { (NGO, CSO) }\end{array}$ & $\begin{array}{l}\text { Subnational; } \\
\text { Lake Simcoe } \\
\text { Region, Ontario, } \\
\text { Canada; } \\
\text { Governance for } \\
\text { water }\end{array}$ & $\begin{array}{l}\text { Local ENGO targeted national level. But } \\
\text { national level irresponsive to local issues. } \\
\text { Thereto the ENGO collected local info to } \\
\text { share with subnational and national level, } \\
\text { thereby contributing to building a conducive } \\
\text { environment for change. }\end{array}$ \\
\hline $\begin{array}{l}39 . \\
(208)\end{array}$ & $\begin{array}{l}\text { De Franco, } \\
2015\end{array}$ & $\begin{array}{l}\text { Footnote: } \\
\text { interviews, } \\
\text { workshop, } \\
\text { policy } \\
\text { documents and } \\
\text { NGO reports. }\end{array}$ & $\begin{array}{l}\text { previous two } \\
\text { UN Secretary- } \\
\text { Generals, the } \\
\text { UN secretariat } \\
\text { and the two } \\
\text { Special Advisers } \\
\text { for R2P and } \\
\text { Genocide } \\
\text { Prevention } \\
\text { (administration) }\end{array}$ & $\begin{array}{l}\text { Global, } \\
\text { supranational; } \\
\text { EU, } \\
\text { international for } \\
\text { a; Responsibility } \\
\text { to Protect } \\
\text { (R2P) }\end{array}$ & $\begin{array}{l}\text { First NEs would not target EU, as regional orgs } \\
\text { were not addressees; second, EU would not } \\
\text { be likely to experience core crimes; third, did } \\
\text { not fit with their scepticism towards R2P. but } \\
\text { when voted with NATO action in Libya, there } \\
\text { was dissension within EU and UN wanted to } \\
\text { involve supporting states }\end{array}$ \\
\hline
\end{tabular}


Strategy

Involvement of the right stakeholders (international donors, different ministers) provided a demonstration effect and moral authority for broadening persuasion efforts and acceptance.

Taskforce under head of Gabre-Madhin included study tours to Chicago and India for inspiration.

Legesse convinced donors to pool resources to support the ECX.

In reaction to opposition from buyers, the prime minister organized meeting with entire coffee industry.

Different tactics for different stakeholders at different levels: local smaller traders persuaded, but international buyers eventually with compulsory power: adoption law to manage transaction costs

Mia Farrow published op-ed in wall street journal (ad other media subsequently) criticising China for hosting Sudan. Her actions raised global membership of I 30 million

ENGOs link different kinds of knowledge across scales, translating between citizens, experts and politicians.

Entrepreneurs can thereby act as conduits of info across scales, serving as bridge between actors, and breaking down barriers across scales and between different types of knowledge. Various activities needed to resonate with different levels of government.

RLSC joined forces with Environmental Defense (ED) national actor, and Ontario Nature (ON).

ENGOs lobbied with different levels of government.

NGO's called for a shift in authority from local governance to the provincial level, to a - to be established - Conservation Authority

UN special advisor for genocide prevention met in Brussels with EU key figures to persuade them that EU should prioritize R2P.

Then appoint special advisor for R2P, who was based in EU. She made case for more active role regional organizations
Implications

The ECX rose

attention from

international coffee

buyers and roasters,

who opposed the

trading scheme.

To reach international politics, one needs suitable vehicle for amassing critical support, e.g. UNSG has UN platform, celebrities might use NGO's, IGOs, or building own platform. Or one needs global media event.

But if global

attention, this raises global support and membership and funding for campaign

Through the bridging of entrepreneurs, they are making the governance process more inclusive of diverse voices and contexts.

Hardly led to greater EU involvement, bcoz vagueness concept leaves wiggle room for interpretation

\section{Type}

Institutional

entrepreneurs

Norm

entrepreneur

Institutional

entrepreneurs
Norm

entrepreneur 
Appendix

5. Data extraction table I: continued

\begin{tabular}{|c|c|c|c|c|c|}
\hline$\#$ & $\begin{array}{l}\text { author, } \\
\text { year }\end{array}$ & Methods & Entrepreneur & $\begin{array}{l}\text { Level, locus, } \\
\text { topic }\end{array}$ & Condition \\
\hline $\begin{array}{l}40 . \\
(209)\end{array}$ & $\begin{array}{l}\text { DeRynck, } \\
2016\end{array}$ & No. & $\begin{array}{l}\text { ECB (actors) } \\
\text { (administration) }\end{array}$ & $\begin{array}{l}\text { Supranational } \\
\text { (and national); } \\
\text { EU and EU- } \\
\text { member states; } \\
\text { EU Banking } \\
\text { Union }\end{array}$ & $\begin{array}{l}\text { There was a long standing preference for a } \\
\text { more centralized supervision and a shift in } \\
\text { crisis role from guarantor of price stability } \\
\text { to guardian of sustainability of EMU as such: } \\
\text { I) change in governor and board members, } \\
\text { bringing in new thinking; 2) scale of LTRO } \\
\text { (Long Term Refinancing Operations) increased } \\
\text { chances of moral hazard behaviour by national } \\
\text { supervisors }\end{array}$ \\
\hline $\begin{array}{l}41 . \\
(210)\end{array}$ & $\begin{array}{l}\text { DiRuggiero, } \\
2015\end{array}$ & No. & $\begin{array}{l}\text { International } \\
\text { Labour } \\
\text { Organization } \\
\text { (ILO) as } \\
\text { institution } \\
\text { (administration) }\end{array}$ & $\begin{array}{l}\text { Global;WB, } \\
\text { WHO, ILO; } \\
\text { Decent Work } \\
\text { Agenda }\end{array}$ & $\begin{array}{l}\text { 2008-2009 global economic crisis provided } \\
\text { momentous opportunity for ILO to reframe } \\
\text { DWA with focus on jobs and mobilize } \\
\text { attention to unhealthy working conditions, } \\
\text { which previously had limited agenda access }\end{array}$ \\
\hline
\end{tabular}


This change in governor and board members, brought in new thinking.

German member who came aboard took charge of banking union issues and liaised informally with Germany.

Following crisis ILO collaborated with G20 to promote policy coherence for decent work in direct response to global economic crisis.
Increased support

and eventual adoption

and acceptance of

transferring authority

from national to

EU-level

But complex set of macroeconomic

labour, social and education policies that must be coordinated to promote workers' well-being globally is formidable challenge for ILO in contested policy space.

Moreover complicated bcoz institutions $\mathrm{LO}$ and WB do not operate in same multilateral system.

Global level also difficult due to many global actors that could influence agenda and lack of explicit legal authority to implement agenda through enactment legislation or laws

Bcoz different institutions have different claims, valuesm ideologies, different interpretations of decent work. Mandates institutions and dominance disciplinary orientation explain these differences partly 
Appendix

5. Data extraction table I: continued

\begin{tabular}{|c|c|c|c|c|c|}
\hline$\#$ & $\begin{array}{l}\text { author, } \\
\text { year }\end{array}$ & Methods & Entrepreneur & $\begin{array}{l}\text { Level, locus, } \\
\text { topic }\end{array}$ & Condition \\
\hline $\begin{array}{l}42 . \\
(211)\end{array}$ & $\begin{array}{l}\text { Douglas, } \\
2015\end{array}$ & $\begin{array}{l}\text { Section. } \\
\text { Embedded } \\
\text { multiple case } \\
\text { study. Data } \\
\text { collection: } \\
\text { Interviews, } \\
\text { documentation. }\end{array}$ & $\begin{array}{l}\text { Early adopters } \\
\text { of drug courts } \\
\text { (administration) }\end{array}$ & $\begin{array}{l}\text { Subnational, } \\
\text { national ; US } \\
\text { States; drug } \\
\text { courts }\end{array}$ & $\begin{array}{l}\text { Too little local funding } \\
\text { Little awareness of the idea of drug courts }\end{array}$ \\
\hline
\end{tabular}

\begin{tabular}{|c|c|c|c|c|c|}
\hline $\begin{array}{l}43 . \\
(215)\end{array}$ & $\begin{array}{l}\text { Hartmann, } \\
2015\end{array}$ & $\begin{array}{l}\text { Comparative } \\
\text { case-study. } \\
\text { Collection: } \\
\text { interviews }\end{array}$ & Not defined & $\begin{array}{l}\text { Subnational, } \\
\text { supranational; } \\
\text { Netherlands, } \\
\text { Nijmegen and } \\
\text { Amsterdam; } \\
\text { Water policy }\end{array}$ & $\begin{array}{l}\text { Because cities suffer increasingly from } \\
\text { limited financial means, and because climate } \\
\text { adaptation suffers from low political priority, } \\
\text { strategy to search for links with existing or } \\
\text { planned initiatives to strengthen adaptive } \\
\text { capacity in cities }\end{array}$ \\
\hline $\begin{array}{l}44 . \\
(216)\end{array}$ & $\begin{array}{l}\text { Heinze, } \\
2016\end{array}$ & $\begin{array}{l}\text { Section. } \\
\text { Inductive } \\
\text { qualitative } \\
\text { case study. } \\
\text { Collection: } \\
\text { interviews } \\
\text { (selection } \\
\text { also justified), } \\
\text { observation. } \\
\text { Analysis: } \\
\text { grounded } \\
\text { theory } \\
\text { approach } \\
\text { through coding. }\end{array}$ & $\begin{array}{l}\text { Conversion } \\
\text { organizations } \\
(\mathrm{NGO})\end{array}$ & $\begin{array}{l}\text { Subnational; } \\
\text { USA; health } \\
\text { conversion } \\
\text { foundations }\end{array}$ & \\
\hline $\begin{array}{l}45 . \\
(217)\end{array}$ & $\begin{array}{l}\text { Hermansen, } \\
2015\end{array}$ & No. & $\begin{array}{l}\text { ENGOs, the } \\
\text { Rainforest } \\
\text { Foundation } \\
\text { Norway (RFN) } \\
\text { and The } \\
\text { Norwegian } \\
\text { Society for the } \\
\text { Conservation } \\
\text { of Nature/ } \\
\text { Friends of the } \\
\text { Earth } \\
\text { (FEN) (NGO) }\end{array}$ & $\begin{array}{l}\text { National; } \\
\text { Norway; } \\
\text { Emergence } \\
\text { of Norway's } \\
\text { International } \\
\text { Climate and } \\
\text { Forest Initiative } \\
\text { (NICFI) }\end{array}$ & $\begin{array}{l}\text { Both climate and rainforests were high on the } \\
\text { international agenda at the time. } \\
\text { Letter ENGOs was } 3 \text { days after UN climate } \\
\text { summit bcoz entrepreneurs saw opportunities } \\
\text { there: climate perceived as serious issue, link it } \\
\text { to solution of tropical rainforest. }\end{array}$ \\
\hline $\begin{array}{l}46 . \\
(225)\end{array}$ & $\begin{array}{l}\text { Mostly-tello, } \\
2015\end{array}$ & No. & $\begin{array}{l}\text { Interest groups } \\
(\mathrm{NGO}, \mathrm{CSO})\end{array}$ & $\begin{array}{l}\text { national, USA, } \\
\text { labour rights }\end{array}$ & $\begin{array}{l}\text { Due to limited interest for and attention to } \\
\text { labour rights }\end{array}$ \\
\hline
\end{tabular}


Janet Reno, newly established Attorney General took idea to Washington and began pushing for federal funding

Individuals involved with original drug courts founded National Association of Drug Court Professionals (NADCP) to promote drug court concept, share info and develop guiding principles, support research and lobby Congress. Holding annual conferences for promote drug courts and enable the exchange of info, encouraged local officials to promote reform further in their home states by establishing own state associations, and provide model for how structure courts themselves. Establish National Drug Court Institute to promote research.

Chief Justice (federal gov) created New York State Commission on Drugs and Courts to study and assess reform. Found wide support, but also concern courts would not be realized unless support from state. Thereto created Office of Court Drug Treatment Programs (OCDTP) for supporting establishment courts across every judicial jurisdiction in NY. Provided trainings, and secured 9 million from federal level for financing courts

Conversion foundations built groundwork for effective collaboration by bringing together individuals and groups from across organizations, sectors, and demographic groups in the community. They discovered gaps, realized synergies, and creatively integrated acticities of existing actors. as such they were able to define the social problem locally, develop social capital in their communities and educate potential partners.

Partnerships for educational opportunities. County gvment to learn from experts (local and national experts) about effective management and strategy.

conversion foundations from different states worked together to pool information, support, resources. together they can prioritize, share best practicesm pool resources to secure information and promote their interests to state government.

2 PEs write letter to Prime Minister, and Ministers Finance, Foreign Affairs, International Development: climate action urgent, deforestation as driver GHG; and ask for I billion \$. Letter is based on Stern Review and IPCC report.

On the side organize hearings in parliament, meetings with political parties and ministers. Flew in Brazilian NGO to strengthen case, and give example of deal in Brazil.

Organize meeting w/ Brazilian MinEnv

Therefore activists link labour rights to arguments of trade agreements (competition and export markets)

\section{Policy}

entrepreneurs ideas from federal to local level.

\section{Spreading idea to}

other counties.
Time constraints

limited the possibility for policy entrepreneurs to step in and link with other cities

Collaboration fostered trust and legitimacy of the conversion foundations. Moreover, it created enhanced knowledge and expertise in dealing with health issues.

By grouping tgether different conversion foundations make a stronger statement to state government.

Bcoz climate issue, rainforest seen as attractive solution

Norwegian

Government announces huge project NICFI, worth 500 million \$
Policy

entrepreneurs 
Appendix

5. Data extraction table I: continued

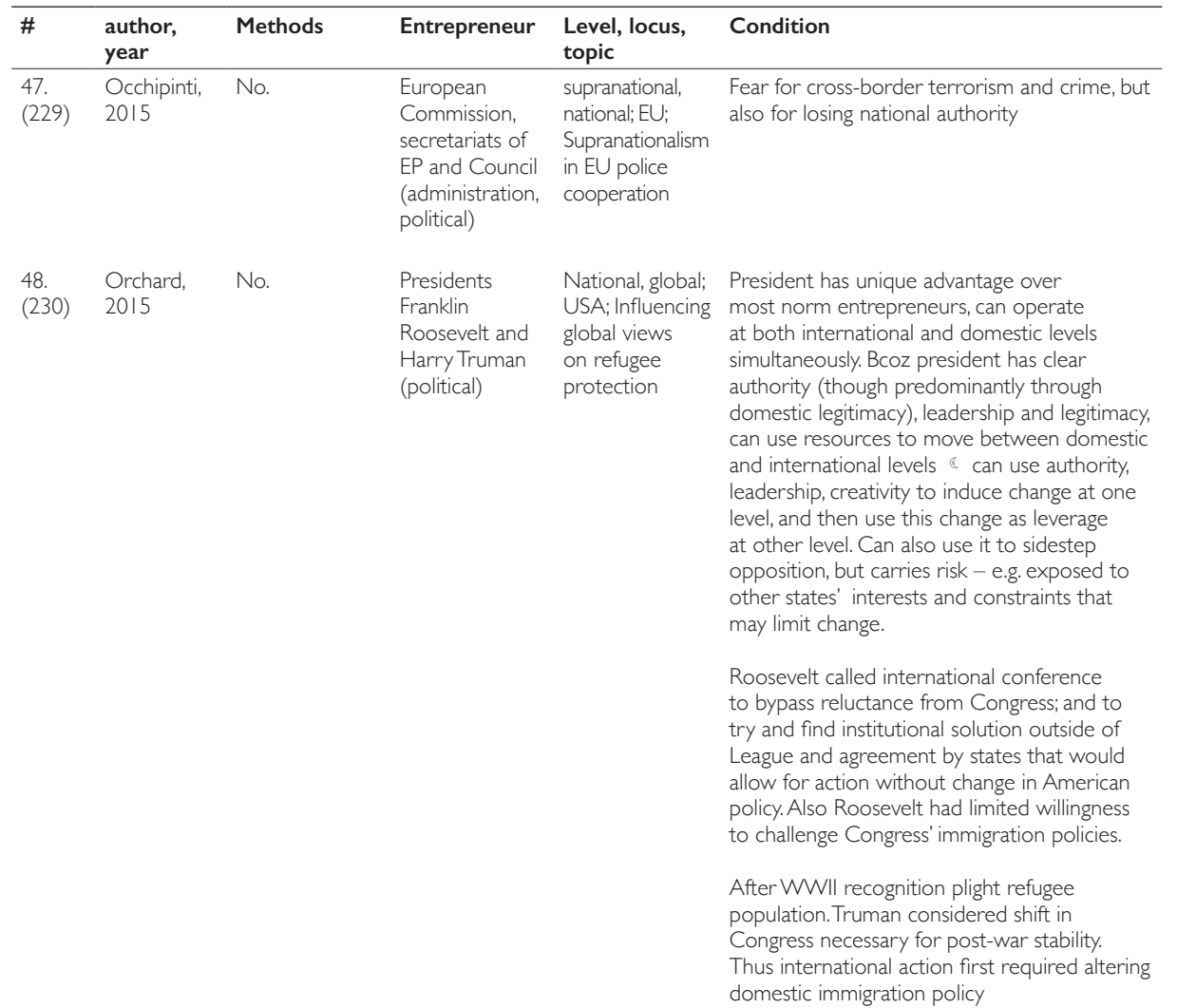


PEs make normative claims to convince member states of their ideas. Present cross-border crime as transnational in nature
Transnational policy

entrepreneur (conceptual) Gaining support of states frequently requires norm entrepreneurs to operate at domestic level, either by persuading domestic actors of relevance new norm by discursively linking it to national interests or by overcoming opposition from domestic veto players or gatekeepers whose agreement is required for change in status quo. this can be done in 2 ways: (1) NE possess own sources of authority or legitimacy to exercise power across borders (however avtions must be seen as to accord with whatever authorizes them to act, and must interact with other global governors, with similar forms of authority at int level). (2) can possess direct connections wit domestic institutions or other ways to be able to mobilize domestic support (requires NE to be empowered by domestic agent).

Roosevelt was long silent on the issue (overstaffed and opposing) but after Austrian Anschluss in 1938 took action: domestically ordered State Dept to combine Austrian and German quotas. Internationally called conference to address refugee problem.

Truman urged Congress to find ways whereby US could fulfil responsibilities towards refugees. Actions led to Displaced Persons Act 1948, which distinguished for first time between migrants and DPs.

To persuade Congress Truman reframed issue of refugee protection as security issue, in line with increasing tensions from CW.

Meanwhile at the int. level Truman used creation new IOs - International Refugee Organization (IRO) and UNHCR and Refugee Convention to transmit norm to international norm and institutionalize it as common state practice.
Roles that both presidents played at international level were moderated by constraints at domestic level as support for global and internal changes to refugee protection required considerable amount of negotiation.

\section{Raising issue at} international level to sidestep opposition at domestic level might expose to range of other states' interests and constraints that might limit his ability to pursue normative change.

If successful internationally, can use success as way to reframe issue and mobilize new domestic constituencies to support change domestically.

Due to international and domestic constraints only outcome of conference was 10 Inter-Governmental Committee on Refugees, with limited mandate to negotiate with german govment.

However with framing refugees as security issue in light of CW, this led raised security concerns and consequently act was adopted to screen aliens and exclude subversives, making immigration more restrictive again
Norm

entrepreneur 
Appendix

5. Data extraction table I: continued

\begin{tabular}{|c|c|c|c|c|c|}
\hline$\#$ & $\begin{array}{l}\text { author, } \\
\text { year }\end{array}$ & Methods & Entrepreneur & $\begin{array}{l}\text { Level, locus, } \\
\text { topic }\end{array}$ & Condition \\
\hline $\begin{array}{l}49 . \\
(237)\end{array}$ & $\begin{array}{l}\text { Shearer, } \\
2015\end{array}$ & $\begin{array}{l}\text { Section. } \\
\text { Collection: } \\
\text { document } \\
\text { review, } \\
\text { interviews, } \\
\text { survey } \\
\text { (selection } \\
\text { justified). } \\
\text { Analysis: social } \\
\text { network } \\
\text { analysis, coding }\end{array}$ & $\begin{array}{l}\text { INGOs: } \\
\text { Partnership } \\
\text { for Maternal, } \\
\text { Newborn } \\
\text { and Child } \\
\text { Health and } \\
\text { Melinda Gates } \\
\text { Foundation } \\
\text { (NGO) }\end{array}$ & $\begin{array}{l}\text { National, global; } \\
\text { Burkina Faso; } \\
\text { Integrated } \\
\text { community case } \\
\text { management of } \\
\text { childhood illness }\end{array}$ & \\
\hline $\begin{array}{l}50 . \\
(240)\end{array}$ & $\begin{array}{l}\text { Uittenbroek, } \\
2016\end{array}$ & $\begin{array}{l}\text { Section. } \\
\text { Explorative } \\
\text { case study. } \\
\text { Collection: } \\
\text { interviews, } \\
\text { policy } \\
\text { documents, } \\
\text { newspaper } \\
\text { articles, online } \\
\text { material (no } \\
\text { justification } \\
\text { selection). }\end{array}$ & $\begin{array}{l}\text { People within } \\
\text { the Philadelphia } \\
\text { Water } \\
\text { Department } \\
\text { (administration) }\end{array}$ & $\begin{array}{l}\text { Subnational; } \\
\text { Philadelphia, } \\
\text { USA; Climate } \\
\text { adaptation } \\
\text { policy (green } \\
\text { stormwater } \\
\text { infrastructure } \\
\text { (GSI).) }\end{array}$ & $\begin{array}{l}\text { Too little finance within water department, } \\
\text { and for implementation collaboration with } \\
\text { other departments was needed. }\end{array}$ \\
\hline $\begin{array}{l}51 . \\
(248)\end{array}$ & $\begin{array}{l}\text { Rietig, } \\
2016\end{array}$ & No. & $\begin{array}{l}\text { International } \\
\text { environmental } \\
\text { NGO's (NGO) }\end{array}$ & $\begin{array}{l}\text { Global; } \\
\text { UNFCCC, } \\
\text { COP climate } \\
\text { negotiations }\end{array}$ & $\begin{array}{l}\text { At the international level, when negotiations } \\
\text { taking plae, different parties have already } \\
\text { decided on their positions and can hardly be } \\
\text { influenced }\end{array}$ \\
\hline
\end{tabular}


Strategy

2 NGO's used their financial and normative influence to strategically define policy problem and to boost its importance on decision-making agenda.

Ensured representation in policy proposal development (which they did not naturally had) through UNICEF. This restructuring ultimately favoured funders interests.

After refusal from funders gridlock. Until UNICEF organized int. meeting on iCCM and invited $\mathrm{MoH}$ stakeholders. One $\mathrm{MoH}$ actor at least convinced of pneumonia, and became entrepreneur back home. Then govment resubmitted proposal including pneumonia treatment

Water department sent people from their department from different levels to meetings of the Parks and Recreation dept.

Water Dept. placed water managers in other depts to learn about the routines of the depts, to learn how to integrate GSI there.

Their framing if GSI focused not solely on climate adaptation, but addressed other challenges in the city in order to gain support for implementation from other depts and the public.

Established pilot projects to convince other depts

INGOs target national countries at the domestic level, when they are forming their positions for the negotiations. or NGO's influence during large international conferences, but an impact will only occur after some time, and not in that particular conference/meeting

\section{Implications \\ Type}

Representation of

UNICEF secured

their say and led to

the favouring of their

interests. However

initially this did not

lead to inclusion of

pneumonia treatment

in proposal.

Need for collaboration

Institutional

between departments,

but other department

were reluctant to

collaborate. 
5. Data extraction table II: strategies

\begin{tabular}{|c|c|c|c|c|}
\hline Article & How & Type & Issue arena & Strategy \\
\hline Ackrill & $\begin{array}{l}\text { Trade commissioner Lamy proposed duty-free quota-free } \\
\text { policy for Least Developed Countries, EBA, to include sugar. } \\
\text { Unrestricted sugar exports would undermine protected, high- } \\
\text { priced, EU market regime. Lamy was fully aware of this and used } \\
\text { it to put pressure on DG-AGRI }\end{array}$ & Hori & Shift? & $\begin{array}{l}\text { Institutional } \\
\text { manipulation }\end{array}$ \\
\hline \multirow[t]{2}{*}{ Arieli } & $\begin{array}{l}\text { Therefore entrepreneurs engage in coalition building on two } \\
\text { spheres: horizontal and vertical. Horizontal: identify cross-border } \\
\text { contacts for cooperation in parallel organizations and functions } \\
\text { to serve personal and/or organizational interests. Vertically: seek } \\
\text { authorization and support from higher level politicians and } \\
\text { bureaucrats for cross-border aspects of their local activity. }\end{array}$ & $\begin{array}{l}\text { Hori } \\
\text { Verti- } \\
\text { BU }\end{array}$ & Enlarge & $\begin{array}{l}\text { Coalition } \\
\text { building }\end{array}$ \\
\hline & $\begin{array}{l}\text { Organized initiative to facilitate communication between mayors } \\
\text { of neighbouring communities and local public. Participated in } \\
\text { seminars and outings to indicate needs }\end{array}$ & $\begin{array}{l}\text { Verti } \\
\text { TD }\end{array}$ & Enlarge & Promote \\
\hline Black & $\begin{array}{l}\text { Both China and Japan took opportunity to spread certain idea } \\
\text { about them as great powers, with different frames }\end{array}$ & $\begin{array}{l}\text { Verti } \\
\text { BU }\end{array}$ & Enlarge & promote \\
\hline Blavoukos & $\begin{array}{l}\text { Papandreou gave speech in september } 1999 \text { in UN General } \\
\text { Assembly to enhance Greek-Turkish relations, because of } \\
\text { underlying assumptions that closer entanglement within EU } \\
\text { would bring forward series of reforms in Turkey that would } \\
\text { eventually necessitate abandonment of aggression in bilateral } \\
\text { relationship }\end{array}$ & $\begin{array}{l}\text { Verti } \\
\mathrm{BU}\end{array}$ & Enlarge & promote \\
\hline \multirow[t]{3}{*}{ Boasson } & $\begin{array}{l}\text { Approaching Copenhagen summit and energy security issue } \\
\text { used by entrepreneurs to create sense of urgency and frame } \\
\text { CCS as solution to these problems. }\end{array}$ & $\begin{array}{l}\text { Verti hori } \\
\text { diago } \\
\text { BU }\end{array}$ & Enlarge & frame \\
\hline & $\begin{array}{l}\text { Linking CCS to renewable energy in the funding mechanism, in } \\
\text { order to gain support from CCS sceptics }\end{array}$ & Hori & $\begin{array}{l}\text { Integrate } \\
\text { (CCS } \\
\text { in NER } \\
\text { funding) }\end{array}$ & $\begin{array}{l}\text { Frame/ } \\
\text { manipulate }\end{array}$ \\
\hline & $\begin{array}{l}\text { Touring capitals of EU member states to promote the } \\
\text { parliaments amendments to the CCS to create leverage for }\end{array}$ & $\begin{array}{l}\text { Verti } \\
\text { TD }\end{array}$ & integrate & $\begin{array}{l}\text { Venue shop? } \\
\text { Promote }\end{array}$ \\
\hline
\end{tabular}


5. Data extraction table Il: continued

\begin{tabular}{|c|c|c|c|c|}
\hline Article & How & Type & Issue arena & Strategy \\
\hline \multirow[t]{9}{*}{ Boekhorst } & $\begin{array}{l}\text { WWF used its national and international network to stimulate } \\
\text { acceptance and application of IRBM. }\end{array}$ & $\begin{array}{l}\text { Verti } \\
\text { BU,TD }\end{array}$ & Enlarge & $\begin{array}{l}\text { Coalition, } \\
\text { promote, shop }\end{array}$ \\
\hline & $\begin{array}{l}\text { Built coalition with Chinese Academy of Sciences and State } \\
\text { Forestry Administration. Led to staff training and site listing for } \\
\text { protection, but not much impact. }\end{array}$ & $\begin{array}{l}\text { Verti } \\
\text { TD }\end{array}$ & Enlarge & coalition \\
\hline & $\begin{array}{l}\text { Built coalitions as well with local stakeholders and governments } \\
\text { in the river basin. Led to discovery of experts and funding } \\
\text { necessary for launching the Living River Program. }\end{array}$ & $\begin{array}{l}\text { Verti } \\
\text { TD }\end{array}$ & Enlarge & Coalition \\
\hline & $\begin{array}{l}\text { Moreover, WWF also established networks internationally by } \\
\text { linking up with the CCICED. WWF provided secretariat for } \\
\text { IRBM Task Force (which was jointly established with CCICED) } \\
\text { WWF managed to incorporate their approach in CCICED } \\
\text { recommendations. Also, WWF through its coalition could deliver } \\
\text { recommendations to the premier of the state council (without } \\
\text { having to pass through ministerial levels). }\end{array}$ & $\begin{array}{l}\text { Verti } \\
\text { BU }\end{array}$ & Enlarge & Coalition \\
\hline & $\begin{array}{l}\text { In parallel, it held close contacts with academic field, led to } \\
\text { media coverage in form of special issue in National Chinese } \\
\text { Geographic, and articles in China Daily Newspaper, creating } \\
\text { awareness in and outside of China. }\end{array}$ & $\begin{array}{l}\text { Verti } \\
\text { TD }\end{array}$ & Enlarge & Promote \\
\hline & $\begin{array}{l}\text { Informed politicians at all levels through field visits, conferences, } \\
\text { lectures etcetera to create support and inform stakeholders. }\end{array}$ & $\begin{array}{l}\text { Verti } \\
\text { TD }\end{array}$ & Enlarge & $\begin{array}{l}\text { Awreness/ } \\
\text { promotion }\end{array}$ \\
\hline & $\begin{array}{l}\text { Started pilot projects in local areas who were willing to get along } \\
\text { with WWF (because it raised living conditions local inhabitants). } \\
\text { WWF organized meetings with local people to explain them } \\
\text { about functioning river system (awareness sessions). Organized } \\
\text { workshops to come up with alternative income generating } \\
\text { activities. Created public support (especially because average } \\
\text { household income rose exponentially). }\end{array}$ & $\begin{array}{l}\text { Verti } \\
\text { TD }\end{array}$ & Enlarge & $\begin{array}{l}\text { Leading by } \\
\text { example }\end{array}$ \\
\hline & $\begin{array}{l}\text { China Council for International Cooperation on Environment } \\
\text { and Development (CCICED) devoted special taskforce to IRBM, } \\
\text { WWF linked up with institution to include recommendations. }\end{array}$ & $\begin{array}{l}\text { Verti } \\
\text { TD }\end{array}$ & Enlarge & $\begin{array}{l}\text { Manipulate } \\
\text { institutions }\end{array}$ \\
\hline & $\begin{array}{l}\text { Site visits, international conference, publications created visibility } \\
\text { and impact }\end{array}$ & $\begin{array}{l}\text { Verti } \\
\text { TD }\end{array}$ & Enlarge & $\begin{array}{l}\text { Awareness/ } \\
\text { promotion }\end{array}$ \\
\hline
\end{tabular}


5. Data extraction table Il: continued

\begin{tabular}{|c|c|c|c|c|}
\hline Article & How & Type & Issue arena & Strategy \\
\hline \multirow[t]{5}{*}{ Bourblanc } & $\begin{array}{l}\text { First brought it to higher administrative levels by bringing } \\
\text { criminal charges against leaders of intensive agriculture (and } \\
\text { not smaller agriculture actors), and subsequently involving the } \\
\text { Dept of Agriculture. DoA drew up first programme to deal } \\
\text { with pollution caused by agriculture. but since program did not } \\
\text { challenge intensive mode of production, further protest from } \\
\text { ERB. }\end{array}$ & $\begin{array}{l}\text { Verti } \\
\text { BU }\end{array}$ & Shift & $\begin{array}{l}\text { Manipulating } \\
\text { inst }\end{array}$ \\
\hline & $\begin{array}{l}\text { ERB started a juridical battle to try to force the French } \\
\text { administration to transpose European legislation into French law. }\end{array}$ & $\begin{array}{l}\text { Verti } \\
\text { BU }\end{array}$ & Integrate & manipulate \\
\hline & $\begin{array}{l}\text { To keep problem on agenda, ERB started to frame water } \\
\text { pollution in terms of nitrate concentration in drinking water and } \\
\text { the impact on human health (e.g. in its columns). }\end{array}$ & Hori & Enlarge & frame \\
\hline & $\begin{array}{l}\text { ERB appealed to EU authorities to have France's failure to } \\
\text { implement binding European legislation (European Directive } \\
\text { on to regulate use drinking water from surface water courses } \\
\text { in which nitrates exceed certain percentage) condemned. } \\
\text { French government convicted in } 2001 \text { and } 2007 \text {, resulting in } \\
\text { major pressure from EU to implement substantial changes in } \\
\text { agricultural practices. }\end{array}$ & $\begin{array}{l}\text { Verti } \\
\text { BU }\end{array}$ & Integrate & manipulate \\
\hline & $\begin{array}{l}\text { Since ERB wanted to place blame on Agriculture sector it did } \\
\text { not support other local NGO collective (CEP) in their campaign } \\
\text { to protest against water delivery services re. nitrates in drinking } \\
\text { water, as this would shift attention away from ag sector (as focus } \\
\text { on drinking water, not water resources), and towards water } \\
\text { service authorities and municipal authorities. }\end{array}$ & Hori & & Frame \\
\hline \multirow[t]{4}{*}{ Buhr } & $\begin{array}{l}\text { British institutional entrepreneurs used rotating presidency of } \\
\text { EU to come up with policy proposal, and emissions trading was } \\
\text { also something the aviation industry could live with. }\end{array}$ & Diago & Enlarge & Manipulate \\
\hline & $\begin{array}{l}\text { Entrepreneurs behind proposal linked arguments about } \\
\text { emissions trading to norms and values in institutional context to } \\
\text { promote preferred policy proposal. }\end{array}$ & $\begin{array}{l}\text { Verti } \\
\text { BU }\end{array}$ & Enlarge & frame \\
\hline & $\begin{array}{l}\text { Checked with different actors and felt little/no resistance to plan } \\
\text { of emissions trading scheme. }\end{array}$ & & & \\
\hline & $\begin{array}{l}\text { Aviation industry, also as entrepreneur, initially developed } \\
\text { proposal for ETS. This was initially developed at UK level and } \\
\text { then brought to EU level. Used EU level to gain broader support } \\
\text { from wider industry (their growth prospects were partly } \\
\text { dependent on environmentally responsible image) }\end{array}$ & $\begin{array}{l}\text { Verti } \\
\text { BU }\end{array}$ & Enlarge & Promote \\
\hline
\end{tabular}


5. Data extraction table Il: continued

\begin{tabular}{|c|c|c|c|c|}
\hline Article & How & Type & Issue arena & Strategy \\
\hline \multirow[t]{5}{*}{ Carter } & $\begin{array}{l}\text { FotE identified the government's failure to deliver emissions } \\
\text { reduction targets, defined a solution in the form of a climate } \\
\text { change bill, took Cameron for visit to Arctic to see impacts of } \\
\text { climate change, and eventually won cross-party political support } \\
\text { for it. }\end{array}$ & $\begin{array}{l}\text { Verti } \\
\text { TD }\end{array}$ & Enlarge & Promote \\
\hline & $\begin{array}{l}\text { Tony Blair pushed climate change onto international agenda } \\
\text { already before FoE took it up. ( } \mathrm{G} 8 \text { and } \mathrm{EU} \text { presidencies). through } \\
\text { Stern report other parties began promoting and framing low } \\
\text { carbo economy as opportunity for business. }\end{array}$ & $\begin{array}{l}\text { Verti } \\
\text { BU }\end{array}$ & Enlarge & promote \\
\hline & $\begin{array}{l}\text { David Miliband (Secretary of State at DEFRA) created new } \\
\text { government institution, Inter Departmental office for Climate } \\
\text { Change (OCC) that represented all main departments } \\
\text { affecting GHG emissions, including environment, energy, } \\
\text { transport, business, overseas development, foreign office, } \\
\text { cabinet office, treasury. Was given responsibility for developing } \\
\text { and passing climate change bill (which would normally have } \\
\text { been undertaken by internal DEFRA team). As such different } \\
\text { (conflicting) interests together to generate consensus. Effect was } \\
\text { noticeable undermining of treasury's formerly influence }\end{array}$ & Hori & Enlarge & Manipulate \\
\hline & $\begin{array}{l}\text { David Miliband took issue of EU ETS cap and turned it into major } \\
\text { symbolic battle within cabinet on governments environmental } \\
\text { credentials }\end{array}$ & $\begin{array}{l}\text { Verti } \\
\text { (diago) } \\
\text { TD }\end{array}$ & Enlarge? & promote \\
\hline & The third venue shift was the creation of a new ministry, the & Hori & Integrate & Manipulate \\
\hline
\end{tabular}

Department for Energy and Climate Change (DECC), in

October 2008. It combined the energy and climate portfolios previously split between the DTI (renamed the Department for Business, Enterprise and Regulatory Reform (BERR)) and DEFRA, with the aim of institutionalizing a coordinated approach to CCEP. Under an energetic Secretary of State, Ed Miliband, DECC quickly

adopted ambitious emissions reductions at home and abroad as its main priority and began to develop the policies required by the $\mathrm{EU}$ and CCA targets. 
5. Data extraction table Il: continued

\begin{tabular}{|c|c|c|c|c|}
\hline Article & How & Type & Issue arena & Strategy \\
\hline \multirow[t]{5}{*}{ Diez } & $\begin{array}{l}\text { Official launch of campaign at UN office Mexico, with presence } \\
\text { various NGOs, IOs, CSOs by government (promoting) }\end{array}$ & $\begin{array}{l}\text { Verti } \\
\text { BU }\end{array}$ & Enlarge & Promote \\
\hline & $\begin{array}{l}\text { As a reaction to the debate and to counter opposition to } \\
\text { their campaign, entrepreneurs decided to pursue } 2 \text { strategies: } \\
\text { first, expand alliance they had formed in favour of campaign, } \\
\text { by integrating international actors (PHO and UNAIDS). Asked } \\
\text { them to sign onto the initiative to allow them to present the } \\
\text { campaign as a collective initiative. } 2 \text { orgs started stating that } \\
\text { Mexico had to abide by international recommendations to fight } \\
\text { homophobia. (networking, institution) }\end{array}$ & $\begin{array}{l}\text { Verti } \\
\text { BU }\end{array}$ & Enlarge & $\begin{array}{l}\text { Coalition, } \\
\text { manipulate }\end{array}$ \\
\hline & $\begin{array}{l}\text { Assembly held series of consultations, regional fora, and meetings } \\
\text { with experts and members of civil society at large. After } \\
\text { consultations published report in which members presented } \\
\text { antidiscrimination draft bill and recommended establishment of } \\
\text { national council tasked with } 2 \text { main objectives: ensuring that such } \\
\text { law be implemented and promoting more generally a culture of } \\
\text { tolerance in the country. }\end{array}$ & $\begin{array}{l}\text { Verti } \\
\text { BU }\end{array}$ & Enlarge & coalition \\
\hline & $\begin{array}{l}\text { Report (in which members presented antidiscrimination draft } \\
\text { bill and recommended establishment of national council tasked } \\
\text { with } 2 \text { main objectives: ensuring that such law be implemented } \\
\text { and promoting more generally a culture of tolerance in the } \\
\text { country) was taken over by Fox and sent to Congress without } \\
\text { changes }\end{array}$ & $\begin{array}{l}\text { Verti } \\
\text { BU }\end{array}$ & Enlarge & manipulate \\
\hline & $\begin{array}{l}\text { Alliance developed arguments counter opposition and convince } \\
\text { government actors and public at large of need campaign, based }\end{array}$ & Hori & Enlarge & frame \\
\hline
\end{tabular}
on 2 frames: 1) homophobia as obstacle to fight aids (based on scientific data) thus involving public health; 2) human rights: prohibited discrimination against homosexuals 
5. Data extraction table Il: continued

\begin{tabular}{ll}
\hline Article & How \\
\hline Font & Entrepreneurs participated in technical meeting hosted by \\
& European Commission. \\
& Group of entrepreneurs also frequently provided info and \\
& lodged complaints to the European Commission. Also presented \\
petitions and questions to European Parliament, all of which \\
alleged that National Water Plan went against several EU \\
environmental directives (Environmental groups considered that \\
the large-scale infrastructure proposed in the Plan, in particular \\
the Ebro diversion, had negative effects on Special Areas of \\
Conservation and Special Protection Areas that constituted \\
the Natura 2000 Network, and that it would have severe \\
consequences for most water ecosystems).
\end{tabular}

Variety of social organizations launched intensive networking Verti campaign in Brussels in order to sell ideas opposed to EU BU financing of the work that was projected in the National Water Plan. These activities led to European Commission contacting Spain's Ministry of Environment to obtain information to decide on its own position. Thereafter send a letter to ministry to express their concern. Thereafter recommended it to produce strategic impact assessment

In 200 I entrepreneurs participated in Blue March to Brussels, Verti where they lodged complaints about the NWP to the European BU Commission and European Parliament $\rightarrow$ gained media attention $\rightarrow$ to activate resources and gain support

To put pressure on the government of Spain to withdraw the Verti 200I National Water Plan, different entrepreneurs, Greenpeace, BU WWF-Spain, SEO/Birdlife, and social movements, launched national and supra-national campaigns that condemned social, economic, and environmental consequences of the plan

Scientific actors as entrepreneurs undertook studies that Verti questioned the Plan, and adviced the European Commission BU on the plan, including strategic impact assessment, and socioeconomic assessment of transfer projects included in plan, to transform dominant policy image. WWF Spain for instance produced environmental assessment for impact projected dams and water transfers and their impact on Natura 2000 sites.

Forbes Conceptual: spanning levels is required to realise change. 'boundary bridging' as adjacent fields influencing each other through alternative viewpoints and practices. Need for actors to pass on these ideas - entrepreneurs.

I) microlevel institutional work: opportunity recognition: Hori reframing of health issues as stemming from socio-economic inequalities, making it a social issue as well. As such, integration was encouraged and current policy framed as failure. Entrepreneurs were also within institutions (NHS board, city council). agreed that integration would address problems, only however not sure what it should look like.

2) mesolevel inst work: designing new inst field: design to make Hori $\mathrm{NHS}$ and city council work on an equal basis.

3) macro-level inst work: legitimizing new institutional field: Verti at 2 levels, locally w/ city NHS members and professions, and TD nationally $\mathrm{w} /$ executive civil servants and ministers. had to negotiate and discuss a lot to convince people of added value

$\begin{array}{lll}\text { Type } & \text { Issue arena } & \text { Strategy } \\ \text { Verti } & \text { Enlarge } & \text { coalition } \\ \text { BU } & & \end{array}$

Integrate manipulate $\mathrm{BU}$ 西

mante

Enlarge Manipulate,
coalition

Shift manipulate

Enlarge promote

enlarge Promote

Enlarge, frame

integrate

Integrate Manipulate

Enlarge promote 
5. Data extraction table Il: continued

\begin{tabular}{|c|c|c|c|c|}
\hline Article & How & Type & Issue arena & Strategy \\
\hline \multirow[t]{3}{*}{ Gorton } & $\begin{array}{l}\text { Gutkauskas (Lithuania) worked for min ag and dept land use } \\
\text { and reclamation, and brought together scientists to prepare } \\
\text { programme on groundwater protection and sustainable } \\
\text { agriculture, program accepted and funded by government in } \\
1993 \text {. }\end{array}$ & Hori & Enlarge & Coalbuil \\
\hline & $\begin{array}{l}\text { Also founded NGO Tatula Fund, which he used to address } \\
\text { conferences and meetings, also internationally, and in EU- } \\
\text { context. This internationalized local problems. }\end{array}$ & $\begin{array}{l}\text { Verti } \\
\text { BU }\end{array}$ & Enlarge & $\begin{array}{l}\text { Manipulate, } \\
\text { promote }\end{array}$ \\
\hline & $\begin{array}{l}\text { In Poland, research carried out by Institute for Land Reclamation } \\
\text { and Grassland Farming (IMUZ), funded by US Environmental } \\
\text { Protection Agency, under leadership of PE Sapek. Findings were } \\
\text { framed as threat to human health, requiring investments for } \\
\text { improvement animal waste management. This led to many funds } \\
\text { coming in }\end{array}$ & $\begin{array}{l}\text { Diago } \\
\text { Hori } \\
\text { Verti } \\
\text { BU }\end{array}$ & Enlarge & $\begin{array}{l}\text { Promote } \\
\text { Frame }\end{array}$ \\
\hline \multirow[t]{2}{*}{ Grinstein } & $\begin{array}{l}\text { Entrepreneurs started short-term demonstration project in } \\
3 \text { states, to overcome reluctance from public welfare policy } \\
\text { (demonstrating, support) }\end{array}$ & $\begin{array}{l}\text { Verti } \\
\text { TD }\end{array}$ & Enlarge & $\begin{array}{l}\text { Leading by } \\
\text { example }\end{array}$ \\
\hline & $\begin{array}{l}\text { Efforts of non-profit orgs were critical in moving IDA policy } \\
\text { dialogue to national level, by using national platforms at } \\
\text { conferences, web sites, networking expertise to disseminate } \\
\text { pivotal research findings emerging from American Dream } \\
\text { Policy Demonstration (ADD), a large-scale multi-site IDA } \\
\text { demonstration project. (networking/promoting, support) }\end{array}$ & $\begin{array}{l}\text { Verti } \\
\text { BU }\end{array}$ & Shift & Promote \\
\hline \multirow[t]{2}{*}{ Hammond } & $\begin{array}{l}\text { Meanwhile, he also intervened in the development of the policy } \\
\text { in the province. He suggested the city of Dalian establish an } \\
\text { MLG system to provide an example - which happened. Dalian } \\
\text { served as an example for other cities throughout China.Through } \\
\text { example served to expand the experience, methods and } \\
\text { support that could be drawn upon. }\end{array}$ & $\begin{array}{l}\text { Verti } \\
\text { TD }\end{array}$ & Enlarge & $\begin{array}{l}\text { Leading by } \\
\text { example }\end{array}$ \\
\hline & $\begin{array}{l}\text { Duoji shifted policy onto national agenda and pushed for } \\
\text { implementation, by mentioning it in speech at Tenth National } \\
\text { Civil Affairs Congress (because, according to the author, he as } \\
\text { a minister was unable to provide legislative or fiscal support for } \\
\text { the policy) }\end{array}$ & $\begin{array}{l}\text { Verti } \\
\text { BU }\end{array}$ & Shift & promote \\
\hline \multirow[t]{2}{*}{ lusmen } & $\begin{array}{l}\text { Commission officials in DG ELARG highlighted how the } \\
\text { Romanian case has provided them with knowledge and } \\
\text { expertise in key principles and implementation mechanisms } \\
\text { underlying the UNCRC (demonstrate - resources) }\end{array}$ & $\begin{array}{l}\text { Verti } \\
\text { TD }\end{array}$ & Shift & $\begin{array}{l}\text { Leading by } \\
\text { example }\end{array}$ \\
\hline & $\begin{array}{l}\text { Frattini used the example of Romania and its child-rights policy } \\
\text { (which provided knowledge and expertise) to find support for } \\
\text { an EU-wide policy on children's rights (demonstrating - support) }\end{array}$ & $\begin{array}{l}\text { Verti } \\
\text { TD }\end{array}$ & Shift & $\begin{array}{l}\text { Leading by } \\
\text { example }\end{array}$ \\
\hline Kugelberg & $\begin{array}{l}\text { Aileen Robertson, (state secretary for public health) individual } \\
\text { responsible for advising countries within WHO European } \\
\text { Region on public health and national nutrition policy, proposed } \\
\text { to undertake Health Impact Assessment from the CAP (EU) } \\
\text { to convince the Ministry of Agriculture, Food and Forestry to } \\
\text { support the food and nutrition plan, and eventually brought } \\
\text { together ministry health and ministry agriculture, food, forestry } \\
\text { because their objectives were met and CAP could fund } \\
\text { (resources - institution/networking) }\end{array}$ & Diago & Integrate & $\begin{array}{l}\text { Frame, } \\
\text { manipulate }\end{array}$ \\
\hline
\end{tabular}


5. Data extraction table Il: continued

\begin{tabular}{|c|c|c|c|c|}
\hline Article & How & Type & Issue arena & Strategy \\
\hline \multirow[t]{6}{*}{ Maltby } & $\begin{array}{l}\text { Conceptual: while each Commission DG has own overlapping, } \\
\text { but distinct purview within Council's often general aims and } \\
\text { direction, in this case there are synergies between DGs trade, } \\
\text { External Relations, Energy, and Climate on interlinking issues } \\
\text { related to energy. Strategically minded actors frame initiatives } \\
\text { to fit with certain institutional venues. Different venues may } \\
\text { have different priorities and perceive EU concern differently, yet } \\
\text { solutions need not be mutually exclusive. }\end{array}$ & & & \\
\hline & $\begin{array}{l}\text { In its communications the Commission increasingly referred } \\
\text { to energy security as supranational issue to be solved at } \\
\text { Commission level }\end{array}$ & Verti & Shift & $\begin{array}{l}\text { Manipulate, } \\
\text { promote }\end{array}$ \\
\hline & $\begin{array}{l}\text { UK's EU presidency study concluded that stronger EU energy } \\
\text { policy cooperation was necessary to improve security of } \\
\text { supplies. This was to secure national gas security, as UK had } \\
\text { always been exporter but then became net importer of gas } \\
\text { (resources) - whereas UK had been one of most important } \\
\text { opposers of joint policy }\end{array}$ & $\begin{array}{l}\text { Verti } \\
\text { BU }\end{array}$ & Shift & Promote \\
\hline & $\begin{array}{l}\text { Commission has created multiple different policy frames to } \\
\text { make energy legislation at supranational level viable and enhance } \\
\text { support for a common energy policy: security, environmental } \\
\text { protection (framing - institution/support) }\end{array}$ & Diago & Shift & Frame \\
\hline & $\begin{array}{l}\text { Identification surpranational scale of energy governance as } \\
\text { necessary solution to policy problem is one which is socially } \\
\text { constructed. }\end{array}$ & & & \\
\hline & $\begin{array}{l}\text { Commission utilized expert studies to establish knowledge- } \\
\text { based authority on the issue of energy }\end{array}$ & $\begin{array}{l}\text { Verti } \\
\text { BU }\end{array}$ & Shift & $?$ \\
\hline \multirow[t]{6}{*}{ Meijerink } & $\begin{array}{l}\text { Example smaller scale implementation to gain experience with } \\
\text { the proposed policy and demonstrate feasibility and benefits } \\
\text { of newly proposed approaches (such as Plan Stork in the } \\
\text { Netherlands or floodplain restoration in Bodrogköz area before } \\
\text { it was adopted at the national level) }\end{array}$ & $\begin{array}{l}\text { Verti } \\
\text { TD }\end{array}$ & Enlarge & $\begin{array}{l}\text { Leading by } \\
\text { example }\end{array}$ \\
\hline & $\begin{array}{l}\text { a minister in Indonesia purposefully moved a specific department } \\
\text { from one ministry to another in order to minimize the influence } \\
\text { of the conservative old guard to enable smoother processes. }\end{array}$ & Hori & Shift & Manipulate \\
\hline & $\begin{array}{l}\text { Donor organizations are in position to impose change through } \\
\text { formulation of conditions to funding. }\end{array}$ & & & \\
\hline & $\begin{array}{l}\text { WWF in China managed to gain support for ecosystem } \\
\text { restoration projects by addressing economic needs of the local } \\
\text { population at the same time. }\end{array}$ & $\begin{array}{l}\text { Verti } \\
\text { TD }\end{array}$ & Enlarge & promote \\
\hline & $\begin{array}{l}\text { Manipulating venues to have their own ideas or their coalition } \\
\text { represented where policy-relevant issues are discussed, and } \\
\text { bypass those who resist the change proposed. }\end{array}$ & & & Manipulate \\
\hline & $\begin{array}{l}\text { Venue-shopping: for local initiatives to be scaled up, they need to } \\
\text { be linked to higher level }\end{array}$ & $\begin{array}{l}\text { Verti } \\
\text { BU }\end{array}$ & Enlarge & Promote \\
\hline
\end{tabular}


5. Data extraction table Il: continued

\begin{tabular}{lllll}
\hline Article & How & Type & Issue arena & Strategy \\
\hline Mintrom & $\begin{array}{l}\text { Networking across state lines for I) learning about details of Hori } \\
\text { innovations elsewhere (and gain expertise) this can increase } \\
\text { the credibility of the entrepreneur, because they can more } \\
\text { readily give authoritative-sounding responses to questions or } \\
\text { objections raised concerning proposed policy innovation; 2) }\end{array}$ & $\begin{array}{l}\text { Enlarge/ } \\
\text { diversify }\end{array}$ & Coalition \\
& $\begin{array}{l}\text { draw upon experts from other states to give testimony on } \\
\text { earlier experiences with policy innovation; 3) what strategies are } \\
\text { successful in other states for selling particular innovation }\end{array}$ & & \\
& Bush and his team used their experience from implementing a Verti & Enlarge & Leading by \\
Miskel & example
\end{tabular}

Mukhtarov Conceptual: identify (I) scale-based strategies, emphasize importance to target narratives at multiple venues across scales of governance, construct problems and solutions as pertinent to certain geographical scale, engage in networking and coalitionbuilding that span scales of governance. (2) meaning-based strategies, underline importance of developing ideas and linking them to narratives and dominant ideas in policy setting in quest for legitimacy, and presenting them in politically palatable way. (3) context-based strategies, imply necessity to understand context in which narratives are advanced and may involve enrolling some actors in coalitions while excluding others, and keeping alert to opportunities to advance opportunities at particular time and place

(framing) PARC proposed to approach the 2 protected sites Ver as an integrated national park, however this was met with TD reluctance from the provincial authorities who did not want to share authority. Also competition between which level would get authority over certain jurisdiction (thus not successful!)

Link with IUCN $\rightarrow$ recommend implementation at UNESCO Verti share information, discuss best practices, release joint resolutions $\rightarrow$ establish working groups $\rightarrow$ develop collaborative policy initiatives; formulated proposal for EU reform

Trans-governmental network of data privacy authorities framed Verti issue of supranational data privacy protection as prerequisite for $\mathrm{BU}$ further market and administrative integration in Europe to get their support (and making it transnational instead of domestic issue). They played on symbolic importance of the single market to both Commission and single member states

Data authorities threatened to block trans-border data flows, Verti (55) Shift changing the regulatory reversion point (that is, changing $\mathrm{BU}$ regulatory status-quo that would exist in absence supranational legislation, altering cost-benefit to other policymakers of inaction) to create support for their proposals 
5. Data extraction table Il: continued

\begin{tabular}{|c|c|c|c|c|}
\hline Article & How & Type & Issue arena & Strategy \\
\hline Palmer & $\begin{array}{l}\text { European Commission encouraged use of biofuels by linking } \\
\text { it to existing problems within European Union, in tripod style } \\
\text { approach: said that biofuels production may be of particular } \\
\text { interest under CAP for creating new economic resources and } \\
\text { preserving employment in agricultural community; in addition to } \\
\text { mitigating GHGs and enhance energy security. } \\
\text { Depicted biofuels as only readily available means of reducing } \\
\text { road transport GHG emissions, and depicting reduction of road } \\
\text { transport GHG emissions extremely difficult without biofuels } \\
\text { (whereas in reality alternative means were available). } \\
\text { Official } X \text { criticized studies that showed effects on land-use as } \\
\text { poor quality }\end{array}$ & Hori & Enlarge & Frame \\
\hline \multirow[t]{4}{*}{ Perkmann } & $\begin{array}{l}\text { EUREGIO actors engaged in various strategies: }(I) \text { interactional } \\
\text { projects aimed at bringing together actors previously not } \\
\text { connected, from different municipalities, with objective of } \\
\text { mobilizing resources from external agencies such as national } \\
\text { governments. }\end{array}$ & Hori & Shift & coalition \\
\hline & $\begin{array}{l}\text { (2) AEBR presented its case of cross-border collaboration to } \\
\text { politicians in the European Parliament by framing Euregions } \\
\text { within wider discourse of European integration: euregions } \\
\text { as constituting integration on small scale and building europe } \\
\text { from below } \rightarrow \text { border regions explicitly mentioned in European } \\
\text { Constitutional Treaty. }\end{array}$ & $\begin{array}{l}\text { Verti } \\
\text { BU }\end{array}$ & Shift & Promote \\
\hline & $\begin{array}{l}\text { (3) also target local politicians and civil servants. Installed } \\
\text { 'observatory' with branches at various european locations, and } \\
\text { sought out speaking and consulting engagements actoss europe: } \\
80 \text { workshops held, } 60 \text { reports published - all framing euregion } \\
\text { as european integration. }\end{array}$ & $\begin{array}{l}\text { Verti } \\
\text { TD }\end{array}$ & Shift & Promote \\
\hline & $\begin{array}{l}\text { Thus addressed } 3 \text { different fields: intergovernmental } \\
\text { relationships: germany - netherlands; CoE and EU. All have } \\
\text { different characteristics }\end{array}$ & & & \\
\hline
\end{tabular}


5. Data extraction table Il: continued

\begin{tabular}{|c|c|}
\hline Article & How \\
\hline Pralle & $\begin{array}{l}\text { Conceptual: Issue redefinition: shifting not only image of issue } \\
\text { but also the basis for considering those issues - what I call policy } \\
\text { principles: core values, beliefs, or guidelines attached to policies } \\
\text { that help direct decision-making. }\end{array}$ \\
\hline & $\begin{array}{l}\text { Venue shopping searching for alternative policy arenas and } \\
\text { efforts to move decision-making authority to new venues. } \\
\text { Keeping issues out of venues they would rather not participate } \\
\text { in as well as move decision-making to new arenas. Successful } \\
\text { entrepreneurs may force opponents to compete in arenas } \\
\text { where opponents are at disadvantage or to expend resources } \\
\text { waging battles in multiple venues when they would prefer to } \\
\text { concentrate on just one. }\end{array}$ \\
\hline
\end{tabular}

Issue definition and venue shopping often go hand in hand.

PEs might try and redefine an issue to move consideration of it Verti into new policy venue, where decisions, rules, norms, procedures BU differ. Moving seemingly local issue to international policy arena, for example, requires redefining issue to emphasize global implications and importance.

Cities are sensitive to what other cities do. Advocacy groups Verti in cities must form national networks to take advantage BU of openness provided by federal structures; sharing of info and campaign expertise among cities facilitates diffusion of progressive policies.

Different environmental organizations, both regional and Verti national united and launched Campaign for Pesticides Reduction BU (CPR). Shared resources and info about campaigns through internet, email and person.

Also environmental, labour and health organizations linked up to Hori map the various risks of the use of pesticides.

Redefined use of lawn and garden pesticides in 3 ways: (I) Hori challenged ideal of entirely weed-free near-perfect lawn "dandelions are your friend". (2) argument about negative impact of lawn chemicals on children's health sparked chord with general public and were key factor gaining attention to issue; focusing on children to mobilize large segments of population, and because children are positively constructed target populations policymakers often feel pressure to direct policy to them. Trade-off children;'s health and weed-free lawn became powerful frame for rallying public behind bylaws.

(3) involving precautionary principle in debate: policymakers should act to protect human health and environment even in the face of scientific uncertainty.

Hudson, town in Canada, first to assert its jurisdiction over Verti issue of pesticides, functioned as example for activists, who TD, BU subsequently put issue on other municipal agendas, in addition to the national venue where they were pushing (venue adding instead of venue shopping) pro was that companies were not prepared to fight battle at hundreds of city councils around Canada (and because multiple-level coalition was also at local, this was easy for activists, also they had better access to local politicians)
Shift

Manipulate

Enlarge Coalition

Enlarge Coalition

Enlarge Coalition

Enlarge Frame

Enlarge Promote 
5. Data extraction table Il: continued

\begin{tabular}{|c|c|}
\hline Article & How \\
\hline Verger & $\begin{array}{l}\text { Coalition/network of policy entrepreneurs, strategically placed in } \\
\text { influential international organizations, advocate for privatization } \\
\text { and ePPP through scientific and technical style. }\end{array}$ \\
\hline & $\begin{array}{l}\text { Policy prescriptions, beyond blueprints, need to inform } \\
\text { policymakers about necessary conditions (contextual, material } \\
\text { regulatory etc). this is certainly most challenging aspect for policy } \\
\text { entrepreneurs who aspire to prescribe policies aimed at fitting } \\
\text { in a broad range of time-place situations }\end{array}$ \\
\hline
\end{tabular}

Von Heland Establishment school for marine conservation, collaborative Verti investment between district government and Ministry of BU Marine Affairs and Fisheries (again, example of teaming up entrepreneurs for different purposes: whereas the national government used this as a strategy to overcome lack of trained staff to deal with MPAs, for Adhi this was a strategy to ensure the long-term perspective, beyond the electoral interests of politicians. Moreover, school also was a long-term strategy to promote cultural change among not only government institutions but also coastal communities. On top, from national perspective school links to broader national strategy to position Indonesia as leader in ocean issues (president Yudhoyono to initiate CTI, hosting world ocean conference 2009, world coral reef conference 2013)

Adhi and colleagues worked with "Hoga marine research Verti centre" (co-managed by essex university and Operation BU Wallacea - british ecosystem eco-tourism operator) $\rightarrow$ to push for ecosystem stewardship from above by organizations that can inspire and put pressure on local authorities.

Together applied for UNESCO Biosphere Reserves $\rightarrow$ for the Verti use of future conservation and fund raising activities, and also $\mathrm{BU}$ help institutionalize MPA management and ensure that marine environment remains prioritized by politicians $\rightarrow$ and hope that will attract more researchers and improve collaboration with central government.

Adhi from district government partnered with two major NGOs Verti (WWF and TNC) not only to improve park management but $\mathrm{BU}$ also to promote dive tourism, which would be a strong too to enhance the government's and the public's appreciation of marine biodiversity. Partnership $\rightarrow$ also led to investment of money by NGOs in the site

Enlarge Manipulate, coalition

Enlarge Coalition

Enlarge Coalition

Enlarge

Coalition 
5. Data extraction table Il: continued

\begin{tabular}{|c|c|c|c|c|}
\hline Article & How & Type & Issue arena & Strategy \\
\hline \multirow[t]{4}{*}{ Wejs } & $\begin{array}{l}\text { Necessary for entrepreneurs to build legitimacy for adaptation } \\
\text { plans. Used vulnerability as frame to do so }\end{array}$ & & & \\
\hline & $\begin{array}{l}\text { Recruit external expertise and secure funding for work towards } \\
\text { climate-change adaptation in municipality, through externally } \\
\text { funded research projects and networks, which provided } \\
\text { direct contact to climate researchers, whom PE could ask for } \\
\text { downscaled scenarios on issues considered important in local } \\
\text { context. Also access to northern coastal municipalities with } \\
\text { engagement in international network for downscaling solutions } \\
\text { (network, contacts } \rightarrow \text { expertise and funding) }\end{array}$ & $\begin{array}{l}\text { Verti } \\
\text { BU }\end{array}$ & Enlarge & Coalition \\
\hline & $\begin{array}{l}\text { Sought access to regional development funding from EU and } \\
\text { Danish regional authority, to create large projects, which gather } \\
\text { knowledge resources from different partners worldwide } \\
\text { (universities, research institutes, large companies) }\end{array}$ & $\begin{array}{l}\text { Verti } \\
\text { BU }\end{array}$ & Enlarge & \\
\hline & $\begin{array}{l}\text { Recruit external expertise and secure funding for work towards } \\
\text { climate-change adaptation in municipality, through externally } \\
\text { funded research projects and networks, which provided } \\
\text { direct contact to climate researchers, whom PE could ask for } \\
\text { downscaled scenarios on issues considered important in local } \\
\text { context. Also access to northern coastal municipalities with } \\
\text { engagement in international network for downscaling solutions } \\
\text { (network, contacts } \rightarrow \text { expertise and funding) }\end{array}$ & $\begin{array}{l}\text { Verti } \\
\text { BU }\end{array}$ & Enlarge & Coalition \\
\hline \multirow[t]{4}{*}{ Wigell } & $\begin{array}{l}\text { Aland lobbied with national government finland to establish } \\
\text { co-operative forum between aland and ministry foreign affairs. } \\
\text { Contact group started working: mapping out conflict zones } \\
\text { where aland could serve as example, international study visits and } \\
\text { research about Aland. Group discusses current developments } \\
\text { affecting Aland and initiatives regarding promotion Aland }\end{array}$ & $\begin{array}{l}\text { Verti } \\
\text { BU }\end{array}$ & Enlarge & Promote \\
\hline & $\begin{array}{l}\text { Aland (island) upholds interstate contacts with various states } \\
\text { and has representation in Nordic council to promote itself as } \\
\text { an example. }\end{array}$ & $\begin{array}{l}\text { Verti } \\
\text { BU }\end{array}$ & Enlarge & $\begin{array}{l}\text { Lead by } \\
\text { example }\end{array}$ \\
\hline & $\begin{array}{l}\text { Aland Islands Peace Institute (AIPI) an NGO has been active in } \\
\text { disseminating idea about Aland Example by organizing events } \\
\text { and hosting number of foreign groups (among whom Armenia, } \\
\text { Nagorno-Karabakh, Azerbaijan) who came together for peace } \\
\text { talks. This all to influence its domestic relations with Finnish } \\
\text { government. }\end{array}$ & Verti & Enlarge & promotion \\
\hline & $\begin{array}{l}\text { Finland (MoFA) organized and sponsored seminars and panels } \\
\text { in places such as New York, Brussels, Geneva with aim of } \\
\text { bringing Aland under attention of key orgs such as UN as well as } \\
\text { broader diplomatic community. And brings Aland up in several } \\
\text { other activities such as Ireland Peace talks, OSCE Parliamentary } \\
\text { Assembly Team on Moldova etc. talked about as inspiration } \\
\text { for constructive discussions and resource for Finnish public } \\
\text { diplomacy and brand-building }\end{array}$ & $\begin{array}{l}\text { Verti } \\
\text { BU }\end{array}$ & Enlarge & promote \\
\hline
\end{tabular}


5. Data extraction table Il: continued

\begin{tabular}{|c|c|c|c|c|}
\hline Article & How & Type & Issue arena & Strategy \\
\hline \multirow[t]{3}{*}{ Zhu } & $\begin{array}{l}\text { To reduce the perception of risk among decision-makers: } \\
\text { conducting pilot reforms or leading by example can reduce } \\
\text { political opposition and demonstrate the soundness of the plan } \\
\text { and also market the ideas amongst potential supporters. In } \\
\text { Guizhou, provincial guiding program set prototype for process of } \\
\text { innovation. Guiyang Municipal Housing Reform Office together } \\
\text { with provincial and municipal housing authorities worked } \\
\text { together and implemented reform. Reported success helped } \\
\text { silence opposition in Guizhou and drew positive attention from } \\
\text { all over the country. Demonstrated by Guiyang city, approach } \\
\text { extended to entire province, and then nationwide. Example } \\
\text { silence opposition }\end{array}$ & $\begin{array}{l}\text { Verti } \\
\text { TD, BU }\end{array}$ & Enlarge & $\begin{array}{l}\text { Leading by } \\
\text { example }\end{array}$ \\
\hline & $\begin{array}{l}\text { Created support among local community through media } \\
\text { coverage and informing them and seeking their input. Thereby } \\
\text { the provincial government did not dare to change the policy } \\
\text { direction that was set in, and had to continue after the PE left } \\
\text { the province. }\end{array}$ & $\begin{array}{l}\text { Verti } \\
\text { TD }\end{array}$ & Enlarge & Promote \\
\hline & $\begin{array}{l}\text { To increase legitimacy and support, and given the significance of } \\
\text { work units in the implementation of housing reform, dozens of } \\
\text { consultation meetings were held in different government depts, } \\
\text { research institutes and enterprises to get feedback and support } \\
\text { from employees across wide range of social strata. }\end{array}$ & Verti & Enlarge & Promote \\
\hline Zito & $\begin{array}{l}\text { Scandinavian experts defined problem of acid rain as } \\
\text { transnational, product of long-range air pollution emissions } \\
\text { from other European countries, strove to get issue identified as } \\
\text { serious in European Community and other IOs. UN Economic } \\
\text { Commission for Europe (UN/ECE) was interested, created } \\
\text { Convention on Long-Range Transboundary Air Pollution } \\
\text { (LTRAP) which provided policy framework for exchanging } \\
\text { technical info between member states. }\end{array}$ & $\begin{array}{l}\text { Verti } \\
\text { BU }\end{array}$ & Shift & Frame \\
\hline
\end{tabular}


Appendix

5. Data extraction table Il: continued

\begin{tabular}{|c|c|c|c|c|}
\hline Article & How & Type & Issue arena & Strategy \\
\hline \multirow[t]{7}{*}{ Bjorkdahl } & $\begin{array}{l}\text { When selected as non-permanent member of Security Council, } \\
\text { Sweden draw the Presidential conclusions wherein it linked } \\
\text { conflict prevention and peacekeeping. Worked to keep conflict } \\
\text { prevention on UN agenda, by linking it to R2P, because this was } \\
\text { UN adopted doctrine }\end{array}$ & $\begin{array}{l}\text { Verti } \\
\text { BU }\end{array}$ & Enlarge & Frame \\
\hline & $\begin{array}{l}\text { Sweden attempted to build support by approaching likeminded } \\
\text { countries bilaterally for informal meetings and interpersonal and } \\
\text { argumentative persuasion }\end{array}$ & Hori & Enlarge & Promote \\
\hline & $\begin{array}{l}\text { Established 'Group of Friends for Conflict prevention' and } \\
\text { various ad hoc coalitions with members of security council, to } \\
\text { mobilize support for their ideas. }\end{array}$ & Hori & Enlarge & Coalition \\
\hline & $\begin{array}{l}\text { Diplomatic tactics and persuasion kept conflict prevention on } \\
\text { the EU agenda in times when support for crisis management } \\
\text { grew strong. }\end{array}$ & $\begin{array}{l}\text { Verti } \\
\text { BU }\end{array}$ & Enlarge & Promote \\
\hline & $\begin{array}{l}\text { By occupying the rotating presidency of the } \mathrm{EU} \text { in } 200 \mathrm{I} \text {, Sweden } \\
\text { enjoyed privileged control over procedures, and normative } \\
\text { influence was enhanced. }\end{array}$ & $\begin{array}{l}\text { Verti } \\
\text { BU }\end{array}$ & Enlarge & Manipulate \\
\hline & $\begin{array}{l}\text { Norm entrepreneurship is about building winning coalitions. } \\
\text { Swedish representatives attempted to mobilise support for the } \\
\text { idea of conflict prevention within the UN as well as in the EU, } \\
\text { using informal meetings for interpersonal and argumentative } \\
\text { persuasion. }\end{array}$ & $\begin{array}{l}\text { Verti } \\
\text { BU }\end{array}$ & Enlarge & Coalition \\
\hline & Countries identified as likeminded or crucial to the success of & Hori & Enlarge & Coalition \\
\hline
\end{tabular}

the norm entrepreneurial activities were approached bilaterally

to build a critical mass (Bjorkdahl 2002a). 
5. Data extraction table Il: continued

\begin{tabular}{|c|c|c|c|c|}
\hline Article & How & Type & Issue arena & Strategy \\
\hline \multirow[t]{9}{*}{ Rosen } & $\begin{array}{l}\text { First step for NGO-entrepreneurs was to get president } \\
\text { Indonesia, Yudhoyono on board (as Indonesia would host COP), } \\
\text { therefore they had to liaison with individuals who could provide } \\
\text { access, away from public attention and behind closed doors. }\end{array}$ & Verti & Shift & Coalition \\
\hline & $\begin{array}{l}\text { To do so they first looked into what ongoing processes of } \\
\text { environmental policy making CTI could be linked to to prove } \\
\text { its relevance (such as Yudhoyono's push for impact of climate } \\
\text { change on food security) }\end{array}$ & Diago & Shift & $\begin{array}{l}\text { Frame, } \\
\text { promote }\end{array}$ \\
\hline & $\begin{array}{l}\text { Established CTI coordination committee, senior officials } \\
\text { meetings, national coordination committees, CTI secretariat; } \\
\text { to provide opportunity to engage in both domestic and } \\
\text { international policymaking; and to raise human, financial } \\
\text { resources and institutional capacity (thus targeting international } \\
\text { level) }\end{array}$ & $\begin{array}{l}\text { Verti } \\
\text { BU }\end{array}$ & Enlarge & $\begin{array}{l}\text { Manipulate, } \\
\text { coalition }\end{array}$ \\
\hline & $\begin{array}{l}\text { Institutional entrepreneurs (engaged in organizational issues) } \\
\text { provided technical support and actively facilitated multilateral } \\
\text { negotiations to develop RPOA, develop national agendas, } \\
\text { legal and financial arrangements. PEs mobilized travel funds, } \\
\text { distributing information, delivering logistical support, drafted } \\
\text { documents with right diplomatic wording. }\end{array}$ & Verti & Shift & $\begin{array}{l}\text { Promote, } \\
\text { network }\end{array}$ \\
\hline & $\begin{array}{l}\text { Lack of institutional capacity and resource asymmetries between } \\
\text { the } 6 \text { countries constituted barrier to change and called for } \\
\text { careful facilitation, both in meetings and between meetings, to } \\
\text { avoid deadlock }\end{array}$ & & & \\
\hline & $\begin{array}{l}\text { When the idea had been anchored at highest political level in } \\
\text { Indonesia, it was critical to communicate about CTI in ways that } \\
\text { could secure sufficient outreach and international recognition. } \\
\text { Had to seize opportunity provided by string of scheduled } \\
\text { international events (COP } 8 \text { and APEC meeting) to introduce } \\
\text { CTI to international community. Decided to have parallel } \\
\text { activities from the side of NGOs at the same time as well. (thus } \\
\text { targeting national levels_) }\end{array}$ & $\begin{array}{l}\text { Verti } \\
\text { BU }\end{array}$ & Enlarge & Promote \\
\hline & $\begin{array}{l}\text { After } 9 \text { ? I I and Bali bombings there was interest from US to } \\
\text { invest in Indonesia and reach muslim population, stability in } \\
\text { southeast Asia, CTI provided good opportunity to increase } \\
\text { political presence in region for USA. }\end{array}$ & Verti & Enlarge & Promote \\
\hline & $\begin{array}{l}\text { Before the Manado meeting (where CTI would be signed) there } \\
\text { was daily contact with entrepreneurs and countries to discuss } \\
\text { and prepare for the event. }\end{array}$ & $\begin{array}{l}\text { Verti } \\
\text { BU }\end{array}$ & Enlarge & Coalition \\
\hline & $\begin{array}{l}\text { The impact of institutional entrepreneurship was reinforced } \\
\text { by the appointment of a number of 'CTI officials' within the } \\
\text { six governments. Simultaneously, with NGO support a person } \\
\text { from UN was recruited strengthen the CTI secretariat and } \\
\text { regional coordination, and the US government set up the US } \\
\text { CTISP to deliver support to the countries and galvanize regional } \\
\text { collaboration }\end{array}$ & $\begin{array}{l}\text { Verti } \\
\text { BU }\end{array}$ & Enlarge & Manipulate \\
\hline
\end{tabular}


5. Data extraction table Il: continued

\begin{tabular}{|c|c|c|c|c|}
\hline Article & How & Type & Issue arena & Strategy \\
\hline \multirow[t]{4}{*}{ Alimi } & $\begin{array}{l}\text { Widespread social media coverage, outreach campaigns, } \\
\text { partnerships. }\end{array}$ & $\begin{array}{l}\text { Verti } \\
\text { BU }\end{array}$ & Enlarge & $\begin{array}{l}\text { Promote, } \\
\text { coalition }\end{array}$ \\
\hline & $\begin{array}{l}\text { Joining up with wider community of global drug policy reformers, } \\
\text { to enhance legitimacy. }\end{array}$ & $\begin{array}{l}\text { Verti } \\
\text { BU }\end{array}$ & Enlarge & $\begin{array}{l}\text { Promote, } \\
\text { coalition }\end{array}$ \\
\hline & $\begin{array}{l}\text { Playing within multiple arenas to link its message to wide range } \\
\text { of authorities. }\end{array}$ & & & \\
\hline & $\begin{array}{l}\text { Linking global discourse and local (or regional) implementation } \\
\text { by organizing tailor-made local programmes and activities }\end{array}$ & $\begin{array}{l}\text { Verti } \\
\text { BU,TD }\end{array}$ & Enlarge & \\
\hline \multirow[t]{5}{*}{ Brinkerhof } & $\begin{array}{l}\text { Involvement of the right stakeholders (international donors, } \\
\text { different ministers) provided a demonstration effect and moral } \\
\text { authority for broadening persuasion efforts and acceptance. }\end{array}$ & $\begin{array}{l}\text { Verti } \\
\text { BU }\end{array}$ & Enlarge & $\begin{array}{l}\text { Coalition, } \\
\text { network }\end{array}$ \\
\hline & $\begin{array}{l}\text { Taskforce under head of Gabre-Madhin included study tours to } \\
\text { Chicago and India for inspiration. }\end{array}$ & & & \\
\hline & $\begin{array}{l}\text { Legesse convinced donors to pool resources to support the } \\
\text { ECX. }\end{array}$ & & & \\
\hline & $\begin{array}{l}\text { In reaction to opposition from buyers, the prime minister } \\
\text { organized meeting with entire coffee industry. }\end{array}$ & & & \\
\hline & $\begin{array}{l}\text { Different tactics for different stakeholders at different levels: local } \\
\text { smaller traders persuaded, but international buyers eventually } \\
\text { with compulsory power: adoption law to manage transaction } \\
\text { costs }\end{array}$ & $\begin{array}{l}\text { Verti } \\
\text { BU }\end{array}$ & & \\
\hline Budabin & $\begin{array}{l}\text { Mia Farrow published op-ed in wall street journal (ad other } \\
\text { media subsequently) criticising China for hosting Sudan. Her } \\
\text { actions raised global membership of I } 30 \text { million }\end{array}$ & $\begin{array}{l}\text { Verti } \\
\text { BU }\end{array}$ & Enlarge & promote \\
\hline \multirow[t]{5}{*}{ Davidson } & $\begin{array}{l}\text { ENGOs link different kinds of knowledge across scales, } \\
\text { translating between citizens, experts and politicians. }\end{array}$ & & & \\
\hline & $\begin{array}{l}\text { Entrepreneurs can thereby act as conduits of info across scales, } \\
\text { serving as bridge between actors, and breaking down barriers } \\
\text { across scales and between different types of knowledge.Various } \\
\text { activities needed to resonate with different levels of government. }\end{array}$ & & & \\
\hline & $\begin{array}{l}\text { RLSC joined forces with Environmental Defense (ED) national } \\
\text { actor, and Ontario Nature }(\mathrm{ON}) \text {. }\end{array}$ & $\begin{array}{l}\text { Verti } \\
\text { BU }\end{array}$ & & Coalition \\
\hline & ENGOs lobbied with different levels of government. & $\begin{array}{l}\text { Verti } \\
\text { BU }\end{array}$ & & Promote \\
\hline & $\begin{array}{l}\text { NGO's called for a shift in authority from local governance to } \\
\text { the provincial level, to a - to be established - Conservation } \\
\text { Authority }\end{array}$ & $\begin{array}{l}\text { Verti } \\
\text { BU }\end{array}$ & Shift & $\begin{array}{l}\text { Manipulate, } \\
\text { coalition }\end{array}$ \\
\hline \multirow[t]{2}{*}{ De Franco } & $\begin{array}{l}\text { UN special advisor for genocide prevention met in Brussels with } \\
\text { EU key figures to persuade them that EU should prioritize R2P. }\end{array}$ & $\begin{array}{l}\text { Verti } \\
\text { TD }\end{array}$ & Enlarge & Promote \\
\hline & $\begin{array}{l}\text { Then appoint special advisor for R2P, who was based in EU. She } \\
\text { made case for more active role regional organizations }\end{array}$ & $\begin{array}{l}\text { Verti } \\
\text { BU }\end{array}$ & Enlarge & Manipulate \\
\hline DeRynck & $\begin{array}{l}\text { This change in governor and board members, brought in new } \\
\text { thinking. German member who came aboard took charge of } \\
\text { banking union issues and liaised informally with Germany. }\end{array}$ & Verti & & $\begin{array}{l}\text { Network, } \\
\text { coalition }\end{array}$ \\
\hline
\end{tabular}

banking union issues and liaised informally with Germany. 
5. Data extraction table Il: continued

\begin{tabular}{|c|c|c|c|c|}
\hline Article & How & Type & Issue arena & Strategy \\
\hline DiRuggiero & $\begin{array}{l}\text { Following crisis ILO collaborated with G20 to promote policy } \\
\text { coherence for decent work in direct response to global } \\
\text { economic crisis. }\end{array}$ & Verti & Enlarge & coalition \\
\hline \multirow[t]{3}{*}{ Douglas } & $\begin{array}{l}\text { Janet Reno, newly established Attorney General took idea to } \\
\text { Washington and began pushing for federal funding }\end{array}$ & $\begin{array}{l}\text { Verti } \\
\text { BU }\end{array}$ & Enlarge & Promote \\
\hline & $\begin{array}{l}\text { Individuals involved with original drug courts founded National } \\
\text { Association of Drug Court Professionals (NADCP) to } \\
\text { promote drug court concept, share info and develop guiding } \\
\text { principles, support research and lobby Congress. Holding annual } \\
\text { conferences for promote drug courts and enable the exchange } \\
\text { of info, encouraged local officials to promote reform further in } \\
\text { their home states by establishing own state associations, and } \\
\text { provide model for how structure courts themselves. Establish } \\
\text { National Drug Court Institute to promote research. }\end{array}$ & $\begin{array}{l}\text { Verti } \\
\text { BU }\end{array}$ & Enlarge & $\begin{array}{l}\text { Coalition, } \\
\text { promote }\end{array}$ \\
\hline & $\begin{array}{l}\text { Chief Justice (federal gov) created New York State Commission } \\
\text { on Drugs and Courts to study and assess reform. Found wide } \\
\text { support, but also concern courts would not be realized unless } \\
\text { support from state. Thereto created Office of Court Drug } \\
\text { Treatment Programs (OCDTP) for supporting establishment } \\
\text { courts across every judicial jurisdiction in }\end{array}$ & $\begin{array}{l}\text { Verti } \\
\text { BU }\end{array}$ & Enlarge & Manipulate \\
\hline Hartmann & $\begin{array}{l}\text { NY. Provided trainings, and secured } 9 \text { million from federal level } \\
\text { for financing courts }\end{array}$ & & & \\
\hline \multirow[t]{3}{*}{ Heinze } & $\begin{array}{l}\text { Conversion foundations built groundwork for effective } \\
\text { collaboration by bringing together individuals and groups } \\
\text { from across organizations, sectors, and demographic groups in } \\
\text { the community. They discovered gaps, realized synergies, and } \\
\text { creatively integrated activities of existing actors. as such they } \\
\text { were able to define the social problem locally, develop social } \\
\text { capital in their communities and educate potential partners. }\end{array}$ & & & \\
\hline & $\begin{array}{l}\text { Partnerships for educational opportunities. County gvment to } \\
\text { learn from experts (local and national experts) about effective } \\
\text { management and strategy. }\end{array}$ & $\begin{array}{l}\text { Verti } \\
\text { BU }\end{array}$ & Enlarge & $\begin{array}{l}\text { Network } \\
\text { coalition }\end{array}$ \\
\hline & $\begin{array}{l}\text { conversion foundations from different states worked together } \\
\text { to pool information, support, resources. together they can } \\
\text { prioritize, share best practices, pool resources to secure } \\
\text { information and promote their interests to state government. }\end{array}$ & Hori & & Coalition \\
\hline \multirow[t]{3}{*}{ Hermansen } & $\begin{array}{l}2 \text { PEs - ENGOs Rainforest Foundation Norway (FRN) and } \\
\text { Norwegian Society for the Conservation of Nature/Friends of } \\
\text { the Earth (FEN) write letter to Prime Minister, and Ministers } \\
\text { Finance, Foreign Affairs, International Development: (redefine } \\
\text { issue of rainforests as solution to climate) climate action urgent, } \\
\text { deforestation as driver GHG; and ask for I billion \$. Letter is } \\
\text { based on Stern Review and IPCC report. }\end{array}$ & Hori & Integration & $\begin{array}{l}\text { Frame, } \\
\text { promote }\end{array}$ \\
\hline & $\begin{array}{l}\text { On the side organize hearings in parliament, meetings with } \\
\text { political parties and ministers. Flew in Brazilian NGO to } \\
\text { strengthen case, and give example of deal in Brazil. }\end{array}$ & Verti & $\begin{array}{l}\text { Integration, } \\
\text { enlarge }\end{array}$ & $\begin{array}{l}\text { Leading by } \\
\text { example, } \\
\text { promote }\end{array}$ \\
\hline & Organize meeting w/ Brazilian MinEnv & & & \\
\hline Mostly-tello & $\begin{array}{l}\text { Therefore activists link labour rights to arguments of trade } \\
\text { agreements (competition and export markets) }\end{array}$ & Hori & & Frame \\
\hline Occhipinti & $\begin{array}{l}\text { PEs make normative claims to convince member states of their } \\
\text { ideas. Present cross-border crime as transnational in nature }\end{array}$ & Verti & Shift & Frame \\
\hline
\end{tabular}


5. Data extraction table Il: continued

\begin{tabular}{ll}
\hline Article & How \\
\hline Orchard & (conceptual) Gaining support of states frequently requires norm \\
& entrepreneurs to operate at domestic level, either by persuading \\
domestic actors of relevance new norm by discursively linking it & to national interests or by overcoming opposition from domestic \\
& veto players or gatekeepers whose agreement is required for \\
& change in status quo. this can be done in 2 ways: ( 1 ) NE possess \\
& own sources of authority or legitimacy to exercise power across \\
& borders (however actions must be seen as to accord with \\
& whatever authorizes them to act, and must interact with other \\
& global governors, with similar forms of authority at int level). (2) \\
& can possess direct connections with domestic institutions or \\
& other ways to be able to mobilize domestic support (requires \\
& NE to be empowered by domestic agent).
\end{tabular}

Roosevelt was long silent on the issue (overstaffed and opposing) Verti but after Austrian Anschluss in 1938 took action: domestically BU ordered State Dept to combine Austrian and German quotas. Internationally called conference to address refugee problem.

Truman urged Congress to find ways whereby US could fulfil Verti responsibilities towards refugees. Actions led to Displaced Persons Act 1948, which distinguished for first time between migrants and DPs.

To persuade Congress Truman reframed issue of refugee Hor protection as security issue, in line with increasing tensions from CW.

Meanwhile at the int. level Truman used creation new IOs - Verti International Refugee Organization (IRO) and UNHCR and BU Refugee Convention to transmit norm to international norm and institutionalize it as common state practice.

Shearer 2 NGO's used their financial and normative influence to Verti strategically define policy problem and to boost its importance on decision-making agenda

Ensured representation in policy proposal development (which Verti they did not naturally had) through UNICEF. This restructuring BU ultimately favoured funders interests.

Enlarge Manipulate

After refusal from funders gridlock. Until UNICEF organized Verti int. meeting on $\mathrm{ICCM}$ and invited $\mathrm{MoH}$ stakeholders. One BU $\mathrm{MoH}$ actor at least convinced of pneumonia, and became entrepreneur back home. Then govment resubmitted proposal including pneumonia treatment

Uittenbroek Water department sent people from their department from Hori different levels to meetings of the Parks and Recreation dept.

Water Dept. placed water managers in other depts to learn Hori about the routines of the depts, to learn how to integrate GSI there.

Their framing if GSI focused not solely on climate adaptation, but Hori addressed other challenges in the city in order to gain support for implementation from other depts and the public.

integrate

Promote

Enlarge

Manipulate coalition

Enlarge

Coalition, promote

Established pilot projects to convince other depts

Hori/

Enlarge, integrate 
5. Data extraction table Il: continued

\begin{tabular}{|c|c|c|c|c|}
\hline Article & How & Type & Issue arena & Strategy \\
\hline Rietig & $\begin{array}{l}\text { INGOs target national countries at the domestic level, when } \\
\text { they are forming their positions for the negotiations. or NGO's } \\
\text { influence during large international conferences, but an impact } \\
\text { will only occur after some time, and not in that particular } \\
\text { conference/meeting }\end{array}$ & $\begin{array}{l}\text { Verti } \\
\text { TD }\end{array}$ & Enlarge & $\begin{array}{l}\text { Promote, } \\
\text { coalition }\end{array}$ \\
\hline
\end{tabular}




\section{Annex 2 (belonging to chapter 5)}

\section{Annex material}

Annex I. Selected (and missing) policies from Ministries Environment and

\section{Agriculture}

Table Ia. Agriculture Strategic Plans included in analysis

\begin{tabular}{lll}
\hline$\#$ & Title & Year \\
\hline 1 & Ministry of Agriculture Strategic Plan 2005 - 2009 & 2005 \\
2 & Ministry of Agriculture Strategic Plan 2008 - 2012 & 2008 \\
3 & Ministry of Agriculture, Livestock and Fisheries Strategic Plan 2013 - 2017 & 2013 \\
\hline
\end{tabular}

Table Ib. Agriculture Sectoral Policies included in analysis**

\begin{tabular}{|c|c|c|}
\hline \# & Title & Year \\
\hline I & Strategy for Revitalizing Agriculture 2004 - 2014 & 2004 \\
\hline 2 & National Policy on Cassava Industry & 2007 \\
\hline 3 & National Livestock Policy & 2008 \\
\hline 4 & National Oceans and Fisheries Policy Kenya & 2008 \\
\hline 5 & National Rice Development Strategy 2008 - 2018 & 2008 \\
\hline 6 & National Animal Breeding Policy & 2009 \\
\hline 7 & Agriculture Sector Development Strategy 2009 - 2020 & 2009 \\
\hline 8 & Agriculture (Farm Forestry) Rules & 2009 \\
\hline 9 & National Beekeeping Policy & 2009 \\
\hline 10 & National Seed Policy & 2010 \\
\hline । & National Poultry Policy & 2010 \\
\hline 12 & National Food and Nutrition Security Policy (NFNP) & 2011 \\
\hline 13 & National Agribusiness Strategy & 2012 \\
\hline 14 & The National Agricultural Sector Extension Policy (NASEP) & 2012 \\
\hline 15 & National Horticulture Policy & 2012 \\
\hline 16 & National Agricultural Research System Policy & 2012 \\
\hline 17 & National Dairy Development Policy & 2013 \\
\hline 18 & National Irrigation Policy & 2015 \\
\hline 19 & Kenya Veterinary Policy & 2015 \\
\hline 20 & National Potato Strategy 2016 - 2020 & 2016 \\
\hline 21 & Capacity Building Strategy for Agriculture Sector & 2017 \\
\hline
\end{tabular}

* Not all Agriculture policies could be retrieved, missing policies are listed in table 3. 
Table 2a. Environment Strategic Plans included in analysis

\begin{tabular}{cll}
\hline$\#$ & Title & Year \\
\hline I & National Environmental Management Authority Strategic Plan 2005 - 2010 & 2005 \\
2 & Ministry of Environment and Mineral Resources Strategic Plan 2008 - 2012 & 2008 \\
3 & National Environmental Management Authority Strategic Plan 2013-2018 & 2013 \\
\hline
\end{tabular}

Table 2b. Environment Policies included in analysis

\begin{tabular}{cll}
\hline$\#$ & Title & Year \\
\hline I & National Forest Policy & 2005 \\
2 & National Environment Action Plan Framework 2009-2013 & 2009 \\
3 & National Climate Change Response Strategy & 2010 \\
4 & Draft Wildlife Policy & 2011 \\
5 & National Wildlife Conservation and Management Policy & 2012 \\
6 & National Environment Policy & 2013 \\
7 & National Climate Change Action Plan 20I3-20I7 & 2013 \\
8 & National Forest Policy & 2014 \\
9 & Draft National Climate Change Framework Policy & 2014 \\
I0 & National Solid Waste Management Strategy & 2015 \\
II & Draft National Forest Policy & 2015 \\
I2 & National Adaptation Plan 20 I5-2030 & 2015 \\
I3 & Green Economy Strategy and Implementation Plan 2016-2030 & 2016 \\
14 & National Wildlife Conservation and Management Policy & 2017 \\
\hline
\end{tabular}

**all policies from the Ministry of Environment could be retrieved

Table 3: Agriculture Policies not included in analysis

\begin{tabular}{lll}
\hline$\#$ & Title & Year \\
\hline I & Kenya Rural Development Strategy 2002 - 20I7 & 2002 \\
2 & National Seed Industry Policy & 2004 \\
3 & National Agriculture Sector Extension Policy & 2005 \\
4 & National Horticulture Development Policy & 2005 \\
5 & National Potato Industry Policy & 2006 \\
6 & National Biotechnology and Development Policy & 2006 \\
7 & Nut Crops Development Policy and Bill & 2007 \\
8 & National Water Storage Policy & 2008 \\
9 & National Irrigation and Drainage Policy & 2008 \\
I0 & National Rabbit Development Strategy and Implementation Framework 20 I3-20 I7 & 20 I3 \\
II & Draft Agriculture Policy & 20 I4 \\
\hline
\end{tabular}




\section{Annex 2. Coding instructions \\ Selection documents}

- All strategic plans of both ministries, for consistency and comparability

- In addition, all policies issued/developed/under auspices of Ministries under research or relevant sector ministries [environment and agriculture] in the relevant time period 2003 - 2017 [as far as available]. As there is no comprehensive database from the government on ministerial policies and documents, comprise list of policies based on interviews, from various non-government organizations, academic publications, international organizations, grey literature, based on saturation approach.

\section{Policy frames}

\section{What is the purpose of the coding?}

Central question/purpose of coding policy documents from ministries is: how does the ministry frame issues of agriculture, climate change, environment, food security and development, and linkages among issues?

\section{Which sections to code?}

Code all sentences mentioning one of the following: climate change, agriculture, food security, development, environment (or related concepts). When coding agriculture policies, code all sentences mentioning climate change, development, environment and/or food security (do not code sentences only relating to agriculture). When coding environment policies, code all sentences relating to agriculture, climate change, development and/or food security (do not code sentences only on environment). For an indication of related concepts, see table 4. 
Table 4. Issues to code

\begin{tabular}{|c|c|c|}
\hline Issue & Definition & Words to look for (not exhaustive) \\
\hline Agriculture & $\begin{array}{l}\text { All issues relating to agriculture, } \\
\text { livestock, fisheries, horticulture }\end{array}$ & $\begin{array}{l}\text { Crop, yields, plant breeding, marine resources, } \\
\text { horticulture }\end{array}$ \\
\hline Climate change & $\begin{array}{l}\text { All issues relating to changing/ } \\
\text { uncertain weather patterns, both } \\
\text { mitigation and adaptation (not general } \\
\text { weather conditions) }\end{array}$ & $\begin{array}{l}\text { Climate change, adaptation, mitigation, GHGs, } \\
\text { rising/changing temperatures, changes in } \\
\text { droughts/floods/rainfall, warming }\end{array}$ \\
\hline Development & $\begin{array}{l}\text { All issues relating to the organized } \\
\text { pursuit of human well-being (both } \\
\text { modernizing society, economic growth } \\
\text { and well-being and capabilities) }\end{array}$ & $\begin{array}{l}\text { Industrialization, modernization, growth, } \\
\text { economy, equity, gender, social capital, } \\
\text { livelihoods, happiness }\end{array}$ \\
\hline Environment & $\begin{array}{l}\text { All issues relating to ecosystems, } \\
\text { natural and physical resources, } \\
\text { qualities and characteristics of } \\
\text { locations, places and areas }\end{array}$ & $\begin{array}{l}\text { Environment, soil, wetlands, ecosystem, } \\
\text { marine resources, water, ecology, mountains, } \\
\text { desert(ification), biodiversity }\end{array}$ \\
\hline Food security & $\begin{array}{l}\text { All issues relating to availability, } \\
\text { accessibility, adequacy, and } \\
\text { acceptability of food }\end{array}$ & $\begin{array}{l}\text { Nutrition, food, hunger, starvation, (under) } \\
\text { nourishment, diet }\end{array}$ \\
\hline
\end{tabular}

\section{What is a coding statement, what is it composed of?}

Either of the following or a combination (while mentioning the sections as described above): problem, cause, solution, intervention, general statement (most text sections will be incomplete, containing only one of several of the categories).

\section{How go about coding?}

I. Source - who is the actor speaking, on which occasion, to what audience, in what form.

a. Ministry

i. Ministry Agriculture

ii. Ministry Environment

b. Document type
i. Strategic Plan
ii. Sectoral implementation policy

c. Year

i. Open (between 2002 - 2017) 
2. Sentence - copy full relevant piece of text (either (part of) sentences, paragraph, subchapter to data abstraction table.

a. A quote should contain (a) a statement on an issue other than the host ministry (agriculture: climate change, development, environment, food security; environment: agriculture, climate change, development, food security);

(from Environment Strategic Plan 2008 - 2012) 'the signs of climate change are increasingly obvious'

$\rightarrow$ This quote relates to the issue of climate change

b. OR (b) linkage between two issues (e.g. how ENV and CC relate);

(from Environment Strategic Plan 2008 - 2012) 'GDP growth with an average rate of $10 \%$ per annum will depend on key sectors such as agriculture'

$\rightarrow$ This quote relates to the linkage among agriculture and development

3. Key concepts - Identify key concepts, which relate to the nature of the issue or the linkage. A single quote may have multiple key concepts.

(from Environment Strategic Plan 08 - 12) 'From an environmental point of view, agriculture has long been seen as a major cause of several ills, including erosion, sedimentation, eutrophication and invasive species'

$\rightarrow$ This quote contains multiple linkages, which thus form separate coding units. 'erosion', 'sedimentation', 'eutrophication', 'invasive species' are variously identified as key concept. Although the quotes refer to linkages among agriculture and environment, these do not count as key concepts, because these are not further specified (when the quote would refer to 'sustainable agricultural practices' or 'sustainable intensification', these would be identified as key concepts. 


\begin{tabular}{lllll}
\hline Ministry & Document type & Year & Sentence & \multicolumn{1}{c}{ Key concepts } \\
\hline ENV & Strategic Plan $2008-2012$ & $\begin{array}{l}\text { From an environmental point of view, Erosion } \\
\text { agriculture has long been seen as a major } \\
\text { cause of several ills, including erosion }\end{array}$ \\
ENV Strategic Plan $2008-2012$ & $\begin{array}{l}\text { From an environmental point of view, Sedimentation } \\
\text { agriculture has long been seen as a } \\
\text { major cause of several ills, including }[\ldots] \\
\text { sedimentation }\end{array}$ \\
ENV Strategic Plan 2008-20I2 & $\begin{array}{l}\text { From an environmental point of view, Eutrophication } \\
\text { agriculture has long been seen as a } \\
\text { major cause of several ills, including }[\ldots] \\
\text { eutrophication } \\
\text { ENV Strategic Plan } 2008-2012\end{array}$ & $\begin{array}{l}\text { From an environmental point of view, Invasive species } \\
\text { agriculture has long been seen as a major } \\
\text { cause of several ills, including }[\ldots] \text { invasive } \\
\text { species }\end{array}$ \\
\hline
\end{tabular}

4. Issue(s) - identify issue(s) addressed in quote.

(from Environment Strategic Plan 2008 - 2012) 'GDP growth with an average rate of $10 \%$ per annum will depend on key sectors such as agriculture'

\begin{tabular}{|c|c|c|c|c|c|}
\hline Sentence & $A G$ & CC & DEV & ENV & FS \\
\hline $\begin{array}{l}\text { GDP growth with an average rate of } \\
10 \% \text { per annum will depend on key } \\
\text { sectors such as agriculture }\end{array}$ & & & $x$ & & \\
\hline
\end{tabular}

5. Relationship (if applicable) - what is the direction of the linkage?

(from Environment Strategic Plan 2008 - 2012) 'GDP growth with an average rate of 10\% per annum will depend on key sectors such as agriculture'

$\rightarrow$ This quote contains causal linkage among agriculture and development, whereby agriculture is perceived to cause development

\begin{tabular}{llll}
\hline Sentence & AG & DEV & Relation \\
\hline $\begin{array}{l}\text { GDP growth with an average rate of I0\% per annum will } \\
\text { depend on key sectors such as agriculture }\end{array}$ & $\times$ & AG $\&$ DEV \\
\hline
\end{tabular}

6. Type of statement - choose between problem (negative impact of one sector on the other), OR solution (how [interventions in] one sector could address [problems in] other sector, OR neutral [no relationship is explicated] 
(from Environment Strategic Plan 2008 - 2012) 'GDP growth with an average rate of $10 \%$ per annum will depend on key sectors such as agriculture'

$\rightarrow$ This quote contains causal linkage whereby agriculture is perceived to cause development. No value is indicated in this quote. A 'problem' quote would for instance be 'Climate change severity overcomes national capacity to adapt, leading to increased disasters, including drought and famine.' A 'solution' quote would for instance be: 'Key issues to raise real awareness of the importance of environmental matters within national and local political leaders is to tap on carbon markets'

\begin{tabular}{lllll}
\hline Sentence & AG & DEV & Relation & Type \\
\hline $\begin{array}{l}\text { GDP growth with an average rate of } 10 \% \text { per annum will } \\
\text { depend on key sectors such as agriculture }\end{array}$ & $\times$ & AG $\&$ DEV & neutral \\
\hline
\end{tabular}

\section{Defining the unit of analysis (the 'quote')}

a. Create a separate quote for each issue (if quote is a statement and not contains a linkage)

'poverty and hunger are on the rise'

$\rightarrow$ This sentence relates to the issues of development and food security. Therefore, these should be two separate quotes

\begin{tabular}{llll}
\hline Ministry & Document type & Year & Sentence \\
\hline ENV & Strategic Plan & $2008-2012$ & poverty $[\ldots]$ are on the rise \\
ENV & Strategic Plan & $2008-2012$ & {$[\ldots]$ hunger are on the rise } \\
\hline
\end{tabular}

b. Create a separate quote if the nature of linkage changes

(from Environment Strategic Plan 2008 - 2012) 'From an environmental point of view, agriculture has long been seen as a major cause of several ills, including erosion, sedimentation, eutrophication and invasive species'

$\rightarrow$ This sentence contains multiple linkages among agriculture and environment: erosion, sedimentation, eutrophication, invasive species. It will thus be coded as four separate quotes.

e. Create a separate quote if the direction of the linkage changes 
'economic growth puts a pressure on the quality of the environment, while environmental deterioration hampers the development of people dependent on the environment.'

$\rightarrow$ This sentence contains a linkage among environment and development in two directions: environment impacts on development, and vice versa. It should therefore be coded as two separate quotes.

c. Create a separate quote if the type of statement changes

'climate change threatens agricultural production in some parts of the globe while increasing yields in other areas'

$\rightarrow$ This sentence contains a linkage between climate change and agriculture, whereby the first part of the sentence refers to a problematic relationship whereas the last part of the sentence refers to a positive linkage. It should thus be coded as two separate quotes.

d. In case of a sentence referring to a tripartite linkage among issues, then divide the sentence into two separate quotes, but code for all three issues in both quotes

'climate change threatens agricultural production, thereby jeopardizing Kenya's food security'

$\rightarrow$ This sentence contains a linkage between climate change $\rightarrow$ agriculture $\rightarrow$ food security. It should thus be divided into two separate quotes

\begin{tabular}{llllll}
\hline Sentence & AG & CC & FS & Relation & Type \\
\hline $\begin{array}{l}\text { climate change threatens agricultural production [thereby } \\
\text { jeopardizing Kenya's food security] }\end{array}$ & $\times$ & $\times$ & AG \& DEV & neutral \\
[climate change] threatens agricultural production thereby & $\times$ & $\times$ & $\times$ & & \\
jeopardizing Kenya's food security] & & & & \\
\hline
\end{tabular}

\section{Example data abstraction table}

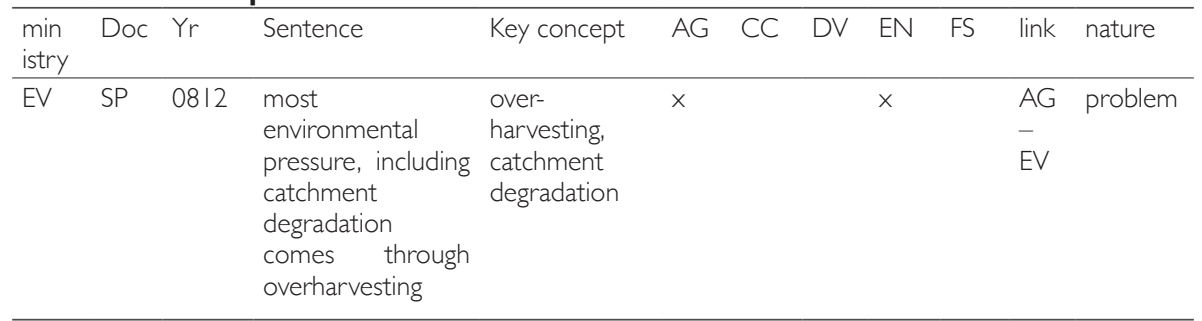




\section{Interview list}

\begin{tabular}{|c|c|c|}
\hline & title & date \\
\hline I. & climate change coordinator NEMA & 04 may 2017 \\
\hline 2. & $\begin{array}{l}\text { Chief, Livestock Production Officer, } \\
\text { Ministry of Agriculture Livestock and } \\
\text { Fisheries }\end{array}$ & 25 April \\
\hline 3. & $\begin{array}{l}\text { Agriculture Council, Dutch Embassy } \\
\text { for Kenya,Tanzania, UNEP }\end{array}$ & I5 May 2017 \\
\hline 4. & CGIAR-CCAFS ILRI & 21 April 2017 \\
\hline 5. & AGRA & 18 may 2017 \\
\hline 6. & KALRO & 02 may 2017 \\
\hline 7. & Climate Change Working Group & \\
\hline 8. & senior scientist, CIAT & 24 May 2017 \\
\hline 9. & development specialist, UNDP & 16 may 2017 \\
\hline 10. & $\begin{array}{l}\text { researcher Wangari Maathai } \\
\text { Institute for Peace and Environment, } \\
\text { environmental governance, }\end{array}$ & 2 May 2017 \\
\hline 11. & $\begin{array}{l}\text { freelance consultant, } \quad \text { (Finance } \\
\text { Innovation for Climate Change Fund) } \\
\text { FICCF }\end{array}$ & 28 april 2017 \\
\hline 12. & $\begin{array}{l}\text { Lead Agriculture Economist, World } \\
\text { Bank }\end{array}$ & 18 may 2017 \\
\hline 13. & $\begin{array}{l}\text { MENR, senior assistant director CC } \\
\text { Directorate }\end{array}$ & 28 april 2017 \\
\hline 14. & fsc, coordinator east Africa & 2 may 2017 \\
\hline 15. & Kenya national coordinator, FAO & 8 May 2017 \\
\hline 16. & COMESA & 4 May 2017 \\
\hline
\end{tabular}



Many contemporary initiatives to address pressing societal challenges such as climate change and food security stress the need to link global to local levels, the agriculture sector to the environment sector, and business organizations to civil society organizations (CSOs). Climate-smart agriculture (CSA) is such an initiative. It emerged in 2010 as an approach with the threefold aim of sustainably increasing production for food security and development, adapting and building resilience to climate change, and reducing greenhouse gas emissions from the agricultural sector. It calls for coordinated action across boundaries among different levels and domains of government, and across public, private, and civil society sectors to realize the proposed transformations. This crossing of boundaries is frequently characterized by various challenges, including competition and turf wars. Although research acknowledges that policy entrepreneurship plays an important role in the crossing of boundaries, its role and function in crossing boundaries remains poorly understood. Boundaries demarcate dividing lines between differing cultures and practices; hence, there is reason to believe that, to cross boundaries, policy entrepreneurs have to undertake particular actions, including maintaining relations across policymaking cultures and coordinating activities across scales. This thus necessitates a particular focus on cross-boundary policy entrepreneurship to better understand these dynamics. This dissertation embeds policy entrepreneurship in context in order to elucidate why, how, and with what effects policy entrepreneurs operate. The aim of this dissertation is to understand how policy entrepreneurship contributes to the crossing of boundaries in order to achieve CSA. This aim is broken down into three separate research questions:

I. How and why do policy entrepreneurs cross boundaries for climatesmart agriculture?

2. How does the policymaking context influence cross-boundary policy entrepreneurship for climate-smart agriculture?

3. How can cross-boundary policy entrepreneurship for climate-smart agriculture be conceptualized?

These questions are addressed from a critical realist perspective. Multiple theories are combined to study the relatively unexplored issues of cross-boundary policy entrepreneurship and processes of CSA policy development. Various qualitative and quantitative methods for data collection and analysis are utilized to gain understanding of the topic under study, collect complementary insights, and ensure 
the validity of findings. This dissertation consists of four academic articles that together address the three research questions.

Using a systematic literature review, chapter 2 analyses the process through which policy entrepreneurs cross boundaries. It identifies and analyses 51 studies on (i) cross-boundary entrepreneurship strategies, (ii) the conditions under which entrepreneurs deploy these strategies, (iii) and the implications of entrepreneurs' actions. The results show that the literature pays limited but increasingly explicit analytical or conceptual attention to cross-boundary policy entrepreneurship, apart from venue shopping strategies. The literature predominantly highlights issue promotion and coalition building as boundary-crossing strategies, and mostly addresses how policy entrepreneurs cross vertical boundaries. Cross-boundary entrepreneurship seems to be facilitated by the following conditions: institutional overlap, complex issue interpretation, power vacuum, and lack of resources. Actions seem not without risks, as most discussed implications of cross-boundary entrepreneurship include opposition, competition over leadership, complexity, increased costs and resource requirements, and a lack of trust and legitimacy.

Chapter 3 is an empirical study analysing cross-boundary policy entrepreneurship for the development of the Global Alliance for Climate-Smart Agriculture (GACSA), a global multi-actor collaboration to address climate change and improve food security and development. Instead of compiling an idiosyncratic list of strategies, I explore policy entrepreneurship as a process embedded within a context. To do so, I construct a framework based on the results of the systematic literature review in chapter 2 to analyse the entrepreneurial strategizing process, consisting of conditions, strategies, and implications. The framework depicts strategizing as a process played out in different rounds, whereby past strategies codetermine present and future contextual conditions, which in turn affect entrepreneurs' strategy choice. Through a congruence case study based on interviews, documents, a survey, and observation I demonstrate that, to cross boundaries, entrepreneurs manoeuvre in a complex environment, adapting their strategies to their interpretation of the policymaking context, thereby partly responding to the implications of their own activities. The entrepreneur's interpretation of the policymaking context thus determines strategy choice, and strategies, alongside other contextual contingencies including global agreements in other arenas or crisis events, codetermine the policymaking context. The empirical research largely affirms the conditions and implications as identified 
in chapter 2. It furthermore demonstrates that the strategizing framework leads to a better understanding of entrepreneurship as a process. It shows that, to cross boundaries, entrepreneurs are confronted with a multiplicity of target audiences, from different, sometimes even competing, backgrounds. This context requires particular strategies from entrepreneurs, including strategically composing varied coalitions, broad interpretation and framing of pet proposals, and organizing highlevel support.

In chapter 4, by studying the development of a National CSA Strategy in Kenya, I further empirically analyse how, why, and with what effect entrepreneurs strategize to cross various boundaries. Chapter 4 follows up on the finding in chapter 3 that policy entrepreneurship should be more firmly embedded in context. The previous chapters take entrepreneurship theory as their point of departure, thereby paying less conceptual attention to the policymaking context. This chapter aims to provide insight into the influence of the policymaking context on cross-boundary policy entrepreneurship. It therefore embeds cross-boundary policy entrepreneurship in the multiple streams, advocacy coalitions, and punctuated equilibrium frameworks to assess each framework's value for explaining entrepreneurial strategizing across boundaries. Qualitative methods, interviews, document content analysis, and observation serve to analyse the process of developing a National CSA Strategy in Kenya. The results demonstrate that the three policy process frameworks combined offer valuable insights into the elements codetermining the boundaries that entrepreneurs target in their strategizing. It highlights how the policymaking context is composed of interests, ideas, and institutions that differ across levels, domains, and sectors. Targeting these varied interests, ideas, and institutions requires additional resources, but also offers opportunities regarding choice of audience and potential resources to tap. This chapter further refines cross-boundary strategies and identifies venue shopping as a way to soften up communities, patchwork framing to address different audiences, demonstrating impartial leadership as a way to create a neutral institutional setting, and process manipulation as a way to bypass complexity and tediousness.

Chapter 5 addresses the question of how policy frames for agriculture, climate change, development, environment, and food security in Kenya have evolved over time, and the factors that contribute to policy frame changes. Because an encompassing processual approach also incorporates an account of the temporal context, this 
chapter analyses relevant policies preceding the Kenya National CSA Strategy. This study thus aims to understand whether CSA policy should be perceived as a transformative tool or business-as-usual and to analyse the conditions and factors influencing agriculture and climate policy development. It enriches insights from the other chapters by revealing the relative role of entrepreneurship, both in terms of its achievements and vis-à-vis other factors. The findings show that CSA policy in Kenya represents a continuation of an existing trend towards increasing interconnectedness rather than the radical transformation that it claims to be. This suggests that CSA is particularly useful in contexts characterized by some level of pre-existing linkages between agriculture, climate change, development, environment, and food security. Whereas strategic plans demonstrate an increasing acknowledgement of complex linkages between agriculture, climate change, development, environment, and food security, sectoral policies display a more erratic development. While strategies are usually adopted rather easily, my findings emphasize that translating these in existing institutional structures is more challenging. Policies are influenced by donors, global and regional fora, and personal networks that might partly overlook Kenya's existing institutional environment.

Chapter 6 synthesizes the key findings from the previous chapters. Most importantly, it concludes that policy entrepreneurs continuously engage in co-defining, erasing, redrawing, and moving boundaries among entities across different levels, domains, and sectors. This is a complex and dynamic process in which entrepreneurship interplays with the wider policymaking context. I refer to this as the strategizing process, whereby entrepreneurs interpret and act upon the policymaking context in order to reconfigure this context, with both intended and unintended effects. This is a continuous process that plays out in different rounds. The strategies that policy entrepreneurs undertake to cross boundaries and push CSA include patchwork framing to attract the interest of actors across boundaries, impartial leadership to create new institutions and facilitate the exchange of ideas, and process manipulation to bypass existing institutions and speed up the complex policymaking process. The process of crossing boundaries is complex because entities across different levels, domains, or sectors have particular backgrounds. These differences exist along the elements of interests, ideas, and institutions. Patchwork framing serves mainly to address interests, whereas impartial leadership and process manipulation relate to altering ideas and institutions. Addressing different interests, ideas, and institutions entails certain challenges related to accommodating discussions among actors 
with different interests, facilitating idea exchange in a suboptimal level playing field, and eroding support for initiatives. CSA accommodates different interests and ideas, enabling the rebranding of existing practices but also serving to streamline discussions and realize small but significant reconfigurations of existing policies.

Institutions may facilitate or hinder the crossing of boundaries. Inclusive taskforces may facilitate the exchange of ideas, but, in my cases, it proved difficult to equalize the authority of different participants. Because each entrepreneur interprets the policymaking context from his/her own unique perspective, interpretations of interests, ideas, institutions and the resultant strategies may differ among entrepreneurs. Entrepreneurs are not the only force determining the policy process; rather, they are an integrated cog in CSA policy processes, who at most codetermine the development of CSA policy. The chapter presents a strategizing framework that brings together the above-listed findings from previous chapters in a coherent picture that presents the most important building blocks and their relations for understanding cross-boundary entrepreneurship for CSA.

My dissertation demonstrates that CSA is a bridging concept that accommodates a wide range of viewpoints and preferences, as its vagueness accommodates differences in interests and ideas, and institutions largely fail to address differences in authority and information. However, these insights do not render policy processes around CSA useless. CSA may focus attention and secure the prioritization of challenges relating to agriculture and climate change on policy agendas worldwide. And although it is not the radical transformation that it often claims to be, I argue that CSA might be a small and gradual step in a long-term process towards an enhanced appreciation of the interrelatedness among very pressing societal challenges, to which policy entrepreneurship contributes in a modest way. 


\section{Acknowledgements}


This PhD project has been an adventurous and valuable journey. Looking back, I considered the PhD trajectory as highly exciting and enjoyable. This journey would not have been possible without the support of many people, to whom I'm deeply grateful.

First and foremost, I'm thankful to my supervisory team for given me their support and sharing their knowledge and skills. In addition, thanks for giving me the independence, time, and environment to develop my talents and employ different exciting activities, also besides my research. Your doors were always open for advice and support. Simultaneously you kept the right distance so I could grow into an independent academic. I would like to thank my promotor Katrien Termeer for her useful feedback. You challenged me to be critical, creative, and also pragmatic at times. Robbert Biesbroek, I highly valued your vast knowledge and meticulous and critical approach. You taught me a lot about academic life. Thanks to Sylvia Karlsson-Vinkhuyzen for being my co-supervisor, for sharing your ideas and for your continuous support.

Thanks to my PAP colleagues Art, Tamara, Otto, Maarit, Jeroen, Sanne, I really enjoyed the inspiring work environment. Special thanks to my (former) roommates and/or fellow PhDs Martijn, Greetje, Mathijs, Timos, Sumit, Brenda, Efrat, Daniel, Pantja, Fred, Andy, Reo, Jonna, Wieke, Yannick, and Rebecca. And thanks to the other PhDs from the Wageningen Centre of Sustainability Governance.

To my otherWUR colleagues Cinthia, Astrid, Sarah, Madeleine, Annemarie, Claudius, Christine, Sander, Henk, Corina, Nico, Pytrik, Saskia, and Maarten with whom I shared the fascination for climate-smart agriculture: thank you. Our discussions and joint events have been a fun and valuable experience to me.Thanks to Anouk for making the commute between Amsterdam and Wageningen so much more fun. Kris, thank you for hosting me in Amsterdam. Who would have guessed we would end up like this. Apart from my colleagues at WUR, I have been able to build a network of bright scholars and peers which greatly inspired me, including the network of people working on policy entrepreneurship, the ARSP network, and the network of (young) ESG scholars.

Many thanks to the people who have supported me in conducting my field work. Robert, Nowella and Tabitha, thank you for your support and nice talks on addressing 
Kenyan bureaucracy and providing me with the valuable contacts I needed to get my research started. Thanks to the University of Nairobi, and particularly $\mathrm{Mr}$ Stephen Tirop and Mr Stephen Maloba for supporting me in my data collection. I had the pleasure to work from the beautiful Gigiri campus on which the Stockholm Environment Institute Africa is located. Thanks SEl for hosting me during my stay, and a special thanks to Dr. Philip Osano for our inspiring discussions. Moreover, my visit to Kenya would not have been half the fun without Cecile and Christine, okidogo and thanks for being my home away from home. My research would not have been possible without the support and collaboration of all interviewees and people who supported me in data collection.

I am grateful to Ben Cashore and his lab for hosting me during my visit to Yale, and thanks to Seiki, Luisa, Katie, Alexandre, Rachel, Wen for showing me around and letting me feel welcome in New Haven.

Last, a big thanks to my friends and family, for helping me maintain my work-life balance and for reminding me of what is most important in life. Joris en Samuel, thanks for being so fantastic, sweet, flexible and understanding, for putting every hurdle into perspective, and for making every issue meaningless. I can't wait to spend the rest of my post-PhD life with you. 


\section{About the author}

Since February 2019 Marijn Faling is working as research fellow partnerships and inclusive development with the Partnerships Resource Centre of the Rotterdam School of Management, Erasmus University. In 2014 she started her $\mathrm{PhD}$ research at the Public Administration and Policy Group of Wageningen University and Research. During her PhD trajectory she went on research visits to the Governance, Environment, and Markets Initiative of the Yale School of Forestry and Environmental Studies, and the Stockholm Environment Institute (SEl) Africa. During her PhD she taught various courses in the field of international governance and public administration, engaged in commissioned research for the PBL Netherlands Environmental Assessment Agency, and has been research editor for the Annual Review of Social Partnerships (ARSP). Previously to her PhD she worked as independent consultant in the field of disaster resilience and governance, and as junior researcher and advisor disaster risk reduction with the Netherlands Red Cross. Marijn received a MSc in Political Science and a MSc in International Development Studies (research master's) from the University of Amsterdam. 


\section{Publications}

\section{Refereed journal publications}

Faling, M. 2018. "Partnering as a research organization: a balancing act." Annual Review of Social Partnerships 13: 74-78.

Faling, M, R Biesbroek, and S Karlsson-Vinkhuyzen. 2018. "The strategizing of policy entrepreneurs towards the Global Alliance for Climate-Smart Agriculture." Global Policy 15 (2):408-419.

Faling, M, R Biesbroek, S Karlsson-Vinkhuyzen, and K Termeer. 2018. "Policy entrepreneurship across boundaries: a systematic literature review." Journal of Public Policy 39 (2): I-30.

Faling, M, J Garard, G Schouten, K Schulz, MVeeger, JVervoort, and L Rutting. 2017. "Innovative participatory research methods in Earth System Governance." Annual Review of Social Partnerships 12:76-80.

Duijsens, R, and M Faling. 2014. "Humanitarian challenges of urbanization in Manila: the position of the Philippine Red Cross in a changing disaster and aid landscape." Resilience 2(3): 168-182.

\section{Other publications}

Hospes, O,A Dewulf, and M Faling. 2016 . "Inclusiveness in public-private partnerships: NGO views and strategies." Report for PBL.

De Milliano, C, M Faling, A Clark-Ginsberg, D Crowley, and P Gibbons. 2015. "Resilience: the holy grail or yet another hype?" in Gibbons, P and HJ Heintze (eds) The humanitarian challenge: 20 years European Network on Humanitarian Action (NOHA), pp. 17-30. 


\title{
Completed training and supervision plan
}

\author{
Marijn Faling \\ Wageningen School of Social Sciences (WASS) \\ Completed Training and Supervision Plan
}

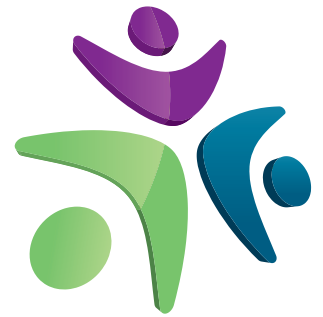

Wageningen School of Social Sciences

\begin{tabular}{|c|c|c|c|}
\hline Learning activity & Institute & Year & ECTS* \\
\hline \multicolumn{4}{|l|}{ A) project related competencies } \\
\hline Writing Research Proposal & WUR & $2014-2015$ & 6 \\
\hline Systematic Approaches to Reviewing Literature & WGS & 2015 & 4 \\
\hline Scientific Writing & WGS & 2015 & 1.8 \\
\hline Governing Climate Change: Polycentricity in Action & INOGOV Spring school & 2018 & 6 \\
\hline Advanced Process Tracing & ECPR, Winter school & 2016 & 3 \\
\hline \multicolumn{4}{|l|}{ B) General research related competencies } \\
\hline Presented research at various conferences & ECPR, ESG, NIG, ASAP & $2015-2018$ & I \\
\hline $\begin{array}{l}\text { Set up, facilitate, maintain CSA@WUR PhD discussion } \\
\text { group }\end{array}$ & WASS/PE\&RC & $2016-2017$ & 2 \\
\hline $\begin{array}{l}\text { Commissioned research: inclusiveness in public-private } \\
\text { partnerships }\end{array}$ & PBL & $2015-2016$ & 2 \\
\hline Associate editorship Annual Review Social Partnerships & ARSP & $2017-2019$ & 2 \\
\hline \multicolumn{4}{|l|}{ C) Career-related competencies } \\
\hline $\begin{array}{l}\text { Lecturing PAP MSc Thesis Ring, PAP20306 and } \\
\text { PAP21306 }\end{array}$ & WUR & $2014-2018$ & 4 \\
\hline Organization Summer School CSA & WASS/PE\&RC & 2016 & 3 \\
\hline Policy advice workshop CSA for MINEZ & MINEZ & 2016 & 1.2 \\
\hline $\begin{array}{l}\text { Research internship: Stockholm Environment Institute } \\
\text { (SEI) Africa }\end{array}$ & SEl & 2017 & 3 \\
\hline Set up, facilitate, maintain CSA@WUR network & WUR & $2015-2017$ & 2 \\
\hline $\begin{array}{l}\text { Visiting researcher at Government, Environment, and } \\
\text { Markets (GEM) Initiative, Yale School of Forestry and } \\
\text { Environmental Studies }\end{array}$ & YALE & 2017 & 2 \\
\hline Total & & & 45 \\
\hline
\end{tabular}



Financial support from Wageningen University for printing this thesis is gratefully acknowledged.

Cover photo by Joris Ranzijn

Cover design by Ferdinand van Nispen and Marijn Faling

Layout by Ferdinand van Nispen, my-thesis.nl

Printed by Proefschriftmaken || www.proefschriftmaken.nl 

